THIAGO BATISTA ROCHA

Sistemas Locais de Produção e seu Ciclo de Vida Um olhar sobre as experiências do estado de São Paulo 
Sistemas Locais de Produção e seu Ciclo de Vida Um olhar sobre as experiências do estado de São Paulo

\begin{abstract}
Dissertação de mestrado para a apresentação ao Departamento de Engenharia de Produção, da Escola Politécnica da Universidade de São Paulo, como exigência para aprovação no exame da pós-graduação - nível Mestrado (stricto sensu).
\end{abstract}

Orientador: Prof. Dr. Renato de Castro Garcia 


\section{AUTORIZAÇÃO DE REPRODUÇÃO}

Autorizo a reprodução e divulgação total ou parcial deste trabalho, por qualquer meio convencional ou eletrônico, para fins de estudo e pesquisa, desde que citado a fonte.

Thiago Batista Rocha

\section{FICHA CATALOGRÁFICA}

\section{Rocha, Thiago Batista}

Sistemas locais de produção e seu ciclo de vida: um olhar sobre as experiências do estado de São Paulo / T.B. Rocha. -São Paulo, 2013.

$116 \mathrm{p}$.

Dissertação (Mestrado) - Escola Politécnica da Universidade de São Paulo. Departamento de Engenharia de Produção.

1. Sistemas de produção - São Paulo 2. Ciclo de vida I. Universidade de São Paulo. Escola Politécnica. Departamento de Engenharia de Produção II. t. 
"É de grande ajuda pensar sobre um sistema industrial regional como possuidor de três dimensões: instituições locais e cultura, estrutura industrial e organização corporativa. Instituições regionais incluem organizações públicas e privadas, assim como universidades, associações de negócios, e governo local, assim como os muito menos formais clubes de hobby, sociedades profissionais, e outros fóruns que criam e sustentam padrões regulares de interações sociais em uma região. Estas instituições moldam e são moldadas pela cultura local, os entendimentos compartilhados e práticas que uniformizam uma comunidade e definem tudo desde o comportamento do mercado de trabalho até atitudes diante do risco. Uma cultura regional não é estática, mas é continuamente reconstruída pela interação social".

Regional Advantage: Culture and Competition in Silicon Valley and Route 128, A. Saxenian (1994).

"Sabemos mais do que podemos dizer".

The Tacit Dimension, M. Polányi (1967). 


\section{Agradecimentos}

Ao Renato de Castro Garcia, orientador do trabalho, que me ensinou a heterodoxia responsável. Se mais não aproveitei de suas lições foi devido unicamente às minhas próprias falhas, uma vez que Renato foi mestre incansável.

A Capes - Coordenação de Aperfeiçoamento de Pessoal de Nível Superior, que financiou através de bolsa vinte quatro meses de elaboração deste trabalho.

Aos colegas da EPUSP - Escola Politécnica da Universidade de São Paulo; pela convivência que me ajudou a suportar o longo trabalho; e especialmente a Guilherme Amaral Gurgel (Camarada), Veneziano Araújo (Vene), Leonardo Augusto (Mineirinho), cujas opiniões sempre inteligentes e ponderadas colaboraram para consolidar várias idéias em estado embrionário.

Aos colegas que participaram da equipe multidisciplinar GEID - Grupo de estudo de Inovação e Desenvolvimento (2010-12); Anelise, Andréa, Luciana, Fernanda, Beto e Diego sob a coordenação de João Eduardo de Morais Pinto Furtado e Renato de Castro Garcia, durante a qual foi elaborada uma primeira versão do capítulo I e II deste trabalho. Agradeço especialmente a Eduardo Urias a época Instituto de GeociênciasUNICAMP, e hoje UNU-MERIT, pela colaboração no processo de consolidação das idéias ali contidas.

Não apenas o apoio de todos esses profissionais foi importante. Também a ajuda emocional, financeira e de "infraestrutura" de minha família e meus amigos. Meus pais, meu irmão, meus sogros, meus cunhados e tantos outros que cuidaram de mim.

A Thais Helena Condez, pelo apoio decisivo e uma participação tão incondicional que foi levada, sem se dar conta, a enveredar pelos meandros inóspitos da "triste ciência". 


\section{Índice de Tabelas}

Tabela 1. Dimensões Qualitativa e Quantitativa: efeito direto e sistêmico ..........................17

Tabela 2. Tipologia dos Sistemas Locais de Produção......................................................... 30

Tabela 3. Divisão setorial: ramos da indústria de transformação selecionados ...................35

Tabela 4. Vínculos empregatícios (RAIS 2010) - unidades de emprego por categoria

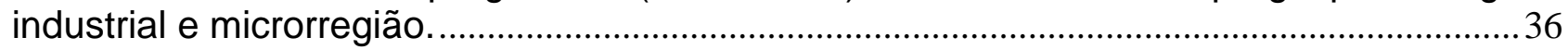

Tabela 5. Número de estabelecimentos (RAIS 2010) - número de empresas por categoria industrial e microrregião.

Tabela 6. Tipologia dos sistemas locais: Indústrias de Transformação selecionadas para o estado de São Paulo, durante o período de 1996 a 2010.

Tabela 7. Ciclo de vida dos sistemas locais em Campinas/SP, evidenciando a presença de Embriões de Sistema Local nas atividades selecionadas da indústria de transformação, durante o período de 1996 a 2010.

Tabela 8. Ciclo de vida dos sistemas locais em Franca/SP, evidenciando a presença de Núcleos de Desenvolvimento Setorial-Regional e Embriões de Sistema Local nas atividades selecionadas da indústria de transformação durante o período de 1996 a 2010.

Tabela 9. Ciclo de vida dos sistemas locais em Votuporanga/SP, evidenciando a presença de Núcleos de Desenvolvimento Setorial-Regional e Embriões de Sistema Local nas atividades selecionadas da indústria de transformação durante o período de 1996 a 2010.

Tabela 10. Ciclo de vida dos sistemas em São Carlos/SP, evidenciando a presença de Núcleos de Desenvolvimento Setorial-Regional e Embriões de Sistema Local nas atividades selecionadas da indústria de transformação durante o período de 1996 a 2010.

Tabela 11. Ciclo de vida dos sistemas em Rio Claro/SP, evidenciando a presença de Embriões de Sistema Local nas atividades selecionadas da indústria de transformação durante o período de 1996 a 2010.

Tabela 12. Ciclo de vida dos sistemas em Limeira/SP, evidenciando a presença de Vetores de Desenvolvimento Local e Embriões de Sistema Local nas atividades selecionadas da indústria de transformação durante o período de 1996 a 2010.

Tabela 13. Ciclo de vida dos sistemas em Piracicaba/SP, evidenciando a presença de Embriões de Sistema Local nas atividades selecionadas da indústria de transformação durante o período de 1996 a 2010. 


\section{Índice de Figuras}

Figura 1. Elementos de um sistema local de produção …………………………………........ 14

Figura 2. Sistemas locais de produção focalizados e heterogêneos....................................15

Figura 3. Alternâncias entre as fases do ciclo de vida......................................................... 41

Figura 4. Média de trabalhador por estabelecimento e número de estabelecimentos:

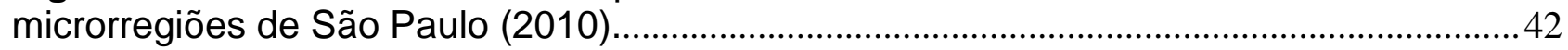

Figura 5. Quociente locacional e coeficiente de concentração no sistema local de Campinas: fabricação de produtos têxteis (CNAE 17), durante o período de 1996 a 2010.

Figura 6. Quociente locacional e coeficiente de concentração no sistema local de Campinas: Fabricação de material eletrônico e de aparelhos e equipamentos de comunicação (CNAE 32), durante o período de 1996 a 2010 ..................................................4

Figura 7. Quociente locacional e coeficiente de concentração no sistema local de Franca: fabricação de couro e artefatos de couro (CNAE 19) durante o período de 1996 a 2010..47

Figura 8. Quociente locacional e coeficiente de concentração no sistema local de Franca: fabricação de artigos de borracha e plástico (CNAE 25) durante o período de 1996 a 2010.

Figura 9. Quociente locacional e coeficiente de concentração no sistema local de Votuporanga: fabricação de móveis e indústrias diversas (CNAE 36) durante o período de 1996 a 2010.

Figura 10. Quociente locacional e coeficiente de concentração no sistema local de Votuporanga: fabricação e montagem de veículos automotores (CNAE 34) durante o período de 1996 a 2010.

Figura 11. Quociente locacional e coeficiente de concentração no sistema local de São Carlos: fabricação de máquinas e equipamentos (CNAE 29) durante o período de 1996 a 2010.

Figura 12. Quociente locacional e coeficiente de concentração no sistema local de São Carlos: fabricação de móveis e indústria diversa (CNAE 36) durante o período de 1996 a 2010.

Figura 13. Quociente locacional e coeficiente de concentração no sistema local de Rio Claro fabricação de produtos minerais e não metálicos (CNAE 26) durante o período de 1996 a 2010 ......

Figura 14. Quociente locacional e coeficiente de concentração no sistema local de Limeira: fabricação de produtos minerais e não metálicos (CNAE 26) durante o período de 1996 a 2010.

Figura 15. Quociente locacional e coeficiente de concentração no sistema local de Rio Claro, Limeira e Piracicaba: fabricação de produtos minerais e não metálicos (CNAE 26) durante o período de 1996 a 2010. 


\section{Sumário}

INTRODUÇÃO

1. A IMPORTÂNCIA DA PROXIMIDADE: "AS SEMENTES NÃO CAEM LONGE DAS ÁRVORES"

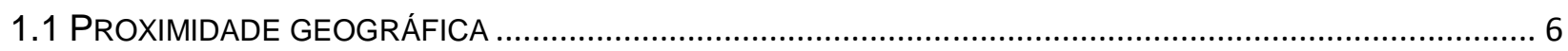

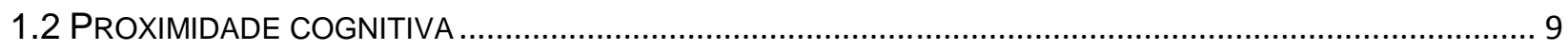

2. DAS FOLHAS A RAIZ: "OS COMPONENTES DE UM SISTEMA LOCAL DE PRODUÇÃO” . 13

3. UMA SEQUÊNCIA DE FENÔMENOS OU FATOS: “AS FASES DO CICLO DE VIDA”............ 19

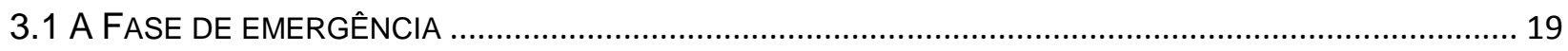

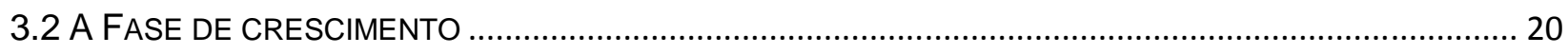

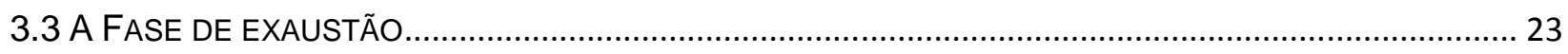

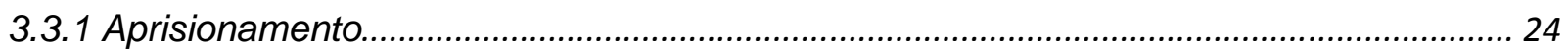

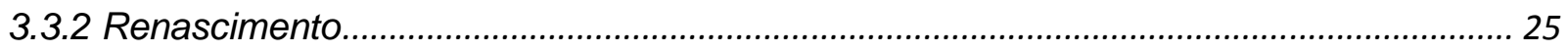

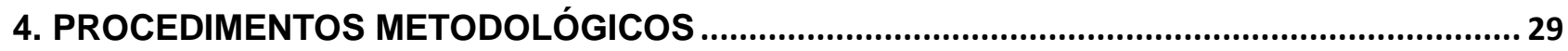

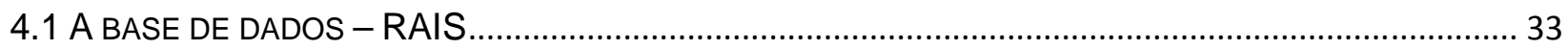

5. A COLHEITA: “DE AGLOMERAÇÕES INDUSTRIAIS A SISTEMAS LOCAIS”........................ 39

5.1 SELEÇÃO DE FRUTOS: “SISTEMAS LOCAIS EM CASOS SELECIONADOS”.......................................... 43

5.1.1 Sistema Local de Campinas: indústria têxtil.................................................................. 44

5.1.2 Sistema de Local de Franca: indústria de calçados....................................................... 46

5.1.3 Sistema Local de Votuporanga: indústria de móveis ...................................................... 48

5.1.4 Sistema Local de São Carlos: indústria de máquinas e equipamentos ........................... 51

5.1.5 Sistemas Locais de Limeira, Piracicaba e Rio Claro: indústria cerâmica .......................... 53

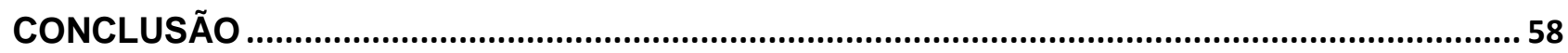

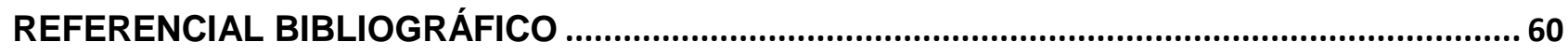




\title{
Resumo
}

A inquietação quanto ao desenvolvimento local ganhou maior visibilidade na década de oitenta em virtude das contínuas e abrangentes mudanças tecnológicas. Esse fenômeno criou a necessidade de um repensar sobre as formas pelas quais se dão os diferentes processos de desenvolvimento local. Diante das múltiplas formas de abordar o tema, esse trabalho teve por objetivo discutir o sistema local de produção e, mais especificamente, as caraterísticas que moldam seu ciclo de vida. Para compreender o processo de evolução analisou-se o ciclo de vida através das alterações em sua importância local (quociente locacional) e importância industrial (coeficiente de concentração) a fim de evidenciar, de maneira empírica, os ciclos. A partir da tipologia dos sistemas locais foi possível identificar a evolução das capacitações locais na indústria de transformação do estado de São Paulo, no período de 1996 a 2010. A análise de quatro fases do ciclo de vida permitiu a identificação das principais atividades industriais nas microrregiões do estado e a fase em que se encontravam frente a evolução dos sistemas locais de produção no período analisado. Adicionalmente, como resultados ressalta-se que o processo de evolução dentro do ciclo de vida ocorre de maneira incremental, e que não há linearidade no processo de evolução entre as fases.

Palavra-chave: ciclo de vida; sistema local de produção; indústria de transformação; tipologia dos sistemas locais.

\begin{abstract}
The current concern about local development has earned greater visibility in the eighties due to the large and continuous technological changes. This phenomenon has prompted the need to rethink about the diversity of local development processes. From the multiple ways to address this issue, the main objective of this research was to discuss the industrial clusters and, more specifically, the characteristics that are involved in shape of their life cycle. We analyzed the life cycle through the local (location quotient) and industrial importance (coefficient of concentration) in order to identify and better understand the evolution process of the cycles. Using the typology of industrial cluster was possible to identify the development of local capabilities in the manufacturing industry of the state of São Paulo, in the period of 1996-2010. We also used four distinct phases in the life cycles in order to identify the industrial activities and their positions in each region, considering the evolution of industrial clusters in the period. Additionally, our results demonstrated that the evolution process of the life cycle occurs incrementally, and there is no linearity in the evolution process between phases.
\end{abstract}

Keywords: life cycle; industrial cluster; manufacturing industry; cluster typology. 


\section{Introdução}

As informações contidas na CNAE - Classificação nacional de atividades econômicas foram utilizadas em diversos estudos, que procuraram mapear alguns aspectos da estrutura industrial dos sistemas locais de produção existentes no estado de São Paulo. A partir desta experiência, houve interesse em dar continuidade à investigação com a incorporação dos dados coletados nos anos recentes, tendo os alicerces da discussão assentados sobre o ciclo de vida dos sistemas locais.

Em princípio haveria diversas razões para supor que entre 1996 a 2010 (período analisado) teriam ocorrido alterações estruturais importantes nos sistemas locais. De um lado, até 2000 a atividade industrial do estado (principal foco deste trabalho) mostrou um crescimento moderado, o que costuma desfavorecer as mudanças estruturais. Do ponto de vista do ciclo de vida, as alterações, quando ocorreram, foram de baixa relevância. De outro lado, a partir de 2000, com a retomada do ciclo de investimento à dinâmica industrial, recursos importantes foram destinados à ampliação e diversificação da indústria local, o que favoreceu a mudança econômica.

Sendo assim, esse trabalho teve origem no interesse de avaliar a repercussão das mudanças estruturais da atividade industrial no estado de São Paulo.

Uma breve apresentação do referencial teórico sobre os sistemas locais de produção será apresentada a seguir, antecedendo a análise empírica deste trabalho.

O conceito de economias externas foi utilizado por Marshall (1890) para explicar a existência de forças econômicas externas à firma. Marshall apresenta três fatores para a emergência de economias externas. O primeiro refere-se ao compartilhamento de recursos naturais. $\mathrm{O}$ segundo a presença de fornecedores especializados de bens e serviços. E o terceiro a presença de efeitos de transbordamento (spill-overs effects) de conhecimento e tecnologia.

A natureza das economias externas está relacionada às formas de aglomeração predominantes. Nos casos de fornecedores especializados de bens e serviços e efeitos de transbordamento as aglomerações se vinculam mais diretamente às características dos produtos e aos processos produtivos. Assim, por exemplo, em setores industriais onde a grande escala produtiva é importante, uma das formas assumidas pela concorrência intra-setorial é a externalização de parcelas do processo produtivo que porventura tem como efeito a emergência de fornecedores especializados. Quanto aos casos em que o efeito de transbordamento é fonte de vantagens competitivas, é preciso distinguir duas situações. Na primeira, o conhecimento (ou tecnologia) apesar 
de heterogêneo, pode ser agrupado em classes distintas e cuja alteração apresenta alguma dificuldade. Na segunda, as modificações do conhecimento são constantes e em que a diferenciação do produto, no sentido de introdução por parte das empresas de alterações em suas mercadorias, é uma arma fundamental na concorrência.

Suzigan et al. (2001; 2006) enfatiza que as vantagens competitivas construídas pelos agentes econômicos são a base para situações de aglomerações distintas. E avança no sentido de fazer uma tipologia dos sistemas locais de produção a partir desta distinção. Dois indicadores são utilizados para a distinção. O primeiro, a importância industrial, é avaliada pelo coeficiente de concentração (CC), ou seja, pelo grau de concentração de uma atividade industrial na região. O segundo, a importância local, é capturada pelo indicador relativo de quociente locacional (QL) que computa a importância da atividade industrial na microrregião comparada a sua relevância no estado de São Paulo. Dessa forma, denominam-se Núcleos de Desenvolvimento Setorial-Regional os sistemas locais que apresentam, simultaneamente, elevada importância industrial e local. O inverso (baixa importância local e industrial) pode ser chamado de Embrião de Sistema Local. Denominam-se por Vetores Avançados os sistemas locais que apresentam elevada importância industrial, porém baixa importância local. O inverso (reduzida importância industrial e elevada importância local) chama Vetor de Desenvolvimento Local.

Todos os conceitos apresentados acima são importantes para caracterizar morfologicamente os sistemas locais e as formas de aglomeração neles presentes. Contudo, são insuficientes enquanto referencial teórico de uma investigação da evolução da estrutura industrial do estado de São Paulo ao longo de quinze anos.

Neste sentido, surge na literatura um enfoque teórico que atribui particular importância ao processo de evolução dos sistemas locais (BERGMAN, 2007; MENZEL \& FORNAHL, 2010). Para estes autores os sistemas locais seguem um padrão evolutivo com parâmetros endógenos e exógenos para o seu surgimento, desenvolvimento e maturação. A evolução dos sistemas locais segue, portanto, uma sequência composta de três fases. A primeira corresponde à fase de emergência, que apesar de ser aleatória, só ocorrerá em local onde houver um acúmulo mínimo de capacitações produtivas, tecnológicas e institucionais. A segunda refere-se à fase de crescimento e, por fim, a terceira à fase de exaustão.

À primeira vista, parece óbvio que o sistema local segue o ciclo de vida de sua respectiva indústria. Visto desta forma, o ciclo de vida do sistema local nada mais é que 
a expressão local da evolução industrial. No entanto, estudos empíricos indicam que diferentes grupos de empresas pertencentes ao mesmo ciclo de vida industrial podem seguir distintas trajetórias de desenvolvimento econômico (SAXENIAN, 1994).

A autora ao contrastar a trajetória de evolução da indústria de informática da Route 128 na região de Boston com a trajetória do Silicon Valley na região da Calífornia, ambas localizadas nos Estados Unidos, evidência que diferentes grupos de empresas em um ramo industrial comum apresentam respostas distintas aos desafios tecnológicos do setor. Isso mostra que o ciclo de vida dos sistemas locais é mais do que apenas uma representação local do ciclo de vida da indústria é de fato o resultado do processo de construção das distintas capacitações locais.

Mesmo num plano teórico, as características estruturais dos sistemas locais não se modificam apenas em decorrência da acumulação interna de capacitações produtivas, mas também são afetadas pelo ritmo da expansão do mercado, pelas alterações nos preços relativos (e, portanto dos custos) e pela forma mais universal e, como quer Schumpeter, mas eficiente de concorrência à inovação.

Um ritmo acelerado de expansão de mercado, seja por razões inerentes ao seu próprio funcionamento, seja pelo crescimento da demanda em geral, costuma ser favorável às modificações de sua composição. A ampliação da produção facilita o ingresso de novas empresas e permite a utilização de escalas maiores e eventualmente mais produtivas. Quando esta expansão corresponde a uma situação de auge cíclico, a ocupação mais intensiva de capacidade que pode ocorrer e provavelmente significará também aumento dos custos da matéria-prima e energia visà-vis de mão de obra, já que o emprego flutua menos que a produção.

As consequências de uma inovação dependem das características desta. Por exemplo, se for acessível apenas a empresas de grande porte, é possível que favoreça os custos, mas dificilmente afetará os preços. A não ser que seja de tal porte que induza à expulsão de empresas menos produtivas, quando o preço poderá cair. Neste caso a concentração aumentaria a partir da queda nas margens de lucro. Por outro lado, também é possível que a inovação favoreça à entrada de novas empresas no mercado, seja por desfazer barreiras à entrada preexistentes, seja por serem as novas empresas as portadoras da inovação. De qualquer maneira, inovações de grande porte geralmente acarretam modificações profundas nas características estruturais da economia. 
Em linhas gerais, o presente trabalho apresenta uma pesquisa sobre as alterações das características estruturais da indústria no estado de São Paulo, à luz do conceito de ciclo de vida. Toma-se como unidade de análise as atividades industriais a dois dígitos. O trabalho foi dividido em cinco capítulos, descritos detalhadamente a seguir.

No capítulo I procurou-se sintetizar as principais dimensões evolvidas na discussão sobre sistemas locais, ponto de partida desta pesquisa. Para descrever os principais traços, agruparam-se as principais contribuições teóricas segundo os critérios proximidade geográfica e proximidade cognitiva. A partir deste quadro, examinam-se no capítulo II, quais são os componentes dos sistemas locais e como suas interações influenciam na dinâmica econômica. Esta breve síntese foi elaborada apenas para aclarar a análise (capítulo III) do ciclo de vida dos sistemas locais feita a seguir, baseada nos trabalhos de Bergman (2007) e Menzel \& Fornahl (2010). Em conjunto com esta análise constroem-se dois indicadores (capítulo IV): o primeiro de importância industrial (coeficiente de concentração) e o segundo de importância local (quociente locacional), para examinar as evoluções (ou involuções) no ciclo de vida dos sistemas locais identificados. Por fim, o último capítulo relata as principais alterações ocorridas nos indicadores. Ao agregá-los por categoria de uso verifica-se que os sistemas locais alteraram de maneira tênue suas dinâmicas econômicas locais e, portanto, as alterações dentro do ciclo de vida, quando ocorreram, foram de reduzida relevância. 


\section{A importância da proximidade: "as sementes não caem longe das árvores"}

Existem inúmeros termos para caracterizar a discussão sobre aglomerados industriais. Dentre os termos mais utilizados podem ser destacados os distritos industriais, aglomerações industriais, redes locais, arranjos locais, milieux inovadores, clusters e sistemas locais de produção, entre outros ${ }^{1}$. Dessa forma, e para os fins deste trabalho, será utilizado o conceito de sistemas locais de produção.

Os sistemas locais de produção são como um sistema localizado de agentes econômicos, políticos e sociais ligados a um mesmo setor ou a outras atividades econômicas, que possuem vínculos produtivos e institucionais. Os vínculos produtivoinstitucionais proporcionam aos produtores um conjunto de benefícios relacionados com a aglomeração das empresas. Neste sentido, como afirma Suzigan et al. (2006: 7);

"Os sistemas locais de produção configuram-se em um sistema complexo em que operam diversos subsistemas de produção, logística e distribuição, comercialização, desenvolvimento tecnológico pesquisa e desenvolvimento (P\&D), laboratórios de pesquisa, universidades, centros de prestação de serviços tecnológicos e onde os fatores econômicos, sociais e institucionais estão fortemente entrelaçados".

Os sistemas locais surgem num momento histórico propício e em razão de condições favoráveis, como o surgimento de conhecimento específico num dado local. A este diferencial são somados outros aspectos, como a existência de mão-de-obra qualificada, infraestrutura etc. Com o início da atividade produtiva, essa forma de organização tende a evoluir e a atrair novas empresas. Estabelece-se, portanto, um círculo virtuoso, que traz vantagens para os diversos atores envolvidos, sobretudo, para a atividade tecnológica (ARTHUR, 1990).

O sistema local de produção de calçados no município de Franca localizado no estado de São Paulo, só para citar um caso não caricatural, exemplifica bem como os sistemas locais de produção se desenvolvem. Em meados do século XIX, a cidade de Franca era um ponto de parada dos tropeiros que se dirigiam do estado de São Paulo para o estado de Minas Gerais. Aos poucos, algumas pessoas que trabalhavam com o

\footnotetext{
${ }^{1}$ Martin \& Sunley (2003) ao analisarem a aplicação destas diferentes terminologias, concluem que as diferentes noções aplicadas para caracterizar o processo de aglomeração industrial tem como resultado uma ampla confusão teórica, que por ventura pode restringir as conclusões e recomendações da pesquisa. - para maiores informações veja: MARTIN, R; SUNLEY. P; (2003). "Deconstructing clusters: chaotic concept or policy panacea?". Journal of Economic Geography, Vol. 3 - pp. 5/35.
} 
couro, fazendo reparo em arreios ou mesmo confeccionando sapatos rústicos, foram se concentrando no município, atraídas pela presença dos potenciais fregueses. A atividade evoluiu e, criou massa crítica o suficiente, para que, na década de vinte (1920), surgisse a primeira fábrica de sapatos de couro, seguida mais tarde por dezenas de outras, a maioria dedicada à produção de calçados masculinos. Atualmente, o município de Franca abriga toda uma cadeia produtiva em torno da produção de calçados, o que envolve desde a presença de curtumes, que beneficiam o couro, até dos fabricantes de calçados, passando pelos fornecedores de componentes, adesivos (cola), máquinas e etc. O setor calçadista não é, porém, o único exemplo de sistema local de produção existente no Brasil. Esse modelo de organização da produção também é comum aos segmentos de cerâmica, extração mineral, confecção de bijuterias, produtos de plásticos, vinicultura, frutas, apicultura, turismo, têxtil, biotecnologia e software (SUZIGAN et al., 2006).

\subsection{Proximidade geográfica}

Diversos são os trabalhos que contribuíram para melhorar compreensão do processo de emergência de um sistema local, desde o estudo de Marshall (1890), até contribuições contemporâneas (i.e: ARTHUR, 1990; FELDMAN, 1993; AUDRETSCH \& FELDMAN, 1996; SAXENIAN, 1994).

Marshall é pioneiro no estudo dos sistemas locais de produção. Ao analisar os sistemas locais da Inglaterra no final do século XIX, mais especificamente, as atividades das pequenas e médias empresas especializadas na área têxtil localizadas em Lancashire e Yorkshire, o autor verificou que os ganhos de produtividade, originados da divisão do trabalho e da utilização incipiente de máquinas, não estavam vinculados somente às firmas de modo individual, as chamadas economias internas. Os ganhos de produtividade estavam vinculados também às economias externas.

As economias internas, grosso modo estão relacionadas com o aumento de escala da produção de uma firma individual, ou seja, corresponde à redução dos custos de produção ocasionados pelo aumento da produção em ampla escala. As economias de custo mais comuns são mão-de-obra, maquinário e materiais. Adicionalmente, a aceleração do processo de divisão do trabalho gera economias relacionadas à criação e difusão de competências produtivas e organizacionais internas à firma. 
Já as economias externas dependem do desenvolvimento do entorno à firma individual, ou seja, dependem da aglomeração de empresas com capacitações similares em um determinado local. A concentração de empresas com objetivos comuns cria vantagens competitivas que não estão presentes em empresas não aglomeradas. As vantagens competitivas são fruto dos retornos de escala criados pela especialização produtiva das empresas aglomeradas. A especialização produtiva é resultado do processo intensivo de divisão do trabalho, que aprisiona (lock-in) as competências das empresas envolvidas gerando ganhos de escala coletivos. Dessa forma, as aglomerações industriais têm maior probabilidade de apresentar resultados econômicos superiores, se comparado às empresas não aglomeradas, haja vista que as economias externas estão enraizadas no âmbito local.

Marshall (1890) apresenta três fatores para a emergência de economias externas. $O$ primeiro refere-se ao compartilhamento de recursos naturais. A disponibilidade de matéria-prima e de fontes de energia, bem como as facilidades nos transporte, desencadearia forças aglomerativas em um determinado local.

O segundo fator refere-se à presença de fornecedores especializados de bens e serviços. Para o autor, os fornecedores especializados são atraídos para dentro dos sistemas locais devido às oportunidades de negócios. A presença de fornecedores especializados nos sistemas locais cumpre um duplo papel, ao mesmo tempo em que se constituem no fator mantenedor da unidade local, os fornecedores especializados aceleram a criação de economias externas no âmbito local. Ou seja, os fornecedores especializados provêm ao sistema local de produção o acesso a produtos e serviços a custos relativamente reduzidos, ampliando os retornos crescentes de escala. Neste sentido, os retornos crescentes de escala criados pela intensificação do processo de divisão do trabalho das empresas aglomeradas não estariam relacionados apenas com o aumento do volume de produção individual. A intensificação do processo de divisão do trabalho acarretaria ganhos de organização e desenvolvimento decorrentes da maior integração entre os agentes. Em suma, o processo de divisão do trabalho em sistemas locais incentiva as diferentes formas de integração entre as empresas, o que facilita, mas não assegura, a maior troca de informações e conhecimentos.

O terceiro, e último fator que justificaria a presença de economias externas em sistemas locais está no que Marshall denominou de efeitos de transbordamento (spillovers effects) de conhecimento e tecnologia. Os transbordamentos de diversas formas podem ocorrer como através da mobilidade da mão-de-obra, ou ainda através de novas 
empresas. Essas novas firmas podem surgir como concorrentes diretas da empresa origem podem ser criadas com a finalidade de atender a um novo nicho de mercado, ou ainda podem se tornar fornecedores especializados para a empresa origem.

Os transbordamentos de conhecimento e tecnologia, assim como os fornecedores especializados, cumprem um duplo papel na explicação marshalliana para às economias externas. Em primeiro lugar, os transbordamentos podem per se gerar sistemas locais de produção, através do aprisionamento das competências locais em uma atividade específica. Dessa forma, o aprisionamento das competências locais, em uma trajetória tecnológica particular, condicionará as possibilidades futuras de desenvolvimento do sistema local. E, segundo, os efeitos de transbordamento reforçam e aceleram os retornos de escala iniciais.

Para Saxenian (2001) uma firma ao se aglomerar a outras se apropria de vantagens competitivas, que acionam o "gatilho" que reforça as vantagens iniciais, ao mesmo tempo em que criam mecanismos de auto-reforço através dos processos dinâmicos de retornos crescentes de escala. Em suma, a proximidade geográfica entre as empresas eleva a probabilidade de ocorrência de aprendizados cooperativos e colaborativos. Este aprendizado pode ocorrer pela partilha de recursos comuns, pela presença de fornecedores especializados e também pelos transbordamentos de conhecimento e tecnologia.

Os trabalhos de Feldman (1993) e Audretsch \& Feldman (1996) abordam a questão do aprendizado através dos transbordamentos de conhecimento e tecnologia. Em ambos os estudos os autores encontram evidência de uma relação positiva e significativa entre as aglomerações produtivas $e$ as atividades pesquisa e desenvolvimento (P\&D). Ou seja, a co-localização da atividade produtiva e da atividade de pesquisa e desenvolvimento não é mera coincidência, na verdade é resultado dos canais de informação e conhecimento construídos pelas empresas locais. Ambos os trabalhos indicam que a transferência de habilidades (transbordamento de conhecimento e tecnologia) depende da natureza do conhecimento.

"A importância da proximidade geográfica depende da natureza do conhecimento envolvido na atividade produtiva” (FELDMAN, 1993). Para a autora, a proximidade geográfica é mais relevante em atividades, nas quais, os conhecimentos tácitos são 
prevalecentes, e possui menor importância nas atividades intensivas em conhecimentos codificados².

O desenvolvimento das tecnologias de comunicação, aparentemente, torna cada vez menos relevante às questões da localização. As observações empíricas demonstram que as atividades intensivas em conhecimento permanecem concentradas em termos geográficos (AUDRESCTH \& FELDMAN, 1996). Neste sentido, a localidade geográfica possui um poder explicativo significativo sobre os desenvolvimentos econômicos e tecnológicos, em especial, nos sistemas locais de produção.

\subsection{Proximidade cognitiva}

A partir dos trabalhos expostos, as pesquisas preocupadas com os efeitos econômicos gerados pelas aglomerações industriais buscaram uma trajetória de compreensão mais detalhada sobre os efeitos dos fluxos locais de conhecimento e seus determinantes para a concentração da atividade tecnológica. Essa trajetória fundamenta-se no pressuposto de que o conhecimento possui características específicas que limitam sua difusão. As características específicas nas quais estes trabalhos se fundamentam referem-se aos conceitos de conhecimento explícito e tácito presente no trabalho de Polanyi (1967).

O conhecimento explícito refere-se ao conhecimento adquirido pelo estudo formal (i.e: livros, manuais, pesquisas, patentes entre outros). Este pode ser apropriado de maneira direta sem a participação de outros indivíduos para a sua construção. Dessa forma, a transferência deste conhecimento para outros indivíduos é facilitada por sua característica codificada. Já o conhecimento tácito dificilmente é transferido sem a presença de interações entre os que detêm o conhecimento tácito e os interessados em adquirí-los. O conhecimento tácito está relacionado de maneira direta com as competências que o indivíduo desenvolveu ao longo de suas experiências práticas com o conhecimento em questão.

Posto isto, o conhecimento não se caracteriza como bem público, cujas características econômicas são a não rivalidade e não exclusividade. De fato, o

\footnotetext{
${ }^{2}$ A próxima seção se ocupará com as peculiaridades do conhecimento (explicito e tácito), especialmente, com a discussão sobre a transferência destes conhecimentos. Por hora fica apenas a indicação de Feldman (1993) que a depender das características especificas do conhecimento, sua mobilidade pode ser facilitada pelas características idiossincráticas do conhecimento.
} 
conhecimento pode até possuir uma natureza de bem não rival, no sentido de que seu uso, por inúmeros indivíduos, simultaneamente ou não, não aumenta seu custo de obtenção. Mas, não parece verdade que o conhecimento possui alguma natureza de bem não exclusivo. A capacidade que um indivíduo tem para utilizar determinado conhecimento é proporcional às capacitações construídas ao longo de sua trajetória de desenvolvimento.

A cumulatividade do processo de criação de novos conhecimentos e tecnologias corresponde à noção de dependência da trajetória. A dependência da trajetória referese à inércia dos processos de aprendizado passados para a formação dos futuros. Os processos dependentes da trajetória têm como definição característica a não ergodicidade, ou seja, possuem um caráter irreversível e histórico do sistema estudado. O passado é irrevogável, ou seja, não pode ser reproduzido com exatidão, na medida em que as condições iniciais não são mais as mesmas.

Cohen \& Levinthal (1990) afirmam que o conhecimento está distribuído de maneira heterogênea entre as empresas e sua natureza tácita e cumulativa assegura que o acesso a conhecimentos relevantes, por outras empresas, não é condição suficiente para tornar seu uso factível. A efetiva transferência de conhecimento requer uma capacidade de absorção mínima para identificar, interpretar e explorar os novos conhecimentos. A capacidade de absorção refere-se à habilidade de reconhecer o valor de um novo conhecimento, assimilá-lo e aplicá-lo a fins comerciais. As firmas com maior capacidade de absorção são, segundo os autores, mais aptas a aproveitar externalidades e transbordamentos tecnológicos provenientes de fontes externas, como outras firmas, universidades ou centros de pesquisa.

Dessa forma, a proximidade geográfica entre as empresas eleva a probabilidade da transferência de conhecimentos tácitos. Ou seja, as empresas em aglomerados industriais possuem maior proximidade cognitiva, e este é um dos motivos apresentados por Audrescth \& Feldman (1996) para justificar o melhor desempenho econômico e tecnológico destas empresas se comparadas às empresas não aglomeradas.

Entretanto, Menzel \& Fornahl (2010) alertam que níveis elevados de proximidade cognitiva podem resultar no aprisionamento negativo das competências locais. $O$ aprisionamento negativo das competências locais, em trajetórias tecnológicas que por ventura se tornem opções erradas, resulta no declínio econômico do aglomerado e, em casos extremos, em sua decadência. 
Os autores afirmam que existem razões não desprezíveis para que as empresas cultivem certas distâncias cognitivas de seus pares aglomerados. Em primeiro lugar a construção de conhecimento requer corpos complementares de conhecimento. A este respeito, a manutenção de certa distância cognitiva tende a ampliar o aprendizado das empresas aglomeradas, ainda que, limite a capacidade de absorção das empresas envolvidas. De outra forma, o excessivo compartilhamento de informações e conhecimentos pode restringir a capacidade de absorção das empresas direcionandoas a uma miopia funcional (MASKELL \& MALMBERG, 2007).

A miopia funcional corresponde à elevada proximidade cognitiva entre as empresas aglomeradas. Esta elevada proximidade cognitiva obscurece a visão das empresas às novas tecnologias e oportunidades de mercado, aprisionando-as em determinada trajetória tecnológica. Dessa forma, caso ocorra uma mudança repentina no processo produtivo (via progresso tecnológico, por exemplo), a empresa nesta condição terá dificuldade de abandonar as rotinas produtivas que obtiveram sucesso no passado, e que atualmente, devido à mudança, se tornaram redundantes.

O segundo ponto levantado para a manutenção de certa distância cognitiva pelas empresas aglomeradas refere-se aos transbordamentos de conhecimento e tecnologia. As diferentes habilidades no domínio de um determinado conhecimento representam barreiras à difusão. A empresa que detêm maior conhecimento sobre uma determinada trajetória tecnológica pode auferir maiores ganhos econômicos se restringir o fluxo deste conhecimento. Neste sentido, se houver uma elevada proximidade cognitiva, os conhecimentos chaves para a exploração desta oportunidade tecnológica podem vazar involuntariamente para outras empresas, que eventualmente podem se tornar novos concorrentes. Assim Menzel \& Fornahl (2010) concluem que o aprendizado pela interação pode ser acompanhado de alguma distância cognitiva sem comprometer as economias externas geradas pela aglomeração.

Para Malmberg \& Maskell (2010), os sistemas locais de produção são bons exemplos do balanceamento entre proximidade e distância cognitiva. Como afirmam os autores, a criação de conhecimentos em sistemas locais de produção ocorre através da variação e do aprofundamento da divisão do trabalho. Na dimensão horizontal (aprendizado entre os concorrentes locais com capacitações similares) o processo de aprendizado é conduzido por uma combinação entre distância cognitiva (variação) e proximidade cognitiva (capacitações similares). $O$ aprendizado horizontal ocorre porque as empresas podem monitorar, comparar e imitar as soluções desenvolvidas pelos 
seus concorrentes. Na dimensão vertical (o aprendizado entre usuário-produtor) o aprendizado ocorre pelo aprofundamento das interações, ou seja, pela especialização em uma determinada competência específica à interação. Isso ocorre por que as relações do tipo usuário-produtor propiciam o compartilhamento de experiências e de benefícios obtidos através da incorporação de melhorias e novas tecnologias no ambiente interno das firmas. 


\section{Das folhas a raiz: "os componentes de um sistema local de produção"}

Os sistemas locais de produção não são apenas constituídos por aglomerados de empresas. Os sistemas locais são constituídos de instituições. As instituições são as portadoras da memória organizacional coletiva, são as portadoras dos princípios organizacionais produtivos benéficos ao sistema local. Os esforços de pesquisa e desenvolvimento efetuados pelas instituições bem com os cursos de capacitação oferecidos à mão-de-obra formam os elementos de ação institucional (MENZEL \& FORNAHL, 2010).

As empresas e as instituições, em aglomerados industriais, que possuem uma área de trabalho comum, possuem na visão dos autores, uma fronteira temática. A fronteira temática delimita os vários ramos de atividade que uma mesma localização pode possuir. "A fronteira temática distingue os sistemas locais de produção do amplo sistema de produção e inovação da região" (MENZEL \& FORNAHL, 2010:212). Os entrelaçamentos estabelecidos entre os atores de um sistema local não estão restritos à fronteira temática. Ou seja, a transferência de conhecimentos tácitos tende a ocorrer de forma limitada no espaço geográfico devido às características intrínsecas do conhecimento (sua natureza tácita e codificada).

Neste sentido, Menzel \& Fornahl (2010) utilizam o conceito de fronteira espacial para se referir aos limites de influência que um sistema local possui no amplo sistema de produção e inovação da região. A fronteira espacial abarca instituições, empresas não aglomeradas e empresas aglomeradas em diferentes fronteiras temáticas. A dependência da trajetória e distâncias cognitivas das empresas e instituições criam as características regionais que as diferenciam das empresas não aglomeradas. A área de confluência entre a fronteira temática e espacial define o ramo de atividade econômica no qual o sistema local irá se especializar. As novas empresas e as estabelecidas, bem como as instituições aglomeradas em um sistema local, iniciarão suas atividades produtivas e de pesquisa de maneira associativa e cooperativa. Essa atividade coletiva se dá, grosso modo ao redor de um tópico específico, ou seja, um ponto focal. A depender do nível de abstração, um sistema local de produção pode possuir inúmeros pontos focais em diversas áreas industriais.

A figura 1 sumariza os elementos constitutivos de um sistema local de produção. Os sistemas locais são compostos, portanto, por empresas estabelecidas e instituições 
que possuem diversos pontos focais e estão envoltos em uma fronteira temática e espacial comum, além de novas empresas criadas pelo transbordamento de conhecimento e tecnologia.

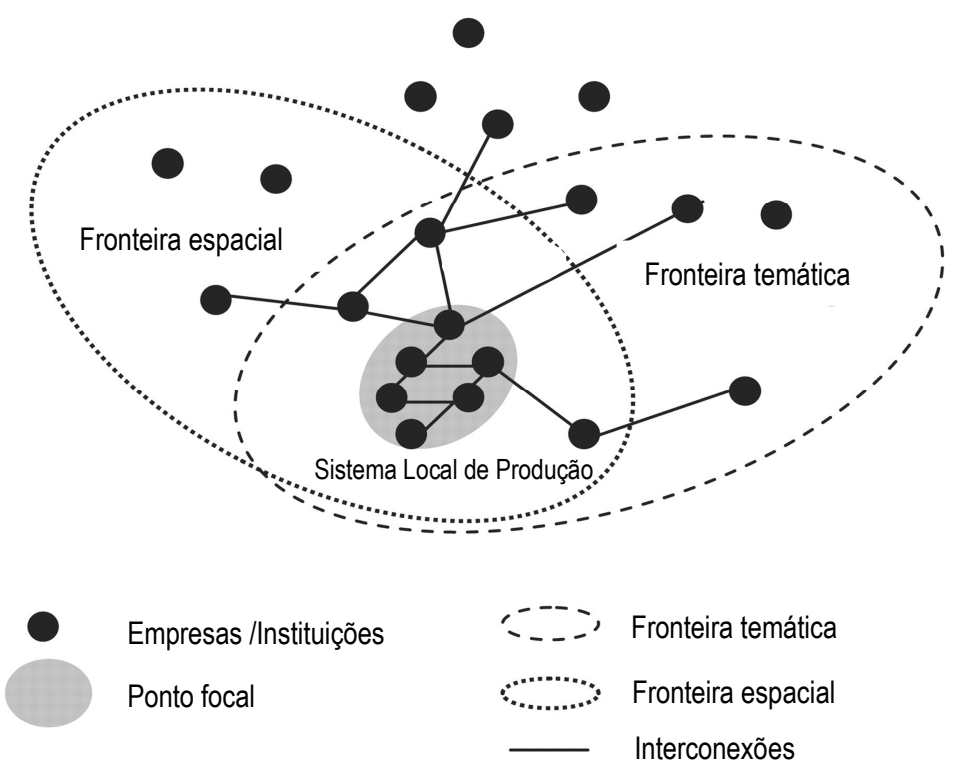

Figura 1. Elementos de um sistema local de produção

FONTE: Menzel \& Fornahl (2010: 214).

A conjugação destes elementos, como afirmam Menzel \& Forhnal (2010) geram quatro agrupamentos distintos: (a) as empresas e instituições que pertencem somente à mesma fronteira temática (linha tracejada); (b) as empresas e instituições que pertencem à mesma fronteira espacial (linha pontilhada); (c) as empresas não aglomeradas, as empresas aglomeradas e instituições, que pertencem à mesma fronteira temática e espacial, e por este motivo construíram um ponto focal, ou seja, construíram o sistema local de produção; e (d) as empresas e instituições que pertencem a diferentes setores em diferentes regiões. Mas, o que determina o grau de diversidade de conhecimento de um sistema local?

A princípio se poderia pensar que o número de atores (empresas estabelecidas, novas empresas e instituições) representaria o grau de diversidade do sistema. Quanto maior o número de atores maior seriam as interrelações entre seus pares. Mas, isso não é necessariamente verdade. A diversidade de conhecimento e tecnologia está relacionada, segundo Menzel \& Fornahl (2010) com a base de conhecimento dos atores envolvidos e com as distâncias cognitivas entre esses atores. 
Um sistema local de produção com um número reduzido de atores pode apresentar uma diversidade local de conhecimento igual, ou até mais elevada, que um sistema local que possui um número, proporcionalmente, maior de atores. Ou seja, o número de atores é condição necessária, mas não suficiente para determinar o grau de diversidade de conhecimento e tecnologia de um sistema local. Os autores descrevem o grau de diversidade de conhecimento e tecnologia através das noções de sistema local focalizado e sistema local heterogêneo. A figura 2 ilustra esta distinção.

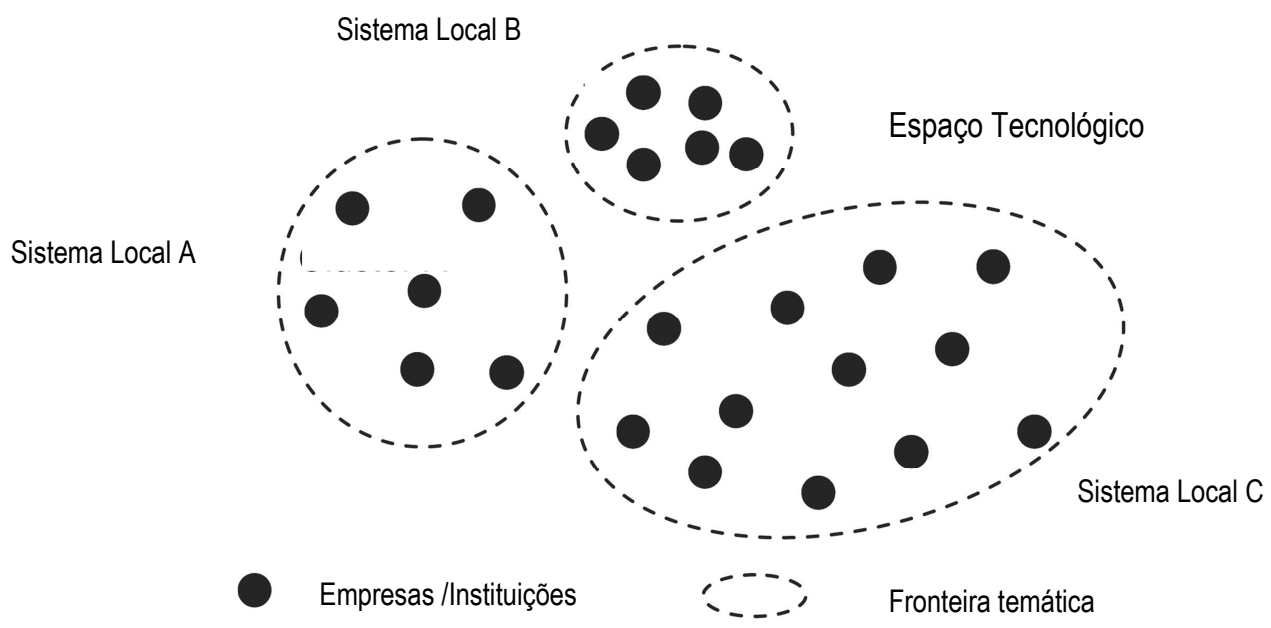

Figura 2. Sistemas locais de produção focalizados e heterogêneos

FONTE: Menzel \& Fornahl (2010: 217).

A figura apresenta configurações distintas de diversidade tecnológica e de conhecimento para um mesmo espaço tecnológico. Existem três pontos que distinguem os sistemas locais de produção apresentados acima.

O primeiro refere-se ao tamanho do sistema local de produção (medido pelo número de atores). O sistema local $\mathrm{A}$ e $\mathrm{B}$ possuem o mesmo número de atores. Já o sistema local $\mathrm{C}$ possui um número de atores mais elevado. O segundo ponto de distinção refere-se à diversidade, que está representado no diagrama pela base de conhecimento específico a cada ator. Dessa forma, o sistema local C, potencialmente, possui uma maior diversidade devido ao maior número de atores. A terceira distinção refere-se às distâncias cognitivas entre os atores de um mesmo sistema local de produção. O sistema local B é mais focalizado, uma vez que suas distâncias cognitivas são estreitas. Adicionalmente, o sistema local B possui o mesmo tamanho do sistema local A, todavia o sistema local A possui uma maior heterogeneidade de conhecimento se comparado a $B$, dado que suas distâncias cognitivas são amplas. Por outro lado o 
sistema local $\mathrm{C}$, potencialmente, possui uma maior diversidade de conhecimento devido ao seu maior número de atores, mas, contudo, apresenta a mesma heterogeneidade de conhecimento que o sistema local $A$, uma vez que os sistemas locais $A$ e $C$ possuem distâncias cognitivas similares.

A combinação entre os fatores: (a) tamanho, (b) base de conhecimento e (c) distância cognitiva levam Menzel e Fornahl (2010) a propor duas dimensões para avaliar a diversidade de conhecimento e tecnologia dos sistemas locais, a saber: dimensão quantitativa e dimensão qualitativa. A dimensão quantitativa refere-se ao número atividades econômicas e o número de postos de trabalho criados ao longo do ciclo de vida do sistema local de produção. A dimensão qualitativa corresponde às distâncias cognitivas entre os atores aglomerados. Para Menzel \& Fornahl (2010) dos inúmeros entrelaçamentos possíveis entre a dimensão quantitativa e qualitativa, "todos estão unidos a um elemento comum à heterogeneidade da base de conhecimento" ( $p$. 221).

A partir do exposto, a dimensão quantitativa consiste no número de empresas e empregados, enquanto a dimensão qualitativa consiste nos conhecimentos e habilidades específicas ao sistema local. Ambas as dimensões não possuem somente um efeito direto sobre o sistema local (medido pelo número de trabalhadores e pela diversidade de conhecimento), mas também influenciam as outras partes do sistema, ou seja, possuem um efeito sistêmico sobre o amplo sistema de produção e inovação da região.

A dimensão quantitativa sistêmica refere-se às formas pelas quais os atores aglomerados utilizam o tamanho do sistema local (número de atores) e os entrelaçamentos para acessar novas competências e tecnologias já existentes no sistema local, mas pouco exploradas para fins comerciais. A dimensão qualitativa sistêmica refere-se aos efeitos que as competências externas ao sistema local têm sobre a dinâmica econômica local.

As dimensões sistêmicas influenciam o processo de construção da fronteira temática e espacial do sistema local. A forma como as interrelações são construídas entre atores aglomerados e não aglomerados definem tanto a fronteira espacial quanto a temática. A fronteira espacial é formada pela dimensão quantitativa sistêmica, ou seja, esta dimensão reflete a localização das empresas e sua capacidade de construir instituições específicas ao sistema local. A dimensão qualitativa sistêmica representa a fronteira temática do sistema local. Uma fronteira temática estreita consiste na 
especialização das empresas aglomeradas em atividades não relacionadas à atividade principal do sistema local e que porventura, deixem de existir no local. Já uma fronteira temática larga refere-se à especialização das empresas aglomeradas em atividades relacionas com a atividade principal do sistema local (i.e. empresas que diversificam suas pesquisas em áreas afins a temática do sistema local e, ao fazê-lo ampliam as competências do sistema local).

Tabela 1. Dimensões Qualitativa e Quantitativa: efeito direto e sistêmico

\begin{tabular}{lll}
\hline EfeitolDimensões & Quantitativa & Qualitativa \\
\hline Direto & $\begin{array}{l}\cdot \text { Tamanho (número de } \\
\text { organizações, atores, e postos de } \\
\text { trabalho). }\end{array}$ & $\begin{array}{l}\cdot \text { Diversidade (Conhecimento, } \\
\text { competências, e formas de } \\
\text { organização). }\end{array}$ \\
\hline Sistêmico & $\begin{array}{l}\cdot \text { Uso do tamanho (percepção do } \\
\text { sistema local, capacidade de ação } \\
\text { coletiva). }\end{array}$ & $\begin{array}{l}\cdot \text { Uso da diversidade (Exploração de } \\
\text { sinergias, rede e cadeia de valor). }\end{array}$ \\
\hline
\end{tabular}

FONTE: Elaborado pelo autor com base em Menzel \& Fornahl (2010: 218).

A dimensão quantitativa direta ou sistêmica sofre constantes alterações ao longo do processo de evolução do ciclo de vida. Por exemplo, na fase de emergência o número de atores que constitui o sistema local é reduzido e, grosso modo, possuem um pequeno porte industrial. Já na fase de crescimento as taxas de criação de novos postos de trabalho sofrem incrementos significativos, porém em algumas poucas atividades econômicas relacionadas (início do processo de especialização produtiva). Neste ponto o sistema local alcança sua fase de sustentação. Neste sentido, o sistema local encontra-se no auge de sua forma produtiva. Esta fase é caracterizada pela cristalização de uma, ou mais, especialidades produtivas (trajetórias tecnológicas). A partir deste momento a taxa de criação de postos de trabalho sofre significativa redução. E, por fim, é alcançada a fase de exaustão do sistema local, caracterizada pela destruição dos postos de trabalho criados nas fases anteriores.

Para a dimensão qualitativa direta e sistêmica os efeitos ao longo o ciclo de vida são outros. $\mathrm{Na}$ fase de emergência do ciclo de vida, os sistemas locais possuem um baixo número de atores com amplas distâncias cognitivas. Ao longo do tempo as economias externas geram novas oportunidades de negócio, que adensam á aglomeração industrial. Nesta fase de crescimento, o número de atores sofre significativos incrementos e as distâncias cognitivas iniciais se reduzem. As interrelações 
empresariais e transbordamentos de conhecimento são os responsáveis pela redução das distâncias cognitivas. O estreitamento dos laços produtivos e tecnológicos entre os atores tornam a trajetória do sistema local focalizada e as distâncias cognitivas iniciais sofrem decréscimos cada vez mais significativos. Quanto mais focalizado o sistema local se torna, menores são as distâncias cognitivas, ou seja, os atores estão cada vez mais imbricados em uma trajetória tecnológica comum. Os sistemas locais de produção iniciam sua fase de exaustão se, e somente se, os atores que compõem o sistema local não forem capazes de manter uma heterogeneidade crítica da base de conhecimento local. Se a base de conhecimento sofrer incrementos suficientes para alterar o modus operandi, o sistema local iniciará um novo ciclo de vida, uma nova fase de crescimento, ou de forma mais disruptiva, uma nova atividade tecnológica.

A evolução dos sistemas locais ao longo do seu ciclo possui um comportamento oscilante entre os extremos do ciclo (a emergência e a exaustão), como prosseguem Menzel \& Fornahl (2010): "as diferentes estratégias empresariais (as diferentes explorações das distâncias cognitivas) resultam, inevitavelmente, em diferentes trajetórias de desenvolvimento, e a utilização desta heterogeneidade pelas empresas tem como resultado diferentes ciclos de vida" (p.219). Ou seja, as dimensões qualitativa e quantitativa assumem distintos papéis ao longo das fases do ciclo de vida do sistema local de produção. 


\section{Uma sequência de fenômenos ou fatos: "as fases do ciclo de vida"}

\subsection{A Fase de emergência}

É difícil definir com precisão a fase de emergência de um sistema local de produção. A principal razão para isto é que quando um sistema local emerge, em um momento histórico propício, sua diversidade de competências é tão baixa que mal pode ser distinguido de outras regiões onde não existem aglomerados industriais.

Para Menzel \& Fornahl (2010) a distinção entre sistemas locais e empresas não aglomeradas se dá pela forma com que os primeiros constroem e selecionam as trajetórias tecnológicas promissoras. As trajetórias tecnológicas podem criar as condições para a emergência das economias externas. Somente a combinação de condições favoráveis como a emergência de conhecimentos específicos em um dado local, a existência de mão-de-obra qualificada, infraestrutura, apoio político e científico, ou uma combinação destes fatores, poderá dar início à atividade produtiva de um sistema local. O sistema local emerge quando os atores aglomerados criam sinergias em torno de uma temática de trabalho comum. O compartilhamento de conhecimentos e processos produtivos cria as condições necessárias para a emergência de economias externas. Ao longo do tempo, os transbordamentos de conhecimento e tecnologia criam os fatores endógenos para o crescimento do sistema local nas novas empresas. $O$ incentivo a emergência de novas empresas são considerados pelos autores as responsáveis pelo crescimento inicial dos sistemas locais (BERGMAN, 2007; MENZEL \& FORNAHL, 2010). Mas, como se criam os incentivos para a emergência de novas empresas?

Para Menzel \& Fornahl (2010), a taxa de nascimento de novas empresas não é função restrita do tamanho (número de empresas, ou empregados) do sistema local, mas sim da forma como este tamanho é utilizado, pelos atores que o compõe, para criar novas oportunidades de negócio ${ }^{3}$. Em outras palavras, um número maior de atores locais não garante um número maior de oportunidades de negócio. A taxa de nascimento das novas empresas está relacionada com a dimensão qualitativa

\footnotetext{
${ }^{3}$ A comparação entre o número de atores de distintos sistemas locais é condição necessária, mas não suficiente para afirmar que um sistema local possui maiores oportunidades de negócios em detrimento de outros. Como afirma Menzel \& Fornahl (2010) o que defini o volume e a intensidade das oportunidades de negócio de um sistema local são as formas pelas quais os autores locais constroem os fluxos de conhecimento e tecnologia entre as empresas aglomeradas e não aglomeradas (veja figura 2).
} 
sistêmica, como prosseguem os autores, "as redes sociais e o ambiente empresarial da região que suportam as novas empresas influenciam na forma como as inúmeras e potenciais empresas são geradas". Adicionalmente, "a dimensão qualitativa sistêmica influência no tipo de novas empresas que emergirá” (p. 225).

$\mathrm{Na}$ dinâmica deste processo, as empresas estabelecidas também buscarão novas oportunidades de negócio. O processo de aprendizado construído, anteriormente, pelas empresas estabelecidas potencializa a redução das distâncias tecnológicas criadas pela emergência de novas empresas. A convergência, fruto desta interação, torna os entrelaçamentos entre novas empresas e empresas estabelecidas bastante possíveis, juntamente com o processo de especialização do trabalho e as oportunidades de apropriação dos retornos crescentes de escala. A conjugação destas forças marca o processo de emergência dos sistemas locais (BERGMAN, 2007).

Menzel \& Fornahl (2001) ainda afirmam que em inúmeros casos os sistemas locais podem não passar da fase de emergência. Há duas razões, segundo os autores, para o malogro da fase de emergência. A primeira delas refere-se à falta de entrelaçamento entre as empresas locais, "quando a capacidade de formar uma temática de trabalho comum desaparece” (MENZEL \& FORNAHL, 2010: 226). Nesta perspectiva, as empresas estabelecidas e novas empresas não compartilham uma temática de trabalho comum, ou seja, eles desenvolvem diferentes trajetórias tecnológicas que, ampliam as distâncias tecnológicas entre os atores envolvidos. A segunda razão para este desfecho se dá através de elevadas taxas de saída de atores do aglomerado sem a respectiva contrapartida de entrada, ou emergência de novas empresas. Dessa forma, ocorre uma desconcentração industrial no local e, as lacunas deixadas na rede pelas empresas que saíram afetam a eficácia do sistema local emergente, uma vez que limita os entrelaçamentos entre os atores envolvidos. Por estes motivos "o sistema local de produção pode nunca passar da fase de emergência” (BERGMAN, 2007: 4).

\subsection{A Fase de crescimento}

As condições de emergência são pré-requisitos necessários para a construção de um sistema local de produção. Após está fase de emergência o sistema local apresenta incrementos significativos no emprego e estabelecimentos, fruto do crescimento acentuado das empresas estabelecidas e das novas empresas aglomeradas. Tanto as empresas estabelecidas quanto as novas empresas agora direcionam seu crescimento 
para uma trajetória tecnologia e econômica específica. A diversidade de conhecimento e distância cognitiva se reduz e as diferentes trajetórias tecnológicas iniciais dão lugar a um conjunto imbricado de trajetórias tecnológicas.

A fase de crescimento se esgota quando o sistema local ajusta-se ao crescimento médio da indústria (AUDRETSCHSCTH \& FELDMAN, 1996; FELDMAN, 1993; BERGMAN, 2007; MENZEL \& FORNAHL, 2010). A principal razão para esse ajuste, segundo os autores, é a redução da diversidade de conhecimento. Diferente de Menzel \& Fornahl (2010), Bergman (2007) afirma que a fase de crescimento do ciclo de vida do sistema local pode ser distinguida e rotulada por duas subfases uma referente à expansão exploratória e outra referente à expansão explotativa.

A subfase de expansão exploratória refere-se à etapa inicial da trajetória de expansão das economias externas. Nesta, as empresas exploram os efeitos benéficos gerados pelas economias externas (i.e. os transbordamentos de conhecimento e tecnologia, a infraestrutura construída no sistema local (recursos comuns), a mão-deobra especializada e os fornecedores especializados em bens e serviços).

"Esta fase corresponde a um "regime tecnológico empreendedor" identificado por (Sidney) Winter (1984: 297) "que é favorável à entrada inovadora, mas desfavorável para as empresas estabelecidas". As empresas estabelecidas estão, nos termos de Winter, em um "regime tecnológico rotinizado" que é dominado pela fase de "expansão explotativa", durante a qual a explotação sistêmica ocorre sobre, as economias de escala do sistema local, sobre os processos tecnológicos eficientes que impulsionam o crescimento da empresa, que muitas vezes são influenciados pelas políticas deliberadas dedicadas à melhoria $e$ ampliação das vantagens benéficas" (p.6).

A subfase de expansão exploratória pode ser descrita, segundo Bergman (2007), como a etapa schumpeteriana do ciclo, uma vez que se origina em uma perturbação tecnológica anterior que estimula o comportamento empreendedor dos empresários e potencializa as novas tecnologias, a busca por novos mercados e novos modelos de negócios.

Após as empresas consolidarem uma trajetória tecnológica promissora a subfase de expansão exploratória é substituída pela subfase de expansão explotativa. Entretanto, como prossegue Bergman (2007: 9):

“É, nesta fase, no entanto, que pode gerar os primeiros desvios que causarão problemas mais tarde. O sucesso das empresas é fácil nesta fase, de modo que existe pouca pressão para a ampliação de pesquisas exploratórias e outras aplicações de seus conhecimentos. É tentador 
concentrar-se no produto mais vendido para produzi-lo em maiores quantidade, e assim gozar das economias de escala".

Ainda para o autor, a redução dos esforços de pesquisa e desenvolvimento em novas oportunidades tecnológicas leva as empresas a concentrar a maior parcela dos seus esforços empresariais na proteção de vantagens competitivas criadas anteriormente. Esse comportamento foi denominado por Maskell \& Malmberg (1999), como um mecanismo de isolamento:

"(...) os mecanismos de isolamento surgem em regiões inovadoras que protegem suas vantagens tecnológicas dos concorrentes externos. Em primeiro lugar, "a eficiência em massa dos ativos" é a ideia de que, historicamente, as aglomerações em atividades tecnológicas como de $P \& D$, ou alguma atividade relacionada à inovação, não são facilmente replicadas pelas empresas de regiões concorrentes. Segundo, as "deseconomias de compressão de tempo" são desvantagens custosas, mas necessárias, que as empresas de uma determinada região devem superar para tentar replicar e dominar as capacitações tecnológicas superiores das empresas estabelecidas em outra região, que podem manter um desempenho superior devido à dinâmica de retornos crescentes" (p. 17).

Até este ponto, a análise se focou no processo pelo qual os sistemas locais amadurecem e se movem para além das fases inovadoras. No entanto, um sistema local em estado estável de maturidade pode não estar preparado para um inesperado distúrbio tecnológico, como os ocorridos durante sua fase inicial de expansão, ou seja, no atual momento as mudanças tecnológicas podem afetar a estabilidade do sistema local.

Maggioni (2005) descreve os seguintes efeitos para um sistema local frente às mudanças tecnológicas disruptivas.

"Enquanto a tecnologia passa por um "progresso normal" o intercâmbio de conhecimentos dentro do sistema local de produção estabelecido tenderá a preservar suas empresas líderes. Quando chegam as novas tecnologias que são descontinuas às anteriores a concentração industrial existente pode ser de pouco valor e, em seguida a resultante é que as novas tecnologias tendem a ser exploradas em novos sistemas locais de produção que não sofrem de deseconomias associadas com o sistema local estabelecido" (p. 21).

Neste sentido, Menzel \& Fornahl (2010) afirmam que as capacitações tecnológicas construídas, ao longo do processo de emergência e crescimento do sistema local, criaram redes de interação entre as empresas aglomeradas e não aglomeradas. Ou seja, os entrelaçamentos entre os atores dentro e fora do sistema local são os 
responsáveis por alimentar o sistema local com novos conhecimentos. Esses novos conhecimentos quando integrados a atividade principal do sistema local alteram de maneira incremental a fronteira temática e as capacitações tecnológicas iniciais do sistema local. Para Bergman (2007), eventos deste tipo colocam desafios qualitativamente diferentes aos sistemas locais maduros bem como aos sistemas locais emergentes.

\subsection{A Fase de exaustão}

A redução do número de empresas bem como a destruição permanente dos postos de trabalho caracteriza a fase de exaustão do ciclo de vida. As novas empresas são eventos raros durante esta fase. Um sistema local em face de exaustão apresenta elementos de aprisionamento. Este aprisionamento é causado pelas restrições cognitivas impostas pelas fases anteriores. A construção de uma base de conhecimento tem como resultado a formação de mão-de-obra altamente qualificada e especializada em uma, ou mais, capacitações tecnológicas. As oportunidades tecnológicas endógenas ao sistema local estão restritas às trajetórias tecnológicas existentes. E, portanto, é baixa a probabilidade de alterações estruturais oriundas de desenvolvimentos tecnológicos internos ao sistema local de produção (MENZEL \& FORNAHL, 2010).

"Com o número de empresas se reduzindo, as redes de pesquisas não são mais necessárias, já que não há nenhuma nova informação a ser transferida. As empresas em sistemas locais de produção já não conseguem permanecer competitivas, se comparadas a empresas verticalmente integradas, dado que o número de nós da rede foi drasticamente reduzido. Quanto menor as redes, menores são as informações e conhecimentos estimulantes que ela pode oferecer, ou seja, menores são as chances de um sistema local de produção inovar em produto, processos, ou novas organizações. O sistema local de produção já possui ampla maturidade, e a região em que está enraizado tornou-se uma área problemática, uma região com pouco potencial endógeno para encontrar novas dinâmicas" (BERGMAN, 2007: 230).

Com o aprisionamento das competências locais, a trajetória tecnológica apresenta poucas oportunidades comerciais e o sistema local entra em exaustão. Entretanto, as causas do aprisionamento não residem apenas na exaustão da trajetória tecnológica. $O$ esgotamento da trajetória tecnológica é um ponto importante, mas o processo de redução da heterogeneidade e diversidade do conhecimento pode estreitar a 
capacidade de resiliência do sistema local de produção. Assim, o sistema local de produção perde a capacidade endógena de sustentar uma diversidade de conhecimento mínima, importante para a exploração de novas oportunidades de negócios.

Para Menzel \& Fornahl (2010), existem dois desfechos para a fase de exaustão do ciclo de vida. Na primeira, os atores que compõem o sistema local não conseguem criar os mecanismos endógenos necessários para a continuidade da atividade econômica e, dessa forma, o sistema local sofre reduções significativas nos postos de trabalho e no número de participantes até sua estagnação e, no limite, seu desaparecimento. No segundo, a quebra do aprisionamento se dá pela criação de novas trajetórias, as quais grosso modo, estão envolvidas com o aumento da heterogeneidade e diversidade de conhecimento. Neste caso, o apoio governamental é fundamental.

Em um destes desfechos, as empresas renovam a trajetória de desenvolvimento vigente através da assimilação de uma nova, e contudo relacionada, tecnologia, muitas vezes existentes em outras localidades. A outra possibilidade de renovação refere-se à ruptura da fase de exaustão, através da transição para campos tecnológicos completamente diferentes.

\subsubsection{Aprisionamento}

Embora raramente apresentada como uma fase distinta do ciclo de vida dos sistemas locais, o aprisionamento descreve como os eventos e decisões passadas "isolaram" os sistemas locais em suas capacitações locais.

Grabher (1993), afirma que o aprisionamento das competências locais corresponde a uma "armadinha da especialização rígida". Grabher (1993) definiu a armadilha de especialização rígida a partir de três tipos distintos de aprisionamento: (a) aprisionamento funcional, que se refere às estruturas hierárquicas rígidas, em que as estreitas relações inter-empresas, especialmente, entre as grandes empresas e seus fornecedores (pequenos e médios), eliminam a necessidade de outros atores no processo de marketing, pesquisa e desenvolvimento. A falta de renovação nos atores que compõem a rede limita a renovação das dinâmicas tecno-econômicas intra-rede; (b) aprisionamento cognitivo, que se refere a erros de interpretação por parte das empresas nas quais tendências são confundidas com crises cíclicas; e (c) aprisionamento político, que se refere a um tecido institucional que visa à preservação 
das estruturas industriais tradicionais. $\mathrm{O}$ aprisionamento político, portanto, cria barreiras estruturais à mudança.

A partir do exposto, Bergman (2007) afirma que grande parte dos elementos da armadilha da especialização rígida está presente na fase de expansão explotativa, a saber, o excesso de orientação interna e pensamento de grupo (aprisionamento cognitivo), laços fortes nos entrelaçamentos locais (aprisionamento funcional), e excessiva dependência de suporte público compensatório (aprisionamento político, dependência a pacotes, ou programas, que tornem o sistema local "artificialmente" viável no mercado). Os fatores apontados reduzem a capacidade de resiliência do sistema local nas diferentes fases de seu ciclo de vida.

\subsubsection{Renascimento}

As empresas em sistemas locais, em face da exaustão, se especializaram em um determinado núcleo de capacitações e tornaram a base de conhecimento local bastante homogênea. A homogeneidade da base de conhecimento apesar de resultar em taxas de crescimento maiores nas fases iniciais do ciclo de vida pode reduzir de maneira nociva à diversidade e heterogeneidade do conhecimento nas fases posteriores.

A primeira possibilidade de reestruturação local apresentada por Bergman (2007) refere-se às interrelações, aos laços, criados entre os atores em diferentes sistemas locais estabelecidos no amplo sistema de produção e inovação da região, ou seja, à diversidade de atores. Estes laços podem ajudar a estimular novos modelos de negócios no sistema local em exaustão. As redes de cooperação e pesquisa construídas entre diferentes sistemas locais que possuem diferentes idades, origens e modelos de negócios proporciona novas perspectivas para o sistema local em exaustão, ou seja, potencializa a renovação, ou emergência, de uma nova dinâmica tecnológica.

A segunda possibilidade de reestruturação local consiste na construção de fontes tecnológicas polivalentes. As rotinas enraizadas e a predisposição tecnológica construída ao longo do processo de desenvolvimento do sistema local aprisionaram as competências locais em uma trajetória de desenvolvimento específicas. Contudo, o amplo sistema de produção e inovação da região contêm perspectivas e recursos tecnológicos não explorados por grande parte das empresas aglomeradas e, que possuem grande valor para a dinâmica tecnológica local. As capacitações locais 
construídas podem, eventualmente, ser empregadas para outros potenciais tecnológicos. Dessa forma, o aproveitamento das competências locais em outras trajetórias tecnológicas pode regenerar a dinâmica econômica local.

A terceira possibilidade de reestruturação local refere-se aos novos conhecimentos gerados pelas universidades e institutos de pesquisa da região, à base científica do conhecimento. A presença de universidades e centros de pesquisa nas proximidades do sistema local em fase de exaustão representa o acesso potencial a uma nova base científica.

Betts \& Lee (2004), afirma que o acesso potencial a novas bases científicas é expresso nas capacitações das universidades e institutos de pesquisa, ou seja, em seu potencial (i) formador (formação de capital humano); (ii) inovador (comercialização direta); (iii) parceiro (projetos e pesquisas conjuntas); (iv) atração de talentos (atração de trabalhadores externos intensivos em conhecimento); (v) facilitador (networking); (vi) geração de conhecimento e infraestrutura de pesquisa; e, (vii) liderança em inovação. Para os autores, sistemas locais de produção próximos a uma base de científica acessível podem ter, de fato, uma forte relação com a atividade de pesquisa e desenvolvimento.

As três possibilidades de reestruturação local, discutidas a partir de Bergman (2007), referem-se ao esforço individual dos atores aglomerados em romper com o aprisionamento das competências locais. Contudo, a ruptura da fase exaustão do ciclo de vida dos sistemas locais tem sido estudada, segundo o próprio autor, por analistas políticos que buscam identificar ações públicas que auxiliem os sistemas locais neste renascimento.

A identificação de mecanismos de ação pública é um passo apropriado, como afirma Bergman, uma vez que as políticas de apoio podem ser utilizadas como uma agenda de ação para os diferentes sistemas locais em exaustão. Contudo, como o autor prossegue, "a simples passagem do tempo" é um fator importante para que surjam "reações espontâneas" nos atores que compõem o sistema local.

Bergman prossegue, "após o reconhecimento da crise de exaustão do sistema local" - Governo pode incentivar "a substituição gradual (e talvez redução) dos atores estabelecidos por incumbentes, à depreciação e substituição da infraestrutura e instituições obsoletas, a reavaliação dos custos unitários e dos bens de capital, e uma apreciação reativa às ideias externas, inovações e tecnologias”. Entretanto, Bergman reconhece que o processo de reestruturação "apesar de doloroso, raramente, poderá 
ser evitado", uma vez que, as empresas estão em processos de miopia funcional, na qual, as capacitações anteriormente construídas tornaram-se redundantes, ou seja, somente através da quebra desta miopia o sistema local poderá renascer. O autor ainda alerta que formas alternativas de ação pública podem ser buscadas em outros sistemas locais de produção, uma vez que estes podem possuir "ativos adicionais (diversidade de atores; fontes de tecnologia polivalente; e base científica de conhecimento) que ajudem, acelerem, ou garantam o processo de reestruturação local" (p. 13).

O processo de (re)construção das competências locais de cada sistema local de produção influencia e é influenciado pelas mudanças em outros sistemas locais através da difusão de conhecimento e tecnologia provida pelo amplo sistema regional de inovação (BERGMAN, 2007). O desenvolvimento do sistema local através das diferentes fases do ciclo de vida é tanto quantitativamente descrito por um crescimento e um declínio no número de empresas e empregados, quanto qualitativamente, pela diversidade e heterogeneidade do conhecimento. A combinação entre a dimensão quantitativa e qualitativa salienta que dois grupos com o mesmo tamanho (número de empresas e trabalhadores) e até mesmo no mesmo ramo de atividade tecnológica, podem estar em diferentes fases do ciclo de vida, a depender do domínio que as empresas aglomeradas possuem sobre as competências específicas à tecnologia (SAXENIAN, 1994; MENZEL \& FORNAHL, 2010).

Os autores afirmam que só há vantagens econômicas para as empresas aglomeradas entre dois momentos específicos ao longo de sua evolução no ciclo de vida. O primeiro momento é, após a emergência, quando a aglomeração de empresas atinge massa crítica o suficiente para desempenhar resultados econômicos superiores aos seus pares isolados. O segundo momento é, após o reconhecimento da exaustão das competências locais, quando não há novas oportunidades de negócios e o desenvolvimento das empresas aglomeradas é inferior aos seus pares isolados. Como prossegue Menzel \& Fornahl, "estes dois pontos marcam as questões cruciais relativas ao desenvolvimento do sistema local de produção, ou seja, como é que um sistema local emergente torna-se um sistema local maduro e como pode ser prevenido o declínio das competências locais".

O tratamento abrangente dessas questões constitui uma tarefa bastante extensa ao passo que em cada fase do ciclo de vida "requer diferentes métodos empíricos e dados". A análise da dimensão quantitativa requer informações como, por exemplo, 
taxa de sobrevivência das empresas, número de novas empresas e número de postos de trabalho. O exame da dimensão qualitativa deve-se concentrar no grau de heterogeneidade do conhecimento (i.e. "dados sobre patentes ou áreas de negócios” p. 232).

Diante do exposto, os procedimentos metodológicos utilizados neste trabalho serão discutidos em seguida. 


\section{Procedimentos metodológicos}

A tipologia dos sistemas locais de produção presentes no trabalho de Suzigan et al. (2001; 2006) apresenta quatro tipos básicos de sistema local. Para o cômputo da tipologia, dois indicadores regionalizados precisam ser combinados, a saber: um índice de especialização, para mensurar a importância local e um coeficiente de concentração, para capturar a importância industrial. O coeficiente de concentração (CC) demonstra a importância de determinada atividade na estrutura econômica de uma da microrregião. Já para a definição da importância local, Suzigan et. al (2001; 2006) utiliza o quociente locacional (QL). O QL mensura o peso da microrregião na composição da atividade industrial dentro do estado de São Paulo, de outra maneira, o QL determina qual o grau de especialização produtiva de uma microrregião em cada uma das atividades econômicas ali existentes. O QL é obtido pela seguinte fórmula:

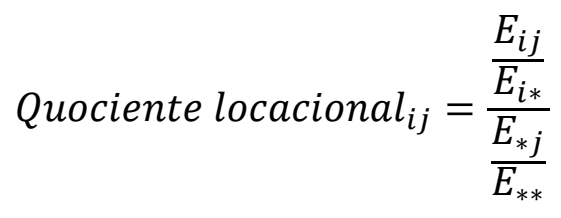

Onde,

$E_{i j}=$ volume de emprego no setor $i$ na microrregião $j$;

$E_{i *}=$ volume de emprego em todas os setores da microrregião $j$

$E_{* j}=$ volume de emprego do setor $i$ em todos as microrregiões de São Paulo; e, $E_{* *}=$ volume de emprego global no Estado de São Paulo.

Em adição ao coeficiente de concentração, bem como ao quociente locacional, Suzigan et al. (2001; 2006) apresenta o "número de estabelecimento" como variável controle. A utilização desta variável controle justifica-se, uma vez que a presença de um elevado QL em uma microrregião pode ser "mera decorrência da presença local de uma (única) grande empresa" o que, de fato, não se caracterizaria como um sistema local. Dessa forma, só foram consideradas atividades econômicas relevantes para o sistema local as atividades industriais que possuíssem no mínimo dez estabelecimentos em uma mesma microrregião. 
A combinação do quociente locacional com o coeficiente de concentração resulta em uma matriz 2x2 que comporta quatro quadrantes da seguinte forma: divide-se 0 quociente locacional em dois grupos: um primeiro representado pelas atividades industriais com reduzida especialização, ou seja, com quociente locacional entre $2<$ $\mathrm{QL} \leq 5$, e um segundo com elevada especialização, $\mathrm{QL}>5$. O coeficiente de concentração, a exemplo do QL, também foi dividido em dois grupos. Um primeiro pertencente às atividades industriais com reduzida importância, cujos percentis de participação no emprego estão entre $1 \%<C C \leq 10 \%$ do total da indústria e, as atividades industriais com elevado grau de participação, CC > 10\%. A resultante desta combinação é a tipologia dos sistemas locais (Tabela 2).

Tabela 2. Tipologia dos Sistemas Locais de Produção

\begin{tabular}{|c|c|c|c|c|}
\hline \multicolumn{3}{|l|}{$\begin{array}{l}\text { Ano: } \\
\text { Microrreaião }\end{array}$} & \multicolumn{2}{|c|}{ Importância para a atividade industrial } \\
\hline \multicolumn{3}{|l|}{ Classe CNAE: } & Reduzida & Elevada \\
\hline \multirow{2}{*}{ Importância Local } & Reduzida & $2<Q L \leq 5$ & Embrião de sistema local & Vetores avançados \\
\hline & Elevada & $\mathrm{QL}>5$ & Vetor de desenvolvimento local & Núcleo de desenvolvimento setorial-regional \\
\hline
\end{tabular}

Observações/Filtros: Número de estabelecimentos $\geq 10 ; \mathrm{QL} \geq 2 ; \mathrm{CC} \geq 1$.

FONTE: SUZIGAN et al. (2006).

O primeiro tipo de sistema local identificado por Suzigan et al. $(2001 ; 2006)$ se destaca por sua importância tanto para o desenvolvimento local (capturado por um índice de especialização), como para a atividade industrial (representada por sua participação no emprego total) e, por este motivo, foi denominado de Núcleo de Desenvolvimento Setorial-Regional (NDS-R). $O$ segundo tipo possui grande importância para a atividade industrial, mas, como afirmam os autores, "por estarem diluídos num tecido econômico muito maior e mais diversificados, têm pouca relevância para o desenvolvimento econômico local ou regional'. Ou seja, a microrregião é importante para a atividade industrial, mas a atividade industrial é pouco importante para a microrregião. Ainda para os autores, estas relações estão associadas às grandes cidades industrializadas e, sobretudo, as regiões metropolitanas. A ampla disponibilidade de recursos complementares muito significativos para a atividade industrial é a marca central deste tipo de sistema local, que foi denominado Vetor Avançado (VA). 
Se de um lado existem sistemas locais que se caracterizam por sua elevada importância para o setor industrial e pelo seu alto grau de diversificação industrial, de outro lado existem sistemas locais que se destacam por sua elevada importância local e reduzida importância setorial. Para os autores, este terceiro tipo de sistema local, grosso modo pode ser considerado um "pólo regional em atividades cuja produção é geograficamente bastante dispersa" e, dessa forma, foi denominado de $\underline{\text { Vetor de }}$ Desenvolvimento Local (VDL). Por fim, um quarto tipo de sistema local foi caracterizado por sua reduzida importância local e setorial, representando um Embrião de Sistema Local (ESL).

Mas, como a tipologia dos sistemas locais pode auxiliar no estudo dos ciclos de vida? O objetivo de Suzigan et al. (2001; 2006), à época da elaboração de seus estudos, não estava em identificar ciclos de vida, mas sim como demonstrado, estava em identificar e mapear as diferentes estruturas industriais dos sistemas locais. Contudo, como demonstrado nos capítulos 2 e 3 deste trabalho, os parâmetros utilizados por Menzel \& Fornahl (2010) para identificar e mapear o ciclo de vida, ao menos em sua dimensão quantitativa, são similares aos usados por Suzigan et al. (2001; 2006) para a construção da tipologia - alterações na número de estabelecimentos e postos de trabalho. Ou seja, o esforço de identificação e mapeamento da tipologia dos sistemas locais incorpora alterações na dimensão quantitativa, descrita por Menzel \& Fornahl (2010) como parâmetros que auxiliam na definição das fases do ciclo.

Menzel \& Fornahl (2010), definem a fase de emergência como a fase pela qual o sistema local possui reduzido número de estabelecimentos e postos de trabalho. Neste sentido, os parâmetros que definem um Embrião de Sistema Local na tipologia descrita por Suzigan et al. (2001; 2006) possuem características similares ${ }^{4}$ à fase de emergência: reduzida importância industrial (1\%<CC $\leq 10 \%)$ e local $(2<\mathrm{QL} \leq 5)$. Ou

\footnotetext{
${ }^{4}$ A seção 3.1 deste trabalho descreve a fase de emergência através da concepção de Bergman (2007) e Menzel \& Fornahl (2010). Em ambos os trabalhos a fase de emergência é descrita como um fenômeno aleatório que necessita de condições mínimas para ocorrer - para maiores detalhes sobre as condições mínimas veja Arthur (1990). Neste sentido, a tipologia dos sistemas locais, descrita por Suzigan et al. (2001; 2006), não abarca a completude do fenômeno da aleatoriedade para a emergência dos sistemas locais. Contundo, ela comporta as características mínimas que descrevem uma atividade industrial como relevante para o sistema local. E, para os fins deste trabalho são características o suficiente para considera-la como pertencente à fase de emergência.
} 
seja, os embriões de sistema local representam para os fins deste trabalho, a fase de emergência do ciclo de vida.

Ao longo do tempo e com o aumento dos parâmetros (número de estabelecimentos e postos de trabalho) o sistema local deixa a fase de emergência para trás e avança um estágio em seu ciclo. Menzel \& Fornahl (2010) reconhecem que os incrementos nos parâmetros são condições suficientes para que o sistema local alcance a fase de crescimento. Na tipologia dos sistemas locais os incrementos nos parâmetros podem gerar evoluções distintas a depender do comportamento da base industrial local e da base industrial do estado de São Paulo. Por exemplo, o aumento do volume de emprego em uma atividade industrial pode ser o suficiente para apresentar alterações na base industrial local - capturada pelas alterações no quociente locacional - o que deslocaria a atividade industrial na tipologia dos sistemas locais de um Embrião de Sistema Local para um Vetor de Desenvolvimento Local. Isso só ocorrerá se os incrementos no número de estabelecimentos e emprego local não alterarem sua participação no setor industrial. Assim como a atividade industrial, a base industrial do setor no estado de São Paulo pode ter aumentado. Se o aumento na base industrial do estado não compensar o aumento da base industrial local, os incrementos nos parâmetros locais podem alterar a participação industrial - capturados pelo CC. E, assim a atividade industrial inicialmente categorizada como Embrião de Sistema Local pode evoluir para um Vetor Avançado (Figura 1). As alterações desta natureza são consideradas, para os fins deste trabalho, evoluções da fase de emergência para a fase de crescimento do ciclo de vida.

Após a fase de intenso crescimento nos parâmetros, o sistema local inicia uma fase de crescimento moderado, na qual os incrementos nos parâmetros são marginais, como reposição no quadro de trabalhadores, ou contratações temporárias para suportar a sazonalidade da produção industrial (MENZEL \& FORNAHL, 2010). Para a tipologia dos sistemas locais, a fase de crescimento moderado é a fase de sustentação dos incrementos anteriores, podendo ser caracterizada como Núcleo de Desenvolvimento Setorial-Regional. A depender das alterações industriais que ocorreram na fase de crescimento acelerado, ou seja, se o Embrião de Sistema Local se tornou um Vetor de Desenvolvimento Local, ou um Vetor Avançado, os incrementos nos parâmetros para torna-los um Núcleo de Desenvolvimento Setorial-Regional serão distintos. Para um Vetor de Desenvolvimento Local, os incrementos nos parâmetros locais precisam mais que compensar os incrementos nos parâmetros do estado de São 
Paulo para se tornar um Núcleo de Desenvolvimento Setorial-Regional. Já para um Vetor Avançado o crescimento dos parâmetros locais não podem ser compensados pelo crescimento nos parâmetros do estado de São Paulo para se tornar um Núcleo de Desenvolvimento Setorial-Regional.

Por fim, a fase de exaustão é definida pelo decrescimento no número de estabelecimentos e emprego (MENZEL \& FORNAHL, 2010). A redução do número de estabelecimentos e emprego na tipologia dos sistemas locais reduz tanto a importância industrial como a local, a depender do comportamento da base industrial local e da base industrial do estado de São Paulo. Por exemplo, no caso de uma redução superior no parâmetro local comparada à redução no parâmetro do estado de São Paulo, um Núcleo de Desenvolvimento Setorial-Regional regredirá para um Vetor de Desenvolvimento Local. No inverso (redução nos parâmetros local inferior à redução nos parâmetros do estado de São Paulo), um Núcleo de Desenvolvimento SetorialRegional regredirá para um Vetor Avançado, e assim sucessivamente, até um Embrião de Sistema Local, ou ainda até sua perda total de relevância para a tipologia capturada pelo filtro de no mínimo número de estabelecimentos $\geq 10$, QL $\geq 2$ e coeficiente de concentração $\geq 1$.

Posto isto, o presente trabalho utiliza a tipologia dos sistemas locais proposta por Suzigan et al. (2001; 2006) para identificar e mapear os ciclos de vida descritos por Menzel \& Fornahl (2010).

\subsection{A base de dados - RAIS}

A Relação Anual de Informações Sociais (RAIS) compila informações sobre os estabelecimentos e empregados a partir dos vínculos empregatícios formais de um ano-base. Sua área amostral compreende todo o território brasileiro. As informações sobre o emprego são apresentadas segundo os critérios de (i) estoque (número de empregos) e (ii) movimentação de mão-de-obra empregada (admissões e desligamentos), subdivididas por gênero, por faixa etária, por grau de instrução, por rendimento médio e por faixas de rendimentos em salários mínimos. As categorias podem ser desagregadas até os níveis municipais, além de combinadas às subatividades econômicas (quatro dígitos da Classificação Nacional da Atividade Econômica - CNAE), de ocupações profissionais, qualificação dos empregados e outras informações sociais. As informações são obtidas a partir dos registros 
administrativos por estabelecimento. Neste sentido, cada unidade de uma empresa é considerada um estabelecimento.

Para o diagnóstico dos sistemas locais foram selecionados dois aspectos, a saber: (i) número de vínculos empregatícios e (ii) número de estabelecimentos. Entretanto, como verificado nos capítulos anteriores, a análise dos sistemas locais requer uma visão abrangente, que inter-relacione outros aspectos além das empresas e da mão de obra local. Podem ser citados, entre estes, as instituições de apoio, o poder público, a estrutura industrial, a disponibilidade de capital, entres outros fatores. Todavia, para os fins analíticos deste trabalho, os esforços de identificação e mapeamento foram direcionados exclusivamente para os dois primeiros aspectos.

Para os fins deste trabalho foram utilizados os dados de empregos $\mathrm{e}$ estabelecimentos da RAIS referentes ao período de 1996 a 2010. A base de dados da RAIS foi delimitada em dois diferentes níveis:

(a) Dimensão setorial - utilizou-se a desagregação setorial segundo as classes de atividade econômica (dois dígitos) definidas na Classificação Nacional de Atividades Econômicas (CNAE) do Instituo Brasileiro de Geografia e Estatística (IBGE). Nesta são abarcadas casos selecionados da indústria de transformação acrescida da indústria de software, pesquisa e desenvolvimento e serviços (Tabela 3);

(b) Dimensão geográfica - utilizaram-se as sessenta e três microrregiões correspondentes ao estado de São Paulo. (a tabela 4 e 5 apresenta uma amostra da RAIS 2010 para os dados utilizados).

Suzigan et al. (2006: 18) apresenta como uma vantagem do uso da RAIS, justamente a elevada desagregação setorial e geográfica das informações. Para os autores, o detalhamento das informações contidas na RAIS é "o que torna possível, sem a necessidade do recurso a tabulações especiais, obter e processar diretamente os dados desagregados, em termos espaciais, até o nível de municípios e, em termos setoriais, até o nível de classes de indústrias a 4 dígitos da CNAE”. Outra vantagem da utilização da RAIS, ainda na visão dos autores, está na elevada "uniformidade, que permite comparar a distribuição dos setores da atividade econômica ao longo do tempo". Entretanto, Suzigan et al. (2006) prossegue, "as vantagens apontadas são contrabalanceadas por algumas deficiências". 
Tabela 3. Divisão setorial: ramos da indústria de transformação selecionados

\begin{tabular}{ll}
\hline Divisão & Categoria industrial \\
\hline 17 & Fabricação de produtos têxteis \\
18 & Confecção de artigos do vestuário e acessórios \\
19 & Preparação de couros e fabrç. de artefatos de couro \\
24 & Fabricação de produtos quimicos \\
25 & Fabricação de artigos de borracha e plástico \\
26 & Fabricação de produtos de minerais não-metálicos \\
27 & Metalurgia básica \\
28 & Fabricação de produtos de metal (exceto máquinas e equipamentos) \\
29 & Fabricação de máquinas e equipamentos \\
31 & Fabricação de máquinas, aparelhos e materiais elêtricos \\
32 & Fabrç. de material elêtronico e de aparelhos e equipamentos de comunicação \\
33 & Fabrç. de equipamentos de instrumentação para usos médico-hospitalares \\
34 & Fabrç. e montagem de veículos automotores, reboques e carroceria \\
35 & Fabricação de outros equipamentos de transporte \\
36 & Fabricação de móveis e indústrias diversas \\
37 & Reciclagem \\
72 & Atividades de informática e serviços relacionados \\
73 & Pesquisa e desenvolvimento \\
74 & Serviços prestados principalmente as empresas \\
\hline
\end{tabular}

FONTE: Elabora pelo autor com base na RAIS/MTE.

A primeira insuficiência refere-se à compilação única e exclusiva das relações contratuais formais. Neste sentido, a RAIS omite uma parcela dos trabalhadores e dos ocupados cujas relações contratuais não são formalizadas. Para Suzigan et al. (2006), os estudos sobre sistemas locais de produção sofrem poucas perdas analíticas devido a essa deficiência, uma vez que "é menos provável que o grau de informalidade das relações trabalhistas atinja parcelas significativas dos ocupados" em sistemas locais. Todavia, não se pode desconsiderar algum grau de perda analítica especialmente em regiões em desenvolvimento (norte e nordeste), na qual as relações informais prevalecem.

A segunda insuficiência refere-se à utilização do método de autoclassificação (pelas empresas) na coleta das informações primárias sem qualquer contrapartida regulatória do órgão coletor. Mas, qual é o viés da coleta? Para Suzigan et al. (2006) como a coleta dos dados é feita pelo estabelecimento, a empresa declarante, normalmente a matriz, pode, eventualmente, optar por uma resposta única referente a todas as sedes. Dessa forma, o agrupamento dos dados individuais em uma única série, obscurece a real informação. Ou seja, inviabiliza a identificação, e por implicação lógica 0 mapeamento, de alguns sistemas locais, uma vez que estes ficarão ocultos pela 


\section{autoclassificação da empresa matriz. Outra questão refere-se ao caso de empresas} diversificadas.

Tabela 4. Vínculos empregatícios (RAIS 2010) - unidades de emprego por categoria industrial e microrregião.

\begin{tabular}{|c|c|c|c|c|c|c|c|c|c|c|c|c|c|c|c|c|c|c|c|}
\hline Divisão & 17 & 18 & 19 & 24 & 25 & 26 & 27 & 28 & 29 & 31 & 32 & 33 & 34 & 35 & 36 & 37 & 72 & 73 & 74 \\
\hline Jales & 50 & 355 & 386 & 54 & 72 & 421 & 51 & 241 & 64 & 10 & 63 & 20 & 548 & 46 & 164 & 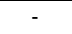 & 26 & 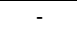 & 373 \\
\hline Fernandopolis & 58 & 778 & 82 & 433 & 105 & 124 & 10 & 203 & 112 & 67 & 23 & - & 74 & - & 791 & 16 & 43 & - & 565 \\
\hline Votuporanga & 64 & 800 & 30 & 27 & 132 & 121 & - & 263 & 227 & 5 & 3 & 32 & 2,492 & 1 & 4,008 & 6 & 21 & 1 & 458 \\
\hline Sao Jose do Rio Preto & 223 & 4,500 & 639 & 3,024 & 1,856 & 1,721 & 542 & 6,113 & 1,979 & 1,933 & 37 & 569 & 1,975 & 68 & 8,064 & 79 & 1,185 & 89 & 9,267 \\
\hline Catanduva & 41 & 625 & 170 & 399 & 273 & 151 & 316 & 784 & 2,980 & 423 & 119 & 53 & 211 & - & 523 & 60 & 125 & 3 & 1,901 \\
\hline Auriflama & 11 & 1,360 & 2 & 1 & 7 & 10 & - & 25 & 28 & - & - & - & - & 1 & 193 & - & 23 & 2 & 81 \\
\hline Nhandeara & - & 189 & 14 & 2,456 & 158 & 11 & 38 & 439 & 325 & 1 & - & 1 & 17 & 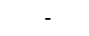 & 270 & - & 15 & - & 963 \\
\hline Novo Horizonte & 36 & 1,286 & - & 566 & 133 & 73 & - & 71 & 283 & 43 & - & - & - & - & 444 & 8 & 17 & - & 147 \\
\hline Barretos & - & 124 & 54 & 264 & 691 & 89 & 2 & 129 & 203 & 11 & - & 34 & 9 & - & 26 & 8 & 2 & - & 648 \\
\hline Sao Joaquim & 5 & 337 & 202 & 2,555 & 22 & 46 & 1,204 & 666 & 775 & 669 & 4 & 48 & 304 & 2 & 75 & 7 & 44 & 22 & 814 \\
\hline Ituverava & 13 & 26 & 61 & 77 & 17 & 129 & & 208 & 303 & 1 & - & - & 12 & 1 & 420 & - & 11 & - & 485 \\
\hline Franca & 192 & 1,001 & 26,108 & 1,135 & 2,333 & 171 & 83 & 551 & 640 & 45 & - & 34 & 34 & 20 & 347 & 13 & 314 & - & 2,733 \\
\hline Jaboticabal & 152 & 686 & 8 & 1,769 & 3,699 & 555 & 1,219 & 2,557 & 2,302 & 91 & 1 & 4 & 199 & 119 & 674 & 1 & 190 & 73 & 2,590 \\
\hline Ribeirao Preto & 366 & 2,546 & 440 & 5,389 & 2,142 & 1,225 & 1,269 & 5,262 & 11,488 & 1,301 & 102 & 2,795 & 856 & 110 & 2,546 & 128 & 1,476 & 27 & 24,273 \\
\hline Batatais & 85 & 866 & 12 & 1,869 & 226 & 94 & 751 & 224 & 1,065 & 70 & 3 & 15 & 567 & 14 & 115 & 1 & 14 & - & 469 \\
\hline Andradina & 5 & 29 & 29 & 1,536 & 70 & 204 & . & 121 & 41 & 2 & - & 8 & 56 & - & 106 & 78 & 25 & 3 & 1,178 \\
\hline Aracatuba & 60 & 652 & 718 & 1,997 & 110 & 339 & 83 & 539 & 1,957 & 66 & - & 303 & 75 & 10 & 1,354 & 22 & 353 & - & 2,262 \\
\hline Birigui & 427 & 1,671 & 17,015 & 724 & 962 & 762 & 47 & 939 & 428 & 375 & 26 & 37 & 55 & 264 & 1,562 & 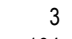 & 83 & - & 1,155 \\
\hline Lins & 77 & 1,176 & 1,474 & 4,317 & 79 & 41 & 81 & 403 & 115 & 80 & 14 & 3 & 21 & - & 7 & 104 & 56 & - & 2,051 \\
\hline Bauru & 772 & 1,561 & 136 & 1,398 & 902 & 501 & 18 & 1,831 & 1,721 & 3,039 & 78 & 238 & 284 & 121 & 1,036 & 72 & 765 & 45 & 18,993 \\
\hline Jau & 379 & 2,110 & 11,310 & 1,989 & 646 & 1,425 & 212 & 1,102 & 1,175 & 768 & 237 & 566 & 2,204 & 13 & 1,922 & 53 & 162 & 3 & 1,510 \\
\hline Avare & 29 & 1,916 & - & 1,411 & 541 & 348 & 115 & 172 & 114 & 154 & - & 2 & 40 & 27 & 243 & - & 38 & - & 1,816 \\
\hline Botucatu & 1,029 & 720 & 41 & 561 & 819 & 657 & 55 & 784 & 310 & 1 & - & 11 & 4,272 & 1,830 & 159 & 5 & 109 & 148 & 1,908 \\
\hline Arare & ,838 & 3,446 & 3 & 808 & 1,104 & 901 & 254 & 1,815 & 8,039 & 911 & 10 & 216 & 857 & 1,998 & 318 & 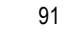 & 712 & 71 & 6,978 \\
\hline Sao Carlos & 1,410 & 365 & 96 & 547 & 678 & 1,065 & 417 & 2,226 & 7,491 & 77 & 156 & 1,159 & 1,109 & 7 & 1,712 & 68 & 240 & 282 & 5,670 \\
\hline Rio Claro & 269 & 967 & 27 & 1,519 & 3,205 & 3,363 & 197 & 1,649 & 5,266 & 1,731 & 41 & 867 & 217 & 239 & 3,444 & 50 & 95 & 17 & 4,753 \\
\hline Limeira & 706 & 1,723 & 340 & 4,315 & 3,721 & 8,613 & 2,483 & 6,139 & 7,137 & 1,238 & 264 & 252 & 8,058 & 1,347 & 5,620 & 222 & 410 & 3 & 4,548 \\
\hline Piracicaba & 3,519 & 3,738 & 97 & 1,977 & 1,765 & 3,122 & 2,130 & 3,994 & 16,014 & 560 & 75 & 353 & 3,697 & 73 & 1,894 & 367 & 357 & 694 & 8,457 \\
\hline Pirassununga & 2( & 266 & 41 & 9 & 729 & 2,993 & 27 & 423 & 64 & 1,543 & - & 489 & 5 & 21 & 893 & 50 & 23 & - & 1,110 \\
\hline Boa Vista & 706 & 1,311 & 127 & 676 & 946 & 4, & 428 & 2,400 & 2,899 & 259 & 22 & 33 & 134 & 149 & 30 & 41 & 116 & 43 & 2,324 \\
\hline Moji-Mirim & 2,506 & 733 & 79 & 2,049 & 1,013 & 1,817 & 1,104 & 2,407 & 4,002 & 1,304 & 46 & 491 & 9,474 & 714 & 2,089 & 44 & 257 & - & 6,198 \\
\hline Campinas & 30,823 & 10,478 & 350 & 24,743 & 20,119 & 10,313 & 5,353 & 16,457 & 21,710 & 6,821 & 335 & 3,729 & 32,594 & 3,814 & 5,201 & 581 & 17,537 & 3,389 & 84,805 \\
\hline Amparo & 2,940 & 2,037 & 120 & 2,658 & 295 & 427 & 65 & 831 & 636 & 56 & 2 & 301 & 81 & - & 76 & - & 62 & - & 780 \\
\hline Dracena & 45 & 9 & 1 & 2,134 & 126 & 1,510 & 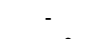 & 88 & 205 & 4 & . & 1 & 18 & - & 256 & 3 & 41 & - & 932 \\
\hline Adam & 1 & 1,953 & 615 & 2,194 & 14 & 102 & 9 & 266 & 268 & - & - & 0 & 110 & - & 782 & 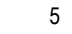 & 82 & - & 2,474 \\
\hline Preside & 48 & 1,360 & 1,977 & 4,598 & 372 & 828 & 56 & 925 & 340 & 703 & 526 & 31 & 366 & 64 & 496 & 35 & 529 & 5 & 3,169 \\
\hline Tupa & 595 & 115 & 46 & 50 & 70 & 155 & - & 201 & 461 & 7 & 7 & 105 & 89 & - & 278 & 10 & 101 & - & 488 \\
\hline Marilia & 197 & 43 & 27 & 241 & 1,558 & 442 & 134 & 2,303 & 3,446 & 2,755 & 125 & 165 & 108 & 108 & 216 & 15 & 308 & 8 & 2,874 \\
\hline Assis & 2 & 14 & 5 & 402 & 112 & 20 & - & 634 & 328 & 11 & 6 & 3 & - & - & 158 & - & 154 & - & 2,333 \\
\hline Ourinhos & 69 & 5,012 & 496 & 2,138 & 263 & 95 & 4 & 759 & 1,561 & 60 & - & 28 & 45 & 4 & 1,143 & 19 & 139 & - & 2,293 \\
\hline Itapeva & 3 & 654 & 1 & 194 & 136 & 625 & 321 & 89 & 50 & 2 & - & 21 & 2 & - & 51 & 77 & 14 & - & 625 \\
\hline Itapetininga & 572 & 1,893 & 2 & 876 & 47 & 389 & 10 & 63 & 39 & 279 & - & 3 & 16 & 4 & 618 & - & 66 & - & 1,888 \\
\hline Tatui & 2,958 & 2,033 & 39 & 1,918 & 2,118 & 2,715 & 1,338 & 2,487 & 534 & 3,247 & - & 43 & 310 & 87 & 2,387 & 28 & 205 & 11 & 5,581 \\
\hline Capao & - & 8 & - & 5 & 15 & 87 & 1 & 19 & 24 & - & - & 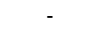 & - & - & 16 & - & 1 & - & 247 \\
\hline Piedade & 6 & 29 & 17 & 195 & 73 & 190 & 41 & 290 & 170 & 45 & 101 & 450 & 214 & - & 37 & 82 & 27 & - & 1,628 \\
\hline Sorocaba & 5,617 & 5,165 & 75 & 5,383 & 14,191 & 5,422 & 8,238 & 12,605 & 14,390 & 757 &, 917 & 1,649 & 4,198 & 1,129 & 4,444 & 336 & ,197 & 155 & 32,074 \\
\hline Jundiai & 2,849 & 1,997 & 4 & 6,241 & 9,783 & 5,095 & 1,550 & 7,750 & 5,227 & 3,661 & 310 & 343 & 9,990 & 491 & 773 & 187 & 8,094 & 234 & 19,608 \\
\hline Bragance & 6,246 & 2,723 & 250 & 2,599 & 3,038 & 2,601 & 947 & 4,123 & 3,689 & 5,289 & 270 & 543 & 2,744 & 276 & 1,234 & 105 & 344 & 12 & 18,233 \\
\hline Cam & 14 & 4 & 1 & & - & 12 & - & 33 & - & - & - & - & - & - & 37 & - & 31 & - & 455 \\
\hline Sao J & 2,349 & 1,023 & 43 & 4,837 & 5,498 & 3,819 & 5,958 & 7,435 & 9,79 & 1,897 & 3,861 & 1,182 & 23,624 & 4,602 & 883 & 643 & 1,971 & 417 & 51,211 \\
\hline Guaratingueta & 423 & 414 & 8 & 3,036 & 1,669 & 772 & 2,088 & 1,299 & 1,466 & 329 & - & 57 & 4,651 & 262 & 407 & 70 & 189 & 1 & 3,157 \\
\hline Bananal & - & 1 & - & - & - & - & - & - & 113 & - & - & - & - & - & 31 & - & 5 & - & 24 \\
\hline Paraibuna & 1 & 1 & - & 111 & 116 & 60 & - & 681 & 59 & 86 & - & - & 568 & - & 15 & - & 31 & - & 268 \\
\hline Carag & 2 & 66 & - & 1 & 7 & 220 & - & 96 & 37 & 1 & - & 1 & 4 & 15 & 104 & 5 & 34 & - & 1,647 \\
\hline Registro & 38 & 385 & 3 & 129 & 82 & 42 & - & 233 & 13 & 9 & - & 6 & 23 & - & 78 & 1 & 17 & 1 & 1,491 \\
\hline Itanhaem & 28 & 53 & 2 & 14 & 5 & 138 & 63 & 30 & 6 & 23 & 2 & 4 & - & - & - & - & 55 & - & 681 \\
\hline Osasco & 1,928 & 3,729 & 33 & 13,013 & 12,762 & 2,383 & 3,299 & 658 & 73 & 6,169 & 467 & 1,917 & 6,943 & 281 & 3,177 & 413 & 24,764 & 5 & 126,741 \\
\hline Franco da Rocha & 968 & 551 & 244 & 1,012 & 3,108 & 633 & 275 & 1,992 & 1,244 & 417 & 72 & 146 & 750 & - & 787 & 102 & 193 & - & 6,053 \\
\hline Guarulhos & 9,345 & 3,242 & 755 & 13,660 & 17,602 & 4,477 & 8,203 & 14,908 & 9,548 & 6,056 & 743 & 763 & 14,351 & 1,095 & 4,172 & 744 & 622 & 17 & 21,522 \\
\hline & 2,768 & 1,242 & 169 & 10,548 & 9,046 & 1,685 & 1,226 & 5,965 & 4,808 & 3,337 & 1,686 & 1,034 & 4,613 & 588 & 3,655 & 153 & 3,356 & 5 & 40,648 \\
\hline Sao Paulo & 25,946 & 89,114 & 6,094 & 73,237 & 71,897 & 20,708 & 21,872 & 80,778 & 67,820 & 31,508 & 9,992 & 13,701 & 103,561 & 4,301 & 28,487 & 1,500 & 96,253 & 2,749 & 844,021 \\
\hline Moji das Cruzes & 5,205 & 1,859 & 496 & 6,386 & 5,456 & 5,165 & 3,795 & 7,552 & 6,255 & 5,601 & 863 & 840 & 4,796 & 368 & 3,640 & 909 & 1,110 & 13 & 31,820 \\
\hline Santos & 260 & 796 & 103 & 3,196 & 227 & 800 & 5,236 & 4,300 & 1,317 & 43 & 13 & 146 & 237 & 1,012 & 342 & 271 & 1,078 & 15 & 25,858 \\
\hline
\end{tabular}

FONTE: Elabora pelo autor com base na RAIS/MTE. 
Tabela 5. Número de estabelecimentos (RAIS 2010) - número de empresas por categoria industrial e microrregião.

\begin{tabular}{|c|c|c|c|c|c|c|c|c|c|c|c|c|c|c|c|c|c|c|c|}
\hline Divisão & 17 & 18 & 19 & 24 & 25 & 26 & 27 & 28 & 29 & 31 & 32 & 33 & 34 & 35 & 36 & 37 & 72 & 73 & 74 \\
\hline Jales & 10 & 37 & 5 & 4 & 7 & 18 & 1 & 25 & 10 & 2 & 3 & 7 & 9 & 2 & 15 & - & 7 & - & 145 \\
\hline Fernandopolis & 7 & 45 & 3 & 4 & 7 & 15 & 1 & 24 & 13 & 3 & 1 & - & 7 & - & 27 & 1 & 10 & - & 128 \\
\hline Votuporanga & 8 & 61 & 9 & 6 & 24 & 11 & - & 43 & 19 & 2 & 1 & 5 & 17 & 2 & 175 & 1 & 16 & 1 & 125 \\
\hline Sao Jose do Rio Preto & 39 & 418 & 40 & 74 & 116 & 106 & 27 & 301 & 131 & 52 & 5 & 25 & 55 & 10 & 427 & 18 & 172 & 5 & 1,111 \\
\hline Catanduva & 9 & 71 & 11 & 24 & 26 & 16 & 9 & 56 & 41 & 13 & 5 & 4 & 14 & - & 39 & 8 & 26 & 2 & 229 \\
\hline Auriflama & 3 & 76 & 2 & 1 & 1 & 2 & - & 5 & 4 & - & - & - & - & 1 & 10 & - & 5 & 1 & 32 \\
\hline Nhandeara & - & 21 & 1 & 5 & 10 & 4 & 2 & 16 & 5 & 1 & - & 1 & 1 & - & 20 & - & 3 & - & 48 \\
\hline Novo Horizonte & 5 & 76 & - & 4 & 9 & 13 & - & 11 & 11 & 2 & - & - & - & - & 16 & 1 & 6 & - & 65 \\
\hline Barretos & - & 21 & 7 & 14 & 16 & 12 & 1 & 19 & 9 & 3 & - & 5 & 3 & - & 7 & 3 & 2 & - & 177 \\
\hline Sao Joaquim da Barra & 4 & 21 & 20 & 7 & 6 & 9 & 6 & 40 & 25 & 6 & 2 & 7 & 6 & 1 & 17 & 2 & 16 & 2 & 210 \\
\hline Ituverava & 4 & 8 & 5 & 4 & 2 & 12 & 1 & 14 & 9 & 1 & - & - & 3 & 1 & 19 & - & 6 & - & 86 \\
\hline Franca & 25 & 132 & 1,938 & 48 & 94 & 32 & 12 & 85 & 58 & 4 & - & 6 & 6 & 3 & 58 & 5 & 59 & 1 & 418 \\
\hline Jaboticabal & 9 & 59 & 2 & 35 & 46 & 54 & 18 & 96 & 72 & 9 & 1 & 2 & 11 & 3 & 56 & 2 & 43 & 3 & 451 \\
\hline Ribeirao Preto & 31 & 217 & 32 & 176 & 121 & 113 & 47 & 306 & 368 & 41 & 11 & 108 & 39 & 10 & 176 & 10 & 196 & 12 & 1,863 \\
\hline Batatais & 2 & 49 & 1 & 11 & 4 & 13 & 17 & 38 & 41 & 6 & 1 & 2 & 14 & 2 & 10 & 1 & 5 & 1 & 101 \\
\hline Andradina & 1 & 11 & 5 & 4 & 5 & 14 & - & 24 & 10 & 1 & - & 2 & 4 & - & 31 & 3 & 10 & 1 & 180 \\
\hline Aracatuba & 8 & 81 & 12 & 24 & 12 & 25 & 2 & 64 & 22 & 6 & - & 10 & 6 & 2 & 70 & 3 & 35 & - & 369 \\
\hline Birigui & 35 & 164 & 419 & 22 & 58 & 89 & 5 & 91 & 31 & 6 & 2 & 2 & 8 & 8 & 68 & 2 & 23 & - & 250 \\
\hline Lins & 2 & 23 & 14 & 10 & 9 & 6 & 1 & 21 & 6 & 2 & 2 & 1 & 2 & - & 4 & 3 & 16 & - & 147 \\
\hline Bauru & 27 & 97 & 12 & 34 & 43 & 50 & 5 & 104 & 90 & 30 & 7 & 17 & 14 & 12 & 70 & 10 & 98 & 5 & 746 \\
\hline Jau & 22 & 186 & 613 & 44 & 45 & 84 & 21 & 109 & 68 & 34 & 3 & 14 & 25 & 4 & 85 & 5 & 28 & 1 & 355 \\
\hline Avare & 1 & 41 & - & 14 & 19 & 28 & 5 & 26 & 8 & 4 & - & 2 & 3 & 2 & 16 & 1 & 13 & - & 162 \\
\hline Botucatu & 8 & 48 & 6 & 12 & 24 & 43 & 2 & 52 & 16 & 2 & - & 3 & 16 & 4 & 23 & 3 & 27 & 10 & 228 \\
\hline Araraquara & 534 & 190 & 13 & 53 & 51 & 72 & 14 & 134 & 136 & 23 & 2 & 27 & 18 & 8 & 50 & 10 & 78 & 4 & 572 \\
\hline Sao Carlos & 20 & 57 & 14 & 33 & 54 & 41 & 12 & 170 & 111 & 12 & 13 & 45 & 7 & 3 & 42 & 7 & 57 & 14 & 488 \\
\hline Rio Claro & 21 & 87 & 3 & 43 & 47 & 70 & 6 & 82 & 59 & 7 & 1 & 27 & 7 & 4 & 47 & 6 & 24 & 2 & 332 \\
\hline Limeira & 44 & 131 & 18 & 49 & 140 & 167 & 95 & 382 & 295 & 47 & 14 & 26 & 79 & 18 & 433 & 28 & 63 & 1 & 618 \\
\hline Piracicaba & 67 & 306 & 10 & 86 & 86 & 125 & 52 & 282 & 283 & 34 & 6 & 33 & 39 & 4 & 94 & 19 & 65 & 11 & 826 \\
\hline Pirassununga & 7 & 25 & 6 & 10 & 20 & 123 & 1 & 46 & 11 & 13 & - & 7 & 2 & 2 & 56 & 5 & 11 & 1 & 201 \\
\hline Sao Joao da Boa Vista & 19 & 118 & 16 & 23 & 46 & 218 & 16 & 134 & 91 & 11 & 1 & 7 & 9 & 4 & 55 & 4 & 32 & 3 & 429 \\
\hline Moji-Mirim & 29 & 92 & 5 & 45 & 48 & 100 & 25 & 143 & 140 & 35 & 5 & 15 & 28 & 17 & 90 & 6 & 43 & - & 416 \\
\hline Campinas & 743 & 920 & 21 & 357 & 477 & 426 & 108 & 976 & 774 & 161 & 69 & 149 & 167 & 45 & 363 & 43 & 572 & 46 & 4,186 \\
\hline Amparo & 110 & 235 & 24 & 12 & 21 & 60 & 8 & 56 & 32 & 4 & 1 & 6 & 3 & - & 19 & - & 14 & - & 153 \\
\hline Dracena & 9 & 8 & 1 & 6 & 7 & 109 & - & 12 & 6 & 1 & - & 1 & 6 & - & 19 & 1 & 12 & - & 119 \\
\hline Adamantina & 7 & 44 & 9 & 11 & 6 & 14 & 1 & 28 & 17 & - & - & 3 & 6 & - & 27 & 1 & 16 & 1 & 160 \\
\hline Presidente Prudente & 12 & 120 & 50 & 27 & 29 & 100 & 5 & 96 & 34 & 17 & 14 & 7 & 18 & 7 & 58 & 4 & 67 & 3 & 680 \\
\hline Tupa & 8 & 27 & 3 & 6 & 8 & 11 & - & 12 & 20 & 2 & 1 & 5 & 7 & - & 28 & 1 & 10 & - & 126 \\
\hline Marilia & 11 & 63 & 7 & 34 & 47 & 45 & 5 & 100 & 87 & 41 & 10 & 15 & 8 & 6 & 45 & 6 & 55 & 2 & 456 \\
\hline Assis & 4 & 33 & 1 & 13 & 12 & 25 & - & 47 & 21 & 4 & 2 & 1 & - & - & 23 & - & 32 & - & 249 \\
\hline Ourinhos & 6 & 170 & 34 & 24 & 19 & 78 & 2 & 53 & 55 & 4 & - & 10 & 6 & 2 & 23 & 3 & 27 & - & 297 \\
\hline Itapeva & 3 & 50 & 2 & 4 & 6 & 35 & 1 & 18 & 9 & 1 & - & 1 & 1 & - & 9 & 4 & 7 & - & 141 \\
\hline Itapetininga & 4 & 47 & 3 & 8 & 5 & 23 & 1 & 12 & 8 & 5 & - & 3 & 4 & 1 & 18 & - & 7 & - & 169 \\
\hline Tatui & 41 & 166 & 3 & 35 & 42 & 84 & 6 & 100 & 44 & 14 & - & 7 & 5 & 1 & 61 & 4 & 23 & 2 & 258 \\
\hline Capao Bonito & - & 7 & - & 2 & 1 & 13 & 1 & 5 & 4 & - & - & - & 1 & - & 1 & - & 1 & - & 65 \\
\hline Piedade & 3 & 19 & 1 & 7 & 5 & 25 & 2 & 20 & 10 & 2 & 5 & 3 & 5 & - & 9 & 3 & 11 & - & 128 \\
\hline Sorocaba & 102 & 238 & 12 & 128 & 238 & 231 & 68 & 540 & 335 & 87 & 29 & 65 & 72 & 23 & 186 & 19 & 175 & 10 & 1,662 \\
\hline Jundiai & 25 & 113 & 1 & 92 & 140 & 111 & 32 & 278 & 210 & 44 & 10 & 26 & 40 & 5 & 78 & 14 & 121 & 3 & 823 \\
\hline Braganca Paulista & 72 & 207 & 15 & 81 & 110 & 174 & 23 & 224 & 157 & 48 & 14 & 21 & 32 & 7 & 109 & 10 & 87 & 5 & 644 \\
\hline Campos do Jordao & 24 & 11 & 1 & - & - & 6 & - & 7 & - & - & - & - & - & - & 9 & - & 5 & - & 73 \\
\hline Sao Jose dos Campos & 51 & 123 & 8 & 110 & 92 & 112 & 34 & 300 & 193 & 39 & 51 & 63 & 65 & 32 & 88 & 25 & 248 & 12 & 1,893 \\
\hline Guaratingueta & 16 & 48 & 1 & 37 & 43 & 52 & 4 & 66 & 23 & 1 & - & 7 & 2 & 6 & 28 & 8 & 30 & 2 & 334 \\
\hline Bananal & - & 1 & - & - & - & - & - & - & 3 & - & - & - & - & - & 3 & - & 1 & - & 14 \\
\hline Paraibuna/Paraitinga & 1 & 3 & - & 2 & 2 & 12 & - & 11 & 5 & 1 & - & - & 2 & - & 5 & - & 5 & - & 47 \\
\hline Caraguatatuba & 2 & 18 & - & 1 & 2 & 21 & - & 17 & 5 & 1 & - & 1 & 1 & 4 & 13 & 1 & 15 & - & 272 \\
\hline Registro & 6 & 18 & 1 & 6 & 8 & 27 & - & 16 & 4 & 1 & - & 1 & 5 & - & 15 & 2 & 10 & 1 & 192 \\
\hline Itanhaem & 4 & 7 & 1 & 2 & 2 & 18 & 3 & 12 & 3 & 1 & 1 & 1 & 1 & - & 3 & - & 12 & - & 112 \\
\hline Osasco & 59 & 241 & 14 & 212 & 337 & 106 & 72 & 330 & 296 & 98 & 40 & 69 & 76 & 14 & 151 & 23 & 641 & 2 & 2,631 \\
\hline Franco da Rocha & 17 & 63 & 2 & 43 & 107 & 25 & 18 & 85 & 50 & 17 & 5 & 12 & 17 & - & 19 & 8 & 30 & - & 184 \\
\hline Guarulhos & 133 & 281 & 25 & 227 & 338 & 115 & 139 & 475 & 268 & 97 & 23 & 30 & 120 & 22 & 107 & 51 & 124 & 1 & 1,030 \\
\hline Itapecerica da Serra & 29 & 89 & 9 & 157 & 183 & 66 & 17 & 185 & 156 & 64 & 36 & 36 & 43 & 10 & 126 & 11 & 137 & 2 & 888 \\
\hline Sao Paulo & 1,121 & 8,066 & 379 & 1,316 & 2,549 & 635 & 614 & 3,980 & 2,701 & 1,108 & 381 & 808 & 823 & 116 & 2,024 & 139 & 4,971 & 115 & 29,946 \\
\hline Moji das Cruzes & 63 & 144 & 20 & 115 & 144 & 124 & 93 & 271 & 144 & 68 & 13 & 24 & 63 & 8 & 102 & 35 & 157 & 4 & 929 \\
\hline Santos & 16 & 120 & 10 & 45 & 18 & 43 & 8 & 122 & 67 & 10 & 2 & 20 & 12 & 36 & 71 & 9 & 141 & 2 & 1,754 \\
\hline
\end{tabular}

FONTE: Elabora pelo autor com base na RAIS/MTE. 
Nestas, a empresa matriz pode eventualmente, declarar todas as suas atividades em um mesmo código CNAE. Ou seja, mais uma vez a autoclassificação sem contrapartida regulatória pode resultar em efeitos importantes: "nos casos de empresas multi-plantas que declarem todo o volume de emprego na mesma unidade produtiva, geralmente na matriz, e de empresas multiprodutos que declarem enquadrar-se apenas na atividade correspondente ao seu produto principal', de acordo com Suzigan et al. (2006).

A terceira insuficiência refere-se ao uso da variável emprego como variável-base. Para Suzigan et al. (2006), utilizar a variável emprego como variável-base implica na negligência de uma série de diferenças inter-regionais e intersetoriais de tecnologia e produtividade. É por este motivo que diferentes sistemas locais, com um volume de emprego similar, eventualmente, podem apresentar produção física, ou valores monetários, bastante distintos. Adicionalmente, o uso do emprego como variável-base negligência as diferentes combinações de intensidade entre capital e trabalho existentes nas diferentes indústrias, "superestimando a importância de indústrias mais intensivas em trabalho e subestimando indústrias mais intensivas em capital e menos geradoras de emprego".

A quarta e última insuficiência apontada por Suzigan et al. (2006) diz respeito ao caráter declaratório da RAIS. Neste sentido, as considerações analíticas efetuadas para pequenas empresas e regiões menos desenvolvidas partir dos dados da RAIS podem implicar em distorções, uma vez que nessas regiões a ocorrência de empresas não declarantes prevalece.

Feitas as ressalvas quanto aos limites analíticos da base de dados RAIS/MTE devese reforçar que para os propósitos deste estudo a RAIS é à base de dados disponível mais adequada. "Frente a suas virtudes e deficiências, os dados da RAIS/MTE possibilitam construir indicadores de concentração geográfica de indústrias e de localização ou especialização regional de atividades produtivas que, por sua vez, são instrumentos essenciais para identificar, delimitar e caracterizar sistemas locais" (SUZIGAN et al. 2006: 19). 


\section{A colheita: "de aglomerações industriais a sistemas locais"}

A partir dos dados da RAIS a dois dígitos para o estado de São Paulo, e com base na metodologia anteriormente apresentada, foram identificados os sistemas locais de produção no estado. Essas aglomerações ao serem enquadradas na tipologia dos sistemas locais, que para os fins deste trabalho representam as fases do ciclo de vida, ao menos em sua dimensão quantitativa, resultaram na seguinte estrutura (tabela 6).

Tabela 6. Tipologia dos sistemas locais: Indústrias de Transformação selecionadas para o estado de São Paulo, durante o período de 1996 a 2010.

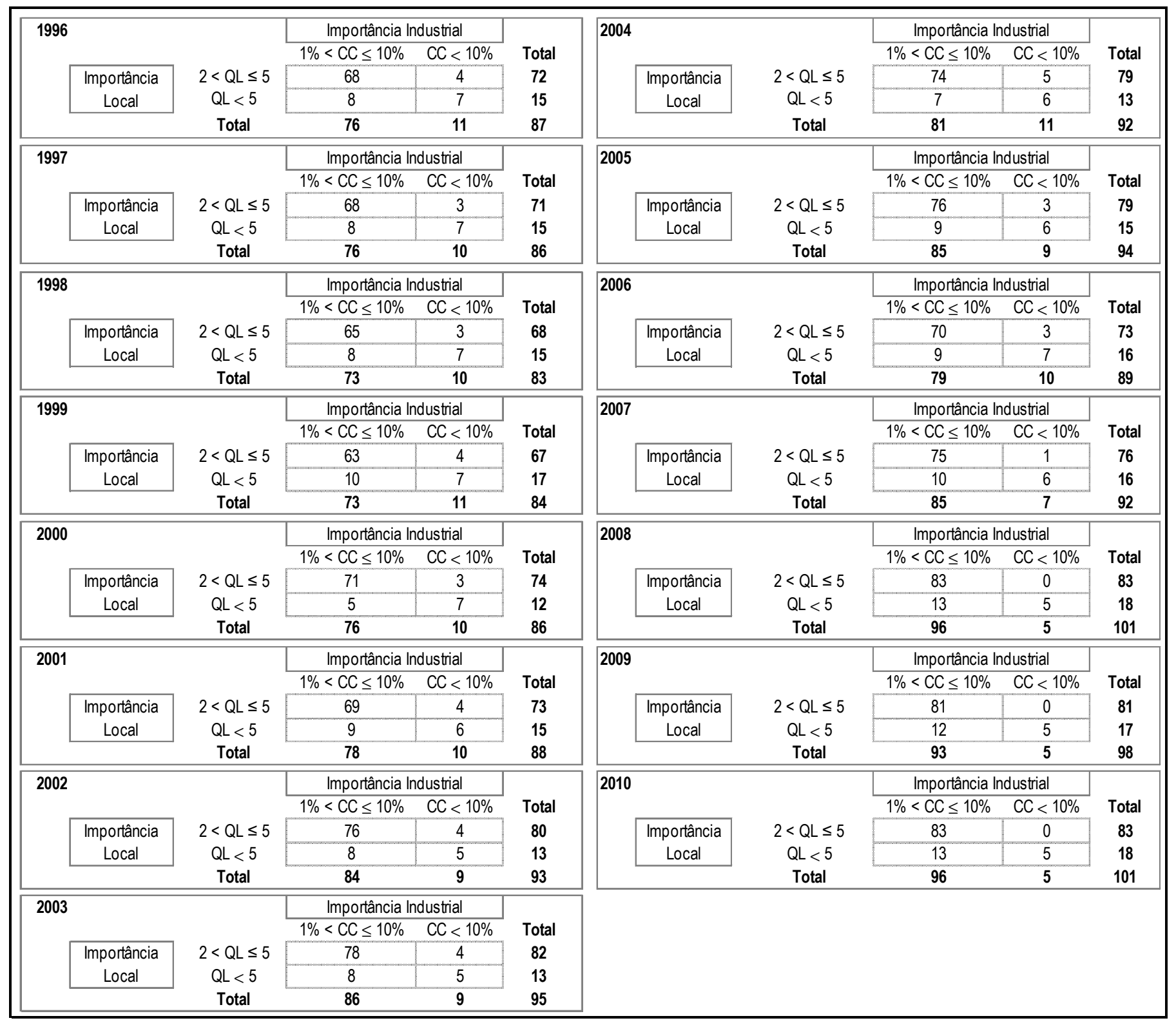

Observações/Filtros: Número de estabelecimentos $\geq 10 ; \mathrm{QL} \geq 2 ; \mathrm{CC} \geq 1$.

FONTE: Elaborado pelo autor com base nos dados da RAIS.

A construção do ciclo de vida para os sistemas locais de produção foi realizada de maneira independente em cada um dos quinze anos analisados. De modo que todos os 
ramos industriais pudessem apresentar evolução (ou involução) nos critérios definidos pela metodologia. Ou seja, as alterações no coeficiente de concentração ou no quociente locacional, ou em ambos, acarretariam em alterações nas fases do ciclo de vida, podendo até apresentar mudanças erráticas ao longo do tempo. Isto posto, definiu-se que a presença de uma fase do ciclo em vinte e cinco por cento da amostra (4 anos) seria um indicador suficiente para classificá-lo como o padrão predominante. Isto significa que a probabilidade de um ramo industrial estar em uma fase do ciclo é igual entre as quatro possíveis. Neste sentido, as chances de um ramo industrial, por exemplo, estar classificada como Vetor de Desenvolvimento Local, no primeiro ano de análise e, posteriormente, evoluir para um Vetor Avançado (ou retroceder para um Embrião de Sistema Local), e assim sucessivamente é de $1 / 4 \times 1 / 4 \times 1 / 4=1 / 64$. Já a chance de uma atividade industrial classificada como Embrião de Sistema Local em uma microrregião estar classificada de maneira distinta em outras microrregiões é de três chances em doze possíveis, ou seja, 1/4. Com base nesta árvore de probabilidade equiprovável, compreende-se que o formato sugerido para a obtenção das fases do ciclo é confiável.

A categoria que apresentou maior dispersão ao longo do período analisado foi a de Embrião de Sistema Local. O rigor conservador dos filtros fez com que as atividades industriais selecionadas nesta categoria fossem a mais numerosa (ver tabela 06, quadrante superior esquerdo, $1 \%<\mathrm{CC} \leq 10 \%$ vs. $2<\mathrm{QL} \leq 5$ ). Os Embriões de Sistema Local (fase de emergência) foram responsáveis por $80 \%$ das aglomerações identificadas em média ao longo dos anos analisados. Já os Vetores de Desenvolvimento Local (fase de crescimento acelerado) representaram 10\%, os Vetores Avançados (fase de crescimento acelerado) representaram 3\% e os Núcleos de Desenvolvimento Setorial-Regional (fase de crescimento moderado) representaram $7 \%$.

Ainda na tabela 6, o quadrante superior direito (CC >10\% vs. $2<\mathrm{QL} \leq 5)$ representa os Vetores Avançados, ou seja, as atividades industriais aqui selecionadas são relativamente pouco importantes em termos da estrutura produtiva local, mas possuem elevada participação no total do emprego da classe, o que significa que são muito importantes para o setor industrial do estado de São Paulo. Como afirma Suzigan et al. (2006) essas aglomerações são típicas das regiões metropolitanas e de áreas em que se verificam elevada densidade industrial e diversificação da estrutura produtiva. Já o quadrante inferior esquerdo da tabela $05(1 \%<\mathrm{CC} \leq 10 \%$ vs. $\mathrm{QL}>5)$ representa os 
Vetores de Desenvolvimento Local. E, por fim o quadrante inferior direito (CC > 10\% vs. QL > 5) representam os Núcleos de Desenvolvimento Setorial-Regional.

Alguns ramos industriais apresentaram alterações ao longo do seu ciclo de vida (veja anexos XXI a LXXXIX). Quanto a isso, parece indispensável tentar extrair algum resumo ou conclusão de ordem geral. A maior parcela das mudanças ocorreu entre os padrões que guardam uma maior proximidade entre as estruturas industriais. Contudo, as transformações mais comuns não seguem uma linearidade. De fato, entre as 24 mudanças possíveis, cinco não foram verificadas, a saber, a mudança de VA para NDR-S, ESL para NDS-R; ESL para VA, VDL para VA (o inverso também é valido). O baixo número de amostras (15 anos) pode ter corroborado com a variação tênue dos indicadores e, por este motivo não foi verificado todo o potencial de alternância nas fases do ciclo de vida. Uma síntese das relações entre as fases do ciclo de vida são apresentadas na figura 3, a seguir.

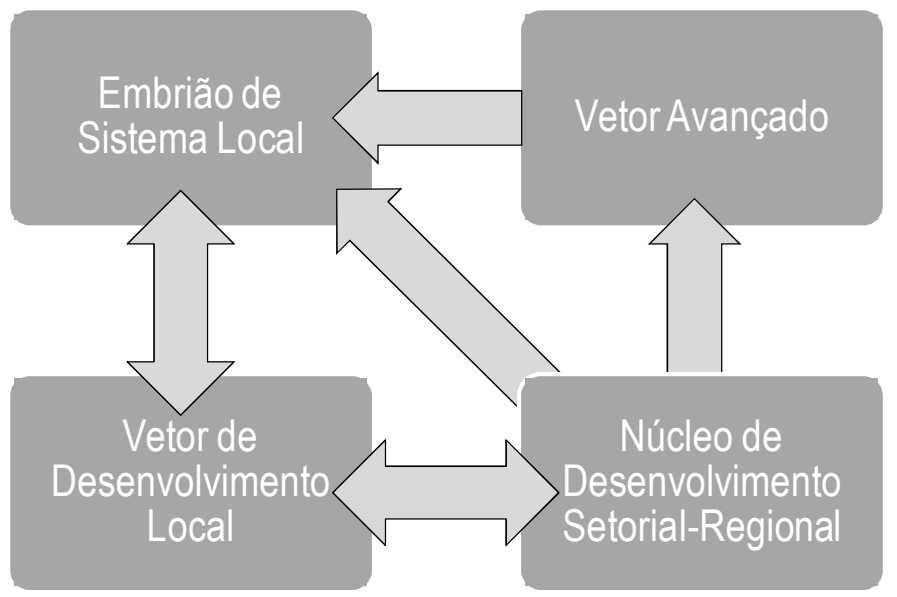

Nota: As flechas indicativas das principais alterações informam apenas os casos em que, pelo menos, uma atividade industrial migrou de uma fase do ciclo para outra em determinado período.

Figura 3. Alternâncias entre as fases do ciclo de vida.

FONTE: Elaborado pelo autor.

Nota-se que em regra as mudanças nas fases do ciclo ocorreram de forma incremental, ou seja, mudanças radicais apesar de existentes são casos raros. Este fato, ao mesmo tempo em que corrobora com a noção teórica de que mudanças radicais da estrutura produtiva são pouco frequentes, reforça a efetividade do argumento metodológico adotado na identificação das fases do ciclo, ou seja, o critério de que é parte constitutiva de uma fase do ciclo à atividade industrial que reincidir em três das quatro fases possíveis. 
Uma comparação entre as atividades industriais selecionadas e as microrregiões do estado e São Paulo mostra a heterogeneidade em termos de importância relativa dos ramos industriais a dois dígitos, bem como da importância local (veja anexos I a XXX). As ponderações utilizadas para a construção dos ciclos de vida nos ramos de atividade industrial em cada microrregião fornecem esta evidência. A dispersão da atividade industrial é bastante elevada nas microrregiões mais distantes da microrregião de São Paulo, refletindo a importância da microrregião de São Paulo para o entendimento da lógica industrial do estado (Figura 4). Os exemplos são notórios: enquanto os ramos têxteis e moveleiros encontram-se distantes de São Paulo ${ }^{5}$, os ramos produtos químicos e serviços encontram-se bastante próximos. Obtêm-se resultados análogos para os demais ramos de atividade.

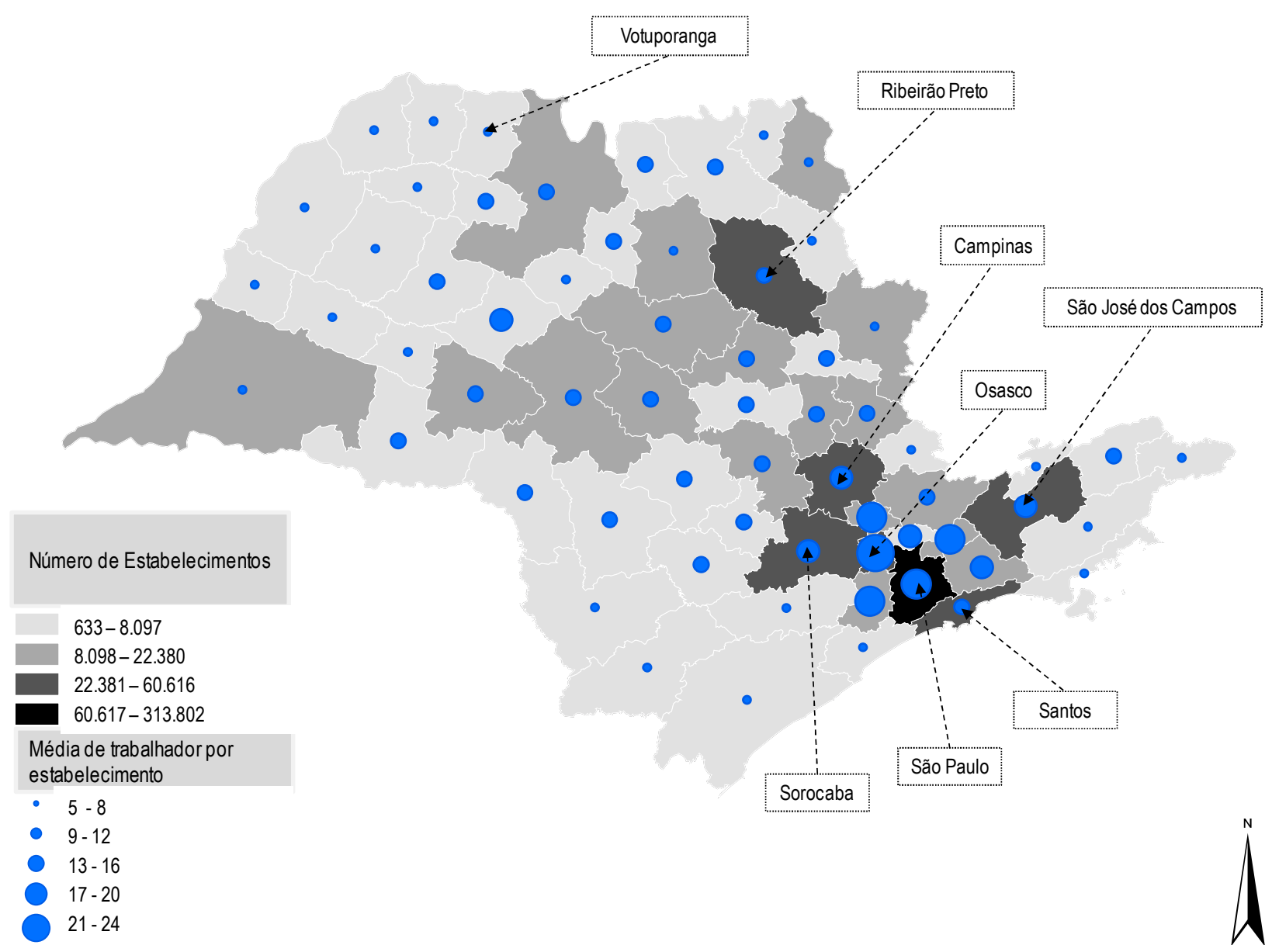

Figura 4. Média de trabalhador por estabelecimento e número de estabelecimentos: microrregiões de São Paulo (2010). FONTE: Elaborado pelo autor.

${ }^{5}$ De fato, as regiões metropolitanas, como São Paulo, Osasco e Guarulhos só para citar alguns exemplos possuem grande diversidade industrial e, neste sentido, atividades industriais como têxtil e fabricação de móveis têm sua importância local e industrial reduzida pelo efeito da diversidade. 
A analogia entre as estruturas industriais do estado, no que se refere à ponderação dos diversos ramos de atividade, indica uma semelhança básica nos padrões de produção e de consumo, não obstante a diversidade dos níveis de industrialização. Reflete, em última análise, a força de atração de São Paulo ${ }^{6}$, e suas economias de urbanidades, na cena industrial brasileira. Por outro lado, a grande semelhança na dispersão industrial é bastante expressiva, na medida em que acentua a heterogeneidade da estrutura industrial nos vários ramos industriais, no entorno de São Paulo. A comparação entre as microrregiões de Jaú, Adamantina entres tantas outras (ver anexos XXXI a LXXXIX), facilitada pela identificação dos ciclos, mostra uma notável semelhança entre estas microrregiões, embora a importância de algumas microrregiões para o objetivo deste trabalho seja maior que outras (em função de sua menor dispersão industrial local, isto é, maior ocorrência de estabelecimentos industriais). Estes resultados confirmam a conclusão de outros trabalhos, onde se destaca a similaridade do tecido industrial nestas regiões, independente das diferenças do tamanho do mercado local (provavelmente em função do centro de consumo do estado ser a própria região metropolitana de São Paulo).

Em síntese, os tipos de estrutura industrial, acima de qualquer outra consideração, parecem constituir de fato uma forma bastante eficiente de caracterizar a organização industrial ao nível técnico.

\subsection{Seleção de frutos: "sistemas locais em casos selecionados"}

Antes de passar a investigar os resultados por categoria de análise é interessante fazer algumas considerações de ordem mais geral a respeito da evolução de algumas daquelas variáveis. Quanto ao coeficiente de concentração ${ }^{7}$ (ou importância industrial) cabem algumas observações. O indicador de importância industrial é constituído pela participação no emprego formal de um ramo industrial em uma microrregião dividido pela somatória do emprego formal na microrregião. Os dois componentes apresentaram em geral movimentos conjuntos ao longo do período, de modo que o coeficiente de concentração manteve uma variação tênue, ou seja, houve uma relativa estabilidade no quadrante superior da tipologia (Figura 1 e Tabela 6). Em raros

\footnotetext{
${ }^{6}$ As regiões metropolitanas possuem em geral economias de aglomeração, provenientes da proximidade geográfica dos agentes econômicos. Contudo, ao mesmo tempo em que se constroem as economias de aglomeração, as regiões metropolitanas incorrem em deseconomias de aglomeração. $O$ balanceamento entre economias e deseconomias de aglomeração amplia (ou reduz) a força de atração da região.

${ }^{7}$ Para maiores detalhes do coeficiente de concentração veja anexos XV a XXX.
} 
momentos observou-se uma evolução significante em um ramo industrial relativamente à estrutura industrial da microrregião. O mesmo é válido para os quocientes locacionais ${ }^{8}$.

Adicionalmente, os sistemas locais que serão apresentados a seguir foram selecionados por se constituírem em casos bastante interessantes em termos de processo de construção das capacitações locais para o estado de São Paulo e, especificamente, para a dinâmica dos ciclos de vida.

\subsubsection{Sistema Local de Campinas: indústria têxtil}

De fato, a microrregião de Campinas na divisão CNAE 17 (fabricação de produtos têxteis) apresentou estabilidade como Embrião de Sistema Local ao longo de toda a série estudada. Nota-se que aumento da importância local no fim da década de 90 não foi o suficiente para alterar a fase do ciclo de vida (Figura 5).

Um exame detalhado do caso de Campinas mostra que as empresas ali localizadas diversificaram sua base industrial, ou seja, a divisão do trabalho ocorreu em atividades industriais não relacionadas à atividade principal e, que porventura, serviram para renovar as dinâmicas econômicas locais (Tabela 7).

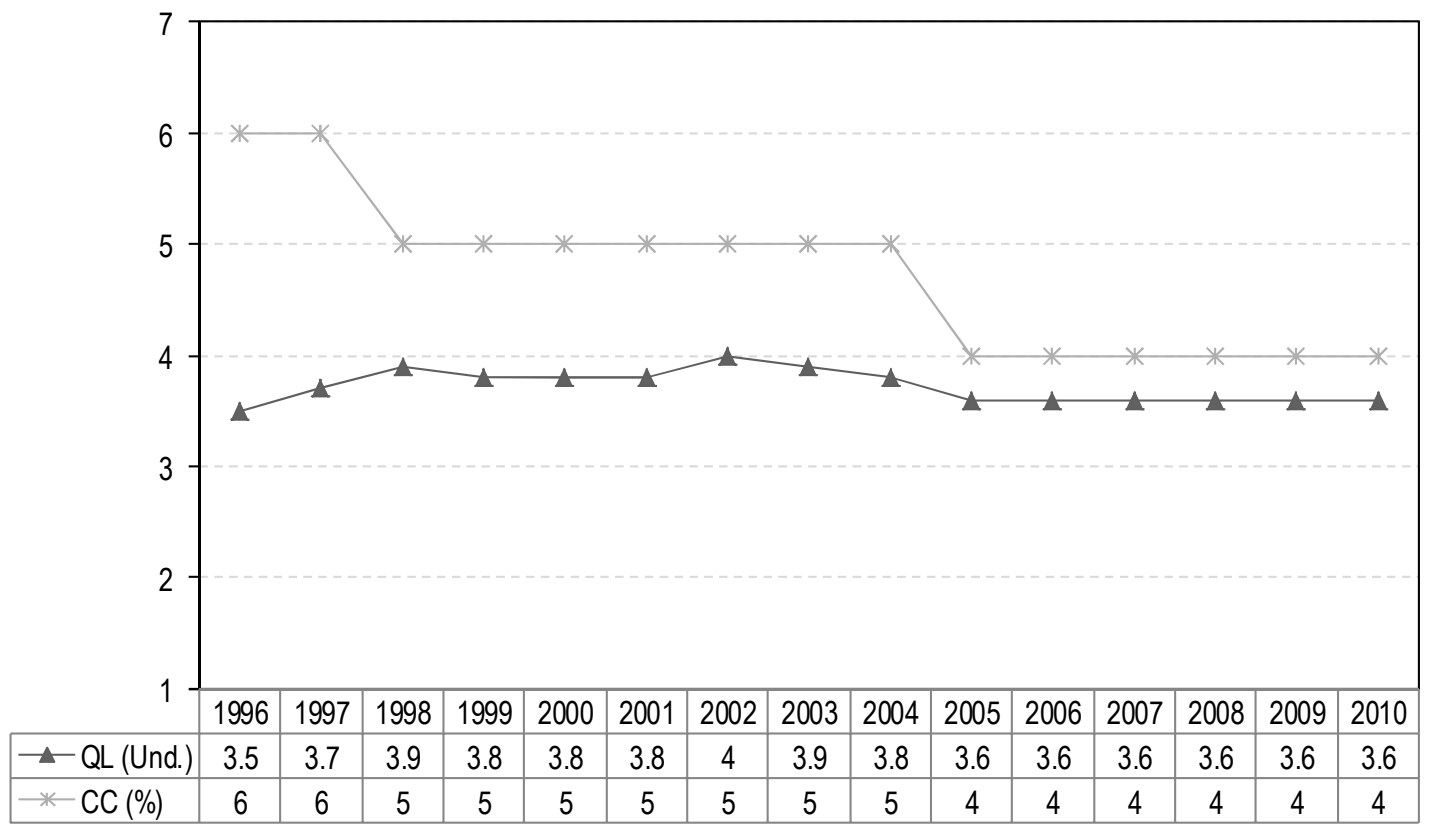

Figura 5. Quociente locacional e coeficiente de concentração no sistema local de Campinas: fabricação de produtos têxteis (CNAE 17), durante o período de 1996 a 2010.

FONTE: Elaborado pelo autor.

\footnotetext{
${ }^{8}$ Para maiores detalhe do quociente locacional veja os anexos I a XV.
} 
Tabela 7. Ciclo de vida dos sistemas locais em Campinas/SP, evidenciando a presença de Embriões de Sistema Local nas atividades selecionadas da indústria de transformação, durante o período de 1996 a 2010.

\begin{tabular}{|c|c|c|c|c|c|c|c|c|c|c|c|c|c|c|c|c|c|c|c|c|}
\hline Divisão & 17 & 18 & 19 & 24 & 25 & 26 & 27 & 28 & 29 & 31 & 32 & 33 & 34 & 35 & 36 & 37 & 72 & 73 & 74 & \\
\hline 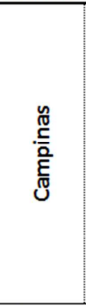 & 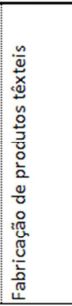 & 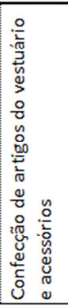 & 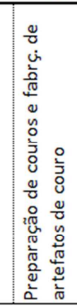 & 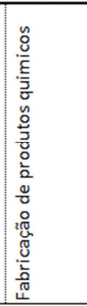 & 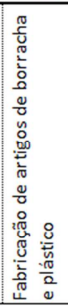 & 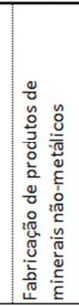 & 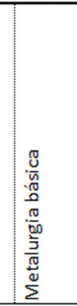 & 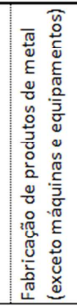 & 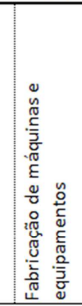 & 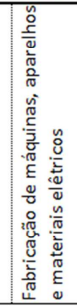 & 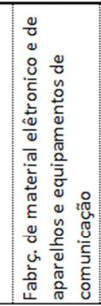 & 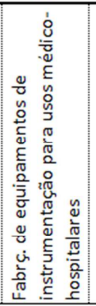 & 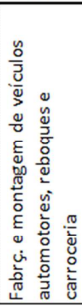 & 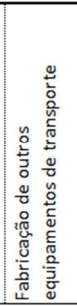 & 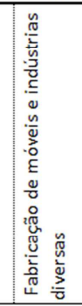 & 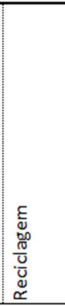 & 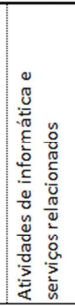 & 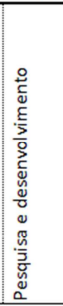 & 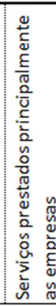 & \\
\hline 1996 & ESL & & 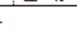 & - & & & - & $\omega$ & - & & - & - & - & 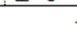 & 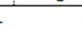 & & & & & - \\
\hline 1997 & ESL & & - & - & & & - & & - & & - & - & - & & - & & & & & - \\
\hline 1998 & ESL & & . & ESL & & & - & & - & & - & - & - & & - & & & & & - \\
\hline 1999 & ESL & & - & ESL & & & - & & - & & ESL & - & - & & - & & & & & - \\
\hline 2000 & ESL & & & ESL & & & & & & & ESL & & & & & & & & & \\
\hline 2001 & ESL & & . & - & & & - & & - & & ESL & - & - & & - & & & & & - \\
\hline 2002 & ESL & & - & ESL & & & - & & - & & ESL & - & - & & - & & & & & - \\
\hline 2003 & ESL & & - & ESL & & & - & & - & . & ESL & - & - & & - & & & & & - \\
\hline 2004 & ESL & & - & - & & & - & & - & & ESL & - & - & & - & & & & & - \\
\hline 2007 & ESL & & - & - & & & - & & - & & ESL & - & - & & - & & & & & - \\
\hline 2008 & ESL & & - & - & & & - & & - & & ESL & - & - & & - & & & & & - \\
\hline 2009 & ESL & & . & - & & & - & & - & & ESL & - & - & & - & & & & & - \\
\hline 2010 & ESL & & $=$ & - & & & - & 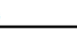 & - & & ESL & - & - & 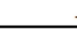 & $=$ & & & & & - \\
\hline
\end{tabular}

FONTE: Elaborado pelo autor com base nos dados da RAIS/MTE.

A divisão CNAE 32 (fabricação de material eletrônico e de aparelhos e equipamentos de comunicação) na microrregião de Campinas, apesar de não ter apresentado um evolução em seu ciclo de vida, apresenta relevância significativa como Embrião de Sistema Local desde o início dos anos 2000 (Figura 6).

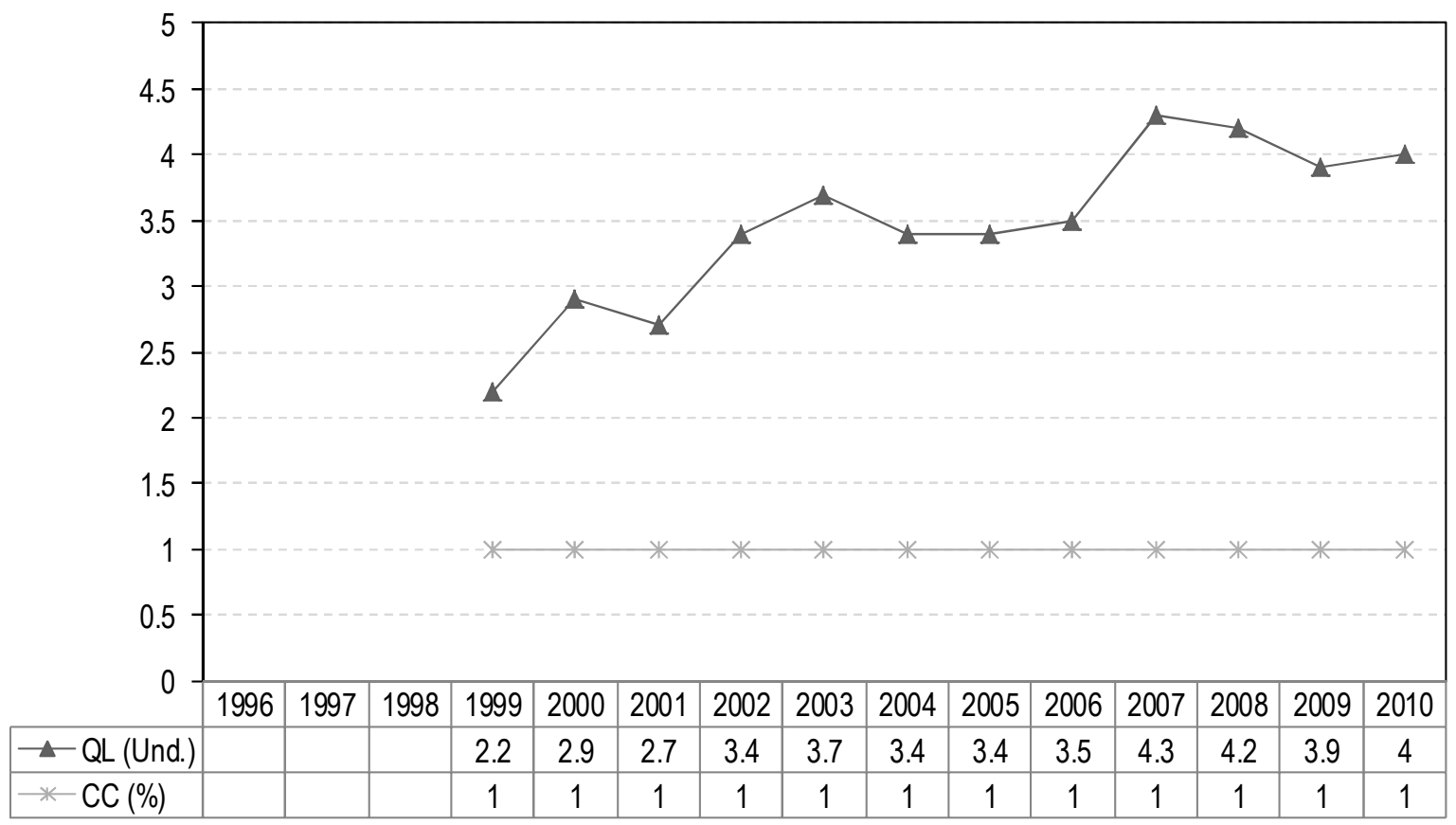

Figura 6. Quociente locacional e coeficiente de concentração no sistema local de Campinas: Fabricação de material eletrônico e de aparelhos e equipamentos de comunicação (CNAE 32), durante o período de 1996 a 2010.

FONTE: Elaborado pelo autor. 


\subsubsection{Sistema de Local de Franca: indústria de calçados}

Como já destacado no capítulo 1, a região de Franca é um dos casos mais interessantes de sistema local de produção do estado. A região saiu de um ponto de parada dos tropeiros no início do século XIX passando por pequenos artesões que reparavam arreios e confeccionavam sapatos rústicos para se tornar, respeitando as temporalidades, o segundo maior produtor de calçados do país - o estado Rio Grande do Sul, o maior produtor de calçados do país (SUZIGAN et al., 2001).

A tabela 8 e a figura 7 apresentam os detalhes da estrutura industrial de Franca, onde pode ser confirmada a evolução, anteriormente discutida, relacionada à forte especialização na fabricação de calçados, divisão CNAE 19 (preparação de couros e fabricação de artefatos de couro).

Tabela 8. Ciclo de vida dos sistemas locais em Franca/SP, evidenciando a presença de Núcleos de Desenvolvimento Setorial-Regional e Embriões de Sistema Local nas atividades selecionadas da indústria de transformação durante o período de 1996 a 2010.

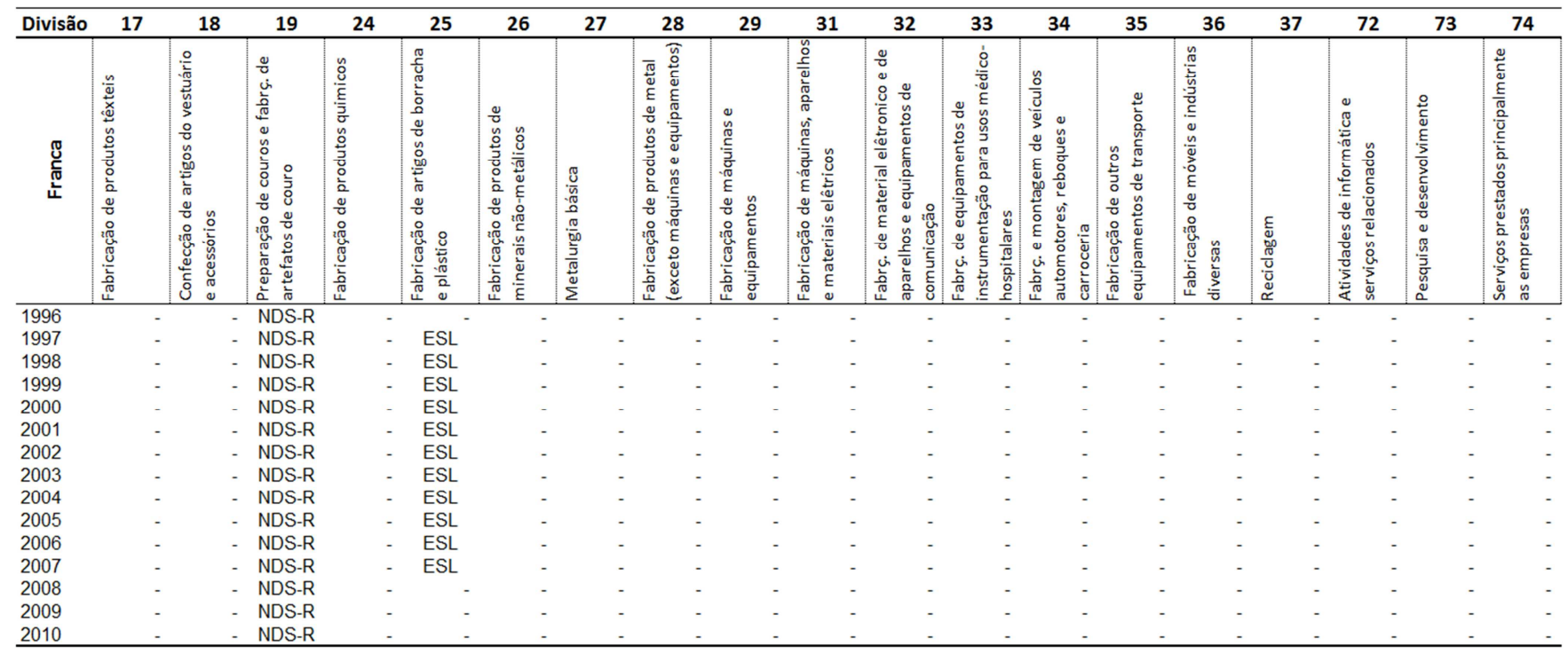

FONTE: Elaborado pelo autor com base nos dados da RAIS/MTE. 


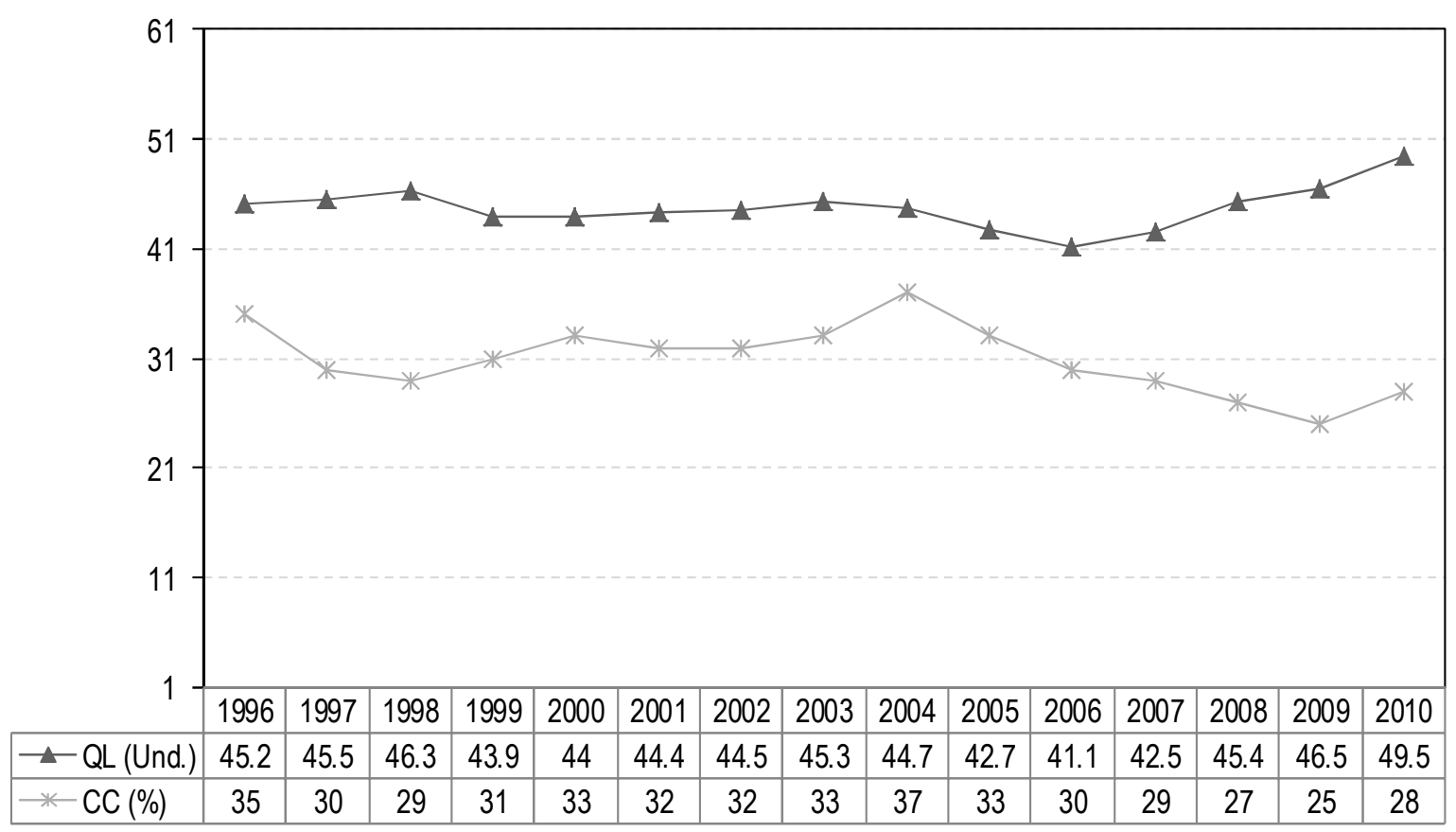

Figura 7. Quociente locacional e coeficiente de concentração no sistema local de Franca: fabricação de couro e artefatos de couro (CNAE 19) durante o período de 1996 a 2010.

FONTE: Elaborado pelo autor.

Dessa forma, ao longo de toda à amostra analisada a atividade de calçados em Franca se apresenta como um Núcleo de Desenvolvimento Setorial-Regional. A estrutura industrial de Franca é caracterizada pela completude de seu tecido industrial. Em termos ampliados, Franca abriga toda uma cadeia produtiva em torno da produção de calçados, curtumes, que beneficiam o couro, fabricantes de calçados, passando pelos fornecedores de componentes, adesivos (cola), máquinas e etc.

Neste sentido, é completamente justificável que a divisão CNAE 25 (fabricação de artigos de borracha e plástico) apresente relevância na economia local, uma vez que a indústria de calçados introduziu plásticos e borrachas, como um de seus competentes principais há décadas. De modo que seu caráter subordinado à fabricação de calçados torna justificável sua fase no ciclo como Embrião de Sistema Local (Figura 8). 


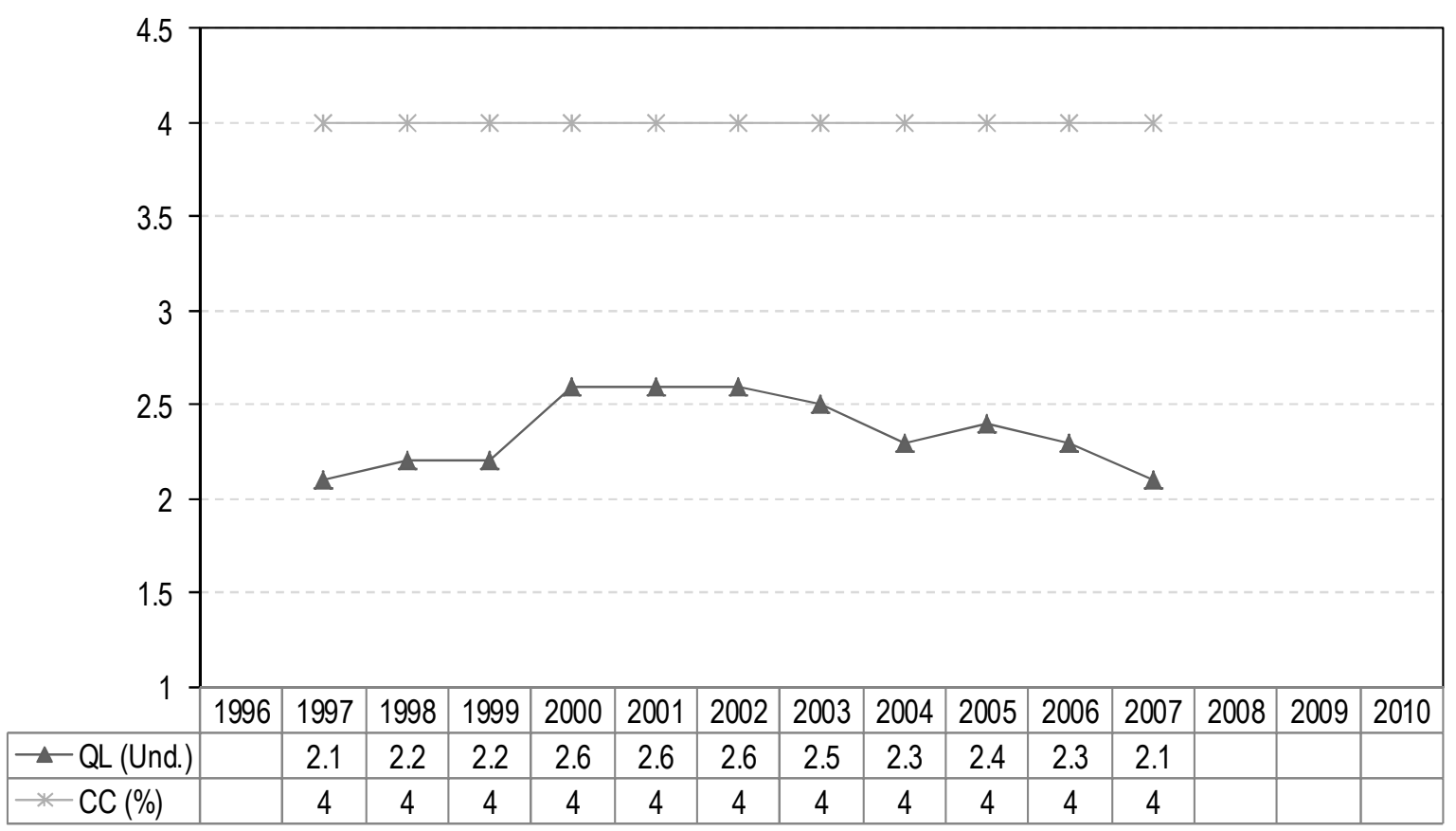

Figura 8. Quociente locacional e coeficiente de concentração no sistema local de Franca: fabricação de artigos de borracha e plástico (CNAE 25) durante o período de 1996 a 2010.

FONTE: Elaborado pelo autor.

Diferente do sistema local de Campinas (especializado em produtos têxteis), a fronteira temática do sistema local de Franca apresenta uma estrutura estreita, ou seja, a divisão do trabalho exerceu pressões para à especialização em uma atividade econômica diferente, mas subordinada à primeira, como é o caso da atividade industrial plástico e borrachas.

\subsubsection{Sistema Local de Votuporanga: indústria de móveis}

O sistema local de Votuporanga possui uma forte especialização na fabricação de móveis e indústrias diversas (divisão CNAE 36, Figura 9). A indústria moveleira é caracterizada pela forte pulverização de sua atividade industrial. Um grande número de pequenas empresas dispersas é sua norma, entretanto, contrariando o senso comum à microrregião de Votuporanga concentra um volume numeroso de fabricantes de móveis cerca de 180 estabelecimentos com 4.000 vínculos empregatícios formais (Tabela 4 e 5). Adicionalmente, Votuporanga apresenta uma baixa diversificação industrial. Somente a atividade industrial de fabricação e montagem de veículos automotores (CNAE 34) apresentou a relevância para a tipologia dos sistemas locais - veja tabela 9 e figura 10 


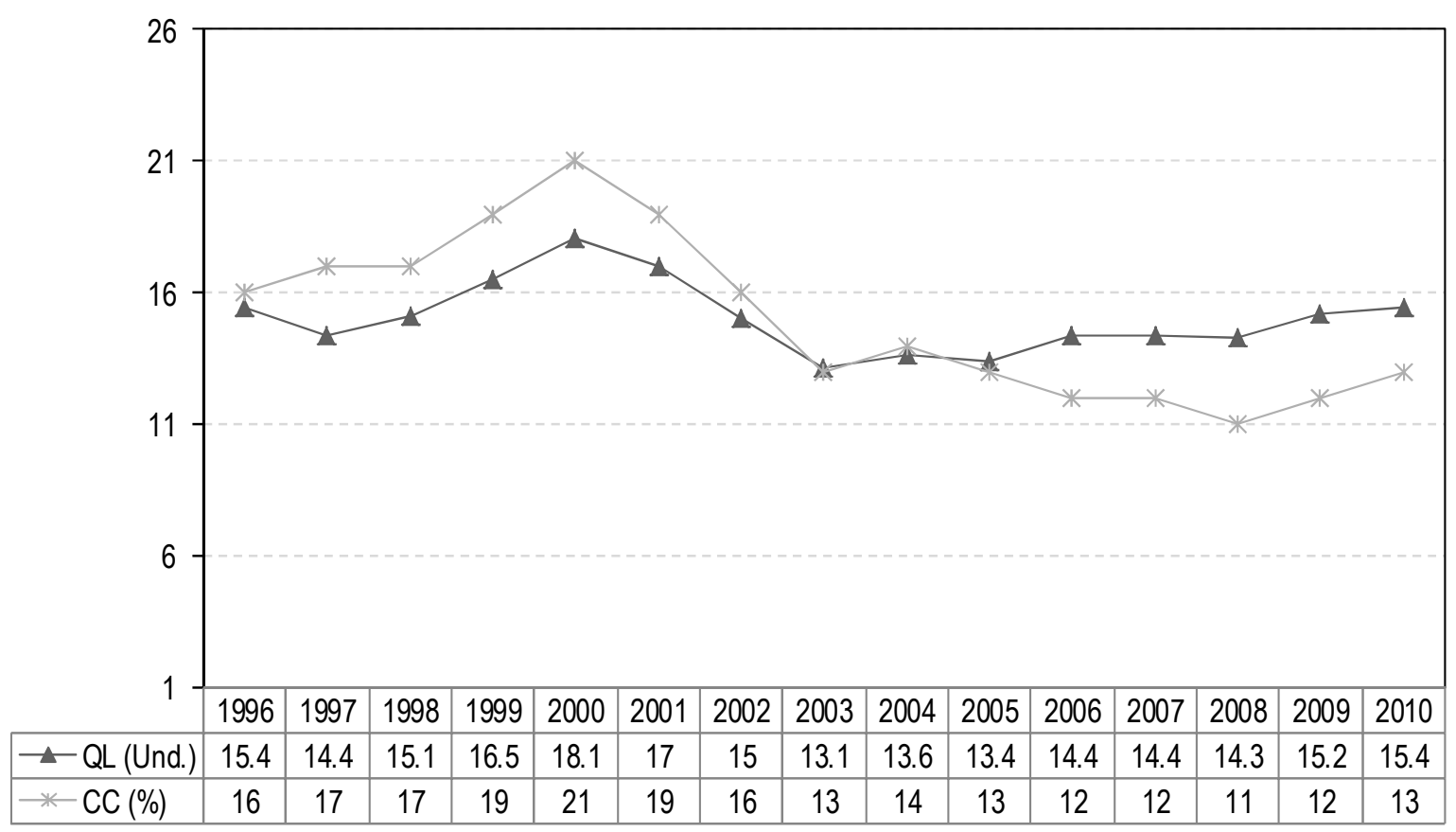

Figura 9. Quociente locacional e coeficiente de concentração no sistema local de Votuporanga: fabricação de móveis e indústrias diversas (CNAE 36) durante o período de 1996 a 2010.

FONTE: Elaborado pelo autor.

Tabela 9. Ciclo de vida dos sistemas locais em Votuporanga/SP, evidenciando a presença de Núcleos de Desenvolvimento Setorial-Regional e Embriões de Sistema Local nas atividades selecionadas da indústria de transformação durante o período de 1996 a 2010.

\begin{tabular}{|c|c|c|c|c|c|c|c|c|c|c|c|c|c|c|c|c|c|c|c|c|}
\hline Divisão & 17 & 18 & 19 & 24 & 25 & 26 & 27 & 28 & 29 & 31 & 32 & 33 & 34 & 35 & 36 & 37 & 72 & 73 & & 44 \\
\hline 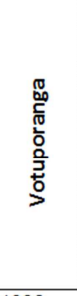 & 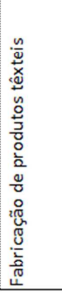 & 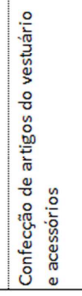 & 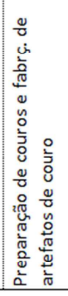 & 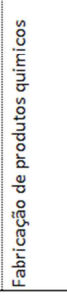 & 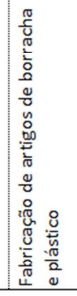 & 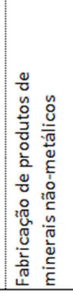 & 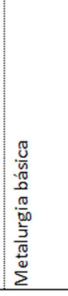 & 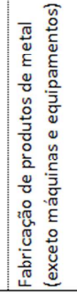 & 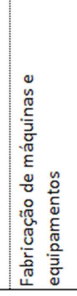 & 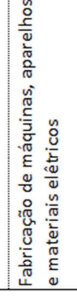 & 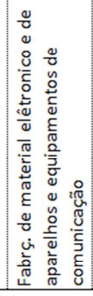 & 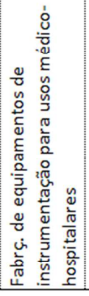 & 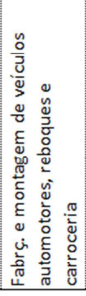 & 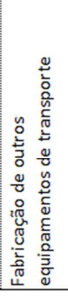 & 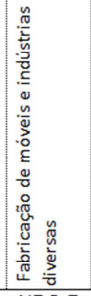 & 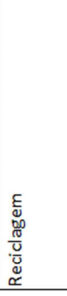 & 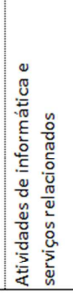 & 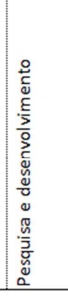 & 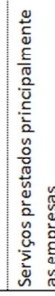 & 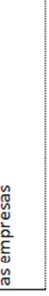 \\
\hline 1996 & & 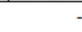 & & & & & & & & & - & - & - & & NDS-R & & & & & - \\
\hline 1997 & & & & & & & & & & & - & - & - & & NDS-R & & & & & - \\
\hline 1998 & & & & & & & & & & & - & - & - & & NDS-R & & & & & - \\
\hline 1999 & & & & & & & & & & & - & - & - & & NDS-R & & & & & - \\
\hline 2000 & & & & & & & & & & & - & - & - & & NDS-R & & & & & - \\
\hline 2001 & & & & & & & & & & & - & - & - & & NDS-R & & & & & - \\
\hline 2002 & & ESL & & & & & & & & & - & - & - & & NDS-R & & & & & - \\
\hline 2003 & & & & & & & & & & & - & - & ESL & & NDS-R & & & & & - \\
\hline 2004 & & & & & & & & & & & - & - & ESL & & NDS-R & & & & & - \\
\hline 2005 & & & & & & & & & & & - & - & ESL & & NDS-R & & & & & - \\
\hline 2006 & & & & & & & & & & & - & - & ESL & & NDS-R & & & & 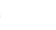 & - \\
\hline 2007 & & & & & & & & & & & - & - & ESL & & NDS-R & & & & & - \\
\hline 2008 & & & & & & & & & & & - & - & ESL & & NDS-R & & & & . & - \\
\hline 2009 & & & & & & & & & & & - & - & ESL & & NDS-R & & & & & - \\
\hline 2010 & & 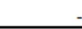 & & & & & & & & & - & - & ESL & & NDS-R & & & & & - \\
\hline
\end{tabular}

FONTE: Elaborado pelo autor com base nos dados da RAIS/MTE. 


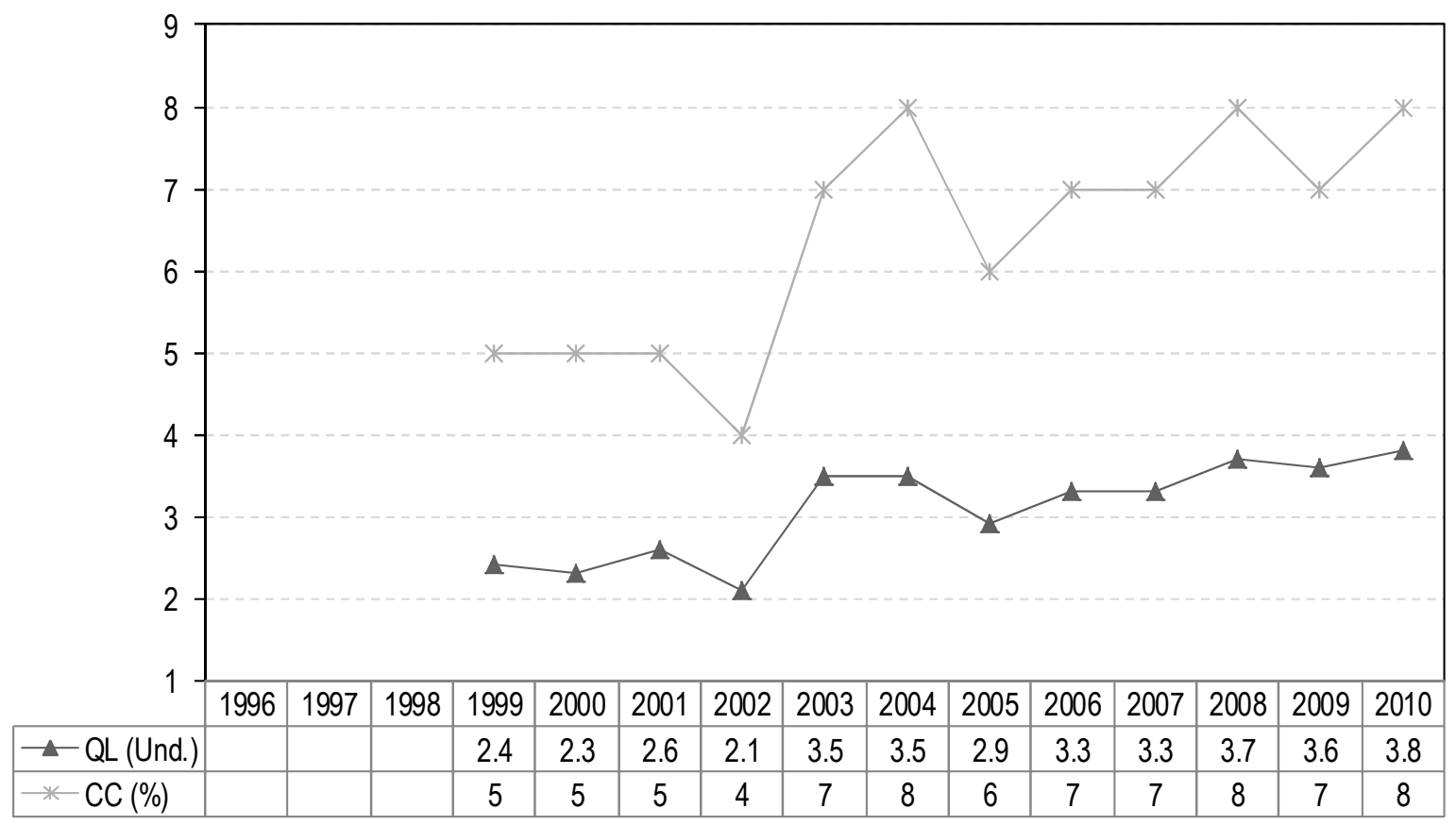

Figura 10. Quociente locacional e coeficiente de concentração no sistema local de Votuporanga: fabricação e montagem de veículos automotores (CNAE 34) durante o período de 1996 a 2010.

FONTE: Elaborado pelo autor.

Suzigan et. al. (2001) em uma série de entrevistas realizadas com o empresariado local, não conseguiu identificar um denominador comum para a fase de emergência do sistema local moveleiro na região de Votuporanga. Contudo, a justificativa encontrada para a aderência desta atividade a fase de Núcleo de Desenvolvimento SetorialRegional esta na "ação conjunta" do empresariado local. Os autores alegam que as dificuldades econômicas enfrentadas no início dos anos 90 pela indústria local geraram um processo de reestruturação produtiva que culminou em uma "construção institucional para obter vantagens competitivas".

Uma associação entre a indústria local e o SEBRAE - Serviço Brasileiro de Apoio às Micro e Pequenas Empresas; foi efetuada para adicionar valor ao produto local, à época. Alterações no desenho do produto (design), bem como, no gerenciamento de propaganda (marketing) foram fundamentais para o aprimoramento da competitividade local. Adicionalmente, políticas locais de incentivo como parcerias com o SENAI Sistema Nacional de Aprendizagem Industrial, para o treinamento de trabalhadores; e desenvolvimento tecnológico com o CETEMO - Centro Tecnológico do Mobiliário; auxiliaram as empresas a auferir ganhos substâncias de produtividade. 
O sistema local moveleiro de Votuporanga resume bem uma característica encontrada em abundância na experiência internacional à prevalência das forças de cooperação relativamente às competitivas. Para Furtado (2004) este tipo de característica, isto é, a prevalência de forças de cooperação às de competição, é encontrado em raros momentos no tecido industrial brasileiro, uma vez que a normal é a prevalência das forças de competição.

\subsubsection{Sistema Local de São Carlos: indústria de máquinas e equipamentos}

O sistema local de São Carlos, segundo a tipologia, possui destaque na fabricação de máquinas e equipamentos (CNAE 29). Nota-se que o sistema local de São Carlos manteve-se como um Núcleo de Desenvolvimento Setorial-Regional ao longo de dez anos (1996-2006), perdendo destaque tanto localmente (redução do quociente locacional) quanto setorialmente (redução do coeficiente de concentração) a partir de 2007 (Figura 11). Esta perda de prevalência se deve à diversificação local. A tabela 10 mostra como outras divisões CNAEs ganharam significância industrial na região ao longo deste triênio, especialmente, a divisão 36 (fabricação de móveis).

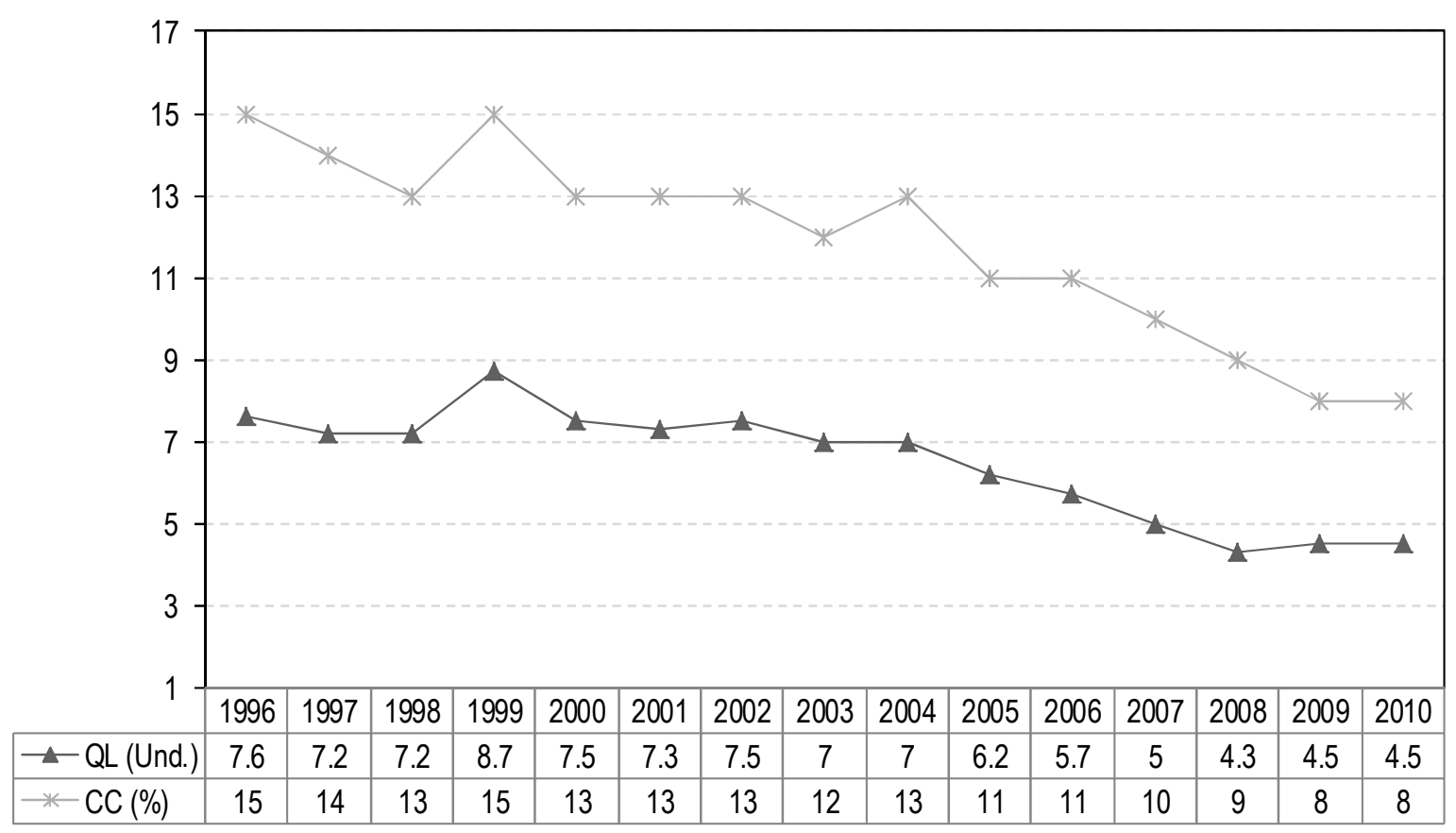

Figura 11. Quociente locacional e coeficiente de concentração no sistema local de São Carlos: fabricação de máquinas e equipamentos (CNAE 29) durante o período de 1996 a 2010.

FONTE: Elaborado pelo autor 
Tabela 10. Ciclo de vida dos sistemas em São Carlos/SP, evidenciando a presença de Núcleos de Desenvolvimento Setorial-Regional e Embriões de Sistema Local nas atividades selecionadas da indústria de transformação durante o período de 1996 a 2010.

\begin{tabular}{|c|c|c|c|c|c|c|c|c|c|c|c|c|c|c|c|c|c|c|c|c|}
\hline Divisão & 17 & 18 & 19 & 24 & 25 & 26 & 27 & 28 & 29 & 31 & 32 & 33 & 34 & 35 & 36 & 37 & 72 & 73 & 74 & \\
\hline $\begin{array}{l}\text { on } \\
\text { 는 } \\
\text { o } \\
\text { ñ }\end{array}$ & 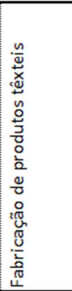 & 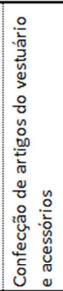 & 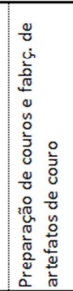 & 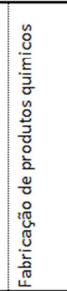 & 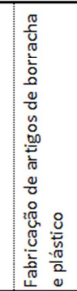 & 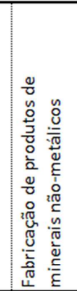 & 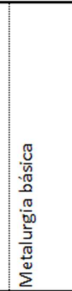 & 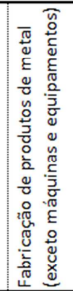 & 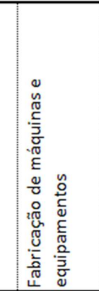 & 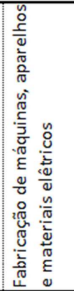 & 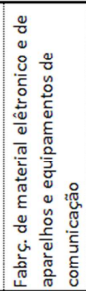 & 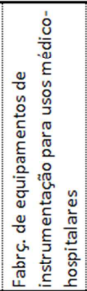 & 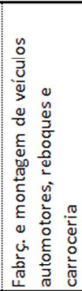 & 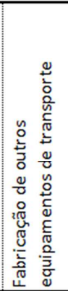 & 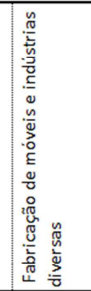 & 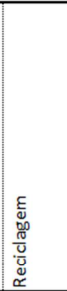 & 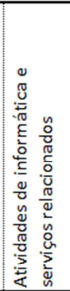 & 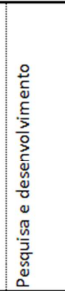 & 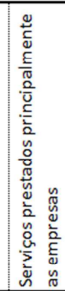 & \\
\hline 1996 & & & & & - & 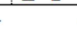 & & & - NDS-R & 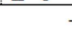 & - & - & - & & ESL & & & & & - \\
\hline 1997 & & & & & - & & & & - NDS-R & & - & - & & & ESL & & & & & - \\
\hline 1998 & ESL & & & & - & . & & & - NDS-R & - & - & - & - & & ESL & & & & & - \\
\hline 1999 & 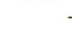 & & & & - & . & & & - NDS-R & . & - & - & & & ESL & & & & & - \\
\hline 2000 & . & & & & - & . & & & - NDS-R & 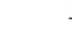 & 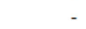 & - & 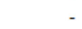 & & ESL & & & & & - \\
\hline 2001 & & & & & - & & & & - NDS-R & & - & - & - & & ESL & & & & & - \\
\hline 2002 & . & & & & - & . & & & - NDS-R & . & 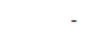 & - & 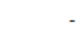 & & ESL & & & & & - \\
\hline 2003 & . & & & & - & . & & & - NDS-R & . & - & - & 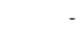 & & $\mathrm{ESL}$ & & & & & - \\
\hline 2004 & & & & & - & & & & - NDS-R & . & 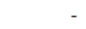 & 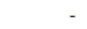 & - & & ESL & & & & & - \\
\hline 2005 & . & & & & - & . & & & NDS-R & . & - & - & - & & $\mathrm{ESL}$ & & & & & - \\
\hline 2006 & & & & & - & & & & NDS-R & ESL & - & - & - & & - & & & & & - \\
\hline 2007 & & & & & - & & & & ESL & . & - & ESL & - & & ESL & & & & & - \\
\hline 2008 & ESL & & & & - & 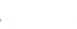 & & & ESL & . & - & ESL & - & & ESL & & & & & - \\
\hline 2009 & ESL & & & & - & & & & ESL & - & . & ESL & - & & ESL & & & & & - \\
\hline 2010 & & & & & - & . & & & $E S L$ & . & - & ESL & - & & ESL & & & & & - \\
\hline
\end{tabular}

FONTE: Elaborado pelo autor com base nos dados da RAIS/MTE.

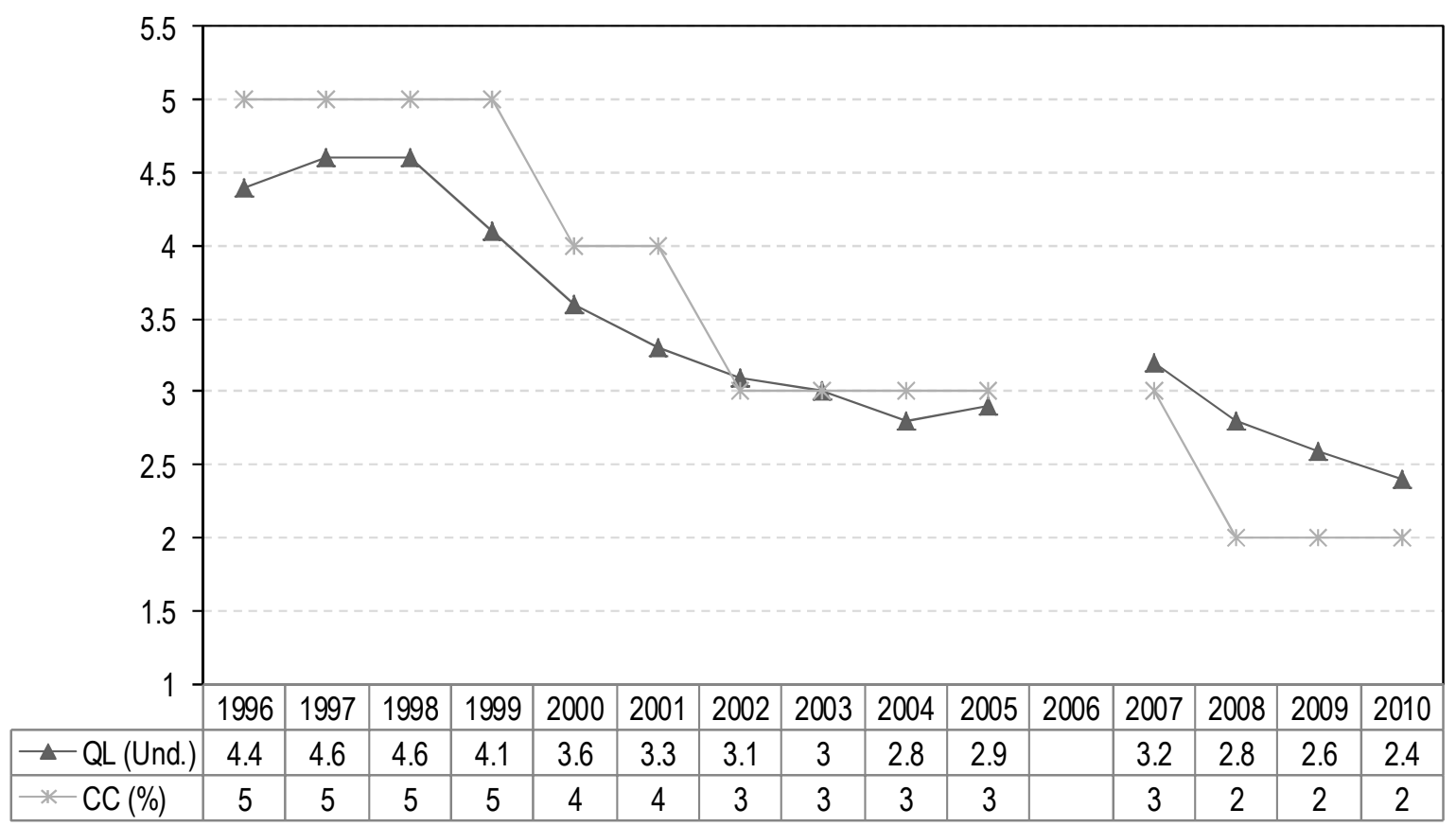

Figura 12. Quociente locacional e coeficiente de concentração no sistema local de São Carlos: fabricação de móveis e indústria diversa (CNAE 36) durante o período de 1996 a 2010.

FONTE: Elaborado pelo autor

A atividade industrial fabricação de móveis no sistema local de São Carlos (Figura 12) evolui-o de um Embrião de Sistema Local para um Vetor de Desenvolvimento 
Local, ou seja, ganhou importância local. Soma-se a isso a divisão 33 (fabricação de equipamentos médico-hospitalares) que após 2006 alcançou relevância na tipologia como Embrião de Sistema Local (tabela 10).

Adicionalmente, em 2006 a indústria moveleira de São Carlos apresentou um QL abaixo de filtro de relevância de $\mathrm{QL}>2$, a saber, QL: 1.9, ou seja, atividade não alcançou os critérios mínimos estabelecidos pela metodologia. Uma consulta às bases de dados da RAIS mostra que no ano de 2005 havia 57 estabelecimentos com um total de 2.018 postos de trabalho nesta atividade industrial para a microrregião de São Carlos. Já no ano de em 2006 havia 51 estabelecimentos com um total de 1.167 postos de trabalho. E mais ainda no ano de 2007 havia 55 estabelecimentos com um total de 2.097. Dessa forma, a exclusão da atividade moveleira na tipologia dos Sistemas Locais no ano de 2006 se deve muito provavelmente pela ausência de dados (a seção 4.1 deste trabalho aborda a auto-declaração, sem uma contrapartida regulatória, como uma insuficiência da RAIS).

\subsubsection{Sistemas Locais de Limeira, Piracicaba e Rio Claro: indústria cerâmica}

As cidades de Santa Gertrudes, Limeira, Cordeirópolis, Ipeúna, Piracicaba, Araras e Rio Claro formam o pólo cerâmico do estado de São Paulo. De acordo com a Associação Paulista das Cerâmicas de Revestimento (Aspacer), são 48 indústrias, responsáveis por 13 mil empregos diretos e 195 mil indiretos. O sistema local de Rio Claro composta pelas cidades de Rio Claro e Santa Gertrudes (figura 13) possui especialização na produção de cerâmicas - divisão 26 da CNAE - seguida por Piracicaba (Figura 15); vide tabela 10 e 11. Já as microrregiões de Limeira (figura 14) e Piracicaba são especializadas na produção de máquinas e equipamentos (divisão 29) para a indústria cerâmica. 
Tabela 11. Ciclo de vida dos sistemas em Rio Claro/SP, evidenciando a presença de Embriões de Sistema Local nas atividades selecionadas da indústria de transformação durante o período de 1996 a 2010.

\begin{tabular}{|c|c|c|c|c|c|c|c|c|c|c|c|c|c|c|c|c|c|c|c|c|}
\hline Divisão & 17 & 18 & 19 & 24 & 25 & 26 & 27 & 28 & 29 & 31 & 32 & 33 & 34 & 35 & 36 & 37 & 72 & 73 & & 74 \\
\hline $\begin{array}{l}\frac{0}{0} \\
\frac{10}{0} \\
\frac{0}{\alpha}\end{array}$ & 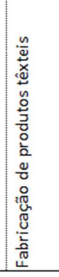 & 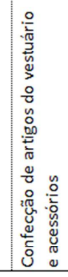 & 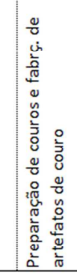 & 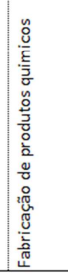 & 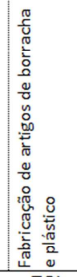 & 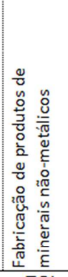 & 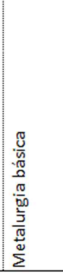 & 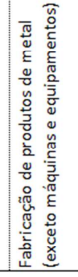 & 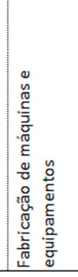 & 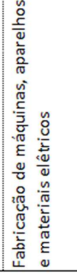 & 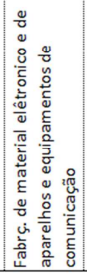 & 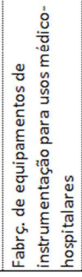 & 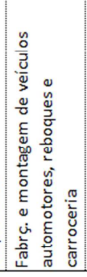 & 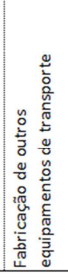 & 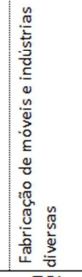 & 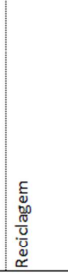 & 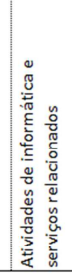 & 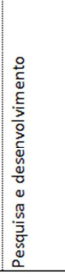 & 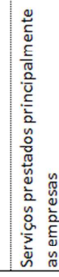 & \\
\hline 1996 & & & - & & ESL & ESL & & . & - & & - & - & - & & $\mathrm{ESL}$ & & 2 & & & - \\
\hline 1997 & & & - & & ESL & ESL & & . & - & ESL & - & - & 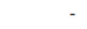 & & - & & & & & - \\
\hline 1998 & & & - & & ESL & ESL & & & . & ESL & - & - & - & & . & & & & & - \\
\hline 1999 & & & - & & ESL & ESL & & ESL & . & 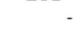 & - & - & - & & . & & & & & - \\
\hline 2000 & & & - & & ESL & ESL & & ESL & . & - & - & - & - & & 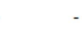 & & & & & - \\
\hline 2001 & & & - & & ESL & ESL & & ESL & . & ESL & - & ESL & - & & - & & & & & - \\
\hline 2002 & & & - & & ESL & ESL & & ESL & . & - & - & ESL & - & & - & & & & & - \\
\hline 2003 & & & - & & ESL & ESL & & . & ESL & ESL & - & ESL & - & & ESL & & & & & - \\
\hline 2004 & & & - & & ESL & ESL & & . & ESL & ESL & - & ESL & 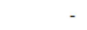 & & ESL & & & & & - \\
\hline 2005 & & & - & & 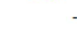 & ESL & & . & . & VDL & - & ESL & - & & 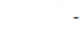 & & & & & - \\
\hline 2006 & & & - & & 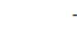 & ESL & & . & 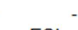 & NDS-R & - & ESL & - & & ES & & & & & - \\
\hline 2007 & & & - & & & ESL & & . & ESL & NDS-R & - & & - & & ESL & & & & & - \\
\hline 2008 & & & - & & ESL & VDL & & . & ESL & - & - & ESL & - & & VDL & & & & & - \\
\hline 2009 & & & - & & ESL & ESL & & . & ESL & - & - & ESL & - & & - & & & & & - \\
\hline 2010 & & & - & & $\mathrm{ESL}$ & $\mathrm{VDL}$ & & & $\mathrm{ESL}$ & - & - & ESL & - & & VDL & & & & & - \\
\hline
\end{tabular}

FONTE: Elaborado pelo autor com base nos dados da RAIS/MTE.

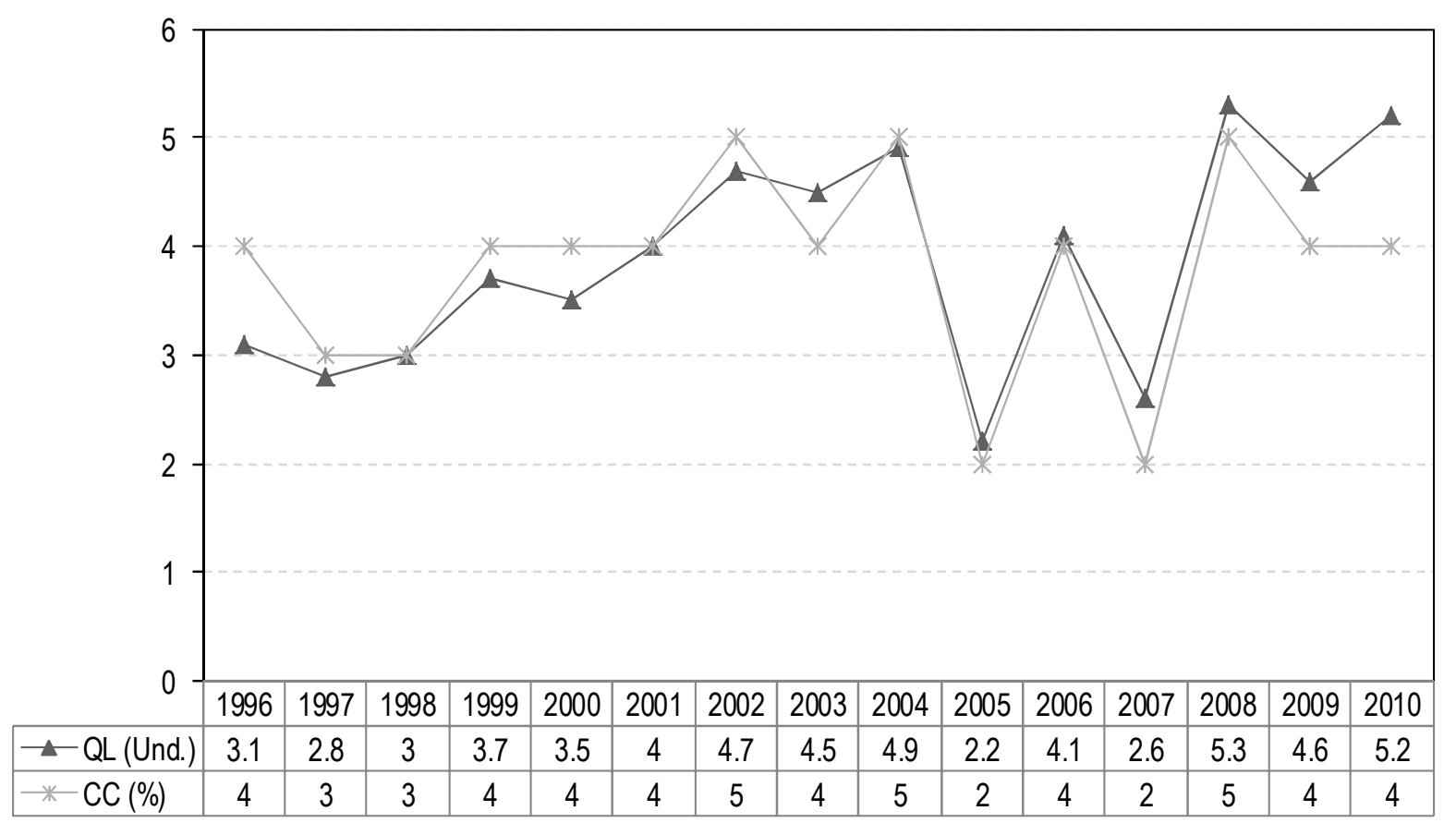

Figura 13. Quociente locacional e coeficiente de concentração no sistema local de Rio Claro fabricação de produtos minerais e não metálicos (CNAE 26) durante o período de 1996 a 2010.

FONTE: Elaborado pelo autor 
Tabela 12. Ciclo de vida dos sistemas em Limeira/SP, evidenciando a presença de Vetores de Desenvolvimento Local e Embriões de Sistema Local nas atividades selecionadas da indústria de transformação durante o período de 1996 a 2010.

\begin{tabular}{|c|c|c|c|c|c|c|c|c|c|c|c|c|c|c|c|c|c|c|c|c|}
\hline Divisão & 17 & 18 & 19 & 24 & 25 & 26 & 27 & 28 & 29 & 31 & 32 & 33 & 34 & 35 & 36 & 37 & 72 & 73 & 7 & 4 \\
\hline 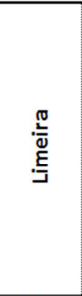 & 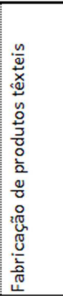 & 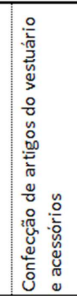 & 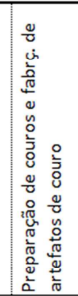 & 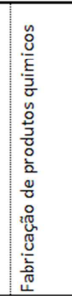 & 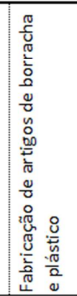 & 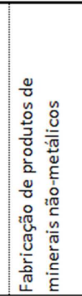 & 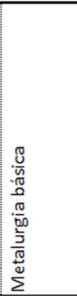 & 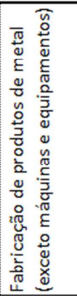 & 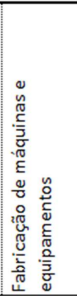 & 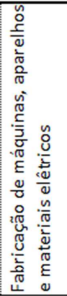 & 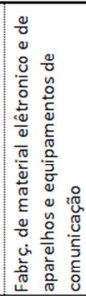 & 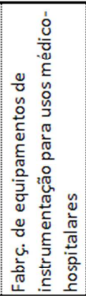 & 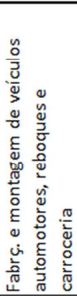 & 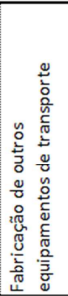 & 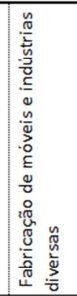 & 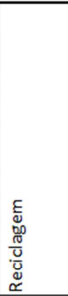 & 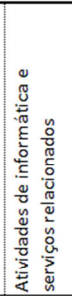 & 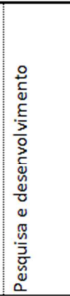 & 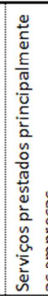 & \\
\hline 1996 & & 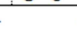 & 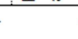 & 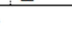 & & VDL & - & - & ESL & & - & - & - & & ESL & & & & & - \\
\hline 1997 & & . & . & & & VDL & - & - & ESL & & - & - & - & & ESL & & & & & - \\
\hline 1998 & & . & & & & VDL & - & - & ESL & & - & - & ESL & & ESL & & & & & - \\
\hline 1999 & & . & & & & VDL & - & - & ESL & & 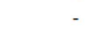 & - & - & & ESL & & & & & - \\
\hline 2000 & & . & . & & & VDL & - & - & ESL & & - & - & - & & ESL & & & & & - \\
\hline 2001 & & . & . & & & VDL & - & - & ESL & & 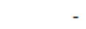 & - & - & & ESL & & & & & - \\
\hline 2002 & & . & . & & & VDL & - & - & ESL & & - & - & - & & ESL & & & & & - \\
\hline 2003 & & . & . & & & VDL & - & ESL & ESL & & 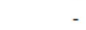 & - & - & & ESL & & & & & - \\
\hline 2004 & & . & . & & & VDL & - & $\mathrm{ESL}$ & ESL & & . & - & . & & ESL & & & & & - \\
\hline 2005 & & . & & & & VDL & . & ESL & ESL & & - & - & ESL & & ESL & & & & & . \\
\hline 2006 & & . & . & . & & VDL & - & ESL & 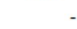 & & - & - & ESL & & ES & & & & & - \\
\hline 2007 & & . & . & & & VDL & ESL & ESL & 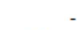 & & - & - & ESL & & ESL & & & & & - \\
\hline 2008 & & . & . & & & VDL & . & $\mathrm{ESL}$ & ESL & & - & - & ESL & & ESL & & & & & - \\
\hline 2009 & & . & . & & & VDL & ESL & ESL & ESL & & - & - & ESL & & ESL & & & & & - \\
\hline 2010 & & - & . & & & VDL & ESL & ESL & ESL & & - & - & ESL & & ESL & & & & & - \\
\hline
\end{tabular}

FONTE: Elaborado pelo autor com base nos dados da RAIS/MTE.

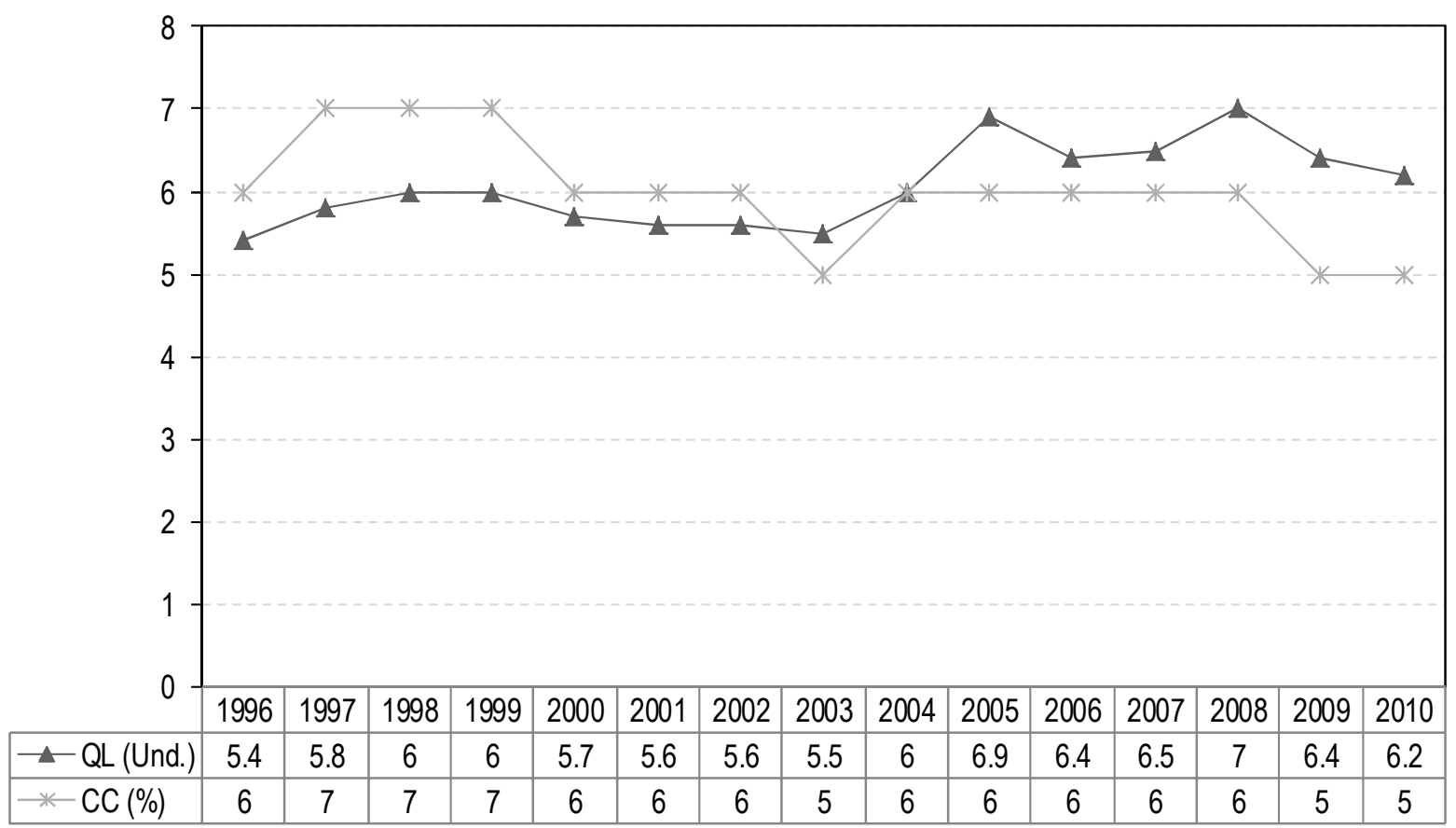

Figura 14. Quociente locacional e coeficiente de concentração no sistema local de Limeira: fabricação de produtos minerais e não metálicos (CNAE 26) durante o período de 1996 a 2010.

FONTE: Elaborado pelo autor 
Tabela 13. Ciclo de vida dos sistemas em Piracicaba/SP, evidenciando a presença de Embriões de Sistema Local nas atividades selecionadas da indústria de transformação durante o período de 1996 a 2010.

\begin{tabular}{|c|c|c|c|c|c|c|c|c|c|c|c|c|c|c|c|c|c|c|c|c|}
\hline Divisão & 17 & 18 & 19 & 24 & 25 & 26 & 27 & 28 & 29 & 31 & 32 & 33 & 34 & 35 & 36 & 37 & 72 & 73 & 7 & 4 \\
\hline $\begin{array}{l}\frac{\pi}{0} \\
\frac{0}{0} \\
\frac{\pi}{20} \\
\frac{\pi}{2}\end{array}$ & 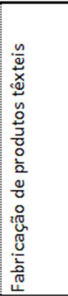 & 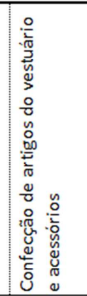 & 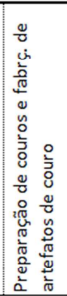 & 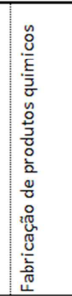 & 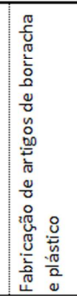 & 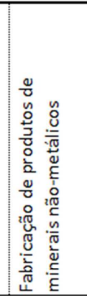 & 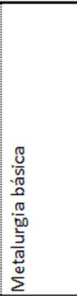 & 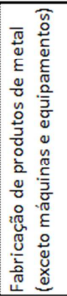 & 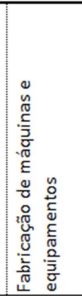 & 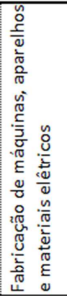 & 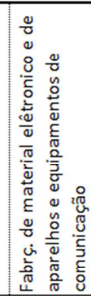 & 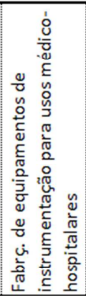 & 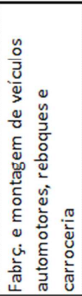 & 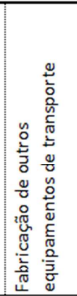 & 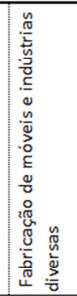 & 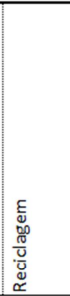 & 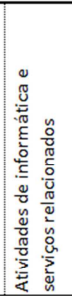 & 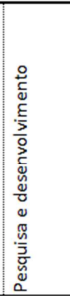 & 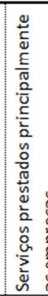 & \\
\hline 1996 & & ESL & & 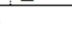 & (n) & - & ESL & & ESL & & - & - & - & 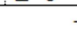 & & & & & & - \\
\hline 1997 & & ESL & & & & - & . & & ESL & & - & - & - & & & & & & & - \\
\hline 1998 & & ESL & & & & - & - & & ESL & & - & - & - & & & & & & & - \\
\hline 1999 & & $\mathrm{ESL}$ & & & & - & - & & ESL & & - & - & - & & & & & & & - \\
\hline 2000 & & ESL & & & & - & - & & ESL & & - & - & . & & & & & & & - \\
\hline 2001 & & ESL & & & & ESL & - & & ESL & & - & - & - & & & & & & & - \\
\hline 2002 & & ESL & & & & ESL & . & & ESL & & - & - & - & & & & & & & - \\
\hline 2003 & & ESL & & & & - & - & & ESL & & - & - & - & & & & & & & - \\
\hline 2004 & & . & & & & - & - & & ESL & & - & - & - & & & & & & & - \\
\hline 2005 & & - & & & & ESL & ESL & & ESL & & - & - & - & & & & & & & . \\
\hline 2006 & & - & & . & & - & - & & ESL & & . & . & - & & & & & & & - \\
\hline 2007 & & - & & & & - & - & & ESL & & - & - & - & & & & & & & - \\
\hline 2008 & & - & & & & - & - & & ESL & & - & - & - & & & & & & & - \\
\hline 2009 & & - & & & & ESL & - & & ESL & & - & - & - & & & & & & & . \\
\hline 2010 & ESL & - & & & & ESL & - & & ESL & & - & - & - & & & & & & & - \\
\hline
\end{tabular}

FONTE: Elaborado pelo autor com base nos dados da RAIS/MTE.

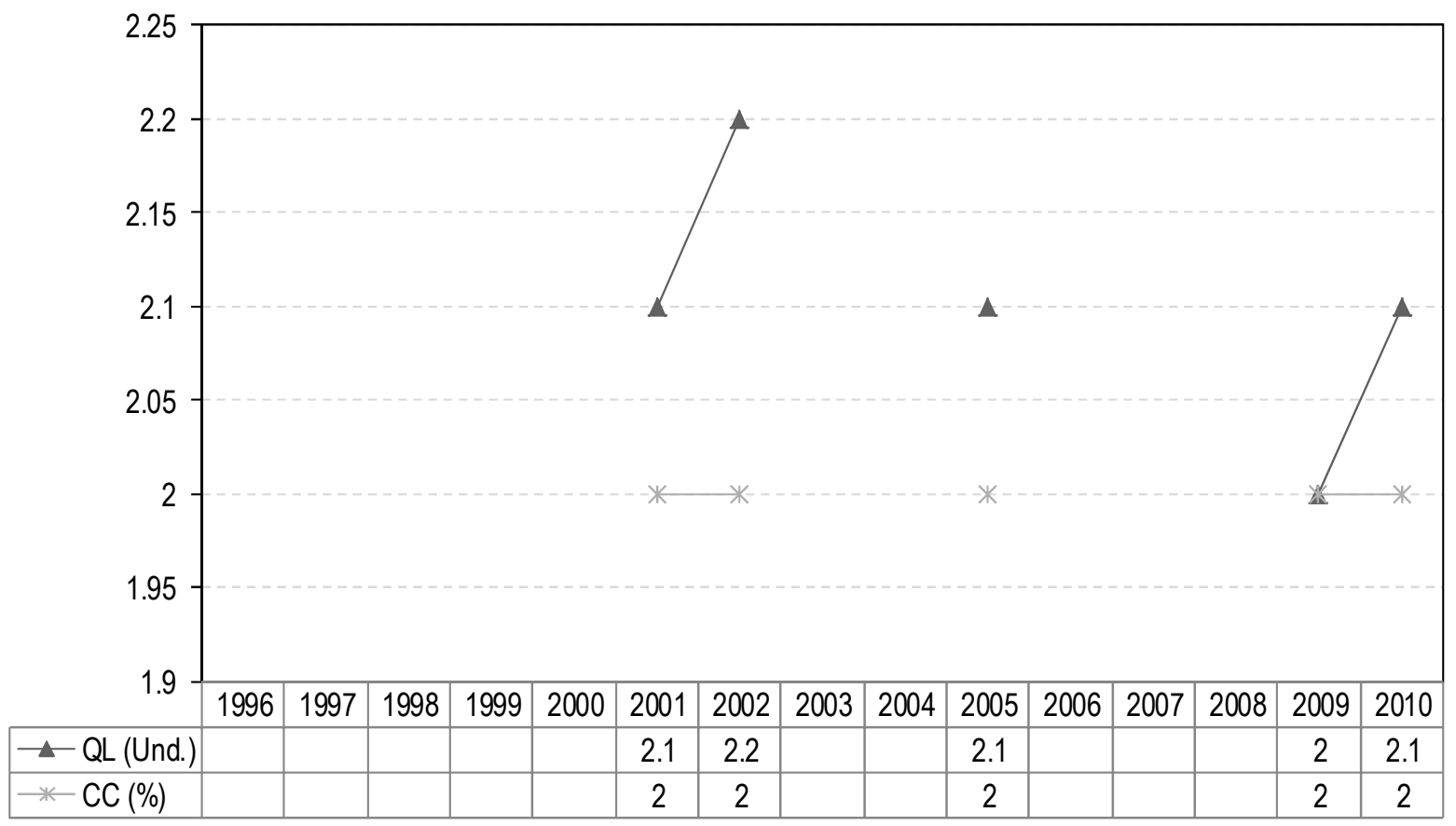

Figura 15. Quociente locacional e coeficiente de concentração no sistema local de Rio Claro, Limeira e Piracicaba: fabricação de produtos minerais e não metálicos (CNAE 26) durante o período de 1996 a 2010.

FONTE: Elaborado pelo autor

Na perspectiva dos ciclos as microrregiões de Rio Claro e Piracicaba encontram-se no estágio de crescimento, como demonstra a tabela 11 e 13, essas microrregiões foram classificadas como vetores de desenvolvimento local na fabricação de produtos 
minerais não metálicos (CNAE 26). Já a microrregião de Limeira apresentou destaque na produção de produtos de cerâmica (tabela 12), bem como na indústria moveleira que se encontra em um estágio embrionário. Contudo, isso não descarta a importância da microrregião de Limeira para o pólo cerâmico, somente reforça que sua importância para o pólo está na produção de máquinas e equipamentos. Vale ressaltar que as microrregiões que compõe o pólo cerâmico possuem uma forte diversificação industrial (tabelas 11, 12 e 13) que podem auxiliar, mas nunca assegurar, a renovação das capacitações locais em caso de ruptura abrupta da dinâmica econômica local. 


\section{Conclusão}

O objetivo deste trabalho foi o de efetuar um levantamento da estrutura industrial dos sistemas locais e seus ciclos de vida para as microrregiões do estado de São Paulo no período de 1996 a 2010. A partir de suas características produtivas, a amostra de empresas e estabelecimentos foi em seguida submetida a uma análise baseada em critérios relativos ao emprego - coeficiente de concentração e quociente local - e aos estabelecimentos - número mínimo de empresas para a constituição de um sistema local de produção. Em outras palavras, não se preocupou propriamente em testar hipóteses específicas, e a relevância dos principais resultados e conclusões está diretamente relacionada à metodologia empregada, tanto na escolha dos indicadores quanto nos critérios de classificação das fases do ciclo.

Para compreender o processo de evolução analisou-se o ciclo de vida através das alterações sua importância local (quociente locacional) e importância industrial (coeficiente de concentração) a fim de evidenciar, de maneira empírica, os ciclos. A partir da tipologia dos sistemas locais foi possível identificar a evolução das capacitações locais na indústria de transformação do estado de São Paulo.

A identificação das quatro fases do ciclo de vida cumpre o objetivo principal do trabalho, uma vez que foi realizada por meio de método estatístico de ampla aceitação acadêmica, revelada por sua capacidade de apontar padrões entre os casos (microrregiões, nesse trabalho), segundo o comportamento das variáveis. As similaridades expressas nos resultados de aplicação da técnica aos quinze anos da RAIS representam uma configuração confiável dos padrões identificados, a qual foi reforçada quando analisadas as mudanças das fases do ciclo.

Além disso, ao respeitar o elemento analítico destacado por Menzel \& Fornahl (2010) e apontado no referencial teórico, qual seja, o de que os sistemas locais possuem especificidades envoltas no processo de construção das capacitações locais, o trabalho avançou nesta compreensão. Entre os resultados do trabalho destaca-se que o primeiro processo de evolução dentro do ciclo de vida ocorre de maneira incremental, e conclui-se que não há linearidade no processo de evolução, a norma é um corportamento errático entre as fases.

Para finalizar, cabem ainda algumas considerações gerais quanto ao alcance e as limitações deste trabalho.

Foi advertido na introdução sobre a pretensão de não ir muito além de um "mapeamento" da estrutura dos ciclos de vida dos sistemas locais no estado de São 
Paulo, a um nível de desagregação que tornasse possível revelar as particularidades técnicas e econômicas das indústrias, sem perder de vista as características que exercem os respectivos padrões de aglomeração. Admite-se com isso que um levantamento preliminar da estrutura industrial dos sistemas locais de São Paulo a partir destes critérios (coeficiente de concentração e quociente locacional) pode se constituir num subsídio de alguma importância para uma discussão mais ampla e qualitativa da dinâmica dos sistemas locais. Naturalmente, o fato de este trabalho investigar os sistemas locais num corte temporal específico (15 anos), e não a dinâmica de suas transformações acaba por restringir seu poder explicativo.

$\mathrm{Na}$ mesma ordem de preocupação, podem-se mencionar dois tipos de limitação implícitos neste trabalho. O primeiro, inerente à natureza do material empírico empregado, diz respeito ao fato de dispor somente de dados referentes ao número de emprego e estabelecimentos, o que forçosamente exclui a esfera de circulação do capital (comercial e financeiro), de importância crescente à medida que a concorrência rompe seus vínculos tradicionais com a atividade produtiva. Um segundo aspecto restritivo que se prende ao caráter estrutural da análise está no tratamento até certo ponto "esquemático" dado a grande empresa e ao capital estrangeiro. A posição em que são colocadas as empresas internacionais, sem um destaque especial na análise, não implica em supor para estas uma equivalência com demais grupos nacionais, ao contrário, admite-se que exerçam influência decisiva na determinação do padrão de industrialização, no grau de concentração e formas de concorrência.

Entretanto, como a abordagem empregada está centrada nas características estruturais e endógenas da indústria, o que em princípio possibilitaria indicar o grau e a diversidade de formas em que os padrões internacionais se fazem presentes, foi possível esclarecer aspectos específicos da indústria paulista. Procurou-se evitar um estudo genérico das estratégias e mecanismos decisórios no âmbito empresarial, substituindo-o pela análise de suas manifestações concretas, ao nível da produção industrial. 


\section{Referencial Bibliográfico}

ARTHUR, W. B. (1990). "Silicon Valley Locational Clusters: When do Increasing Returns Imply Monopoly". Mathematical Social Sciences, Vol. 19 - pp. 235/51.

AUDRETSCH, D; FELDMAN, M. (1996). "R\&D Spillovers and the Geography of Innovation and Production". American Economic Association, vol. 83 (6) - pp. 630/40.

BERGMAN, E. M. (2007), "Cluster life cycles: an emerging synthesis" In C. Karlsson (ed.), Handbook of Research on Cluster Theory. Edward Elgar: Cheltenham, UK, pp. $114 / 32$.

BETTS, J. R; LEE, C.W. B. (2004). "Universities as Drivers of Regional and National Innovation: An Assessment of the Linkages from Universities to Innovation and Economic Growth." Presented at John Deutsch Institute Conference "Higher Education in Canada", 13 -14 February, Queens University.

COHEN, W.M; LEVINTHAL, D. A. (1990). Absorptive capacity: a new perspective on learning and innovation. Administrative Science Quarterly, Vol. 35 (1) - pp. 128/52.

FELDMAN, M. P. (1993). "An examination of the geography of innovation". Industrial and Corporate Change, Vol. 2 (3) - pp. 451/70.

FURTADO, J. (2004). "Padrões de Inovação da Indústria Brasileira", Instituto Fernando Henrique Cardoso. http://www.inovacao.unicamp.br/report/inte-furtado.shtml

GRABHER, G. (1993). "The weakness of strong ties: the lock-in of regional development in the Ruhr area", In G. Grabher (ed), The Embedded Firm: On the Socioeconomics of Industrial Networks. London: Routledge - pp. 255/77.

IPARDES - Instituto Paranaense de Desenvolvimento Econômico e Social e SEPL Secretaria de Estado de Planejamento e Coordenação Geral, Governo do Estado do Paraná (2006). Arranjos Produtivos Locais do Estado do Paraná - identificação, caracterização e construção de tipologia. Curitiba: IPARDES.

KRUGMAN, P. (1991). Geography and Trade. The MIT Press, Cambridge, MA.

MAGGIONI, M. A. (2005). "The rise and fall of industrial clusters: technology and the life cycle of region", Institut d'Economia de Barcelona, Facultat de Ciències Econòmiques i Empresarials/Universitat de Barcelona.

MALMBERG, A; MASKELL, P. (2010). "An Evolutionary Approach to Localized Learning and Spatial Clustering" In The Handbook of Evolutionary Economic Geography - (ed.) Ron Boschma e Ron Martin.(2010). Cheltenham, UK. Ed. Edward Elgar - pp. 391/405.

MARSHALL, A. (1890). Principles of Economics: Introdution Notes. Macmilan, London.

MARTIN, R; SUNLEY. P; (2003). "Deconstructing clusters: chaotic concept or policy panacea?". Journal of Economic Geography, Vol. 3 - pp. 5/35.

MASKELL, P; MALMBERG, A. (1999). "Localized learning and industrial competitiveness". Cambridge Journal of Economics, Vol. 23 (2) - pp. 167/86.

MASKELL, P; MALMBERG, A. (2007). Myopia, knowledge development and cluster evolution, Journal of Economic Geography, Vol. 7 (5) - pp. 603/18.

MENZEL, M; FORNAHL, D. (2010). Cluster Life Cycles - Dimensions and Rationales of Cluster Evolution. Industrial and Corporate Change, Vol. 19 (1) - pp. 205/38. 
POLANYI, M. (1967). The Tacit Dimension. New York: Anchor Day Books.

SAXENIAN, A. (1994). "Inside-Out: Regional Networks and Industrial Adaptation in Silicon Valley and Route 128" In The Sociology of Economic Life - (ed.) Mark Granovetter e Richard Swedberg. (2001). Colorado, US. Ed. Westview press - pp. $357 / 75$.

SUZIGAN, W. et al. (2001) "Clusters ou Sistemas Locais de Produção: Mapeamento, Tipologia e Sugestões de Políticas". Revista de Economia Política, Vol. 24 (96) - pp. $543 / 62$.

SUZIGAN, W. et al. (2006). "Identificação, Mapeamento e Caracterização Estrutural de Arranjos produtivos locais no Brasil". Instituto de Pesquisa Econômica Aplicada - IPEA da Diretoria de Estudos Setoriais - DISET.

WINTER, S. (1984). "Schumpeterian competition in alternative technological regimes", Journal of Economic Behaviour and Organisation, Vol. 5 - pp. 287/320. 
Anexo I. Quociente Locacional para as atividades da indústria de transformação selecionadas - São Paulo/1996.

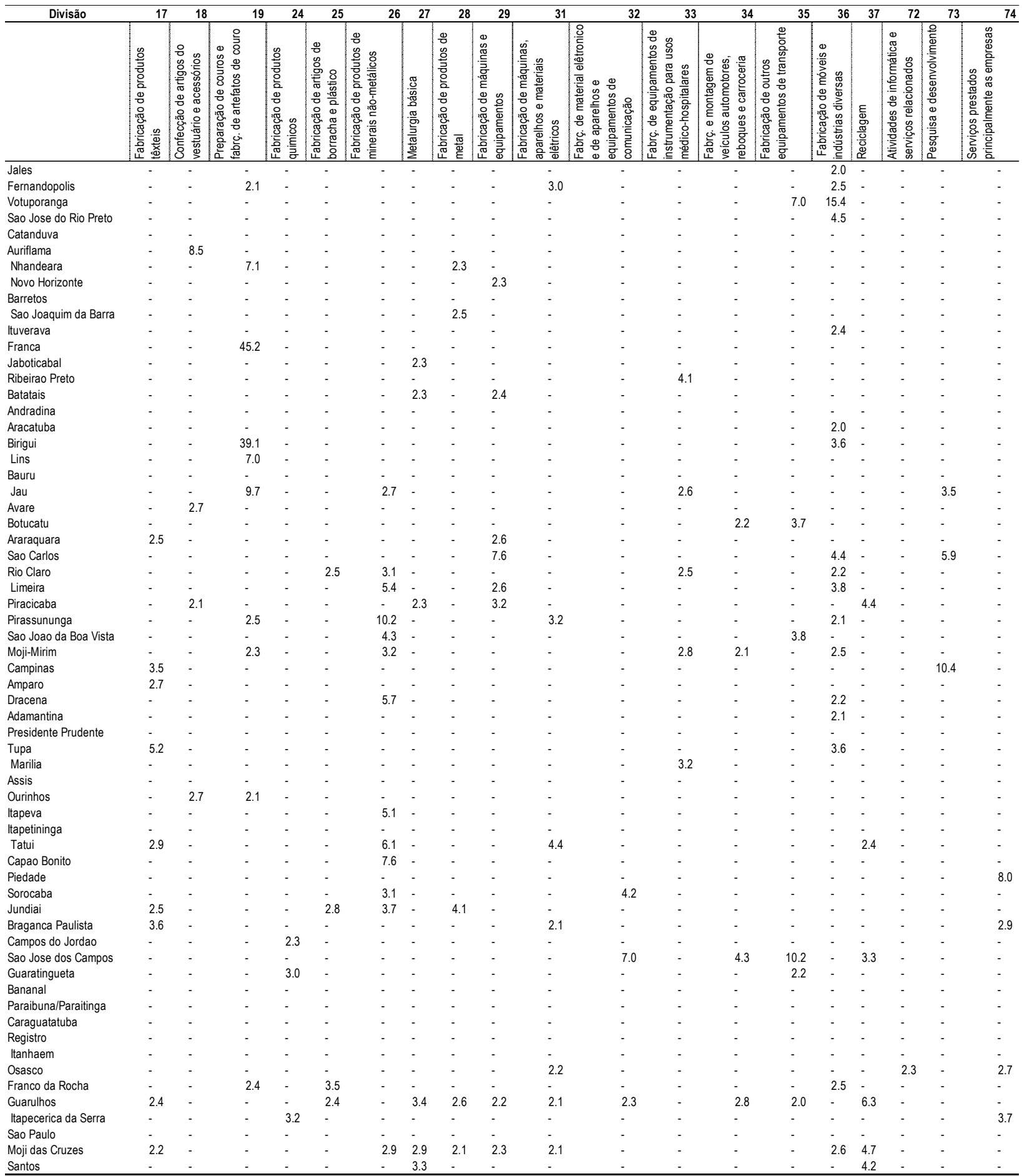

Observações/Filtro: QL $\geq 2$.

FONTE: Elaborado pelo auto com base nos dados da RAIS/MTE. 
Anexo II. Quociente Locacional para as atividades da indústria de transformação selecionadas - São Paulo/1997.

\begin{tabular}{|c|c|c|c|c|c|c|c|c|c|c|c|c|c|c|c|c|c|c|c|c|c|}
\hline Divisão & 17 & 18 & 19 & 24 & 25 & & 26 & 27 & 28 & 29 & 31 & 32 & 33 & 34 & 35 & 36 & 37 & 72 & 73 & 74 & $\underline{4}$ \\
\hline & 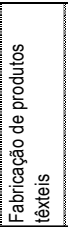 & 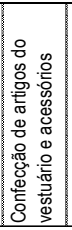 & 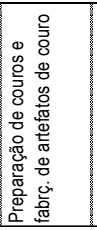 & 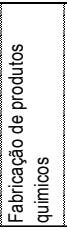 & 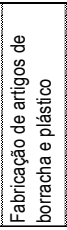 & 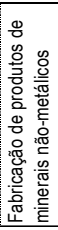 & & 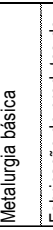 & 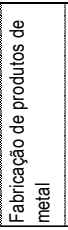 & 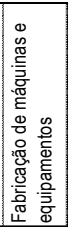 & 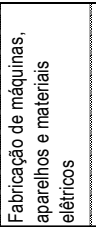 & 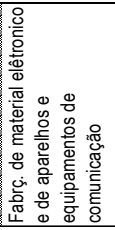 & 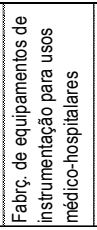 & 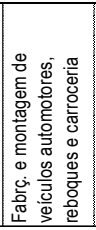 & 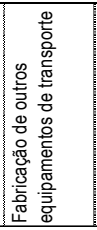 & 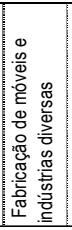 & 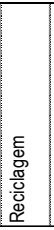 & 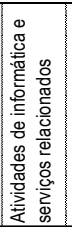 & 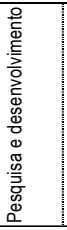 & 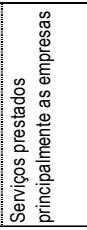 & \\
\hline Jales & - & - & 3.0 & - & - & & 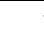 & - & - & - & - & - & - & - & - & - & - & - & - & - & \\
\hline Fernandopolis & - & 2.3 & 2.1 & - & - & & . & - & - & - & 2.8 & - & - & - & - & 2.5 & - & - & - & - & \\
\hline Votuporanga & - & - & - & - & - & & . & - & - & - & - & - & - & - & 7.4 & 14.4 & - & - & - & - & \\
\hline Sao Jose do Rio Preto & - & - & - & - & - & & . & - & - & - & - & - & - & - & - & 4.4 & - & - & - & - & \\
\hline Catanduva & - & - & - & - & - & & & - & - & - & - & - & - & - & - & - & - & - & - & - & \\
\hline Auriflama & - & 10.0 & - & - & - & & & - & - & - & - & - & - & - & - & - & - & - & - & - & \\
\hline Nhandeara & - & 2.4 & 6.7 & - & - & & . & - & 2.1 & - & - & - & - & - & - & - & - & - & - & - & \\
\hline Novo Horizonte & - & 2.8 & - & - & - & & . & - & - & 2.3 & - & - & - & - & - & - & - & - & - & - & \\
\hline Barretos & - & - & - & - & - & & - & - & - & - & - & - & - & - & - & - & - & - & - & - & \\
\hline Sao Joaquim da Barra & - & - & - & - & - & & - & - & 2.2 & - & - & - & - & - & - & - & - & - & - & - & \\
\hline Ituverava & - & - & - & - & - & & - & - & - & - & - & - & - & - & - & 2.2 & - & - & - & - & \\
\hline Franca & - & - & 45.5 & - & 2.1 & & - & - & - & - & - & - & - & - & - & - & - & - & - & - & \\
\hline Jaboticabal & - & - & - & - & - & & - & 2.5 & - & - & - & - & - & - & - & - & - & - & - & - & \\
\hline Ribeirao Preto & - & - & - & - & - & & - & - & - & - & - & - & 3.7 & - & - & - & - & - & - & - & \\
\hline Batatais & - & 2.0 & - & - & - & & - & 2.1 & - & 2.9 & - & - & - & - & - & - & - & - & - & - & \\
\hline Andradina & - & - & - & - & - & & - & - & - & - & - & - & - & - & - & - & - & - & - & - & \\
\hline Aracatuba & - & - & 2.2 & - & - & & - & - & - & - & - & - & - & - & - & 2.0 & - & - & - & - & \\
\hline Birigui & - & - & 38.7 & - & - & & - & - & - & - & - & - & - & - & - & 3.5 & - & - & - & - & \\
\hline Lins & - & - & 9.9 & - & - & & - & - & - & - & - & - & - & - & - & - & - & - & - & - & \\
\hline Bauru & - & - & - & - & - & & - & - & - & - & - & - & - & - & - & - & - & - & - & - & \\
\hline Jau & - & - & 11.8 & - & - & & 3.0 & - & - & - & - & - & 2.2 & - & - & - & - & - & - & - & \\
\hline Avare & - & 2.1 & - & - & - & & - & - & - & - & - & - & - & - & - & - & - & - & - & - & \\
\hline Botucatu & 2.4 & - & - & - & - & & - & - & - & - & - & - & - & - & 3.3 & - & - & - & 2.6 & - & \\
\hline Araraquara & 2.6 & - & - & - & - & & - & - & - & 2.8 & - & - & - & - & - & - & - & - & - & - & \\
\hline Sao Carlos & - & - & - & - & - & & - & - & - & 7.2 & - & - & - & - & - & 4.6 & - & - & 13.3 & - & \\
\hline Rio Claro & - & - & - & - & 3.1 & & 2.8 & - & - & - & - & - & 2.5 & - & - & - & - & - & - & - & \\
\hline Limeira & - & - & - & - & - & & 5.8 & - & - & 3.2 & - & - & - & - & - & 4.0 & 2.6 & - & - & - & \\
\hline Piracicaba & - & 2.1 & - & - & - & & - & - & - & 3.2 & - & - & - & - & - & - & 4.1 & - & 2.8 & - & \\
\hline Pirassununga & - & - & 2.4 & - & - & & 9.5 & - & - & - & 3.3 & - & - & - & - & - & - & - & - & - & \\
\hline Sao Joao da Boa Vista & - & - & - & - & - & & 5.1 & - & - & - & - & - & - & - & 2.5 & - & - & - & - & - & \\
\hline Moji-Mirim & - & - & - & - & - & & 3.2 & - & - & - & - & - & 2.8 & 2.2 & - & 2.3 & - & - & - & - & \\
\hline Campinas & 3.7 & - & - & - & - & & - & - & - & - & - & - & - & - & - & - & - & - & 4.3 & - & \\
\hline Amparo & 3.7 & - & - & - & - & & - & - & - & - & - & - & - & - & - & - & - & - & - & - & \\
\hline Dracena & - & - & - & - & - & & 7.3 & - & - & - & - & - & - & - & - & - & - & - & - & - & \\
\hline Adamantina & - & 2.0 & - & - & - & & - & - & - & - & - & - & - & - & - & - & - & - & - & - & \\
\hline Presidente Prudente & - & - & - & - & - & & - & - & - & - & - & - & - & - & - & - & - & - & - & - & \\
\hline Tupa & 5.8 & - & - & - & - & & - & - & - & - & - & - & - & - & - & 2.5 & - & - & - & - & \\
\hline Marilia & - & - & - & - & - & & - & - & 2.2 & - & - & - & 2.7 & - & - & - & - & - & - & - & \\
\hline Assis & - & - & - & - & - & & - & - & - & - & - & - & - & - & - & - & - & - & - & - & \\
\hline Ourinhos & - & 3.0 & 2.3 & - & - & & - & - & - & - & - & - & - & - & - & - & - & - & - & - & \\
\hline Itapeva & - & - & - & - & - & & 4.2 & - & - & - & - & - & - & - & - & - & - & - & - & - & \\
\hline Itapetininga & - & 2.3 & - & - & - & & - & - & - & - & - & - & - & - & - & - & - & - & - & - & \\
\hline Tatui & 4.2 & - & - & - & 2.6 & & 6.2 & - & - & - & 4.4 & - & - & - & - & - & - & - & - & - & \\
\hline Capao Bonito & - & - & - & - & - & & 6.1 & - & - & - & - & - & - & - & - & - & - & - & - & - & \\
\hline Piedade & - & - & - & - & - & & - & - & - & - & - & - & - & - & - & - & - & - & - & 7.1 & \\
\hline Sorocaba & - & - & - & - & - & & 3.1 & - & - & - & 2.6 & 4.5 & - & - & - & - & - & - & - & - & \\
\hline Jundiai & 2.0 & - & - & 2.1 & - & & 4.0 & - & 3.9 & - & - & - & - & - & - & - & 3.8 & - & - & - & \\
\hline Braganca Paulista & 4.4 & - & - & - & - & & - & - & - & - & 2.1 & - & - & - & - & - & - & - & - & 2.6 & \\
\hline Campos do Jordao & - & - & - & - & - & & - & - & - & - & - & - & - & - & - & - & - & - & - & - & \\
\hline Sao Jose dos Campos & - & - & - & - & - & & - & 4.7 & - & - & - & 6.9 & - & 2.3 & 11.2 & - & 3.5 & - & - & - & \\
\hline Guaratingueta & - & - & - & 2.8 & - & & - & - & - & - & - & - & - & 2.0 & 2.5 & - & - & - & - & - & \\
\hline Bananal & - & - & - & - & - & & - & - & 4.0 & - & - & - & - & - & - & - & - & - & - & - & \\
\hline Paraibuna/Paraitinga & - & - & - & - & - & & - & - & - & - & - & - & 2.6 & - & - & - & - & - & - & - & \\
\hline Caraguatatuba & - & - & - & - & - & & - & - & - & - & - & - & - & - & - & - & - & - & - & - & \\
\hline Registro & - & - & - & - & 2.9 & & - & - & - & - & - & - & - & - & - & - & - & - & - & - & \\
\hline Itanhaem & - & - & - & - & - & & - & - & - & - & - & - & - & - & - & - & - & - & - & - & \\
\hline Osasco & - & - & - & - & - & & - & - & - & - & - & - & - & - & - & - & - & 2.4 & 3.5 & 3.4 & \\
\hline Franco da Rocha & - & - & 2.2 & - & 3.6 & & - & - & - & - & - & - & - & - & - & 2.1 & - & - & - & - & \\
\hline Guarulhos & 2.5 & - & - & 2.2 & 2.5 & & - & 2.5 & 2.1 & - & - & 2.8 & - & 2.8 & 4.1 & - & 3.6 & - & - & - & \\
\hline Itapecerica da Serra & - & - & - & 3.3 & 2.3 & & - & - & - & - & - & - & - & - & - & - & 2.3 & - & - & 3.6 & \\
\hline Sao Paulo & - & - & - & - & - & & - & - & - & - & - & - & - & - & - & - & - & - & - & - & \\
\hline Moji das Cruzes & - & - & - & - & - & & 2.8 & 2.3 & 2.1 & - & - & - & - & - & - & 3.1 & 6.5 & - & 2.3 & - & \\
\hline Santos & - & - & - & - & - & & - & 3.1 & - & - & - & - & - & - & - & - & 5.8 & - & - & - & \\
\hline
\end{tabular}

Observações/Filtro: QL $\geq 2$.

FONTE: Elaborado pelo auto com base nos dados da RAIS/MTE. 
Anexo III. Quociente Locacional para as atividades da indústria de transformação selecionadas - São Paulo/1998.

\begin{tabular}{|c|c|c|c|c|c|c|c|c|c|c|c|c|c|c|c|c|c|c|c|c|c|}
\hline Divisão & 17 & 18 & 19 & 24 & 25 & & 26 & 27 & 28 & 29 & 31 & 32 & 33 & 34 & 35 & 36 & 37 & 72 & 73 & & $\overline{74}$ \\
\hline & 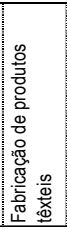 & 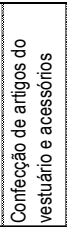 & 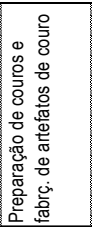 & 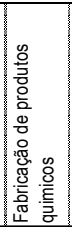 & 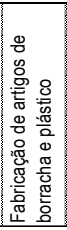 & 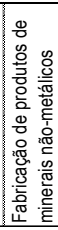 & & 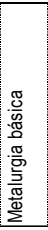 & 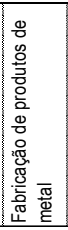 & 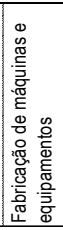 & 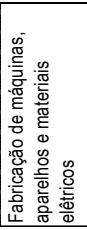 & 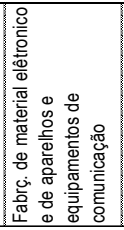 & 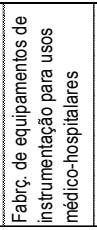 & 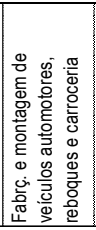 & 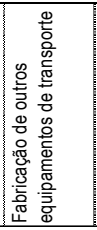 & 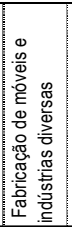 & 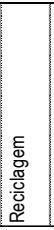 & 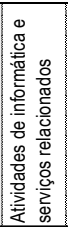 & 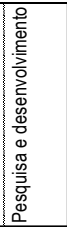 & 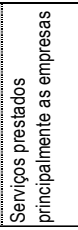 & \\
\hline Jales & - & - & 3.5 & - & - & & - & - & - & - & - & - & - & - & - & 2.1 & - & - & - & - & \\
\hline Fernandopolis & - & 3.0 & - & - & - & & - & - & - & - & 2.8 & - & - & - & - & 2.4 & - & - & - & - & \\
\hline Votuporanga & - & - & - & - & - & & - & - & - & - & - & - & - & - & 5.9 & 15.1 & - & - & - & - & \\
\hline Sao Jose do Rio Preto & - & - & - & - & - & & - & - & - & - & - & - & - & - & - & 4.4 & - & - & - & - & \\
\hline Catanduva & - & - & - & - & - & & - & - & - & - & - & - & - & - & - & - & - & - & - & - & \\
\hline Auriflama & - & 9.5 & - & - & - & & - & - & - & - & - & - & - & - & - & - & - & - & - & - & \\
\hline Nhandeara & - & - & 6.7 & - & - & & - & - & 2.7 & - & - & - & - & - & - & 2.2 & 2.7 & - & - & - & \\
\hline Novo Horizonte & - & 3.1 & - & - & - & & - & - & - & - & - & - & - & - & - & - & - & - & - & - & \\
\hline Barretos & - & - & - & - & - & & - & - & - & - & - & - & 2.1 & - & - & - & - & - & - & - & \\
\hline Sao Joaquim da Barra & - & - & - & - & - & & - & - & - & - & - & - & - & - & - & - & - & - & - & - & \\
\hline Ituverava & - & - & - & - & - & & - & - & - & - & - & - & - & - & - & - & - & - & - & - & \\
\hline Franca & - & - & 46.3 & - & 2.2 & & - & - & - & - & - & - & - & - & - & - & - & - & - & - & \\
\hline Jaboticabal & - & - & - & - & - & & - & 2.2 & - & - & - & - & - & - & - & - & - & - & - & - & \\
\hline Ribeirao Preto & - & - & - & - & - & & - & - & - & - & - & - & 3.9 & - & - & - & - & - & - & - & \\
\hline Batatais & - & 2.3 & - & - & - & & - & 2.6 & - & 2.9 & - & - & - & - & - & - & - & - & - & - & \\
\hline Andradina & - & - & - & - & - & & - & - & - & - & - & - & - & - & - & - & - & - & - & - & \\
\hline Aracatuba & - & - & - & - & - & & - & - & - & - & - & - & - & - & - & 2.3 & - & - & - & - & \\
\hline Birigui & - & - & 44.7 & - & - & & - & - & - & - & - & - & - & - & - & 3.2 & - & - & - & - & \\
\hline Lins & - & - & 4.8 & - & - & & - & - & - & - & - & - & - & - & - & - & - & - & - & - & \\
\hline Bauru & - & - & - & - & - & & - & - & - & - & - & - & - & - & - & - & - & - & - & - & \\
\hline Jau & 2.1 & - & 11.5 & - & - & & 3.1 & - & - & - & - & - & 2.3 & - & - & - & - & - & - & - & \\
\hline Avare & - & - & - & - & - & & - & - & - & - & - & - & - & - & - & - & - & - & - & - & \\
\hline Botucatu & 2.9 & - & - & - & - & & - & - & - & - & - & - & - & - & 4.9 & - & - & - & - & - & \\
\hline Araraquara & 3.5 & - & - & - & - & & - & - & - & 2.4 & - & - & - & - & - & - & - & - & - & - & \\
\hline Sao Carlos & - & - & - & - & - & & - & - & - & 7.2 & - & - & 2.3 & - & - & 4.6 & - & - & 10.0 & - & \\
\hline Rio Claro & - & - & - & - & 3.0 & & 3.0 & - & - & - & 2.0 & - & 2.9 & - & - & - & - & - & - & - & \\
\hline Limeira & - & - & - & - & - & & 6.0 & - & - & 3.3 & - & - & - & - & - & 4.5 & 3.0 & - & - & - & \\
\hline Piracicaba & - & 2.6 & - & - & - & & - & - & - & 4.0 & - & - & - & - & - & - & 4.9 & - & 2.5 & - & \\
\hline Pirassununga & - & - & 2.9 & - & - & & 9.1 & - & - & - & 3.1 & - & - & - & - & - & - & - & - & - & \\
\hline Sao Joao da Boa Vista & - & - & - & - & - & & 5.3 & - & - & - & - & - & - & - & - & - & - & - & - & - & \\
\hline Moji-Mirim & - & - & - & - & - & & 3.2 & - & - & - & - & - & 3.1 & - & - & 2.1 & - & - & - & - & \\
\hline Campinas & 3.9 & - & - & - & - & & - & - & - & - & - & - & 2.1 & - & - & - & - & - & 6.3 & - & \\
\hline Amparo & 4.8 & - & - & - & - & & - & - & - & - & - & - & - & - & - & - & - & - & - & - & \\
\hline Dracena & - & - & - & - & - & & 7.1 & - & - & - & - & - & - & - & - & - & - & - & - & - & \\
\hline Adamantina & - & 2.6 & - & - & - & & - & - & - & - & - & - & - & - & - & 2.6 & - & - & - & - & \\
\hline Presidente Prudente & - & - & - & - & - & & - & - & - & - & - & - & - & - & - & - & - & - & - & - & \\
\hline Tupa & 4.2 & - & - & - & - & & - & - & - & - & - & - & - & - & - & 2.8 & - & - & - & - & \\
\hline Marilia & - & - & - & - & - & & - & - & 2.3 & - & - & - & - & - & - & - & - & - & - & - & \\
\hline Assis & - & - & - & - & - & & - & - & - & - & - & - & - & - & - & - & - & - & - & - & \\
\hline Ourinhos & - & 3.0 & 2.2 & - & - & & - & - & - & - & - & - & - & - & - & - & - & - & - & - & \\
\hline Itapeva & - & - & - & - & - & & 3.9 & - & - & - & - & - & - & - & - & - & - & - & - & - & \\
\hline Itapetininga & - & 2.4 & - & - & - & & - & - & - & - & - & - & - & - & - & - & - & - & - & - & \\
\hline Tatui & 4.2 & - & - & - & 2.3 & & 5.9 & - & - & - & 5.3 & - & - & - & - & - & - & - & - & - & \\
\hline Capao Bonito & - & - & - & - & - & & 5.4 & - & - & - & - & - & - & - & - & - & - & - & - & - & \\
\hline Piedade & - & - & - & - & - & & - & - & - & - & - & - & - & - & - & - & - & - & - & 7.3 & 3 \\
\hline Sorocaba & - & - & - & - & - & & 2.9 & 4.1 & - & 2.3 & 2.5 & 4.1 & - & - & - & - & - & - & - & - & \\
\hline Jundiai & - & - & - & - & - & & 4.0 & - & 4.2 & - & - & - & - & - & - & - & 4.6 & - & - & - & \\
\hline Braganca Paulista & 4.1 & - & - & - & - & & - & - & - & - & - & 2.4 & - & - & - & - & - & - & - & 3.2 & 2 \\
\hline Campos do Jordao & - & - & - & - & - & & - & - & - & - & - & - & - & - & - & - & - & - & - & - & \\
\hline Sao Jose dos Campos & - & - & - & - & - & & - & - & - & - & - & 7.3 & - & 3.9 & 14.4 & - & 2.4 & - & - & - & \\
\hline Guaratingueta & - & - & - & 2.9 & - & & - & - & - & - & - & - & - & - & - & - & - & - & - & - & \\
\hline Bananal & - & - & - & - & - & & - & - & - & - & - & - & - & - & - & - & - & - & - & - & \\
\hline Paraibuna/Paraitinga & - & - & - & - & - & & - & - & - & - & 4.0 & - & - & - & - & - & - & - & - & - & \\
\hline Caraguatatuba & - & - & - & - & - & & - & - & - & - & - & - & - & - & - & - & - & - & - & - & \\
\hline Registro & - & - & - & 2.1 & 2.6 & & - & - & - & - & - & - & - & - & - & - & - & - & - & - & \\
\hline Itanhaem & - & - & - & - & - & & - & - & - & - & - & - & - & - & - & - & - & - & - & - & \\
\hline Osasco & - & - & - & - & - & & - & - & - & - & 2.2 & - & - & - & - & - & - & 2.6 & - & 3. & 1 \\
\hline Franco da Rocha & - & - & 2.6 & - & 3.4 & & - & - & - & - & - & - & - & - & - & 2.1 & - & - & - & - & \\
\hline Guarulhos & 2.4 & - & - & 2.5 & 2.7 & & - & 2.7 & 2.2 & - & 2.1 & - & - & 2.9 & 2.7 & - & 6.5 & - & - & - & \\
\hline Itapecerica da Serra & - & - & - & 3.1 & - & & - & - & - & - & - & - & - & - & - & - & - & - & - & 3.5 & .9 \\
\hline Sao Paulo & - & - & - & - & - & & - & - & - & - & - & - & - & - & - & - & - & - & - & - & \\
\hline Moji das Cruzes & - & - & - & - & - & & 2.4 & - & - & - & - & - & - & - & - & 3.0 & 3.8 & - & - & - & \\
\hline Santos & - & - & - & - & - & & - & 3.2 & - & - & - & - & - & - & - & - & 4.9 & - & - & - & \\
\hline
\end{tabular}

Observações/Filtro: QL $\geq 2$.

FONTE: Elaborado pelo auto com base nos dados da RAIS/MTE. 
Anexo IV. Quociente Locacional para as atividades da indústria de transformação selecionadas - São Paulo/1999.

\begin{tabular}{|c|c|c|c|c|c|c|c|c|c|c|c|c|c|c|c|c|c|c|c|c|}
\hline Divisão & 17 & 18 & 19 & 24 & 25 & 26 & 27 & 28 & 29 & 31 & 3 & 33 & 34 & 35 & 36 & 37 & 72 & & & 74 \\
\hline & 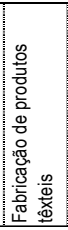 & 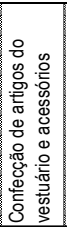 & 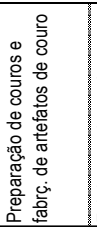 & 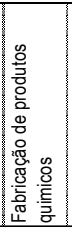 & 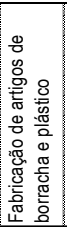 & 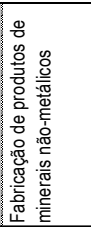 & 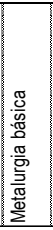 & 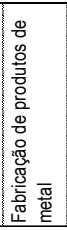 & 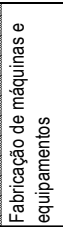 & 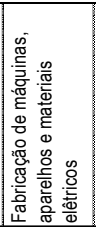 & 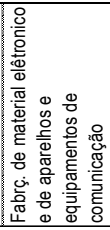 & 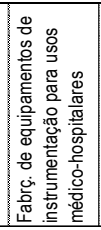 & 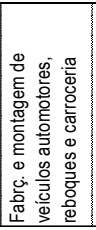 & 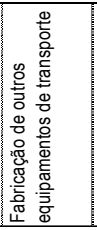 & 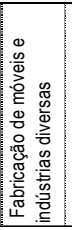 & 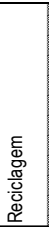 & 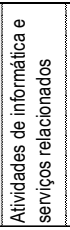 & 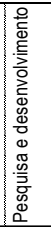 & & 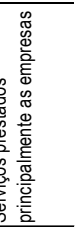 \\
\hline Jales & - & - & 2.5 & - & - & - & - & - & - & - & - & - & - & - & - & - & - & - & & - \\
\hline Fernandopolis & - & 2.9 & - & - & - & - & - & - & - & 2.4 & - & - & - & - & 3.1 & - & - & - & & - \\
\hline Votuporanga & - & - & - & - & - & - & - & - & - & - & - & - & 2.4 & 4.9 & 16.5 & - & - & - & & - \\
\hline Sao Jose do Rio Preto & - & - & - & - & - & - & - & - & - & - & - & - & - & - & 4.3 & - & - & - & & - \\
\hline Catanduva & - & - & - & - & - & - & - & - & - & - & - & - & - & - & - & - & - & - & & - \\
\hline Auriflama & - & 11.9 & - & - & - & - & - & - & - & - & - & - & - & - & - & - & - & - & & - \\
\hline Nhandeara & - & - & 4.5 & - & - & - & - & 3.0 & - & - & - & - & - & - & - & - & - & - & & - \\
\hline Novo Horizonte & - & 3.1 & - & - & - & - & - & - & - & - & - & - & - & - & 5.7 & - & - & - & & - \\
\hline Barretos & - & - & - & - & - & - & - & - & - & - & - & - & - & - & - & - & - & - & & - \\
\hline Sao Joaquim da Barra & - & - & - & - & - & - & - & 2.0 & - & - & - & - & - & - & - & - & - & - & & - \\
\hline Ituverava & - & - & - & - & - & - & - & - & - & - & - & - & - & - & - & - & - & - & & - \\
\hline Franca & - & - & 43.9 & - & 2.2 & - & - & - & - & - & - & - & - & - & - & - & - & - & & - \\
\hline Jaboticabal & - & - & - & - & - & - & 2.0 & - & - & - & - & - & - & - & - & - & - & - & & - \\
\hline Ribeirao Preto & - & - & - & - & - & - & - & - & - & - & - & 4.4 & - & - & - & - & - & - & & - \\
\hline Batatais & - & 2.0 & - & - & - & - & 2.1 & - & 2.9 & - & - & - & - & - & - & - & - & - & & - \\
\hline Andradina & - & - & - & - & - & - & - & - & - & - & - & - & - & - & - & - & - & - & & - \\
\hline Aracatuba & - & - & - & - & - & - & - & - & - & - & - & - & - & - & 2.1 & - & - & - & & - \\
\hline Birigui & - & - & 46.8 & - & - & - & - & - & - & - & - & - & - & - & 3.4 & - & - & - & & - \\
\hline Lins & - & - & 9.7 & - & - & - & - & - & - & - & - & - & - & - & - & - & - & - & & - \\
\hline Bauru & - & - & - & - & - & - & - & - & - & - & - & - & - & - & - & - & - & - & & - \\
\hline Jau & 2.0 & - & 11.5 & - & - & 3.4 & - & - & - & - & - & 2.7 & - & - & - & - & - & - & & - \\
\hline Avare & - & - & - & - & - & - & - & - & - & - & - & - & - & - & - & - & - & - & & - \\
\hline Botucatu & 2.6 & - & - & - & - & - & - & - & - & - & - & - & - & 4.9 & - & 3.1 & - & - & & - \\
\hline Araraquara & 3.5 & - & - & - & - & - & - & - & 2.8 & - & - & - & - & - & - & - & - & - & & - \\
\hline Sao Carlos & 2.0 & - & - & - & - & - & - & - & 8.7 & - & - & 3.0 & - & - & 4.1 & - & - & 9. & & - \\
\hline Rio Claro & - & - & - & - & 3.4 & 3.7 & - & - & - & 2.1 & - & 4.2 & - & - & - & - & - & - & & - \\
\hline Limeira & - & - & - & - & - & 6.0 & - & - & 3.1 & - & - & - & 2.0 & - & 4.5 & 3.6 & - & - & & - \\
\hline Piracicaba & - & 2.4 & - & - & - & - & - & - & 4.0 & - & - & - & - & - & - & 4.2 & - & 2. & & - \\
\hline Pirassununga & - & - & 2.4 & - & - & 10.1 & - & - & - & 2.9 & - & - & - & - & 2.2 & - & - & - & & - \\
\hline Sao Joao da Boa Vista & - & - & - & - & - & 5.3 & - & - & - & - & - & - & - & 2.0 & - & - & - & - & & - \\
\hline Moji-Mirim & - & - & - & - & - & 3.0 & - & - & - & - & - & 2.0 & 2.9 & - & - & - & - & - & & - \\
\hline Campinas & 3.8 & - & - & 2.1 & - & - & - & - & - & - & 2.2 & - & - & - & - & - & - & 6. & & - \\
\hline Amparo & 5.2 & - & - & - & - & - & - & - & 3.0 & - & - & - & - & - & - & - & - & - & & - \\
\hline Dracena & - & - & - & - & - & 7.5 & - & - & - & - & - & - & - & - & - & - & - & - & & - \\
\hline Adamantina & - & 2.4 & - & - & - & - & - & - & - & - & - & - & - & - & 2.5 & - & - & - & & - \\
\hline Presidente Prudente & - & - & - & - & - & - & - & - & - & - & - & - & - & - & - & - & - & - & & - \\
\hline Tupa & 4.1 & - & - & - & - & - & - & - & - & - & - & - & - & - & 3.1 & - & - & - & & - \\
\hline Marilia & - & - & - & - & - & - & - & 2.3 & 2.1 & - & - & - & - & - & - & - & - & - & & - \\
\hline Assis & - & - & - & - & - & - & - & - & - & - & - & - & - & - & - & - & - & - & & - \\
\hline Ourinhos & - & 2.9 & - & - & - & - & - & - & - & - & - & - & - & - & - & - & - & - & & - \\
\hline Itapeva & - & - & - & - & - & 3.3 & - & - & - & - & - & - & - & - & - & - & - & - & & - \\
\hline Itapetininga & - & 2.4 & - & - & - & - & - & - & - & - & - & - & - & - & - & - & - & - & & - \\
\hline Tatui & 4.0 & 2.1 & - & - & 2.6 & 5.7 & - & - & - & 4.9 & - & - & - & - & - & - & - & - & & - \\
\hline Capao Bonito & - & - & - & - & - & 5.1 & - & - & - & - & - & - & - & - & - & - & - & - & & - \\
\hline Piedade & - & - & - & - & - & - & - & - & - & - & - & - & - & - & - & - & - & - & & 6.5 \\
\hline Sorocaba & - & - & - & - & - & 2.9 & 4.3 & - & - & - & 5.3 & - & - & - & - & - & - & - & & - \\
\hline Jundiai & - & - & - & - & 2.5 & 3.8 & - & 4.2 & - & - & - & - & - & - & - & 5.5 & - & - & & - \\
\hline Braganca Paulista & 4.1 & - & - & - & - & - & - & - & - & 2.2 & - & - & - & - & - & - & - & - & & 3.1 \\
\hline Campos do Jordao & - & - & - & - & - & - & - & - & - & - & - & - & - & - & - & - & - & - & & - \\
\hline Sao Jose dos Campos & - & - & - & - & - & - & - & - & - & - & 7.9 & - & 4.1 & 16.6 & - & 3.0 & - & 2. & & - \\
\hline Guaratingueta & - & - & - & 3.0 & - & - & - & - & - & - & - & - & 2.2 & - & - & - & - & - & & - \\
\hline Bananal & - & - & - & - & 2.3 & - & - & - & - & - & - & - & - & - & - & - & - & - & & - \\
\hline Paraibuna/Paraitinga & - & - & - & - & - & - & - & - & - & - & - & - & 2.3 & - & - & - & - & - & & - \\
\hline Caraguatatuba & - & - & - & - & - & - & - & - & - & - & - & - & - & - & - & - & - & - & & - \\
\hline Registro & - & - & - & - & - & - & - & - & - & - & - & - & - & - & - & - & - & - & & - \\
\hline Itanhaem & - & - & - & - & - & - & - & - & - & - & - & - & - & - & - & - & - & - & & - \\
\hline Osasco & - & - & - & - & - & - & - & - & - & - & - & - & - & - & - & - & 2.9 & - & & 2.9 \\
\hline Franco da Rocha & - & - & 2.1 & - & 3.4 & - & - & - & - & - & - & - & - & - & - & - & - & - & & - \\
\hline Guarulhos & 2.8 & - & - & 2.2 & 3.1 & - & 2.4 & 2.4 & - & 3.8 & - & - & 2.2 & 2.1 & - & 5.4 & - & - & & - \\
\hline Itapecerica da Serra & - & - & - & 2.8 & - & - & - & - & - & - & - & - & - & - & - & - & - & - & & 3.9 \\
\hline Sao Paulo & - & - & - & - & - & - & - & - & - & - & - & - & - & - & - & - & - & - & & - \\
\hline Moji das Cruzes & - & - & - & - & - & - & - & 2.1 & - & - & - & - & - & - & 2.7 & 3.0 & - & - & & 2.1 \\
\hline Santos & - & - & - & - & - & - & 5.7 & - & - & - & - & - & - & - & - & 2.9 & - & - & & - \\
\hline
\end{tabular}

Observações/Filtro: QL $\geq 2$.

FONTE: Elaborado pelo auto com base nos dados da RAIS/MTE. 
Anexo V. Quociente Locacional para as atividades da indústria de transformação selecionadas - São Paulo/2000.

\begin{tabular}{|c|c|c|c|c|c|c|c|c|c|c|c|c|c|c|c|c|c|c|c|c|c|}
\hline Divisão & 17 & 18 & 19 & 24 & 25 & & 26 & 27 & 28 & 29 & 31 & 32 & 33 & 34 & 35 & 36 & 37 & 72 & & 3 & 74 \\
\hline & 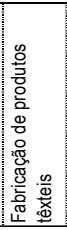 & 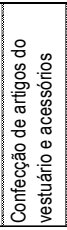 & 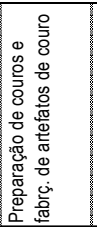 & 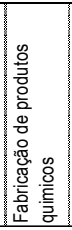 & 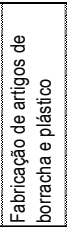 & 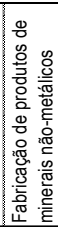 & & 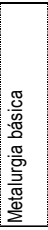 & 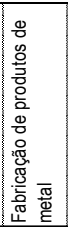 & 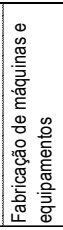 & 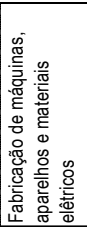 & 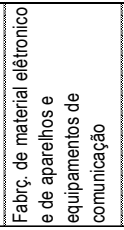 & 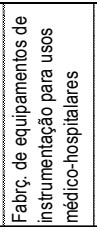 & 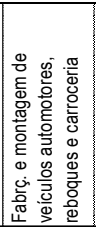 & 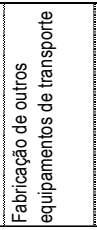 & 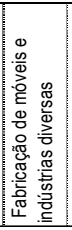 & 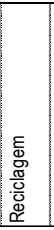 & 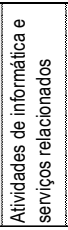 & 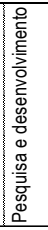 & & 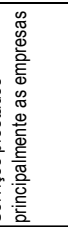 \\
\hline Jales & - & - & 2.3 & - & - & & - & - & - & - & - & - & - & - & - & - & - & - & - & & - \\
\hline Fernandopolis & - & 2.6 & - & - & - & & - & - & - & - & 2.0 & - & - & - & - & 3.0 & . & - & - & & - \\
\hline Votuporanga & - & - & - & - & - & & - & - & - & - & - & - & - & 2.3 & 4.4 & 18.1 & - & - & - & & - \\
\hline Sao Jose do Rio Preto & - & - & - & - & - & & - & - & - & - & - & - & - & - & - & 4.6 & - & - & - & & - \\
\hline Catanduva & - & - & - & - & - & & - & - & - & 2.2 & - & - & - & - & - & - & - & - & - & & - \\
\hline Auriflama & - & 12.8 & - & - & - & & - & - & - & - & - & - & - & - & - & - & - & - & - & & - \\
\hline Nhandeara & - & - & 2.2 & - & - & & - & - & 3.0 & - & - & - & - & - & - & 2.1 & 4.5 & - & - & & - \\
\hline Novo Horizonte & - & 2.8 & - & - & - & & - & - & - & - & - & - & - & - & - & 4.8 & - & - & - & & - \\
\hline Barretos & - & - & - & - & - & & - & - & - & - & - & - & 2.2 & - & - & - & - & - & - & & - \\
\hline Sao Joaquim da Barra & - & - & - & - & - & & - & - & - & - & - & - & - & - & - & - & - & - & - & & - \\
\hline Ituverava & - & - & - & - & - & & - & - & - & - & - & - & - & - & - & - & - & - & - & & - \\
\hline Franca & - & - & 44.0 & - & 2.6 & & - & - & - & - & - & - & - & - & - & - & - & - & - & & - \\
\hline Jaboticabal & - & - & - & - & - & & - & 2.1 & - & - & - & - & - & - & - & - & - & - & - & & - \\
\hline Ribeirao Preto & - & - & - & - & - & & - & - & - & - & - & - & 4.4 & - & - & - & - & - & - & & - \\
\hline Batatais & - & 2.1 & - & - & - & & - & - & - & 2.6 & - & - & - & - & - & - & - & - & - & & - \\
\hline Andradina & - & - & - & - & - & & - & - & - & - & - & - & - & - & - & - & - & - & - & & - \\
\hline Aracatuba & - & - & - & - & - & & - & - & - & - & - & - & - & - & - & - & - & - & - & & - \\
\hline Birigui & - & - & 49.4 & - & - & & - & - & - & - & - & - & - & - & - & 2.9 & - & - & - & & - \\
\hline Lins & - & - & 10.2 & - & - & & - & - & - & - & - & - & - & - & - & - & - & - & - & & - \\
\hline Bauru & - & - & - & - & - & & - & - & - & - & - & - & - & - & - & - & - & - & - & & - \\
\hline Jau & - & - & 11.7 & - & - & & 3.3 & - & - & - & - & - & 2.5 & - & - & - & - & - & - & & - \\
\hline Avare & - & - & - & - & - & & - & - & - & - & - & - & - & - & - & - & 3.1 & - & - & & - \\
\hline Botucatu & 2.5 & - & - & - & - & & - & - & - & - & - & - & - & - & 11.7 & - & - & - & - & & - \\
\hline Araraquara & 3.8 & - & - & - & - & & - & - & - & 2.1 & - & - & - & - & - & - & - & - & - & & - \\
\hline Sao Carlos & - & - & - & - & - & & - & - & - & 7.5 & - & - & 2.2 & - & - & 3.6 & - & - & 8. & & - \\
\hline Rio Claro & - & - & - & - & 3.3 & & 3.5 & - & 2.1 & - & - & - & 3.2 & - & - & - & - & - & - & & - \\
\hline Limeira & - & - & - & - & - & & 5.7 & - & - & 2.8 & - & - & - & - & - & 4.3 & 3.8 & - & - & & - \\
\hline Piracicaba & - & 2.3 & - & - & - & & - & - & - & 3.8 & - & - & - & - & - & - & 4.7 & - & - & & - \\
\hline Pirassununga & - & - & - & - & - & & 9.7 & - & - & - & 3.3 & - & - & - & - & 2.2 & - & - & - & & - \\
\hline Sao Joao da Boa Vista & - & - & - & - & - & & 5.3 & - & - & - & - & - & - & - & - & - & - & - & - & & - \\
\hline Moji-Mirim & - & - & - & - & - & & 3.1 & - & - & - & - & - & 2.4 & 3.2 & - & - & - & - & - & & - \\
\hline Campinas & 3.8 & - & - & 2.1 & - & & - & - & - & - & - & 2.9 & - & - & - & - & - & - & 6. & & - \\
\hline Amparo & 4.8 & 2.2 & - & - & - & & - & - & - & - & - & - & - & - & - & - & - & - & - & & - \\
\hline Dracena & - & - & - & - & - & & 7.2 & - & - & - & - & - & - & - & - & - & - & - & - & & - \\
\hline Adamantina & - & 2.4 & - & - & - & & - & - & - & - & - & - & - & - & - & 2.6 & - & - & - & & - \\
\hline Presidente Prudente & - & - & - & - & - & & - & - & - & - & - & - & - & - & - & - & - & - & - & & - \\
\hline Tupa & 3.6 & - & - & - & - & & - & - & - & - & - & - & - & - & - & 3.2 & - & - & - & & - \\
\hline Marilia & - & - & - & - & - & & - & - & 2.2 & - & - & - & - & - & - & - & - & - & - & & - \\
\hline Assis & - & - & - & - & - & & - & - & - & - & - & - & - & - & - & - & - & - & - & & - \\
\hline Ourinhos & - & 2.9 & - & - & - & & - & - & - & - & - & - & - & - & - & - & - & - & - & & - \\
\hline Itapeva & - & - & - & - & - & & 3.3 & - & - & - & - & - & - & - & - & - & - & - & - & & - \\
\hline Itapetininga & - & 2.5 & - & - & - & & - & - & - & - & - & - & - & - & - & - & - & - & - & & - \\
\hline Tatui & 3.6 & - & - & - & - & & 5.3 & - & - & - & 4.4 & - & - & - & - & 2.3 & - & - & - & & - \\
\hline Capao Bonito & - & - & - & - & - & & 4.5 & - & - & - & - & - & - & - & - & - & - & - & - & & - \\
\hline Piedade & - & - & - & - & - & & - & - & - & - & - & - & - & - & - & - & - & - & - & & 6.5 \\
\hline Sorocaba & - & - & - & - & - & & 2.8 & 4.3 & - & 2.2 & 2.4 & 3.9 & - & - & - & - & - & - & - & & - \\
\hline Jundiai & - & - & - & - & 2.7 & & 3.7 & - & 2.8 & - & - & - & - & - & - & - & 3.8 & - & - & & - \\
\hline Braganca Paulista & 3.9 & - & - & - & - & & - & - & - & - & 2.3 & - & - & - & - & - & - & - & - & & 2.9 \\
\hline Campos do Jordao & - & - & - & - & - & & - & - & - & - & - & - & - & - & - & - & - & - & - & & - \\
\hline Sao Jose dos Campos & - & - & - & - & - & & - & - & - & - & - & 7.4 & - & 4.1 & 16.6 & - & 3.2 & - & - & & - \\
\hline Guaratingueta & - & - & - & 2.9 & - & & - & - & - & - & - & - & - & 2.8 & - & - & - & - & - & & - \\
\hline Bananal & - & - & - & - & 4.3 & & - & - & - & - & - & - & - & - & - & - & - & - & - & & - \\
\hline Paraibuna/Paraitinga & - & - & - & - & - & & - & - & - & - & - & - & - & 2.8 & - & - & - & - & - & & - \\
\hline Caraguatatuba & - & - & - & - & - & & - & - & - & - & - & - & - & - & - & - & - & - & - & & - \\
\hline Registro & - & - & - & - & - & & - & - & - & - & - & - & - & - & - & - & - & - & - & & - \\
\hline Itanhaem & - & - & - & - & - & & - & - & - & - & - & - & - & - & - & - & - & - & - & & - \\
\hline Osasco & - & - & - & - & - & & - & - & - & - & - & - & - & - & - & - & - & 2.9 & 2. & & 2.9 \\
\hline Franco da Rocha & - & - & - & - & 4.1 & & - & - & - & - & - & - & - & - & - & 2.2 & 2.1 & - & - & & - \\
\hline Guarulhos & 2.6 & - & - & 2.5 & 2.9 & & - & 2.7 & 2.4 & - & 3.2 & - & - & 2.2 & 2.0 & - & 4.8 & - & - & & - \\
\hline Itapecerica da Serra & - & - & - & 3.1 & - & & - & - & - & - & - & - & - & - & - & - & - & 2.3 & - & & 3.4 \\
\hline Sao Paulo & - & - & - & - & - & & - & - & - & - & - & - & - & - & - & - & - & - & - & & - \\
\hline Moji das Cruzes & - & - & - & - & - & & 2.4 & 2.1 & 2.3 & - & 2.0 & - & - & - & - & 2.8 & - & - & - & & - \\
\hline Santos & - & - & - & - & - & & - & 3.3 & - & - & - & - & - & - & - & - & 2.3 & - & - & & - \\
\hline
\end{tabular}

Observações/Filtro: QL $\geq 2$.

FONTE: Elaborado pelo auto com base nos dados da RAIS/MTE. 
Anexo VI. Quociente Locacional para as atividades da indústria de transformação selecionadas - São Paulo/2001.

\begin{tabular}{|c|c|c|c|c|c|c|c|c|c|c|c|c|c|c|c|c|c|c|c|c|c|}
\hline Divisão & 17 & 18 & 19 & 24 & 25 & & 26 & 27 & 28 & 29 & 31 & 32 & 33 & 34 & 35 & 36 & 37 & 72 & & 3 & 74 \\
\hline & 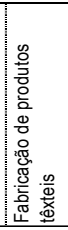 & 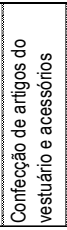 & 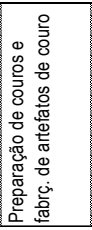 & 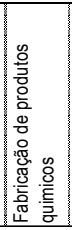 & 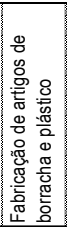 & 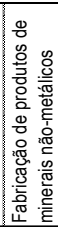 & & 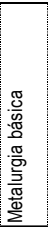 & 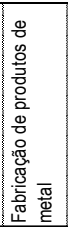 & 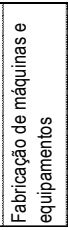 & 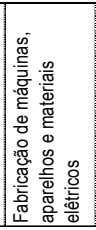 & 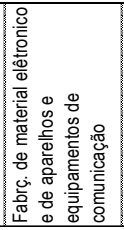 & 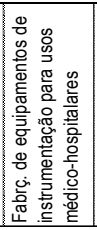 & 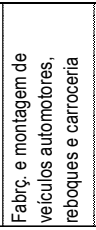 & 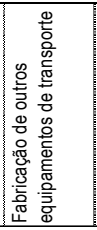 & 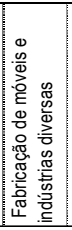 & 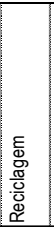 & 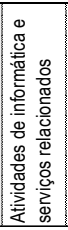 & 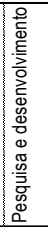 & & 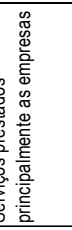 \\
\hline Jales & - & - & - & - & - & & - & - & - & - & - & - & - & - & - & - & - & - & - & & - \\
\hline Fernandopolis & - & 2.4 & - & - & - & & - & - & - & - & - & - & - & - & - & 2.5 & . & - & - & & - \\
\hline Votuporanga & - & - & - & - & - & & - & - & - & - & - & - & - & 2.6 & 4.2 & 17.0 & - & - & - & & - \\
\hline Sao Jose do Rio Preto & - & - & - & - & - & & - & - & - & - & - & - & - & - & - & 4.8 & - & - & - & & - \\
\hline Catanduva & - & - & - & - & - & & - & - & - & - & - & - & - & - & - & - & - & - & - & & - \\
\hline Auriflama & - & 13.1 & - & - & - & & - & - & - & - & - & - & - & - & - & - & - & - & - & & - \\
\hline Nhandeara & - & - & - & - & - & & - & - & 2.9 & - & - & - & - & - & - & - & 7.1 & - & - & & - \\
\hline Novo Horizonte & - & 2.6 & - & - & - & & - & - & - & - & - & - & - & - & - & 4.1 & - & - & - & & - \\
\hline Barretos & - & - & - & - & - & & - & - & - & - & - & - & - & - & - & - & - & - & - & & - \\
\hline Sao Joaquim da Barra & - & - & - & - & - & & - & - & - & - & - & - & - & - & - & - & - & - & - & & - \\
\hline Ituverava & - & - & - & - & - & & - & - & - & - & - & - & - & - & - & - & - & - & - & & - \\
\hline Franca & - & - & 44.4 & - & 2.6 & & - & - & - & - & - & - & - & - & - & - & - & - & - & & - \\
\hline Jaboticabal & - & - & - & - & - & & - & - & - & - & - & - & - & - & - & - & 2.3 & - & - & & - \\
\hline Ribeirao Preto & - & - & - & - & - & & - & - & - & - & - & - & 4.1 & - & - & - & - & - & - & & - \\
\hline Batatais & - & 2.2 & - & - & - & & - & 2.8 & - & 2.4 & - & - & - & - & - & - & - & - & - & & - \\
\hline Andradina & - & - & - & - & - & & - & - & - & - & - & - & - & - & - & - & - & - & - & & - \\
\hline Aracatuba & - & - & - & - & - & & - & - & - & - & - & - & - & - & - & - & - & - & - & & - \\
\hline Birigui & - & - & 46.8 & - & - & & - & - & - & - & - & - & - & - & - & 3.3 & - & - & - & & - \\
\hline Lins & - & - & 11.3 & - & - & & - & - & - & - & - & - & - & - & - & - & - & - & - & & - \\
\hline Bauru & - & - & - & - & - & & - & - & - & - & 2.1 & - & - & - & - & - & - & - & - & & - \\
\hline Jau & - & - & 10.9 & - & - & & 3.2 & - & - & - & - & - & 2.2 & - & - & - & - & - & - & & - \\
\hline Avare & - & - & - & - & - & & - & - & - & - & - & - & - & - & - & - & 2.5 & - & - & & - \\
\hline Botucatu & - & - & - & - & - & & - & - & - & - & - & - & - & - & 9.3 & - & 4.0 & - & - & & - \\
\hline Araraquara & 4.0 & - & - & - & - & & - & - & - & - & - & - & - & - & - & - & - & - & - & & - \\
\hline Sao Carlos & - & - & - & - & - & & - & - & - & 7.3 & - & - & 3.1 & - & - & 3.3 & - & - & 9. & & - \\
\hline Rio Claro & - & - & - & - & 3.2 & & 4.0 & - & 2.1 & - & 2.1 & - & 4.5 & - & - & - & - & - & - & & - \\
\hline Limeira & - & - & - & - & - & & 5.6 & - & - & 2.4 & - & - & - & - & - & 4.3 & 7.5 & - & - & & - \\
\hline Piracicaba & - & 2.2 & - & - & - & & 2.1 & - & - & 4.0 & - & - & - & - & - & - & 3.7 & - & - & & - \\
\hline Pirassununga & - & - & - & - & - & & 8.7 & - & - & - & 2.7 & - & - & - & - & 2.1 & - & - & - & & - \\
\hline Sao Joao da Boa Vista & - & - & - & - & - & & 5.5 & - & - & - & - & - & - & - & - & - & - & - & - & & - \\
\hline Moji-Mirim & 2.1 & - & - & - & - & & 3.2 & - & - & - & - & - & 2.2 & 3.2 & - & - & 2.0 & - & - & & - \\
\hline Campinas & 4.0 & - & - & - & - & & - & - & - & - & - & 2.7 & - & - & - & - & - & - & 6. & & - \\
\hline Amparo & 5.6 & 2.4 & - & - & - & & - & - & - & - & - & - & - & - & - & - & - & - & - & & - \\
\hline Dracena & - & - & - & - & - & & 7.5 & - & - & - & - & - & - & - & - & - & - & - & - & & - \\
\hline Adamantina & - & 2.8 & - & - & - & & - & - & - & - & - & - & - & - & - & 2.8 & - & - & - & & - \\
\hline Presidente Prudente & - & - & 2.1 & - & - & & - & - & - & - & - & - & - & - & - & - & - & - & - & & - \\
\hline Tupa & 4.1 & - & - & - & - & & - & - & - & - & - & - & - & - & - & 4.1 & - & - & - & & - \\
\hline Marilia & - & - & - & - & - & & - & - & 2.0 & - & - & - & - & - & - & - & - & - & - & & - \\
\hline Assis & - & - & - & - & - & & - & - & - & - & - & - & - & - & - & - & - & - & - & & - \\
\hline Ourinhos & - & 2.9 & 2.2 & - & - & & - & - & - & - & - & - & - & - & - & - & - & - & - & & - \\
\hline Itapeva & - & - & - & - & - & & 3.2 & - & - & - & - & - & - & - & - & - & - & - & - & & - \\
\hline Itapetininga & - & 2.4 & - & - & - & & - & - & - & - & - & - & - & - & - & - & - & - & - & & - \\
\hline Tatui & 3.4 & - & - & - & - & & 5.2 & - & - & - & 4.9 & - & - & - & - & 3.0 & - & - & - & & - \\
\hline Capao Bonito & - & - & - & - & - & & 4.2 & - & - & - & - & - & - & - & - & - & - & - & - & & - \\
\hline Piedade & - & - & - & - & - & & - & - & - & - & - & - & - & - & - & - & - & - & - & & 6.1 \\
\hline Sorocaba & - & - & - & - & - & & 2.7 & 4.0 & - & 2.7 & - & 4.2 & - & - & - & - & - & - & - & & - \\
\hline Jundiai & - & - & - & - & 2.5 & & 3.9 & - & 3.8 & - & - & - & - & - & - & - & 3.5 & - & - & & - \\
\hline Braganca Paulista & 3.9 & - & - & - & - & & - & - & - & - & - & - & - & - & - & - & - & - & - & & 2.8 \\
\hline Campos do Jordao & - & - & - & - & - & & - & - & - & - & - & - & - & - & - & - & - & - & - & & - \\
\hline Sao Jose dos Campos & - & - & - & - & - & & - & 2.2 & - & - & - & 5.6 & - & 4.0 & 15.8 & - & 2.4 & - & - & & - \\
\hline Guaratingueta & - & - & - & 2.8 & - & & - & - & - & - & - & - & - & 2.5 & - & - & - & - & - & & - \\
\hline Bananal & - & - & - & - & 3.1 & & - & - & - & - & - & - & - & - & - & - & - & - & - & & - \\
\hline Paraibuna/Paraitinga & - & - & - & - & - & & - & - & - & - & - & - & - & 3.6 & - & - & - & - & - & & - \\
\hline Caraguatatuba & - & - & - & - & - & & - & - & - & - & - & - & - & - & - & - & - & - & - & & - \\
\hline Registro & - & - & - & - & - & & - & - & - & - & - & - & - & - & - & - & - & - & - & & - \\
\hline Itanhaem & - & - & - & - & - & & - & - & - & - & - & - & - & - & - & - & - & - & - & & - \\
\hline Osasco & - & - & - & - & - & & - & - & - & - & - & - & - & - & - & - & - & 2.8 & 2. & & 2.9 \\
\hline Franco da Rocha & - & - & - & - & 2.9 & & - & - & - & - & - & - & - & - & - & 2.3 & - & - & - & & - \\
\hline Guarulhos & 2.6 & - & - & 2.5 & 3.0 & & - & 2.8 & 2.6 & - & 3.6 & - & 2.0 & 2.1 & 2.3 & - & 6.3 & - & - & & - \\
\hline Itapecerica da Serra & - & - & - & 3.0 & - & & - & - & - & - & 2.0 & - & - & - & - & - & - & 2.3 & - & & 3.5 \\
\hline Sao Paulo & - & - & - & - & - & & - & - & - & - & - & - & - & - & - & - & - & - & - & & - \\
\hline Moji das Cruzes & - & - & - & - & - & & 2.5 & - & - & - & - & - & - & - & - & 2.7 & - & - & - & & 2.0 \\
\hline Santos & - & - & - & - & - & & - & 3.1 & - & - & - & - & - & - & - & - & 2.2 & - & - & & - \\
\hline
\end{tabular}

Observações/Filtro: QL $\geq 2$.

FONTE: Elaborado pelo auto com base nos dados da RAIS/MTE. 
Anexo VIl. Quociente Locacional para as atividades da indústria de transformação selecionadas - São Paulo/2002.

\begin{tabular}{|c|c|c|c|c|c|c|c|c|c|c|c|c|c|c|c|c|c|c|c|c|c|}
\hline Divisão & 17 & 18 & 19 & 24 & 25 & & 26 & 27 & 28 & 29 & 31 & 32 & 33 & 34 & 35 & 36 & 37 & 72 & & 3 & 74 \\
\hline & 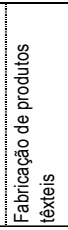 & 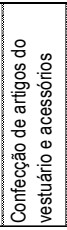 & 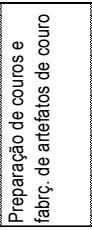 & 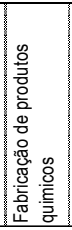 & 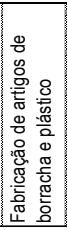 & 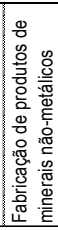 & & 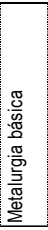 & 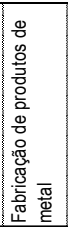 & 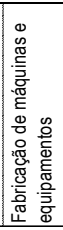 & 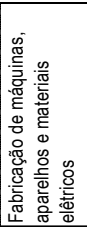 & 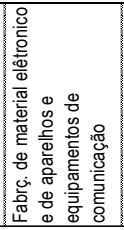 & 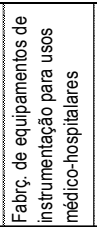 & 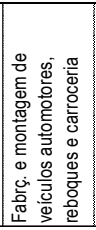 & 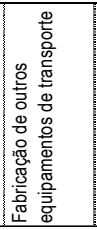 & 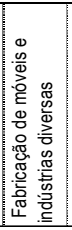 & 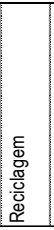 & 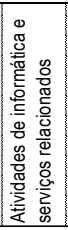 & 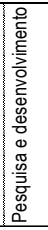 & & 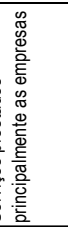 \\
\hline Jales & - & 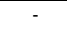 & - & - & - & & - & - & - & - & - & - & - & - & - & - & - & - & - & & - \\
\hline Fernandopolis & - & 2.7 & - & - & - & & - & - & - & - & - & - & - & - & - & 4.2 & & - & - & & - \\
\hline Votuporanga & - & 2.0 & - & - & - & & - & - & - & - & - & - & - & 2.1 & 4.7 & 15.0 & 2.4 & - & - & & - \\
\hline Sao Jose do Rio Preto & - & - & - & - & - & & - & - & - & - & - & - & - & - & - & 4.8 & - & - & - & & - \\
\hline Catanduva & - & - & - & - & - & & - & - & - & - & - & - & - & - & - & - & - & - & - & & - \\
\hline Auriflama & - & 11.6 & - & - & - & & - & - & - & - & - & - & - & - & - & - & - & - & - & & - \\
\hline Nhandeara & - & - & - & - & - & & - & - & 2.4 & - & - & - & - & - & - & - & 7.9 & - & - & & - \\
\hline Novo Horizonte & - & 3.5 & - & - & - & & - & - & - & - & - & - & - & - & - & 3.9 & - & - & - & & - \\
\hline Barretos & - & - & - & - & - & & - & - & - & - & - & - & - & - & - & - & - & - & - & & - \\
\hline Sao Joaquim da Barra & - & - & - & - & - & & - & - & - & - & - & - & - & - & - & - & - & - & - & & - \\
\hline Ituverava & - & - & - & - & - & & 2.0 & - & - & - & - & - & - & - & - & - & - & - & - & & - \\
\hline Franca & - & - & 44.5 & - & 2.6 & & - & - & - & - & - & - & - & - & - & - & - & - & - & & - \\
\hline Jaboticabal & - & - & - & - & - & & - & - & - & - & - & - & - & - & - & - & - & - & - & & - \\
\hline Ribeirao Preto & - & - & - & - & - & & - & - & - & - & - & - & 4.2 & - & - & - & - & - & - & & - \\
\hline Batatais & - & 2.2 & - & - & - & & - & 3.6 & - & 2.5 & - & - & - & - & - & - & - & - & - & & - \\
\hline Andradina & - & - & - & - & - & & - & - & - & - & - & - & - & - & - & - & - & - & - & & - \\
\hline Aracatuba & - & - & - & - & - & & - & - & - & - & - & - & - & - & - & 2.0 & - & - & - & & - \\
\hline Birigui & - & - & 44.6 & - & - & & - & - & - & - & - & - & - & - & - & 3.3 & - & - & - & & - \\
\hline Lins & - & - & 11.8 & - & - & & - & - & - & - & - & - & - & - & - & - & - & - & - & & - \\
\hline Bauru & - & - & - & - & - & & - & - & - & - & 2.3 & - & - & - & - & - & - & - & - & & - \\
\hline Jau & 2.1 & - & 11.3 & - & - & & 2.7 & - & - & - & - & 2.0 & 2.4 & - & - & - & - & - & - & & - \\
\hline Avare & - & 2.1 & - & - & - & & - & - & - & - & - & - & - & - & - & - & 2.5 & - & - & & - \\
\hline Botucatu & - & 2.2 & - & - & - & & - & - & - & - & - & - & - & 2.0 & 10.9 & - & 4.2 & - & - & & - \\
\hline Araraquara & 4.1 & - & - & - & - & & - & - & - & 2.2 & - & - & - & - & - & - & - & - & - & & - \\
\hline Sao Carlos & - & - & - & - & - & & - & - & - & 7.5 & - & - & 3.4 & - & - & 3.1 & - & - & 7. & & - \\
\hline Rio Claro & - & - & - & - & 3.0 & & 4.7 & - & 2.0 & - & 2.1 & - & 4.5 & - & - & - & - & - & - & & - \\
\hline Limeira & - & - & - & - & - & & 5.6 & - & - & 2.4 & - & - & - & - & - & 4.1 & 6.5 & - & - & & - \\
\hline Piracicaba & - & 2.2 & - & - & - & & 2.2 & - & - & 4.1 & - & - & - & - & - & - & 4.3 & - & 2. & & - \\
\hline Pirassununga & - & - & - & - & - & & 7.7 & - & - & - & 2.8 & - & - & - & - & 2.1 & - & - & - & & - \\
\hline Sao Joao da Boa Vista & - & - & - & - & - & & 5.4 & - & - & - & - & - & - & - & - & - & - & - & - & & - \\
\hline Moji-Mirim & 3.2 & - & - & - & - & & 2.6 & - & - & - & - & - & - & 3.2 & - & - & - & - & - & & - \\
\hline Campinas & 3.9 & - & - & 2.1 & - & & - & - & - & - & - & 3.4 & - & - & - & - & - & - & 5. & & - \\
\hline Amparo & 5.8 & 2.3 & - & - & - & & - & - & - & - & - & - & - & - & - & - & - & - & - & & - \\
\hline Dracena & - & - & - & - & - & & 7.2 & - & - & - & - & - & - & - & - & - & - & - & - & & - \\
\hline Adamantina & - & 2.8 & - & - & - & & - & - & - & - & - & - & - & - & - & 2.7 & - & - & - & & - \\
\hline Presidente Prudente & - & - & 2.7 & - & - & & - & - & - & - & - & - & - & - & - & - & - & - & - & & - \\
\hline Tupa & 4.4 & - & - & - & - & & - & - & - & - & - & - & - & - & - & 3.5 & 4.1 & - & - & & - \\
\hline Marilia & - & - & - & - & - & & - & - & 2.1 & 2.1 & - & - & - & - & - & - & - & - & - & & - \\
\hline Assis & - & - & - & - & - & & - & - & - & - & - & - & - & - & - & - & - & - & - & & - \\
\hline Ourinhos & - & 3.3 & - & - & - & & - & - & - & - & - & - & - & - & - & - & - & - & - & & - \\
\hline Itapeva & - & - & - & - & - & & 4.3 & - & - & - & - & - & - & - & - & - & - & - & - & & - \\
\hline Itapetininga & - & 2.5 & - & - & - & & - & - & - & - & - & - & - & - & - & - & - & - & - & & - \\
\hline Tatui & - & - & - & - & - & & 4.8 & - & - & - & 6.1 & - & - & - & - & 2.8 & 2.5 & - & - & & - \\
\hline Capao Bonito & - & - & - & - & - & & 3.8 & - & - & - & - & - & - & - & - & - & - & - & - & & - \\
\hline Piedade & - & - & - & - & - & & - & - & - & - & - & - & - & - & - & - & - & - & - & & 4.7 \\
\hline Sorocaba & - & - & - & - & - & & 2.9 & 4.4 & - & 2.0 & - & 3.2 & 2.3 & 2.0 & - & - & - & - & - & & - \\
\hline Jundiai & - & - & - & - & 2.6 & & 4.1 & - & 3.8 & - & - & - & - & - & - & - & 2.8 & - & - & & - \\
\hline Braganca Paulista & 3.6 & - & - & - & - & & - & - & - & - & 2.4 & - & - & - & - & - & - & - & - & & 2.7 \\
\hline Campos do Jordao & - & - & - & - & - & & - & - & - & - & - & - & - & - & - & - & - & - & - & & - \\
\hline Sao Jose dos Campos & - & - & - & - & - & & - & 2.4 & - & - & - & 5.0 & - & 3.7 & 17.6 & - & 2.9 & - & - & & - \\
\hline Guaratingueta & - & - & - & 2.6 & - & & - & - & - & - & - & - & - & 2.8 & - & - & - & - & - & & - \\
\hline Bananal & - & - & - & - & 2.3 & & - & - & - & - & - & - & - & - & - & - & - & - & - & & - \\
\hline Paraibuna/Paraitinga & - & - & - & - & - & & - & - & - & - & - & - & - & 3.3 & - & - & - & - & - & & - \\
\hline Caraguatatuba & - & - & - & - & - & & - & - & - & - & - & - & - & - & - & - & - & - & - & & - \\
\hline Registro & - & - & - & - & - & & - & - & - & - & - & - & - & - & - & - & - & - & - & & - \\
\hline Itanhaem & - & - & - & - & - & & - & - & - & - & - & - & - & - & - & - & - & - & - & & - \\
\hline Osasco & - & - & - & - & - & & - & - & - & - & - & - & - & - & - & - & - & 2.8 & - & & 2.9 \\
\hline Franco da Rocha & - & - & 2.0 & - & 3.0 & & - & - & - & - & - & - & - & - & - & 2.2 & - & - & - & & - \\
\hline Guarulhos & 2.4 & - & - & 2.4 & 3.0 & & - & 3.0 & 2.5 & - & 3.7 & - & - & - & 2.5 & - & 5.0 & - & - & & - \\
\hline Itapecerica da Serra & - & - & - & 2.5 & - & & - & - & - & - & 2.0 & - & - & - & - & - & - & - & - & & 3.5 \\
\hline Sao Paulo & - & - & - & - & - & & - & - & - & - & - & - & - & - & - & - & - & - & - & & - \\
\hline Moji das Cruzes & - & - & - & - & - & & 2.4 & - & - & - & 2.0 & - & - & - & - & 2.6 & 2.4 & - & - & & - \\
\hline Santos & - & - & - & 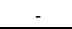 & - & & - & 3.1 & - & - & - & - & - & - & - & - & 2.4 & - & - & & - \\
\hline
\end{tabular}

Oantos

FONTE: Elaborado pelo auto com base nos dados da RAIS/MTE. 
Anexo VIII. Quociente Locacional para as atividades da indústria de transformação selecionadas - São Paulo/2003.

\begin{tabular}{|c|c|c|c|c|c|c|c|c|c|c|c|c|c|c|c|c|c|c|c|c|c|}
\hline Divisão & 17 & 18 & 19 & 24 & 25 & & 26 & 27 & 28 & 29 & 31 & 32 & 33 & 34 & 35 & 36 & 37 & 72 & & 3 & 74 \\
\hline & 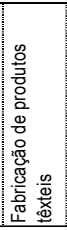 & 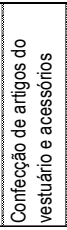 & 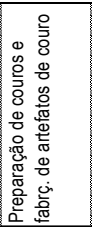 & 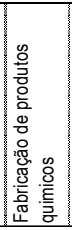 & 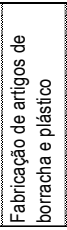 & 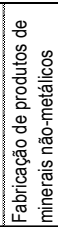 & & 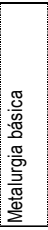 & 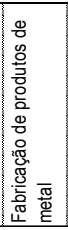 & 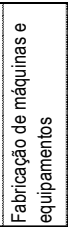 & 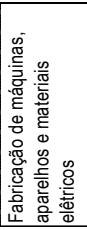 & 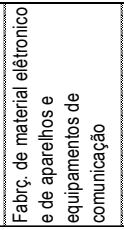 & 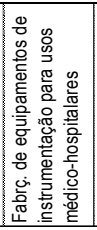 & 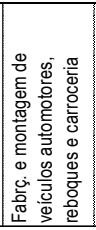 & 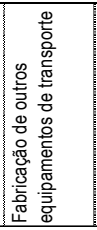 & 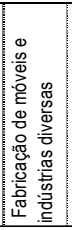 & 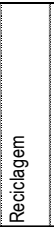 & 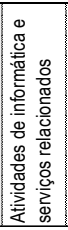 & 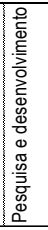 & & 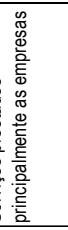 \\
\hline Jales & - & - & - & - & - & & - & - & - & - & - & - & - & - & - & - & - & - & - & & - \\
\hline Fernandopolis & - & 2.0 & - & - & - & & - & - & - & - & - & - & - & - & - & 4.1 & & - & - & & - \\
\hline Votuporanga & - & - & - & - & - & & - & - & - & - & - & - & - & 3.5 & - & 13.1 & 2.3 & - & - & & - \\
\hline Sao Jose do Rio Preto & - & - & - & - & - & & - & - & - & - & - & - & 2.0 & - & - & 4.4 & - & - & - & & - \\
\hline Catanduva & - & - & - & - & - & & - & - & - & - & - & - & - & - & - & - & - & - & - & & - \\
\hline Auriflama & - & 11.4 & - & - & - & & - & - & - & - & - & - & - & - & - & - & - & - & - & & - \\
\hline Nhandeara & - & - & - & - & - & & - & - & - & - & - & - & - & - & - & - & 7.6 & - & - & & - \\
\hline Novo Horizonte & - & 3.0 & - & - & - & & - & - & - & - & - & - & - & - & - & 2.3 & - & - & - & & - \\
\hline Barretos & - & - & - & - & - & & - & - & - & - & - & - & - & - & - & - & - & - & - & & - \\
\hline Sao Joaquim da Barra & - & - & - & - & - & & - & 4.1 & - & - & - & - & - & - & - & - & - & - & - & & - \\
\hline Ituverava & - & - & - & - & - & & - & - & - & - & - & - & - & - & - & - & - & - & - & & - \\
\hline Franca & - & - & 45.3 & - & 2.5 & & - & - & - & - & - & - & - & - & - & - & - & - & - & & - \\
\hline Jaboticabal & - & - & - & - & - & & - & - & - & - & - & - & - & - & - & - & - & - & - & & - \\
\hline Ribeirao Preto & - & - & - & - & - & & - & - & - & - & - & - & 4.1 & - & - & - & - & - & - & & - \\
\hline Batatais & - & 2.2 & - & - & - & & - & 4.0 & - & 2.5 & - & - & - & - & - & - & - & - & - & & - \\
\hline Andradina & - & - & - & - & - & & - & - & - & - & - & - & - & - & - & - & - & - & - & & - \\
\hline Aracatuba & - & - & - & - & - & & - & - & - & - & - & - & - & - & - & 2.1 & - & - & - & & - \\
\hline Birigui & - & - & 42.1 & - & - & & - & - & - & - & - & - & - & - & - & 3.5 & - & - & - & & - \\
\hline Lins & - & - & 11.3 & - & - & & - & - & - & - & - & - & - & - & - & - & - & - & - & & - \\
\hline Bauru & - & - & - & - & - & & - & - & - & - & 2.3 & - & - & - & - & - & - & - & - & & - \\
\hline Jau & - & - & 12.1 & - & - & & 2.3 & - & - & - & - & - & 2.7 & - & - & - & - & - & - & & - \\
\hline Avare & - & 2.9 & - & - & - & & - & - & - & - & - & - & - & - & - & - & - & - & - & & - \\
\hline Botucatu & - & 3.1 & - & - & - & & - & - & - & - & - & - & - & 2.6 & 10.8 & - & 2.3 & - & - & & - \\
\hline Araraquara & 4.2 & - & - & - & - & & - & - & - & 3.1 & - & - & - & - & - & - & - & - & - & & - \\
\hline Sao Carlos & - & - & - & - & - & & - & - & - & 7.0 & - & - & 2.6 & - & - & 3.0 & - & - & 7. & & - \\
\hline Rio Claro & - & - & - & - & 3.0 & & 4.5 & - & - & 2.1 & 2.6 & - & 4.4 & - & - & 2.7 & - & - & - & & - \\
\hline Limeira & - & - & - & - & - & & 5.5 & - & 2.0 & 2.2 & - & - & - & - & - & 4.1 & 4.7 & - & - & & - \\
\hline Piracicaba & - & 2.1 & - & - & - & & - & - & - & 4.4 & - & - & - & - & - & - & 5.0 & - & - & & - \\
\hline Pirassununga & - & - & - & - & - & & 7.6 & - & - & - & 3.5 & - & - & - & - & 2.0 & - & - & - & & - \\
\hline Sao Joao da Boa Vista & - & - & - & - & - & & 5.2 & - & - & - & - & - & - & - & - & - & - & - & - & & - \\
\hline Moji-Mirim & 2.5 & - & - & - & - & & 2.2 & - & - & - & - & - & - & 3.3 & - & 2.3 & 2.4 & - & - & & - \\
\hline Campinas & 3.8 & - & - & 2.1 & - & & - & - & - & - & - & 3.7 & - & - & - & - & - & - & 6. & & - \\
\hline Amparo & 5.3 & 2.5 & - & - & - & & - & - & - & - & - & - & - & - & - & - & 2.1 & - & - & & - \\
\hline Dracena & - & - & - & - & - & & 7.2 & - & - & - & - & - & - & - & - & - & - & - & - & & - \\
\hline Adamantina & - & 3.9 & - & - & - & & - & - & - & - & - & - & - & - & - & 2.6 & - & - & - & & - \\
\hline Presidente Prudente & - & - & 3.0 & - & - & & - & - & - & - & - & - & - & - & - & - & - & - & - & & - \\
\hline Tupa & 4.0 & - & - & - & - & & - & - & - & - & - & - & - & - & - & 3.0 & 3.1 & - & - & & - \\
\hline Marilia & - & - & - & - & - & & - & - & - & 2.4 & - & - & - & - & - & - & - & - & - & & - \\
\hline Assis & - & - & - & - & - & & - & - & - & - & - & - & - & - & - & - & - & - & - & & - \\
\hline Ourinhos & - & 3.4 & - & - & - & & - & - & - & - & - & - & - & - & - & - & - & - & - & & - \\
\hline Itapeva & - & - & - & - & - & & 2.7 & - & - & - & - & - & - & - & - & - & - & - & - & & - \\
\hline Itapetininga & - & 2.3 & - & - & - & & - & - & - & - & - & - & - & - & - & - & - & - & - & & - \\
\hline Tatui & 3.9 & - & - & - & - & & 5.0 & - & - & - & 6.3 & - & - & - & - & 2.5 & - & - & - & & - \\
\hline Capao Bonito & - & - & - & - & - & & 3.2 & - & - & - & - & - & - & - & - & - & - & - & - & & - \\
\hline Piedade & - & - & - & - & - & & - & - & - & - & - & - & - & - & - & - & - & - & - & & 3.7 \\
\hline Sorocaba & - & - & - & - & - & & 2.5 & 4.5 & - & - & 2.3 & 2.3 & 2.2 & - & - & - & - & - & - & & - \\
\hline Jundiai & - & - & - & - & 2.4 & & 3.8 & - & 4.0 & - & - & - & - & - & - & - & 2.5 & - & - & & - \\
\hline Braganca Paulista & 3.8 & - & - & - & - & & - & - & - & - & 3.4 & - & - & - & - & - & - & - & - & & 2.3 \\
\hline Campos do Jordao & - & - & - & - & - & & - & - & - & - & - & - & - & - & - & - & - & - & - & & - \\
\hline Sao Jose dos Campos & - & - & - & - & - & & - & 2.4 & - & - & - & 4.4 & - & 3.9 & 17.2 & - & 2.9 & - & - & & - \\
\hline Guaratingueta & - & - & - & 2.7 & - & & - & - & - & - & - & - & - & 3.6 & - & - & - & - & - & & - \\
\hline Bananal & - & - & - & - & - & & - & - & - & - & - & - & - & - & - & - & - & - & - & & - \\
\hline Paraibuna/Paraitinga & - & - & - & - & - & & - & - & - & - & - & - & - & 3.2 & - & - & - & 2.5 & - & & - \\
\hline Caraguatatuba & - & - & - & - & - & & - & - & - & - & - & - & - & - & - & - & - & - & - & & - \\
\hline Registro & - & - & - & - & - & & - & - & - & - & - & - & - & - & - & - & - & - & - & & - \\
\hline Itanhaem & - & - & - & - & - & & - & - & - & - & - & - & - & - & - & - & - & - & - & & - \\
\hline Osasco & - & - & - & - & - & & - & - & - & - & - & - & - & - & - & - & - & 2.8 & - & & 2.9 \\
\hline Franco da Rocha & - & - & - & - & 2.5 & & - & - & - & - & - & - & - & - & - & 2.2 & - & - & - & & - \\
\hline Guarulhos & 2.6 & - & - & 2.3 & 3.0 & & - & 3.5 & 2.5 & - & 3.5 & - & - & - & 2.4 & - & 4.4 & - & - & & - \\
\hline Itapecerica da Serra & - & - & - & 2.8 & - & & - & - & - & - & - & - & - & - & - & - & - & - & - & & 2.8 \\
\hline Sao Paulo & - & - & - & - & - & & - & - & - & - & - & - & - & - & - & - & - & - & - & & - \\
\hline Moji das Cruzes & - & - & - & - & - & & 2.6 & 2.1 & - & - & 2.1 & - & - & - & - & 2.6 & - & 2.3 & - & & - \\
\hline Santos & - & - & - & - & - & & - & 3.0 & - & - & - & - & - & - & - & - & 2.2 & & - & & - \\
\hline
\end{tabular}

Oantos

FONTE: Elaborado pelo auto com base nos dados da RAIS/MTE. 
Anexo IX. Quociente Locacional para as atividades da indústria de transformação selecionadas - São Paulo/2004.

\begin{tabular}{|c|c|c|c|c|c|c|c|c|c|c|c|c|c|c|c|c|c|c|c|c|c|}
\hline Divisão & 17 & 18 & 19 & 24 & 25 & & 26 & 27 & 28 & 29 & 31 & 32 & 33 & 34 & 35 & 36 & 37 & 72 & 7 & 74 & $\underline{4}$ \\
\hline & 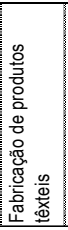 & 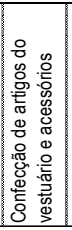 & 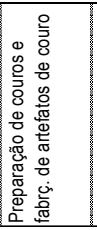 & 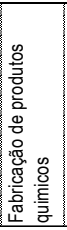 & 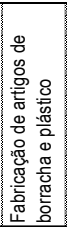 & 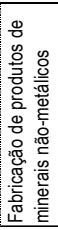 & & 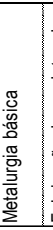 & 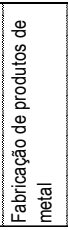 & 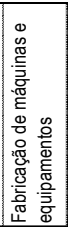 & 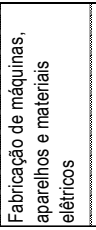 & 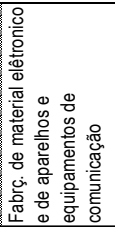 & 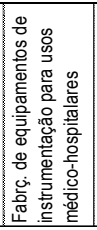 & 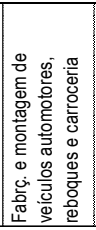 & 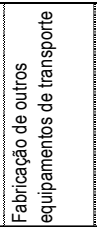 & 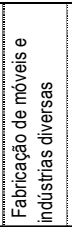 & 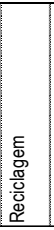 & 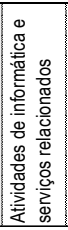 & 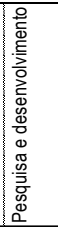 & 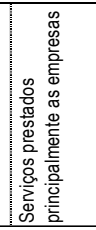 & \\
\hline Jales & - & - & - & - & - & & 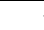 & - & - & - & - & - & - & - & - & - & - & - & - & 2.0 & \\
\hline Fernandopolis & - & - & - & - & - & & . & - & - & - & - & - & - & - & - & 3.6 & - & - & - & - & \\
\hline Votuporanga & - & - & - & - & - & & . & - & - & - & - & - & - & 3.5 & - & 13.6 & - & - & - & - & \\
\hline Sao Jose do Rio Preto & - & - & - & - & - & & . & - & - & - & - & - & - & - & - & 4.4 & - & - & - & - & \\
\hline Catanduva & - & - & - & - & - & & & - & - & - & - & - & - & - & - & - & - & - & - & - & \\
\hline Auriflama & - & 12.8 & - & - & - & & & - & - & - & - & - & - & - & - & - & - & - & - & - & \\
\hline Nhandeara & - & - & - & - & - & & . & - & - & - & - & - & - & - & - & - & 4.4 & - & - & - & \\
\hline Novo Horizonte & - & 3.1 & - & - & - & & . & - & - & - & - & - & - & - & - & - & - & - & - & - & \\
\hline Barretos & - & - & - & - & - & & - & - & - & - & - & - & - & - & - & - & - & - & - & - & \\
\hline Sao Joaquim da Barra & - & - & - & - & - & & - & 4.1 & - & - & - & - & - & - & - & - & - & - & - & - & \\
\hline Ituverava & - & - & - & - & - & & - & - & - & - & - & - & - & - & - & - & - & - & - & - & \\
\hline Franca & - & - & 44.7 & - & 2.3 & & - & - & - & - & - & - & - & - & - & - & - & - & - & - & \\
\hline Jaboticabal & - & - & - & - & - & & - & - & - & - & - & - & - & - & - & - & - & - & - & - & \\
\hline Ribeirao Preto & - & - & - & - & - & & - & - & - & - & - & - & 4.1 & - & - & - & - & - & - & - & \\
\hline Batatais & - & 2.4 & - & - & - & & - & 4.5 & - & 2.5 & - & - & - & - & - & - & - & - & - & - & \\
\hline Andradina & - & - & - & - & - & & - & - & - & - & - & - & - & - & - & - & - & - & - & - & \\
\hline Aracatuba & - & - & - & - & - & & - & - & - & - & - & - & - & - & - & 2.4 & - & - & - & - & \\
\hline Birigui & - & - & 40.0 & - & - & & - & - & - & - & - & - & - & - & - & 3.4 & - & - & - & - & \\
\hline Lins & - & - & 10.4 & - & - & & - & - & - & - & - & - & - & - & - & - & - & - & - & - & \\
\hline Bauru & - & - & - & - & - & & - & - & - & - & 2.3 & - & - & - & - & - & - & - & - & - & \\
\hline Jau & - & - & 14.1 & - & - & & - & - & - & - & - & - & 2.5 & - & - & - & - & - & - & - & \\
\hline Avare & - & 2.9 & - & - & - & & - & - & - & - & - & - & - & - & - & - & - & - & - & - & \\
\hline Botucatu & - & 3.7 & - & - & - & & - & - & - & - & - & - & - & 2.2 & 11.2 & - & - & - & - & - & \\
\hline Araraquara & 4.8 & - & - & - & - & & - & - & - & 2.3 & - & - & - & - & 2.7 & - & - & - & - & - & \\
\hline Sao Carlos & - & - & - & - & - & & - & - & - & 7.0 & - & - & 2.4 & - & - & 2.8 & - & - & 6.9 & - & \\
\hline Rio Claro & - & - & - & - & 2.6 & & 4.9 & - & - & 2.0 & 4.0 & - & 4.6 & - & - & 3.2 & - & - & - & - & \\
\hline Limeira & - & - & - & - & - & & 6.0 & - & 2.0 & 2.2 & - & - & - & - & - & 4.0 & 3.5 & - & - & - & \\
\hline Piracicaba & - & - & - & - & - & & - & - & - & 4.7 & - & - & - & - & - & - & 4.2 & - & - & - & \\
\hline Pirassununga & - & - & - & - & - & & 7.3 & - & - & - & 3.8 & - & - & - & - & 2.2 & - & - & - & - & \\
\hline Sao Joao da Boa Vista & - & - & - & - & - & & 5.4 & - & - & - & 2.1 & - & - & - & - & - & - & - & - & - & \\
\hline Moji-Mirim & 2.9 & - & - & - & - & & 2.1 & - & - & - & - & - & - & 3.8 & - & 2.2 & - & - & - & - & \\
\hline Campinas & 3.6 & - & - & - & - & & - & - & - & - & - & 3.4 & - & - & - & - & - & - & 6.0 & - & \\
\hline Amparo & 6.1 & 2.7 & - & 2.1 & - & & - & - & - & - & - & - & - & - & - & - & 4.0 & - & - & - & \\
\hline Dracena & - & - & - & - & - & & 7.2 & - & - & - & - & - & - & - & - & - & - & - & - & - & \\
\hline Adamantina & - & 3.9 & - & - & - & & - & - & - & - & - & - & - & - & - & 2.1 & - & - & - & - & \\
\hline Presidente Prudente & - & - & 3.4 & - & - & & - & - & - & - & - & - & - & - & - & - & - & - & - & - & \\
\hline Tupa & 4.1 & - & - & - & - & & - & - & - & - & - & - & - & - & - & 2.3 & 2.8 & - & - & - & \\
\hline Marilia & - & - & - & - & - & & - & - & - & 2.5 & - & 2.3 & - & - & - & - & - & - & - & - & \\
\hline Assis & - & - & - & - & - & & - & - & - & - & - & - & - & - & - & - & - & - & - & - & \\
\hline Ourinhos & - & 3.8 & - & - & - & & - & - & - & - & - & - & - & - & - & - & - & - & - & - & \\
\hline Itapeva & - & - & - & - & - & & 2.5 & - & - & - & - & - & - & - & - & - & - & - & - & - & \\
\hline Itapetininga & - & 2.3 & - & - & - & & - & - & - & - & - & - & - & - & - & - & - & - & - & - & \\
\hline Tatui & 2.7 & - & - & - & - & & 4.5 & - & - & - & 6.4 & - & - & - & - & 2.7 & - & - & - & - & \\
\hline Capao Bonito & - & - & - & - & - & & 2.9 & - & - & - & - & - & - & - & - & - & - & - & - & - & \\
\hline Piedade & - & - & - & - & - & & - & - & - & - & - & - & - & - & - & - & - & - & - & 3.3 & \\
\hline Sorocaba & - & - & - & - & - & & 2.7 & 4.2 & - & - & 2.2 & 3.0 & 2.1 & - & - & - & - & - & - & - & \\
\hline Jundiai & - & - & - & - & 2.4 & & 3.8 & - & 4.4 & - & - & - & - & - & - & - & 2.6 & 2.2 & - & - & \\
\hline Braganca Paulista & 4.7 & - & - & - & - & & - & - & - & - & 3.8 & - & - & - & - & - & - & - & - & 2.1 & \\
\hline Campos do Jordao & - & - & - & - & - & & - & - & - & - & - & - & - & - & - & - & - & - & - & - & \\
\hline Sao Jose dos Campos & - & - & - & - & - & & - & 2.4 & - & - & - & 4.8 & - & 3.7 & 17.3 & - & 2.9 & - & - & - & \\
\hline Guaratingueta & - & - & - & 2.6 & - & & - & - & - & - & - & - & - & 3.8 & - & - & - & - & - & - & \\
\hline Bananal & - & - & - & - & - & & - & - & - & - & - & - & - & - & - & - & - & - & - & - & \\
\hline Paraibuna/Paraitinga & - & - & - & - & - & & - & - & - & - & - & - & - & 2.8 & - & - & - & - & - & - & \\
\hline Caraguatatuba & - & - & - & - & - & & - & - & - & - & - & - & - & - & - & - & - & - & - & - & \\
\hline Registro & - & - & - & - & - & & - & - & - & - & - & - & - & - & - & - & - & - & - & - & \\
\hline Itanhaem & - & - & - & - & - & & - & - & - & - & - & - & - & - & - & - & - & - & - & - & \\
\hline Osasco & - & - & - & - & - & & - & - & - & - & - & - & - & - & - & - & - & 2.8 & - & 2.8 & \\
\hline Franco da Rocha & - & - & - & - & 2.9 & & - & - & - & - & - & - & - & - & - & - & - & - & - & - & \\
\hline Guarulhos & 2.6 & - & - & 2.4 & 2.9 & & - & 3.5 & 2.4 & - & 3.2 & - & - & - & 2.3 & - & 3.8 & - & - & - & \\
\hline Itapecerica da Serra & - & - & - & 2.9 & 2.1 & & - & - & - & - & - & - & - & - & - & - & - & - & - & 2.8 & \\
\hline Sao Paulo & - & - & - & - & - & & - & - & - & - & - & - & - & - & - & - & - & - & - & - & \\
\hline Moji das Cruzes & - & - & - & - & - & & 2.7 & 2.2 & - & - & 2.2 & - & - & - & - & 2.7 & - & - & - & - & \\
\hline Santos & - & - & - & - & - & & - & 2.8 & - & - & - & - & - & - & - & - & - & - & - & - & \\
\hline
\end{tabular}

Observações/Filtro: QL $\geq 2$.

FONTE: Elaborado pelo auto com base nos dados da RAIS/TEM 
Anexo X. Quociente Locacional para as atividades da indústria de transformação selecionadas - São Paulo/2005.

\begin{tabular}{|c|c|c|c|c|c|c|c|c|c|c|c|c|c|c|c|c|c|c|c|c|c|}
\hline Divisão & 17 & 18 & 19 & 24 & 25 & & 26 & 27 & 28 & 29 & 31 & 32 & 33 & 34 & 35 & 36 & 37 & 72 & 7 & 74 & $\underline{4}$ \\
\hline & 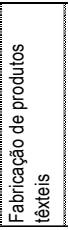 & 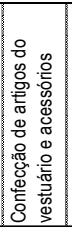 & 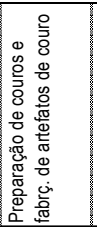 & 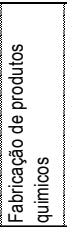 & 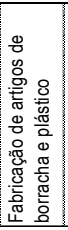 & 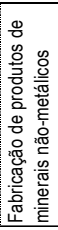 & & 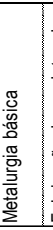 & 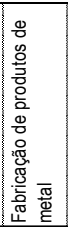 & 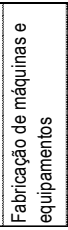 & 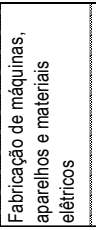 & 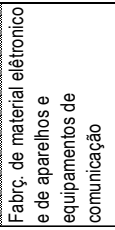 & 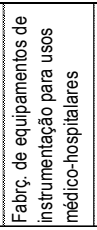 & 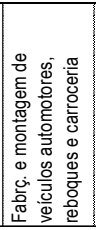 & 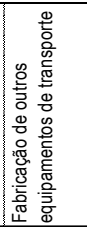 & 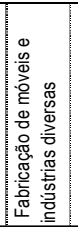 & 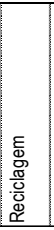 & 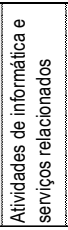 & 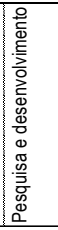 & 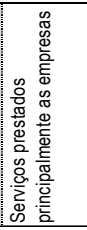 & \\
\hline Jales & - & - & - & - & - & & 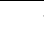 & - & - & - & - & - & - & - & - & - & - & - & - & - & \\
\hline Fernandopolis & - & - & - & - & - & & . & - & - & - & - & - & - & - & - & 3.1 & - & - & - & - & \\
\hline Votuporanga & - & - & - & - & - & & . & - & - & - & - & - & - & 2.9 & - & 13.4 & - & - & - & - & \\
\hline Sao Jose do Rio Preto & - & - & - & - & - & & . & - & - & - & - & - & - & - & - & 4.3 & - & - & - & - & \\
\hline Catanduva & - & - & - & - & - & & & - & - & - & - & - & - & - & - & - & - & - & - & - & \\
\hline Auriflama & - & 12.3 & - & - & - & & & - & - & - & - & - & - & - & - & - & - & - & - & - & \\
\hline Nhandeara & - & - & 2.4 & - & - & & . & - & - & - & - & - & - & - & - & - & 3.7 & - & - & - & \\
\hline Novo Horizonte & - & 4.0 & - & - & - & & . & - & - & - & - & - & - & - & - & - & - & - & - & - & \\
\hline Barretos & - & - & - & - & - & & - & - & - & - & - & - & - & - & - & - & - & - & - & - & \\
\hline Sao Joaquim da Barra & - & - & - & - & - & & - & 3.7 & - & - & - & - & - & - & - & - & - & - & - & - & \\
\hline Ituverava & - & - & - & - & - & & - & - & - & - & - & - & - & - & - & 2.4 & - & - & - & - & \\
\hline Franca & - & - & 42.7 & - & 2.4 & & - & - & - & - & - & - & - & - & - & - & - & - & - & - & \\
\hline Jaboticabal & - & - & - & - & - & & - & - & - & - & - & - & - & - & - & - & - & - & - & - & \\
\hline Ribeirao Preto & - & - & - & - & - & & - & - & - & - & - & - & 4.0 & - & - & - & - & - & - & - & \\
\hline Batatais & - & 2.7 & - & - & - & & - & 4.0 & - & 2.3 & - & - & - & - & - & - & - & - & - & - & \\
\hline Andradina & - & - & - & - & - & & - & - & - & - & - & - & - & - & - & - & - & - & - & - & \\
\hline Aracatuba & - & - & - & - & - & & - & - & - & - & - & - & - & - & - & 2.4 & - & - & - & - & \\
\hline Birigui & - & - & 40.4 & - & - & & - & - & - & - & - & - & - & - & - & 3.5 & - & - & - & - & \\
\hline Lins & - & - & 12.3 & - & - & & - & - & - & - & - & - & - & - & - & - & - & - & - & - & \\
\hline Bauru & - & - & - & - & - & & - & - & - & - & 2.3 & - & - & - & - & - & - & - & - & - & \\
\hline Jau & - & - & 16.2 & - & - & & - & - & - & - & - & - & 2.6 & - & - & - & - & 2.5 & - & - & \\
\hline Avare & - & 2.9 & - & - & - & & - & - & - & - & - & - & - & - & - & - & - & - & - & - & \\
\hline Botucatu & - & 3.6 & - & - & - & & - & - & - & - & - & - & - & 2.3 & 10.4 & - & 2.1 & - & - & - & \\
\hline Araraquara & 5.2 & - & - & - & - & & - & - & - & 2.0 & - & - & - & - & 3.6 & - & - & - & - & - & \\
\hline Sao Carlos & - & - & - & - & - & & - & - & - & 6.2 & - & - & 3.1 & - & - & 2.9 & - & - & 8.2 & - & \\
\hline Rio Claro & - & - & - & - & - & & 2.2 & - & - & - & 6.1 & - & 3.9 & - & - & - & - & - & - & - & \\
\hline Limeira & - & - & - & - & - & & 6.9 & - & 2.2 & 2.3 & - & - & - & 2.5 & - & 4.7 & 4.3 & - & - & - & \\
\hline Piracicaba & - & - & - & - & - & & 2.1 & 2.0 & - & 4.4 & - & - & - & - & - & - & 3.3 & - & - & - & \\
\hline Pirassununga & - & - & - & - & - & & 7.2 & - & - & - & 3.6 & - & - & - & - & 2.4 & - & - & - & - & \\
\hline Sao Joao da Boa Vista & - & - & - & - & - & & 5.4 & - & - & - & - & - & - & - & - & - & - & - & - & - & \\
\hline Moji-Mirim & 3.2 & - & - & - & - & & 2.1 & - & - & - & - & - & - & 3.7 & - & 2.2 & - & - & - & - & \\
\hline Campinas & 3.6 & - & - & - & - & & - & - & - & - & - & 3.4 & - & - & - & - & - & - & 6.2 & - & \\
\hline Amparo & 5.6 & 2.7 & - & 2.3 & - & & - & - & - & - & - & - & - & - & - & - & 5.0 & - & - & - & \\
\hline Dracena & - & - & - & - & - & & 8.0 & - & - & - & - & - & - & - & - & - & - & - & - & - & \\
\hline Adamantina & - & 4.6 & 2.1 & - & - & & - & - & - & - & - & - & - & - & - & 2.1 & - & - & - & - & \\
\hline Presidente Prudente & - & - & 4.3 & - & - & & - & - & - & - & - & - & - & - & - & - & - & - & - & - & \\
\hline Tupa & 3.9 & - & - & - & - & & - & - & - & - & - & - & - & - & - & - & 2.2 & - & - & - & \\
\hline Marilia & - & - & - & - & - & & - & - & - & 2.1 & 2.0 & 2.9 & - & - & - & - & - & - & - & - & \\
\hline Assis & - & - & - & - & - & & - & - & - & - & - & - & - & - & - & - & - & - & - & - & \\
\hline Ourinhos & - & 4.3 & - & - & - & & - & - & - & - & - & - & - & - & - & - & - & - & - & - & \\
\hline Itapeva & - & - & - & - & - & & 2.7 & - & - & - & - & - & - & - & - & - & - & - & - & - & \\
\hline Itapetininga & - & 2.3 & - & - & - & & - & - & - & - & - & - & - & - & - & - & - & - & - & - & \\
\hline Tatui & 3.5 & - & - & - & - & & 3.9 & 2.0 & - & - & 5.3 & - & - & - & - & 2.7 & - & - & - & - & \\
\hline Capao Bonito & - & - & - & - & - & & 3.0 & - & - & - & - & - & - & - & - & - & - & - & - & - & \\
\hline Piedade & - & - & - & - & - & & - & - & - & - & - & - & - & - & - & - & - & - & - & - & \\
\hline Sorocaba & - & - & - & - & - & & 2.8 & 4.2 & - & 2.1 & 2.0 & 2.6 & 2.1 & - & - & - & - & - & - & - & \\
\hline Jundiai & - & - & - & - & 2.6 & & 3.7 & - & 4.0 & - & - & - & - & - & - & - & 2.5 & - & - & - & \\
\hline Braganca Paulista & 4.4 & - & - & - & - & & - & - & - & - & 3.3 & - & - & - & - & - & - & - & - & 2.1 & \\
\hline Campos do Jordao & - & - & - & - & - & & - & - & - & - & - & - & - & - & - & - & - & - & - & - & \\
\hline Sao Jose dos Campos & - & - & - & - & - & & - & 2.1 & - & - & - & 4.8 & - & 3.2 & 17.6 & - & 2.1 & - & - & - & \\
\hline Guaratingueta & - & - & - & 2.5 & - & & - & - & - & - & - & - & - & 3.9 & - & - & 3.3 & - & - & - & \\
\hline Bananal & - & - & - & - & - & & - & - & - & - & - & - & - & - & - & - & - & - & - & - & \\
\hline Paraibuna/Paraitinga & - & - & - & - & - & & - & - & - & - & - & - & - & 2.7 & - & - & - & - & - & - & \\
\hline Caraguatatuba & - & - & - & - & - & & - & - & - & - & - & - & - & - & - & - & - & - & - & - & \\
\hline Registro & - & - & - & - & - & & - & - & - & - & - & - & - & - & - & - & - & - & - & - & \\
\hline Itanhaem & - & - & - & - & - & & - & - & - & - & - & - & - & - & - & - & - & - & - & - & \\
\hline Osasco & - & - & - & - & - & & - & - & - & - & - & - & - & - & - & - & - & 2.9 & - & 2.6 & \\
\hline Franco da Rocha & - & - & - & - & 3.5 & & - & - & - & - & - & - & - & - & - & 2.0 & - & - & - & - & \\
\hline Guarulhos & 2.6 & - & - & 2.4 & 3.1 & & - & 3.5 & 2.5 & - & 3.1 & - & - & - & 2.5 & - & 2.7 & - & - & - & \\
\hline Itapecerica da Serra & - & - & - & 3.1 & 2.4 & & - & - & - & - & - & - & - & - & - & - & - & - & - & 2.3 & \\
\hline Sao Paulo & - & - & - & - & - & & - & - & - & - & - & - & - & - & - & - & - & - & - & - & \\
\hline Moji das Cruzes & 2.1 & - & - & - & - & & 2.8 & 2.1 & - & - & 2.7 & - & - & - & - & 2.1 & 3.8 & - & - & - & \\
\hline Santos & - & - & - & - & - & & - & 2.7 & - & - & - & - & - & - & - & - & - & - & - & - & \\
\hline
\end{tabular}

Santos

FONTE: Elaborado pelo auto com base nos dados da RAIS/MTE 
Anexo XI. Quociente Locacional para as atividades da indústria de transformação selecionadas - São Paulo/2006.

\begin{tabular}{|c|c|c|c|c|c|c|c|c|c|c|c|c|c|c|c|c|c|c|c|c|c|}
\hline Divisão & 17 & 18 & 19 & 24 & 25 & & 26 & 27 & 28 & 29 & 31 & 32 & 33 & 34 & 35 & 36 & 37 & 72 & & 3 & 74 \\
\hline & 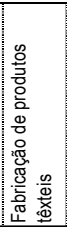 & 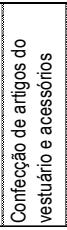 & 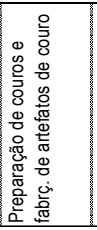 & 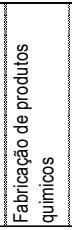 & 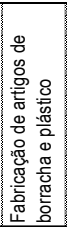 & 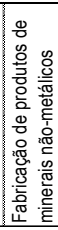 & & 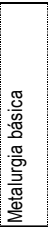 & 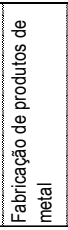 & 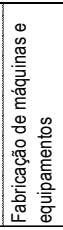 & 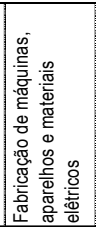 & 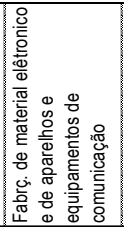 & 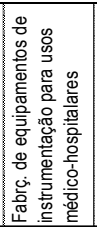 & 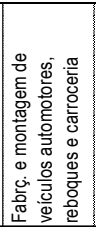 & 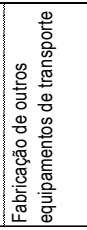 & 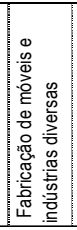 & 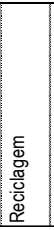 & 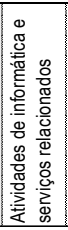 & 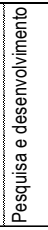 & & 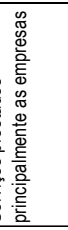 \\
\hline Jales & - & - & 2.2 & - & - & & - & - & - & - & - & - & - & - & - & - & - & - & - & & - \\
\hline Fernandopolis & - & - & - & - & - & & - & - & - & - & - & - & - & - & - & 3.9 & . & - & - & & - \\
\hline Votuporanga & - & - & - & - & - & & - & - & - & - & - & - & - & 3.3 & - & 14.4 & - & - & - & & - \\
\hline Sao Jose do Rio Preto & - & - & - & - & - & & - & - & - & - & - & - & - & - & - & 5.4 & - & - & - & & - \\
\hline Catanduva & - & - & - & - & - & & - & - & - & - & - & - & - & - & - & - & - & - & - & & - \\
\hline Auriflama & - & 12.5 & - & - & - & & - & - & - & - & - & - & - & - & - & - & - & - & - & & - \\
\hline Nhandeara & - & - & - & - & - & & - & - & - & - & - & - & - & - & - & - & 2.5 & - & - & & - \\
\hline Novo Horizonte & - & 4.7 & - & - & - & & - & - & - & - & - & - & - & - & - & - & - & - & - & & - \\
\hline Barretos & - & - & - & - & - & & - & - & - & - & - & - & - & - & - & - & - & - & - & & - \\
\hline Sao Joaquim da Barra & - & - & - & - & - & & - & 3.4 & - & - & - & - & - & - & - & - & - & - & - & & - \\
\hline Ituverava & - & - & - & - & - & & - & - & - & - & - & - & - & - & - & 3.0 & - & - & - & & - \\
\hline Franca & - & - & 41.1 & - & 2.3 & & - & - & - & - & - & - & - & - & - & - & - & - & - & & - \\
\hline Jaboticabal & - & - & - & - & - & & - & - & - & - & - & - & - & - & - & - & - & - & - & & - \\
\hline Ribeirao Preto & - & - & - & - & - & & - & - & - & - & - & - & 3.5 & - & - & - & - & - & - & & - \\
\hline Batatais & - & 2.4 & - & - & - & & - & 3.5 & - & - & - & - & - & - & - & - & - & - & - & & - \\
\hline Andradina & - & - & - & - & - & & - & - & - & - & - & - & - & - & - & - & - & - & - & & - \\
\hline Aracatuba & - & - & 2.3 & - & - & & - & - & - & - & - & - & - & - & - & 2.3 & - & - & - & & - \\
\hline Birigui & - & - & 41.2 & - & - & & - & - & - & - & - & - & - & - & - & 4.1 & - & - & - & & - \\
\hline Lins & - & - & 13.4 & - & - & & - & - & - & - & - & - & - & - & - & - & - & - & - & & - \\
\hline Bauru & - & - & - & - & - & & - & - & - & - & 2.3 & - & - & - & - & - & - & - & - & & - \\
\hline Jau & - & - & 16.2 & - & - & & - & - & - & - & - & - & 2.3 & - & - & - & - & - & - & & - \\
\hline Avare & - & 3.2 & - & - & - & & - & - & - & - & - & - & - & - & - & - & 3.7 & - & - & & - \\
\hline Botucatu & - & 3.5 & - & - & - & & - & - & - & - & - & - & - & 2.4 & 9.4 & - & - & - & - & & - \\
\hline Araraquara & 5.9 & - & - & - & - & & - & - & - & 2.5 & - & - & - & - & 4.5 & - & - & - & - & & - \\
\hline Sao Carlos & - & - & - & - & - & & - & - & - & 5.7 & 2.0 & - & 3.4 & - & - & - & - & - & 5. & & - \\
\hline Rio Claro & - & - & - & - & - & & 4.1 & - & - & - & 15.8 & - & 3.7 & - & - & 4.0 & - & - & - & & - \\
\hline Limeira & - & - & - & - & - & & 6.4 & - & 2.2 & - & - & - & - & 2.5 & 2.4 & 3.5 & 2.3 & - & - & & - \\
\hline Piracicaba & - & - & - & - & - & & - & - & - & 4.4 & - & - & - & - & - & - & 3.7 & - & - & & - \\
\hline Pirassununga & - & - & - & - & - & & 7.2 & - & - & - & 3.2 & - & - & - & - & 2.7 & - & - & - & & - \\
\hline Sao Joao da Boa Vista & - & - & - & - & - & & 5.2 & - & - & - & - & - & - & - & - & - & - & - & - & & - \\
\hline Moji-Mirim & 2.9 & - & - & - & - & & - & - & - & - & - & - & - & 3.7 & - & 2.6 & - & - & - & & - \\
\hline Campinas & 3.6 & - & - & - & - & & - & - & - & - & - & 3.5 & - & 2.1 & - & - & - & - & 7. & & - \\
\hline Amparo & 5.3 & 2.7 & - & 2.6 & - & & - & - & - & - & - & - & - & - & - & - & 4.8 & - & - & & - \\
\hline Dracena & - & - & - & - & - & & 6.5 & - & - & - & - & - & - & - & - & - & - & - & - & & - \\
\hline Adamantina & - & 4.6 & 3.0 & - & - & & - & - & - & - & - & - & - & - & - & 2.3 & - & - & - & & - \\
\hline Presidente Prudente & - & - & 5.1 & - & - & & - & - & - & - & - & - & - & - & - & - & - & - & - & & - \\
\hline Tupa & 3.8 & - & - & - & - & & - & - & - & - & - & - & - & - & - & - & - & - & - & & - \\
\hline Marilia & - & - & - & - & - & & - & - & - & 2.3 & - & 2.6 & - & - & - & - & - & - & - & & - \\
\hline Assis & - & - & - & - & - & & - & - & - & - & - & - & - & - & - & - & - & - & - & & - \\
\hline Ourinhos & - & 4.4 & - & - & - & & - & - & - & - & - & - & - & - & - & 2.1 & - & - & - & & - \\
\hline Itapeva & - & - & - & - & - & & 2.1 & - & - & - & - & - & - & - & - & - & - & - & - & & - \\
\hline Itapetininga & - & 2.2 & - & - & - & & - & - & - & - & - & - & - & - & - & - & - & - & - & & - \\
\hline Tatui & 2.9 & 2.1 & - & - & - & & 3.9 & - & - & - & 4.2 & - & - & - & - & 3.5 & - & - & - & & - \\
\hline Capao Bonito & - & - & - & - & - & & 3.5 & - & - & - & - & - & - & - & - & - & - & - & - & & - \\
\hline Piedade & - & - & - & - & - & & - & - & - & - & - & - & - & - & - & - & - & - & - & & - \\
\hline Sorocaba & - & - & - & - & - & & 2.7 & 3.9 & - & - & - & 2.4 & 2.4 & - & - & - & - & - & - & & - \\
\hline Jundiai & - & - & - & - & 2.5 & & 3.4 & - & 2.3 & - & - & - & - & 2.1 & - & - & - & - & - & & - \\
\hline Braganca Paulista & 4.2 & - & - & - & - & & - & - & - & - & 3.4 & - & - & - & - & - & - & - & - & & 2.1 \\
\hline Campos do Jordao & - & - & - & - & - & & - & - & - & - & - & - & - & - & - & - & - & - & - & & - \\
\hline Sao Jose dos Campos & - & - & - & - & - & & - & 2.5 & - & - & - & 3.3 & - & 3.0 & 17.5 & - & 2.4 & - & - & & - \\
\hline Guaratingueta & - & - & - & 2.1 & - & & - & - & - & - & - & - & - & 3.7 & - & - & 3.6 & - & - & & - \\
\hline Bananal & - & - & - & - & - & & - & - & - & - & - & - & - & - & - & - & - & - & - & & - \\
\hline Paraibuna/Paraitinga & - & - & - & - & - & & - & - & - & - & - & - & - & 2.9 & - & - & - & - & - & & - \\
\hline Caraguatatuba & - & - & - & - & - & & - & - & - & - & - & - & - & - & - & - & - & - & - & & - \\
\hline Registro & - & - & - & - & - & & - & - & - & - & - & - & - & - & - & - & - & - & - & & - \\
\hline Itanhaem & - & - & - & - & - & & - & - & - & - & - & - & - & - & - & - & - & - & - & & - \\
\hline Osasco & - & - & - & - & - & & - & - & - & - & - & - & - & - & - & - & - & 3.3 & - & & 2.4 \\
\hline Franco da Rocha & - & - & - & - & 3.6 & & - & - & - & - & - & - & - & - & - & - & 2.5 & - & - & & - \\
\hline Guarulhos & 2.7 & - & - & 2.3 & 2.9 & & - & 3.6 & 2.4 & - & - & 3.0 & - & 2.0 & 2.0 & - & 3.0 & - & - & & - \\
\hline Itapecerica da Serra & - & - & - & 3.1 & 2.2 & & - & - & - & - & - & - & - & - & - & - & - & - & - & & 2.3 \\
\hline Sao Paulo & - & - & - & - & - & & - & - & - & - & - & - & - & - & - & - & - & - & - & & - \\
\hline Moji das Cruzes & 2.1 & - & - & - & - & & 2.7 & 2.1 & - & - & 2.4 & - & - & - & - & 2.0 & 4.3 & - & - & & - \\
\hline Santos & - & - & - & - & - & & - & 2.7 & - & - & - & - & - & - & - & - & & - & - & & - \\
\hline
\end{tabular}

Santos

Observações/Filtro: QL $\geq 2$.

FONTE: Elaborado pelo auto com base nos dados da RAIS/MTE 
Anexo XIl. Quociente Locacional para as atividades da indústria de transformação selecionadas - São Paulo/2007.

\begin{tabular}{|c|c|c|c|c|c|c|c|c|c|c|c|c|c|c|c|c|c|c|c|c|c|}
\hline Divisão & 17 & 18 & 19 & 24 & 25 & & 26 & 27 & 28 & 29 & 31 & 32 & 33 & 34 & 35 & 36 & 37 & 72 & & 3 & 74 \\
\hline & 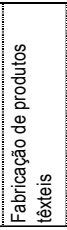 & 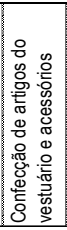 & 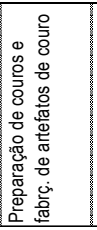 & 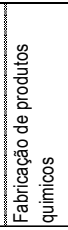 & 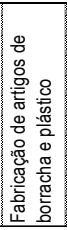 & 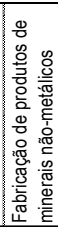 & & 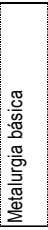 & 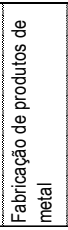 & 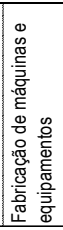 & 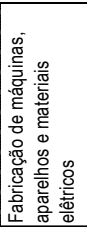 & 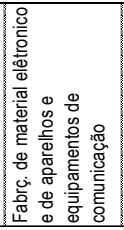 & 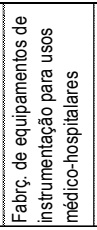 & 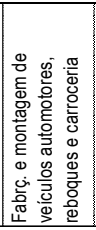 & 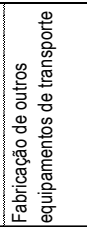 & 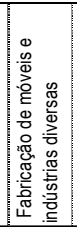 & 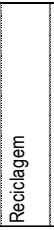 & 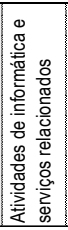 & 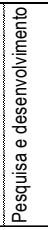 & & 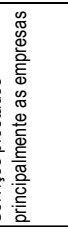 \\
\hline Jales & - & - & 2.5 & - & - & & - & - & - & - & - & - & - & - & - & - & - & - & - & & - \\
\hline Fernandopolis & - & - & - & - & - & & - & - & - & - & - & - & - & - & - & 3.5 & . & - & - & & - \\
\hline Votuporanga & - & - & - & - & - & & - & - & - & - & - & - & - & 3.3 & - & 14.4 & - & - & - & & - \\
\hline Sao Jose do Rio Preto & - & - & - & - & - & & - & - & - & - & - & - & - & - & - & 5.4 & - & - & - & & - \\
\hline Catanduva & - & - & - & - & - & & - & - & - & - & - & - & - & - & - & - & - & - & - & & - \\
\hline Auriflama & - & 13.2 & - & - & - & & - & - & - & - & - & - & - & - & - & 2.9 & - & - & - & & - \\
\hline Nhandeara & - & - & - & - & - & & - & - & - & - & - & - & - & - & - & - & 2.5 & - & - & & - \\
\hline Novo Horizonte & - & 4.6 & - & - & - & & - & - & - & - & - & - & - & - & - & - & - & - & - & & - \\
\hline Barretos & - & - & - & - & - & & - & - & - & - & - & - & - & - & - & - & - & - & - & & - \\
\hline Sao Joaquim da Barra & - & - & - & - & - & & - & 3.2 & - & - & - & - & - & - & - & - & - & - & - & & - \\
\hline Ituverava & - & - & - & - & - & & - & - & - & - & - & - & - & - & - & 2.7 & - & - & - & & - \\
\hline Franca & - & - & 42.5 & - & 2.1 & & - & - & - & - & - & - & - & - & - & - & - & - & - & & - \\
\hline Jaboticabal & - & - & - & - & 2.1 & & - & - & - & - & - & - & - & - & - & - & - & - & - & & - \\
\hline Ribeirao Preto & - & - & - & - & - & & - & - & - & 2.1 & - & - & 3.8 & - & - & - & - & - & - & & - \\
\hline Batatais & - & 2.3 & - & - & - & & - & 3.7 & - & - & - & - & - & - & - & - & - & - & - & & - \\
\hline Andradina & - & - & - & - & - & & - & - & - & - & - & - & - & - & - & - & 3.2 & - & - & & - \\
\hline Aracatuba & - & - & 2.3 & - & - & & - & - & - & - & - & - & - & - & - & - & - & - & - & & - \\
\hline Birigui & - & - & 41.1 & - & - & & - & - & - & - & - & - & - & - & - & 3.9 & - & - & - & & - \\
\hline Lins & - & - & 13.7 & - & - & & - & - & - & - & - & - & - & - & - & - & 8.7 & - & - & & - \\
\hline Bauru & - & - & - & - & - & & - & - & - & - & 2.2 & - & - & - & - & - & - & - & - & & - \\
\hline Jau & - & - & 18.2 & - & - & & - & - & - & - & - & - & 2.3 & - & - & - & - & - & - & & - \\
\hline Avare & - & 2.9 & - & - & - & & - & - & - & - & - & - & - & - & - & - & - & - & - & & - \\
\hline Botucatu & - & 2.4 & - & - & - & & - & - & - & - & - & - & - & 2.8 & 9.8 & - & - & - & 8. & & - \\
\hline Araraquara & 6.3 & - & - & - & - & & - & - & - & 2.8 & - & - & - & - & 4.8 & - & - & - & - & & - \\
\hline Sao Carlos & - & - & - & - & - & & - & - & - & 5.0 & - & - & 3.8 & - & - & 3.2 & - & - & 5. & & - \\
\hline Rio Claro & - & - & - & - & - & & 2.6 & - & - & 2.9 & 20.9 & - & 3.6 & - & - & 4.9 & - & - & - & & - \\
\hline Limeira & - & - & - & - & - & & 6.5 & 2.2 & 2.2 & - & - & - & - & 2.6 & 2.1 & 3.9 & 2.5 & - & - & & - \\
\hline Piracicaba & - & - & - & - & - & & - & - & - & 4.3 & - & - & - & - & - & - & 3.5 & - & - & & - \\
\hline Pirassununga & - & - & - & - & - & & 7.3 & - & - & - & 3.7 & - & 3.6 & - & - & 2.7 & - & - & - & & - \\
\hline Sao Joao da Boa Vista & - & - & - & - & - & & 5.7 & - & - & - & 2.8 & - & - & - & - & - & - & - & - & & - \\
\hline Moji-Mirim & 2.7 & - & - & - & - & & 2.2 & - & - & - & - & - & - & 3.8 & - & 2.3 & - & - & - & & - \\
\hline Campinas & 3.6 & - & - & - & - & & - & - & - & - & - & 4.3 & - & - & - & - & - & - & 6. & & - \\
\hline Amparo & 5.0 & 2.6 & - & 3.0 & - & & - & - & - & - & - & - & - & - & - & - & 2.0 & - & - & & - \\
\hline Dracena & - & - & - & - & - & & 7.0 & - & - & - & - & - & - & - & - & - & - & - & - & & - \\
\hline Adamantina & - & 4.0 & 3.9 & - & - & & - & - & - & - & - & - & - & - & - & 2.1 & - & - & - & & - \\
\hline Presidente Prudente & - & - & 5.4 & - & - & & - & - & - & - & - & - & - & - & - & - & - & - & - & & - \\
\hline Tupa & 3.6 & - & - & - & - & & - & - & - & - & - & - & - & - & - & - & - & - & - & & - \\
\hline Marilia & - & - & - & - & - & & - & - & - & 2.3 & 2.5 & 2.6 & - & - & - & - & - & - & - & & - \\
\hline Assis & - & - & - & - & - & & - & - & - & - & - & - & - & - & - & - & - & - & - & & - \\
\hline Ourinhos & - & 4.8 & - & - & - & & - & - & - & - & - & - & - & - & - & 2.2 & - & - & - & & - \\
\hline Itapeva & - & - & - & - & - & & - & - & - & - & - & - & - & - & - & - & - & - & - & & - \\
\hline Itapetininga & - & 2.9 & - & - & - & & - & - & - & - & - & - & - & - & - & - & - & - & - & & - \\
\hline Tatui & 3.4 & 2.2 & - & - & - & & 4.2 & - & - & - & 4.8 & - & - & - & - & 3.6 & - & - & - & & - \\
\hline Capao Bonito & - & - & - & - & - & & 5.2 & - & - & - & - & - & - & - & - & - & - & - & - & & - \\
\hline Piedade & - & - & - & - & - & & - & - & - & - & - & - & - & - & - & - & - & - & - & & - \\
\hline Sorocaba & - & - & - & - & - & & - & 3.9 & - & 2.5 & - & 2.1 & - & 2.0 & - & - & - & - & - & & - \\
\hline Jundiai & - & - & - & - & 2.5 & & 3.3 & - & 2.0 & - & - & 3.5 & - & 2.5 & - & - & - & 2.0 & - & & - \\
\hline Braganca Paulista & 4.4 & - & - & - & - & & - & - & - & - & 3.9 & - & - & - & - & - & - & - & - & & - \\
\hline Campos do Jordao & - & - & - & - & - & & - & - & - & - & - & - & - & - & - & - & - & - & - & & - \\
\hline Sao Jose dos Campos & - & - & - & - & - & & - & 2.4 & - & - & - & 2.1 & - & 2.9 & 18.5 & - & 2.5 & - & - & & - \\
\hline Guaratingueta & - & - & - & 2.4 & - & & - & 4.1 & - & - & - & - & - & 2.8 & - & - & - & - & - & & - \\
\hline Bananal & - & - & - & - & - & & - & - & - & - & - & - & - & - & - & - & - & - & - & & - \\
\hline Paraibuna/Paraitinga & - & - & - & - & - & & - & - & - & - & - & - & - & 2.8 & - & - & - & - & - & & - \\
\hline Caraguatatuba & - & - & - & - & - & & - & - & - & - & - & - & - & - & - & - & - & - & - & & - \\
\hline Registro & - & - & - & - & - & & - & - & - & - & - & - & - & - & - & - & - & - & - & & - \\
\hline Itanhaem & - & - & - & - & - & & - & - & - & - & - & - & - & - & - & - & - & - & - & & - \\
\hline Osasco & - & - & - & - & - & & - & - & - & - & - & - & - & - & - & - & - & 3.5 & - & & 2.2 \\
\hline Franco da Rocha & - & - & - & - & 3.7 & & - & - & - & - & - & - & - & - & - & - & 3.2 & - & - & & - \\
\hline Guarulhos & 2.9 & - & - & 2.2 & 3.0 & & - & 3.6 & 2.8 & - & - & 2.8 & - & - & - & - & 3.3 & - & - & & - \\
\hline Itapecerica da Serra & - & - & - & 3.3 & 2.1 & & - & - & - & - & - & - & - & - & - & 2.2 & - & - & - & & - \\
\hline Sao Paulo & - & - & - & - & - & & - & - & - & - & - & - & - & - & - & - & - & - & - & & - \\
\hline Moji das Cruzes & 2.2 & - & - & - & - & & 2.6 & 2.2 & - & - & 2.5 & - & - & - & - & 2.4 & 6.6 & - & - & & - \\
\hline Santos & - & - & - & - & - & & - & 2.4 & - & - & - & - & - & - & - & - & & - & - & & - \\
\hline
\end{tabular}

Santos

Observações/Filtro: QL $\geq 2$.

FONTE: Elaborado pelo auto com base nos dados da RAIS/MTE 
Anexo XIII. Quociente Locacional para as atividades da indústria de transformação selecionadas - São Paulo/2008.

\begin{tabular}{|c|c|c|c|c|c|c|c|c|c|c|c|c|c|c|c|c|c|c|c|c|c|}
\hline Divisão & 17 & 18 & 19 & 24 & 25 & & 26 & 27 & 28 & 29 & 31 & 32 & 33 & 34 & 35 & 36 & 37 & 72 & 7 & & 74 \\
\hline & 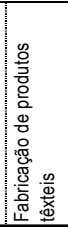 & 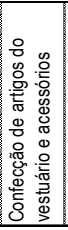 & 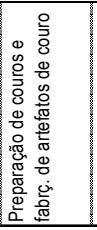 & 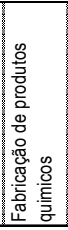 & 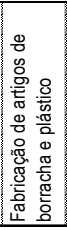 & 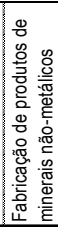 & & 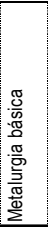 & 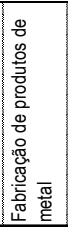 & 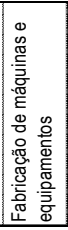 & 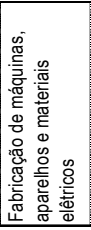 & 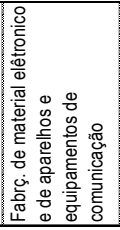 & 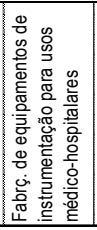 & 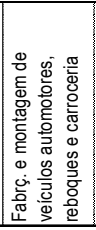 & 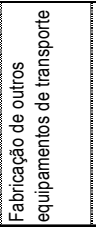 & 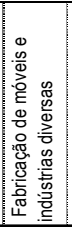 & 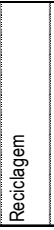 & 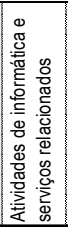 & 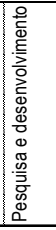 & 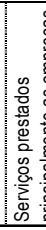 & \\
\hline Jales & - & - & 2.6 & - & - & & - & - & - & - & - & - & - & - & - & - & - & - & - & & - \\
\hline Fernandopolis & - & 2.0 & - & - & - & & - & - & - & - & - & - & - & - & - & 4.1 & - & - & - & & - \\
\hline Votuporanga & - & - & - & - & - & & - & - & - & - & - & - & - & 3.7 & - & 14.3 & - & - & - & & - \\
\hline Sao Jose do Rio Preto & - & - & - & - & - & & - & - & - & - & - & - & - & - & - & 5.0 & - & - & - & & - \\
\hline Catanduva & - & - & - & - & - & & - & - & - & - & - & - & - & - & - & - & - & - & - & & - \\
\hline Auriflama & - & 12.5 & - & - & - & & - & - & - & - & - & - & - & - & - & 2.6 & - & - & - & & - \\
\hline Nhandeara & - & - & 2.3 & - & - & & - & - & - & - & - & - & - & - & - & - & - & - & - & & - \\
\hline Novo Horizonte & - & 5.4 & - & - & - & & - & - & - & - & - & - & - & - & - & 2.8 & - & - & - & & - \\
\hline Barretos & - & - & - & - & - & & - & - & - & - & - & - & - & - & - & - & - & - & - & & - \\
\hline Sao Joaquim da Barra & - & - & - & - & - & & - & 3.3 & - & - & - & - & - & - & - & - & - & - & - & & - \\
\hline Ituverava & - & - & - & - & - & & - & - & - & - & - & - & - & - & - & 2.6 & - & - & - & & - \\
\hline Franca & - & - & 45.4 & - & - & & - & - & - & - & - & - & - & - & - & - & - & - & - & & - \\
\hline Jaboticabal & - & - & - & - & 2.0 & & - & - & - & - & - & - & - & - & - & - & - & - & - & & - \\
\hline Ribeirao Preto & - & - & - & - & - & & - & - & - & 2.1 & - & - & 3.4 & - & - & - & - & - & - & & - \\
\hline Batatais & - & 2.4 & - & - & - & & - & 3.9 & - & 2.3 & - & - & - & - & - & - & - & - & - & & - \\
\hline Andradina & - & - & - & - & - & & - & - & - & - & - & - & - & - & - & - & 2.6 & - & - & & - \\
\hline Aracatuba & - & - & 2.1 & - & - & & - & - & - & - & - & - & - & - & - & - & - & - & - & & - \\
\hline Birigui & - & - & 42.2 & - & - & & - & - & - & - & - & - & - & - & - & 2.7 & - & - & - & & - \\
\hline Lins & - & - & 16.8 & - & - & & - & - & - & - & - & - & - & - & - & - & 6.3 & - & - & & - \\
\hline Bauru & - & - & - & - & - & & - & - & - & - & 2.4 & - & - & - & - & - & - & - & - & & - \\
\hline Jau & - & - & 19.4 & - & - & & - & - & - & - & - & - & 2.3 & - & - & - & - & - & - & & - \\
\hline Avare & - & 2.6 & - & - & - & & - & - & - & - & - & - & - & - & - & - & - & - & - & & - \\
\hline Botucatu & - & 2.0 & - & - & - & & - & - & - & - & - & - & - & 3.3 & 12.7 & - & - & - & 9.6 & & - \\
\hline Araraquara & 7.2 & - & - & - & - & & - & - & - & 3.1 & - & - & - & - & 5.6 & - & - & - & - & & - \\
\hline Sao Carlos & 2.1 & - & - & - & - & & - & - & - & 4.3 & - & - & 3.8 & - & - & 2.8 & - & - & 3.7 & & - \\
\hline Rio Claro & - & - & - & - & 2.4 & & 5.3 & - & - & 3.1 & 2.7 & - & 3.8 & - & - & 6.7 & - & - & - & & - \\
\hline Limeira & - & - & - & - & - & & 7.0 & - & 2.2 & 2.1 & - & - & - & 2.3 & 2.3 & 4.3 & 2.2 & - & - & & - \\
\hline Piracicaba & - & - & - & - & - & & - & - & - & 4.8 & - & - & - & - & - & - & 2.9 & - & 2. & & - \\
\hline Pirassununga & - & - & - & - & - & & 6.8 & - & - & - & 3.3 & - & - & - & - & 2.4 & - & - & - & & - \\
\hline Sao Joao da Boa Vista & - & - & - & - & - & & 5.8 & - & - & - & - & - & - & 2.2 & - & - & - & - & - & & - \\
\hline Moji-Mirim & 2.6 & - & - & - & - & & 2.1 & - & - & - & - & - & - & 3.6 & - & 2.3 & - & - & - & & - \\
\hline Campinas & 3.6 & - & - & - & - & & - & - & - & - & - & 4.2 & - & - & - & - & - & - & 5.2 & & - \\
\hline Amparo & 5.3 & 2.7 & - & 3.2 & - & & - & - & - & - & - & - & - & - & - & - & 2.3 & - & - & & - \\
\hline Dracena & - & - & - & - & - & & 7.5 & - & - & - & - & - & - & - & - & - & - & - & - & & - \\
\hline Adamantina & - & 4.2 & 3.5 & - & - & & - & - & - & - & - & - & - & - & - & 2.1 & - & - & - & & - \\
\hline Presidente Prudente & - & - & 4.1 & - & - & & - & - & - & - & - & - & - & - & - & - & - & - & - & & - \\
\hline Tupa & 3.3 & - & - & - & - & & - & - & - & - & - & - & - & - & - & - & - & - & - & & - \\
\hline Marilia & - & - & - & - & - & & - & - & - & 2.3 & 4.0 & - & - & - & - & - & - & - & - & & - \\
\hline Assis & - & - & - & - & - & & - & - & - & - & - & - & - & - & - & - & - & - & - & & - \\
\hline Ourinhos & - & 4.9 & - & - & - & & - & - & - & - & - & - & - & - & - & 2.0 & - & - & - & & - \\
\hline Itapeva & - & - & - & - & - & & - & - & - & - & - & - & - & - & - & - & - & - & - & & - \\
\hline Itapetininga & - & 3.0 & - & - & - & & - & - & - & - & - & - & - & - & - & - & - & - & - & & - \\
\hline Tatui & 3.6 & 2.2 & - & - & - & & 4.1 & 2.1 & - & - & 6.0 & - & - & - & - & 3.4 & - & - & - & & - \\
\hline Capao Bonito & - & - & - & - & - & & 5.6 & - & - & - & - & - & - & - & - & - & - & - & - & & - \\
\hline Piedade & - & - & - & - & - & & - & - & - & - & - & - & - & - & - & - & - & - & - & & - \\
\hline Sorocaba & - & - & - & - & 2.3 & & - & 3.7 & - & 2.3 & 2.2 & 2.1 & 2.2 & - & - & - & 2.0 & - & - & & - \\
\hline Jundiai & - & - & - & - & 2.5 & & 2.9 & - & 2.2 & - & 2.5 & 4.2 & - & 2.2 & - & - & - & 2.6 & - & & - \\
\hline Braganca Paulista & 4.8 & - & - & - & - & & 2.2 & - & - & - & 4.2 & - & - & - & - & - & - & - & - & & - \\
\hline Campos do Jordao & - & - & - & - & - & & - & - & - & - & - & - & - & - & - & - & - & - & - & & - \\
\hline Sao Jose dos Campos & - & - & - & - & - & & - & 2.4 & - & - & - & 2.7 & - & 2.9 & 17.4 & - & 2.9 & - & - & & - \\
\hline Guaratingueta & - & - & - & 2.2 & - & & - & 3.6 & - & - & - & - & - & 2.6 & - & - & - & - & - & & - \\
\hline Bananal & - & - & - & - & - & & - & - & - & - & - & - & - & - & - & - & - & - & - & & - \\
\hline Paraibuna/Paraitinga & - & - & - & - & - & & - & - & 2.9 & - & - & - & - & 3.0 & - & - & - & - & - & & - \\
\hline Caraguatatuba & - & - & - & - & - & & - & - & - & - & - & - & - & - & - & - & - & - & - & & - \\
\hline Registro & - & - & - & - & - & & - & - & - & - & - & - & - & - & - & - & - & - & - & & - \\
\hline Itanhaem & - & - & - & - & - & & - & - & - & - & - & - & - & - & - & - & - & - & - & & - \\
\hline Osasco & - & - & - & - & - & & - & - & - & - & - & - & - & - & - & - & - & 3.3 & - & & - \\
\hline Franco da Rocha & - & - & - & - & 3.3 & & - & - & - & - & - & - & - & - & - & - & 3.0 & - & - & & - \\
\hline Guarulhos & 2.7 & - & - & 2.5 & 3.0 & & - & 3.5 & 2.5 & - & 2.3 & 2.5 & - & 2.0 & - & - & 3.7 & - & - & & - \\
\hline Itapecerica da Serra & - & - & - & 3.2 & 2.3 & & - & - & - & - & - & - & - & - & - & 2.1 & - & 2.2 & - & & - \\
\hline Sao Paulo & - & - & - & - & - & & - & - & - & - & - & - & - & - & - & - & - & - & - & & - \\
\hline Moji das Cruzes & 2.2 & - & - & - & - & & 2.6 & 2.5 & - & - & 2.5 & - & - & - & - & 2.2 & 6.4 & - & - & & - \\
\hline Santos & - & - & - & - & - & & - & 2.5 & - & - & - & - & - & - & - & - & - & - & - & & - \\
\hline
\end{tabular}

Santos

FONTE: Elaborado pelo auto com base nos dados da RAIS/MTE 
Anexo XIV. Quociente Locacional para as atividades da indústria de transformação selecionadas - São Paulo/2009.

\begin{tabular}{|c|c|c|c|c|c|c|c|c|c|c|c|c|c|c|c|c|c|c|c|c|}
\hline Divisão & 17 & 18 & 19 & 24 & 25 & 26 & $6 \quad 27$ & 28 & 29 & 31 & 3 & 33 & 34 & 35 & 36 & 37 & 72 & 7 & & 74 \\
\hline & 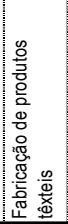 & 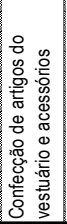 & 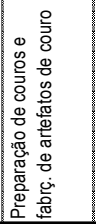 & 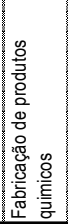 & 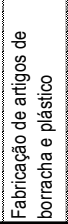 & 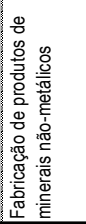 & 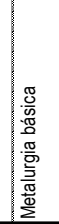 & 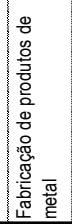 & 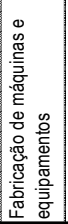 & 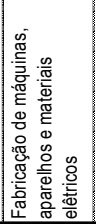 & 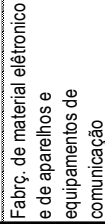 & 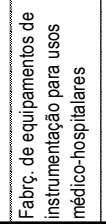 & 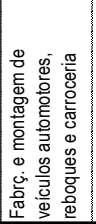 & 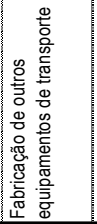 & 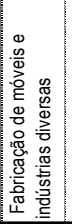 & 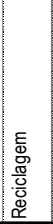 & 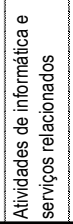 & 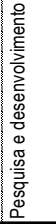 & 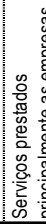 & \\
\hline Jales & - & - & 2.9 & - & - & - & - & - & - & - & - & - & - & - & - & - & - & - & & - \\
\hline Fernandopolis & - & 2.2 & - & - & - & - & - & - & - & - & - & - & - & - & 3.9 & - & - & - & & - \\
\hline Votuporanga & - & - & - & - & - & - & - & - & - & - & - & - & 3.6 & - & 15.2 & - & - & - & & - \\
\hline Sao Jose do Rio Preto & - & - & - & - & - & - & - & - & - & - & - & - & - & - & 4.9 & - & - & - & & . \\
\hline Catanduva & - & - & - & - & - & - & - & - & - & - & - & - & - & - & - & - & - & - & & . \\
\hline Auriflama & - & 13.1 & - & - & - & - & - & - & - & - & - & - & - & - & 2.8 & - & - & - & & . \\
\hline Nhandeara & - & - & - & - & - & - & - & - & - & - & - & - & - & - & - & - & - & - & & - \\
\hline Novo Horizonte & - & 5.4 & - & - & - & - & - & - & - & - & - & - & - & - & 3.2 & - & - & - & & - \\
\hline Barretos & - & - & - & - & - & - & - & - & - & - & - & - & - & - & - & - & - & - & & - \\
\hline Sao Joaquim da Barra & - & - & - & - & - & - & 3.6 & - & - & - & - & - & - & - & - & - & - & - & & - \\
\hline Ituverava & - & - & - & - & - & - & - & - & - & - & - & - & - & - & 3.3 & - & - & - & & - \\
\hline Franca & - & - & 46.5 & - & - & - & - & - & - & - & - & - & - & - & - & - & - & - & & - \\
\hline Jaboticabal & - & - & - & - & 2.0 & - & - & - & - & - & - & - & - & - & - & - & - & - & & - \\
\hline Ribeirao Preto & - & - & - & - & - & - & - & - & 2.0 & - & - & 3.5 & - & - & - & - & - & - & & - \\
\hline Batatais & - & 2.5 & - & - & - & - & 4.6 & - & 2.2 & - & - & - & - & - & - & - & - & - & & - \\
\hline Andradina & - & - & - & - & - & - & - & - & - & - & - & - & - & - & - & 3.5 & - & - & & - \\
\hline Aracatuba & - & - & - & - & - & - & - & - & - & - & - & - & - & - & 2.0 & - & - & - & & - \\
\hline Birigui & - & - & 47.4 & - & - & - & - & - & - & - & - & - & - & - & 3.0 & - & - & - & & - \\
\hline Lins & - & - & 3.4 & 3.9 & - & - & - & - & - & - & - & - & - & - & - & 4.4 & - & - & & - \\
\hline Bauru & - & - & - & - & - & - & - & - & - & 2.3 & - & - & - & - & - & - & - & - & & - \\
\hline Jau & - & - & 20.5 & - & - & - & - & - & - & - & - & 2.3 & - & - & - & - & - & - & & - \\
\hline Avare & - & 2.9 & - & - & - & - & - & - & - & - & - & - & - & - & - & - & - & - & & - \\
\hline Botucatu & - & - & - & - & - & - & - & - & - & - & - & - & 3.4 & 12.4 & - & 2.0 & - & 9.5 & & - \\
\hline Araraquara & 7.4 & - & - & - & - & - & - & - & 3.4 & - & - & - & - & 5.2 & - & - & - & - & & - \\
\hline Sao Carlos & 2.1 & - & - & - & - & - & - & - & 4.5 & - & - & 4.5 & - & - & 2.6 & - & - & 4.6 & & - \\
\hline Rio Claro & - & - & - & - & 2.3 & 4.6 & - & - & 3.5 & 3.1 & - & 3.9 & - & - & 5.7 & - & - & - & & - \\
\hline Limeira & - & - & - & - & - & 6.4 & 2.1 & 2.1 & 2.2 & - & - & - & 2.4 & 2.5 & 4.5 & 2.0 & - & - & & - \\
\hline Piracicaba & - & - & - & - & - & 2.0 & - & - & 4.5 & - & - & - & - & - & - & 2.9 & - & 6.0 & & - \\
\hline Pirassununga & - & - & - & - & - & 7.0 & - & - & - & 3.5 & - & 2.6 & - & - & 2.3 & - & - & - & & - \\
\hline Sao Joao da Boa Vista & - & - & - & - & - & 5.9 & - & - & - & - & - & - & - & - & - & - & - & - & & - \\
\hline Moji-Mirim & 2.4 & - & - & - & - & - & - & - & - & - & - & - & 3.8 & 2.3 & 2.2 & - & - & - & & - \\
\hline Campinas & 3.6 & - & - & - & - & - & - & - & - & - & 3. & - & - & - & - & - & - & 5.4 & & - \\
\hline Amparo & 6.2 & 3.0 & - & 3.5 & - & - & - & - & - & - & - & - & - & - & - & 2.9 & - & - & & - \\
\hline Dracena & - & - & - & - & - & 6.9 & - & - & - & - & - & - & - & - & - & - & - & - & & - \\
\hline Adamantina & - & 3.7 & 3.8 & - & - & - & - & - & - & - & - & - & - & - & 2.2 & - & - & - & & - \\
\hline Presidente Prudente & - & - & 4.9 & - & - & - & - & - & - & - & - & - & - & - & - & - & - & - & & - \\
\hline Tupa & 2.5 & - & - & - & - & - & - & - & - & - & - & - & - & - & - & - & - & - & & - \\
\hline Marilia & - & - & - & - & - & - & - & - & 2.4 & 4.1 & - & - & - & - & - & - & - & - & & - \\
\hline Assis & - & - & - & - & - & - & - & - & - & - & - & - & - & - & - & - & - & - & & - \\
\hline Ourinhos & - & 5.0 & - & - & - & - & - & - & - & - & - & - & - & - & 2.5 & - & - & - & & - \\
\hline Itapeva & - & - & - & - & - & - & - & - & - & - & - & - & - & - & - & 2.1 & - & - & & - \\
\hline Itapetininga & - & 3.1 & - & - & - & - & - & - & - & - & - & - & - & - & - & - & - & - & & - \\
\hline Tatui & 4.1 & 2.1 & - & - & - & 4.9 & 2.7 & - & - & 5.7 & - & - & - & - & 3.9 & - & - & - & & - \\
\hline Capao Bonito & - & - & - & - & - & 5.7 & - & - & - & - & - & - & - & - & - & - & - & - & & - \\
\hline Piedade & - & - & - & - & - & - & - & - & - & - & - & 5.3 & - & - & - & 5.6 & - & - & & - \\
\hline Sorocaba & - & - & - & - & 2.4 & - & 3.9 & - & 2.1 & 2.3 & 2. & - & 2.0 & - & - & - & - & - & & - \\
\hline Jundiai & - & - & - & - & 2.6 & 2.7 & - & - & - & 2.2 & 3.5 & - & 2.1 & - & - & - & 2.8 & - & & - \\
\hline Braganca Paulista & 3.8 & - & - & - & - & 2.0 & - & - & - & 4.9 & - & - & - & - & - & - & - & - & & - \\
\hline Campos do Jordao & - & - & - & - & - & - & - & - & - & - & - & - & - & - & - & - & - & - & & - \\
\hline Sao Jose dos Campos & - & - & - & - & - & - & 2.6 & - & - & - & 3.2 & - & 3.2 & 14.5 & - & 2.1 & - & - & & - \\
\hline Guaratingueta & - & - & - & 2.3 & - & - & 3.2 & - & - & - & - & - & 2.5 & - & - & - & - & - & & - \\
\hline Bananal & - & - & - & - & - & - & - & - & - & - & - & - & - & - & - & - & - & - & & - \\
\hline Paraibuna/Paraitinga & - & - & - & - & - & - & - & 3.6 & - & - & - & - & 2.8 & - & - & - & - & - & & - \\
\hline Caraguatatuba & - & - & - & - & - & - & - & - & - & - & - & - & - & - & - & - & - & - & & - \\
\hline Registro & - & - & - & - & - & - & - & - & - & - & - & - & - & - & - & - & - & - & & - \\
\hline Itanhaem & - & - & - & - & - & - & - & - & - & - & - & - & - & - & - & - & - & - & & - \\
\hline Osasco & - & - & - & - & - & - & - & - & - & - & - & - & - & - & - & - & 3.1 & - & & - \\
\hline Franco da Rocha & 2.0 & - & - & - & 3.6 & - & - & - & - & - & 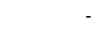 & - & - & - & - & 3.3 & - & - & & - \\
\hline Guarulhos & 2.8 & - & - & 2.5 & 3.1 & - & 3.8 & 2.5 & - & 2.2 & 2. & - & - & - & - & 3.9 & - & - & & - \\
\hline Itapecerica da Serra & - & - & - & 3.1 & 2.4 & - & - & - & - & - & 2.2 & - & - & - & - & - & - & - & & - \\
\hline Sao Paulo & - & - & - & - & - & - & - & - & - & - & - & - & - & - & - & - & - & - & & - \\
\hline Moji das Cruzes & 2.3 & - & - & - & - & 2.6 & 2.5 & - & - & 2.8 & - & - & - & - & - & 6.1 & - & - & & - \\
\hline Santos & - & - & - & - & - & - & 2.3 & - & . & - & - & - & - & - & - & - & - & - & & - \\
\hline
\end{tabular}

Sbstos

FONTE: Elaborado pelo auto com base nos dados da RAIS/MTE 
Anexo XV. Quociente Locacional para as atividades da indústria de transformação selecionadas - São Paulo/2010.

\begin{tabular}{|c|c|c|c|c|c|c|c|c|c|c|c|c|c|c|c|c|c|c|c|c|c|}
\hline Divisão & 17 & 18 & 19 & 24 & 25 & & 26 & 27 & 28 & 29 & 31 & 32 & 33 & 34 & 35 & 36 & 37 & 72 & 7 & & 74 \\
\hline & 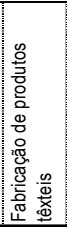 & 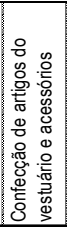 & 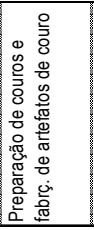 & 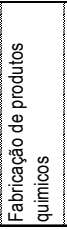 & 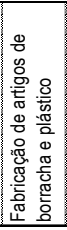 & 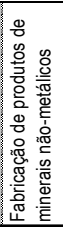 & & 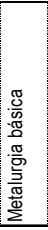 & 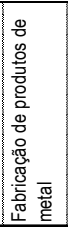 & 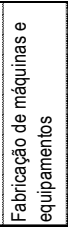 & 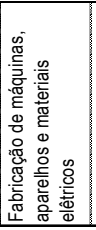 & 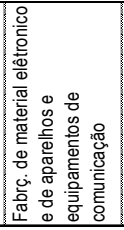 & 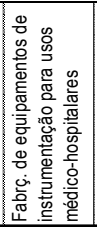 & 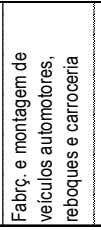 & 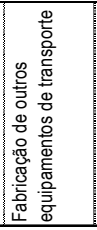 & 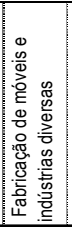 & 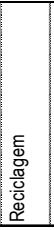 & 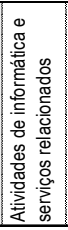 & 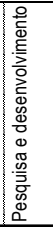 & 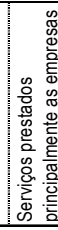 & \\
\hline Jales & - & - & 2.6 & - & - & - & - & - & - & - & - & - & - & - & - & - & - & - & - & & - \\
\hline Fernandopolis & - & 2.5 & - & - & - & . & . & - & - & - & - & - & - & - & - & 4.2 & - & - & - & & - \\
\hline Votuporanga & - & - & - & - & - & . & - & - & - & - & - & - & - & 3.8 & - & 15.4 & - & - & - & & - \\
\hline Sao Jose do Rio Preto & - & - & - & - & - & . & . & - & - & - & - & - & - & - & - & 4.9 & - & - & - & & - \\
\hline Catanduva & - & - & - & - & - & . & . & - & - & 2.8 & - & - & - & - & - & - & - & - & - & & - \\
\hline Auriflama & - & 13.9 & - & - & - & . & . & - & - & - & - & - & - & - & - & 3.3 & - & - & - & & - \\
\hline Nhandeara & - & - & - & 7.7 & - & . & - & - & - & - & - & - & - & - & - & - & - & - & - & & - \\
\hline Novo Horizonte & - & 6.0 & - & 2.0 & - & . & . & - & - & - & - & - & - & - & - & 3.5 & - & - & - & & - \\
\hline Barretos & - & - & - & - & - & . & - & - & - & - & - & - & - & - & - & - & - & - & - & & - \\
\hline Sao Joaquim da Barra & - & - & - & 2.8 & - & . & - & 3.6 & - & - & - & - & - & - & - & - & - & - & - & & - \\
\hline Ituverava & - & - & - & - & - & . & - & - & - & - & - & - & - & - & - & 3.0 & - & - & - & & - \\
\hline Franca & - & - & 49.5 & - & - & . & - & - & - & - & - & - & - & - & - & - & - & - & - & & - \\
\hline Jaboticabal & - & - & - & - & 2.4 & . & - & - & - & - & - & - & - & - & - & - & - & - & - & & - \\
\hline Ribeirao Preto & - & - & - & - & - & . & - & - & - & - & - & - & 3.2 & - & - & - & - & - & - & & - \\
\hline Batatais & - & 2.7 & - & 4.4 & - & . & - & 4.9 & - & 2.4 & - & - & - & - & - & - & - & - & - & & - \\
\hline Andradina & - & - & - & 2.3 & - & . & - & - & - & - & - & - & - & - & - & - & 3.3 & - & - & & - \\
\hline Aracatuba & - & - & 2.1 & - & - & . & - & - & - & - & - & - & - & - & - & 2.7 & - & - & - & & - \\
\hline Birigui & - & - & 45.7 & - & - & . & - & - & - & - & - & - & - & - & - & 2.9 & - & - & - & & - \\
\hline Lins & - & - & 5.7 & 5.3 & - & . & - & - & - & - & - & - & - & - & - & - & 3.7 & - & - & & - \\
\hline Bauru & - & - & - & - & - & . & - & - & - & - & 2.3 & - & - & - & - & - & - & - & - & & - \\
\hline Jau & - & - & 20.5 & - & - & . & - & - & - & - & - & - & 2.1 & - & - & 2.4 & - & - & - & & - \\
\hline Avare & - & 3.5 & - & - & - & . & - & - & - & - & - & - & - & - & - & - & - & - & - & & - \\
\hline Botucatu & - & - & - & - & - & . & - & - & - & - & - & - & - & 3.7 & 11.9 & - & - & - & 4. & & - \\
\hline Araraquara & 8.3 & - & - & - & - & . & - & - & - & 3.0 & - & - & - & - & 5.0 & - & - & - & - & & - \\
\hline Sao Carlos & - & - & - & - & - & . & - & - & - & 4.5 & - & - & 4.7 & - & - & 2.4 & - & - & 4.8 & & - \\
\hline Rio Claro & - & - & - & - & 2.6 & & 5.2 & - & - & 3.7 & 2.9 & - & 4.1 & - & - & 5.6 & - & - & - & & - \\
\hline Limeira & - & - & - & - & - & & 6.2 & 2.4 & 2.1 & 2.3 & - & - & - & 2.4 & 3.0 & 4.2 & 2.2 & - & - & & - \\
\hline Piracicaba & 2.1 & - & - & - & - & & 2.1 & - & - & 4.9 & - & - & - & - & - & - & 3.4 & - & 6. & & - \\
\hline Pirassununga & - & - & - & - & - & & 7.3 & - & - & - & 4.1 & - & 3.7 & - & - & 2.3 & - & - & - & & - \\
\hline Sao Joao da Boa Vista & - & - & - & - & - & & 5.7 & - & - & - & - & - & - & - & - & - & - & - & - & & - \\
\hline Moji-Mirim & 2.2 & - & - & - & - & & - & - & - & - & - & - & - & 4.1 & 2.3 & 2.3 & - & - & - & & - \\
\hline Campinas & 3.6 & - & - & - & - & . & - & - & - & - & - & 4.0 & - & - & - & - & - & - & 5. & & - \\
\hline Amparo & 6.4 & 3.2 & - & 3.2 & - & & - & - & - & - & - & - & 2.3 & - & - & - & - & - & - & & - \\
\hline Dracena & - & - & - & 4.8 & - & & 7.1 & - & - & - & - & - & - & - & - & - & - & - & - & & - \\
\hline Adamantina & - & 4.1 & 3.2 & 3.5 & - & . & - & - & - & - & - & - & - & - & - & 2.8 & - & - & - & & - \\
\hline Presidente Prudente & - & - & 2.9 & 2.1 & - & . & - & - & - & - & - & - & - & - & - & - & - & - & - & & - \\
\hline Tupa & 2.5 & - & - & - & - & . & - & - & - & - & - & - & - & - & - & - & - & - & - & & - \\
\hline Marilia & - & - & - & - & - & . & - & - & - & 2.2 & 4.2 & - & - & - & - & - & - & - & - & & - \\
\hline Assis & - & - & - & - & - & . & - & - & - & - & - & - & - & - & - & - & - & - & - & & - \\
\hline Ourinhos & - & 5.6 & - & - & - & . & - & - & - & - & - & - & - & - & - & 2.1 & - & - & - & & - \\
\hline Itapeva & - & - & - & - & - & . & - & - & - & - & - & - & - & - & - & - & 3.0 & - & - & & - \\
\hline Itapetininga & - & 3.4 & - & - & - & . & - & - & - & - & - & - & - & - & - & - & - & - & - & & - \\
\hline Tatui & 4.2 & 2.1 & - & - & - & & 4.5 & 2.9 & - & - & 5.8 & - & - & - & - & 4.1 & - & - & - & & - \\
\hline Capao Bonito & - & - & - & - & - & & 5.3 & - & - & - & - & - & - & - & - & - & - & - & - & & - \\
\hline Piedade & - & - & - & - & - & . & - & - & - & - & - & - & 5.7 & - & - & - & 4.7 & - & - & & - \\
\hline Sorocaba & - & - & - & - & 2.4 & & - & 3.6 & - & 2.1 & 2.4 & - & - & - & - & - & - & - & - & & - \\
\hline Jundiai & - & - & - & - & 2.6 & & 2.6 & - & - & - & 2.0 & - & - & 2.1 & - & - & - & 2.7 & - & & - \\
\hline Braganca Paulista & 4.4 & - & - & - & - & & 2.1 & - & - & - & 4.7 & - & - & - & - & - & - & - & - & & - \\
\hline Campos do Jordao & - & - & - & - & - & & - & - & - & - & - & - & - & - & - & - & - & - & - & & - \\
\hline Sao Jose dos Campos & - & - & - & - & - & & - & 2.4 & - & - & - & 3.7 & - & 3.0 & 13.7 & - & 2.7 & - & - & & - \\
\hline Guaratingueta & - & - & - & 2.1 & - & . & - & 4.0 & - & - & - & - & - & 2.8 & - & - & - & - & - & & - \\
\hline Bananal & - & - & - & - & - & . & - & - & - & - & - & - & - & - & - & - & - & - & - & & - \\
\hline Paraibuna/Paraitinga & - & - & - & - & - & & - & - & 3.6 & - & - & - & - & 2.6 & - & - & - & - & - & & - \\
\hline Caraguatatuba & - & - & - & - & - & . & - & - & - & - & - & - & - & - & - & - & - & - & - & & - \\
\hline Registro & - & - & - & - & - & . & - & - & - & - & - & - & - & - & - & - & - & - & - & & - \\
\hline Itanhaem & - & - & - & - & - & & - & - & - & - & - & - & - & - & - & - & - & - & - & & - \\
\hline Osasco & - & - & - & - & - & . & - & - & - & - & - & - & - & - & - & - & - & 3.2 & - & & \\
\hline Franco da Rocha & - & - & - & - & 3.2 & & - & - & - & - & - & - & - & - & - & - & 2.8 & - & - & & - \\
\hline Guarulhos & 2.6 & - & - & 2.1 & 3.0 & & - & 3.5 & 2.4 & - & 2.1 & - & - & - & - & - & 3.4 & - & - & & - \\
\hline Itapecerica da Serra & - & - & - & 2.5 & 2.4 & . & - & - & - & - & - & 2.7 & - & - & - & - & - & - & - & & - \\
\hline Sao Paulo & - & - & - & - & - & & - & - & - & - & - & - & - & - & - & - & - & - & - & & - \\
\hline Moji das Cruzes & 2.1 & - & - & - & - & & 2.5 & 2.4 & - & - & 2.9 & - & - & - & - & - & 6.0 & - & - & & - \\
\hline Santos & - & - & - & - & . & & - & 2.3 & - & . & - & - & - & - & - & - & - & - & - & & - \\
\hline
\end{tabular}

Santos

FONTE: Elaborado pelo auto com base nos dados da RAIS/MTE 
Anexo XVI. Coeficiente de concentração para as atividades da indústria de transformação selecionadas - São Paulo/1996.

\begin{tabular}{|c|c|c|c|c|c|c|c|c|c|c|c|c|c|c|c|c|c|c|c|c|}
\hline Divisão & 17 & 18 & 19 & 24 & 25 & 26 & 27 & 28 & 29 & 31 & 32 & 33 & 34 & 35 & 36 & 37 & 71 & 72 & & 74 \\
\hline & 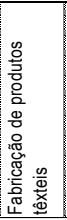 & 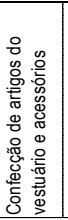 & 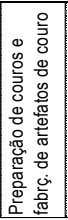 & 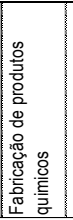 & 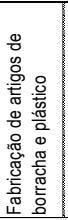 & 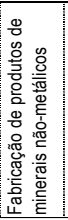 & 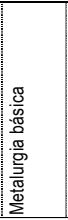 & 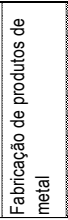 & 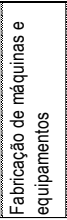 & 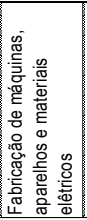 & 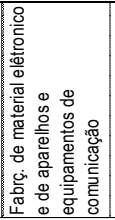 & 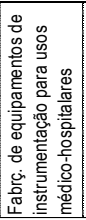 & 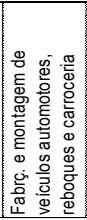 & 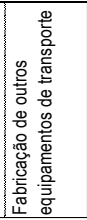 & 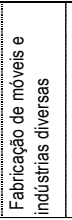 & 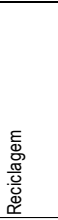 & 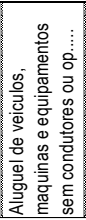 & 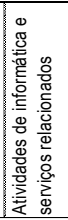 & 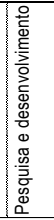 & 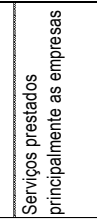 \\
\hline Jales & - & - & - & - & - & - & - & - & - & - & - & - & - & - & 0.02 & - & - & - & - & 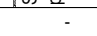 \\
\hline Fernandopolis & - & 0.03 & 0.02 & - & - & - & - & - & - & 0.03 & - & - & 0.01 & - & 0.03 & - & - & - & - & 0.01 \\
\hline Votuporanga & - & 0.02 & - & - & - & - & - & - & - & - & - & - & 0.04 & 0.01 & 0.16 & - & - & - & - & 0.01 \\
\hline Sao Jose do Rio Preto & - & 0.03 & - & - & - & - & - & 0.03 & & - & - & - & - & - & 0.05 & - & - & - & - & 0.03 \\
\hline Catanduva & - & 0.01 & - & - & - & - & - & 0.01 & 0.03 & - & - & - & - & - & - & - & - & - & - & 0.02 \\
\hline Auriflama & - & 0.14 & - & - & 0.03 & - & - & - & - & - & - & - & - & - & 0.02 & - & - & - & - & - \\
\hline Nhandeara & - & 0.02 & 0.05 & - & - & - & 0.01 & 0.04 & - & - & - & - & - & - & 0.02 & - & - & - & - & - \\
\hline Novo Horizonte & - & 0.03 & - & - & - & - & - & - & 0.05 & - & - & - & - & - & - & - & - & - & - & - \\
\hline Barretos & - & - & - & - & - & - & - & - & - & & - & - & - & - & - & - & - & - & - & 0.02 \\
\hline Sao Joaquim da Barra & - & - & - & - & - & - & - & 0.05 & - & 0.01 & - & - & - & - & - & - & - & - & - & 0.04 \\
\hline Ituverava & 0.02 & - & - & 0.02 & - & - & - & - & - & - & - & - & - & - & 0.02 & - & - & - & - & 0.01 \\
\hline Franca & - & - & 0.35 & - & 0.03 & - & - & - & - & - & - & - & - & - & - & - & - & - & - & 0.02 \\
\hline Jaboticabal & - & - & - & & 0.03 & 0.02 & 0.02 & - & 0.03 & & - & & 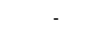 & - & - & - & - & - & - & 0.02 \\
\hline Ribeirao Preto & - & - & - & 0.02 & - & - & - & - & 0.02 & - & - & 0.01 & - & - & - & - & - & - & - & 0.05 \\
\hline Batatais & - & 0.03 & - & - & - & - & 0.02 & - & 0.05 & - & - & - & 0.01 & - & - & - & - & - & - & 0.03 \\
\hline Andradina & - & - & - & - & - & - & - & - & - & - & - & - & - & - & - & - & - & - & - & 0.05 \\
\hline Aracatuba & - & 0.01 & 0.01 & - & - & - & - & - & 0.02 & - & - & - & - & - & 0.02 & - & - & - & - & 0.03 \\
\hline Birigui & - & 0.01 & 0.30 & - & 0.02 & 0.01 & - & 0.02 & - & - & - & - & - & - & 0.04 & - & - & - & - & 0.04 \\
\hline Lins & - & - & 0.05 & - & - & - & - & - & - & - & - & - & - & - & - & - & - & - & - & 0.01 \\
\hline Bauru & 0.01 & - & - & - & 0.01 & - & - & - & - & 0.01 & - & - & - & - & - & - & - & - & - & 0.07 \\
\hline Jau & 0.03 & - & 0.07 & - & - & 0.03 & - & - & 0.01 & - & - & - & - & - & 0.01 & - & - & - & - & 0.03 \\
\hline Avare & - & 0.04 & - & - & - & 0.01 & - & - & - & 0.01 & - & - & - & - & - & - & - & - & - & 0.02 \\
\hline Botucatu & - & 0.03 & - & - & 0.02 & 0.01 & - & - & - & - & - & - & 0.06 & - & - & - & - & - & - & 0.02 \\
\hline Araraquara & 0.04 & 0.02 & - & - & - & - & - & 0.01 & 0.05 & - & - & - & - & - & - & - & - & - & - & 0.04 \\
\hline Sao Carlos & 0.03 & - & - & - & 0.02 & - & - & 0.02 & 0.15 & - & - & - & 0.01 & - & 0.05 & - & - & - & - & 0.05 \\
\hline Rio Claro & - & 0.02 & - & 0.02 & 0.05 & 0.04 & - & 0.03 & 0.03 & 0.02 & - & - & - & - & 0.02 & - & - & - & - & 0.04 \\
\hline Limeira & - & 0.01 & - & - & 0.01 & 0.06 & 0.01 & 0.02 & 0.05 & - & - & - & 0.04 & - & 0.04 & - & - & - & - & 0.02 \\
\hline Piracicaba & 0.02 & 0.03 & - & - & - & 0.02 & 0.02 & 0.02 & 0.06 & 0.01 & - & - & 0.01 & - & - & - & - & - & - & 0.06 \\
\hline Pirassununga & - & 0.01 & 0.02 & - & - & 0.11 & - & - & - & 0.03 & - & - & - & - & 0.02 & - & - & - & - & 0.02 \\
\hline Sao Joao da Boa Vista & - & 0.02 & - & - & - & 0.05 & - & 0.02 & 0.02 & - & - & - & - & - & - & - & - & - & - & 0.02 \\
\hline Moji-Mirim & 0.03 & 0.01 & 0.02 & 0.02 & - & 0.04 & - & 0.02 & 0.03 & & - & - & 0.05 & - & 0.03 & - & - & - & - & 0.03 \\
\hline Campinas & 0.06 & 0.02 & - & 0.04 & 0.02 & 0.02 & 0.01 & 0.02 & 0.03 & 0.02 & - & - & 0.04 & - & - & - & - & - & - & 0.06 \\
\hline Amparo & 0.05 & 0.01 & - & 0.03 & - & 0.01 & - & 0.02 & 0.02 & - & - & - & 0.02 & - & - & - & - & - & - & 0.11 \\
\hline Dracena & - & 0.01 & - & - & - & 0.06 & - & - & 0.01 & - & - & - & - & - & 0.02 & - & - & - & - & 0.03 \\
\hline Adamantina & - & 0.03 & - & - & - & - & - & - & - & - & - & - & - & - & 0.02 & - & - & - & - & 0.08 \\
\hline Presidente Prudente & - & - & 0.01 & - & - & - & - & 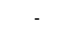 & 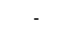 & - & - & 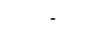 & - & - & - & - & - & - & - & 0.04 \\
\hline Tupa & 0.09 & - & - & - & - & - & - & - & 0.02 & - & - & - & - & - & 0.04 & - & - & - & - & 0.04 \\
\hline Marilia & - & - & - & - & 0.02 & - & - & 0.04 & 0.03 & - & - & - & - & - & 0.01 & - & - & - & - & 0.03 \\
\hline Assis & - & - & - & - & - & - & - & - & - & - & - & - & - & - & - & - & - & - & - & 0.02 \\
\hline Ourinhos & - & 0.04 & 0.02 & - & - & 0.02 & 0.01 & - & 0.01 & - & - & - & - & - & 0.01 & - & - & - & & 0.02 \\
\hline Itapeva & - & - & - & - & - & 0.06 & - & - & 0.01 & - & - & - & - & - & - & - & - & - & - & 0.03 \\
\hline Itapetininga & 0.03 & 0.03 & - & 0.03 & - & - & - & - & - & & - & - & - & - & - & - & - & - & - & 0.02 \\
\hline Tatui & 0.05 & 0.03 & - & 0.01 & 0.04 & 0.07 & - & 0.03 & - & 0.04 & - & - & 0.02 & - & 0.02 & - & - & - & - & 0.08 \\
\hline Capao Bonito & - & - & - & - & - & 0.09 & - & - & - & & - & 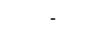 & & - & - & - & - & - & - & 0.02 \\
\hline Piedade & - & - & 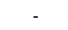 & - & - & & - & - & - & & - & - & 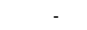 & - & - & - & - & - & - & 0.65 \\
\hline Sorocaba & 0.03 & 0.03 & 0.01 & 0.02 & 0.03 & 0.03 & 0.02 & 0.03 & 0.03 & 0.02 & 0.02 & - & 0.04 & - & 0.02 & - & - & - & - & 0.04 \\
\hline Jundiai & 0.04 & - & 0.01 & 0.03 & 0.05 & 0.04 & - & 0.08 & 0.02 & 0.01 & - & - & 0.02 & - & - & - & - & - & - & 0.06 \\
\hline Braganca $P$ & 0.06 & 0.02 & - & 0.01 & - & - & - & 0.01 & 0.01 & 0.02 & - & - & 0.01 & - & 0.01 & - & - & - & - & 0.23 \\
\hline Campos do Jordao & 0.02 & - & - & 0.05 & 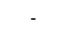 & 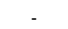 & & & 0.01 & & - & & & 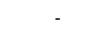 & - & - & - & - & - & 0.02 \\
\hline Sao Jose do & 0.03 & - & - & 0.03 & 0.01 & - & 0.02 & 0.02 & 0.02 & 0.01 & 0.03 & - & 0.11 & 0.02 & - & - & - & - & - & 0.08 \\
\hline Guaratingueta & - & - & - & 0.06 & 0.02 & 0.01 & - & 0.01 & - & - & - & - & 0.04 & - & - & - & - & - & - & 0.03 \\
\hline Bananal & - & - & - & - & - & - & - & - & - & - & - & - & - & - & - & - & - & - & - & - \\
\hline Paraibun & 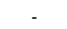 & - & - & - & - & - & - & - & - & - & - & - & - & - & - & - & - & - & - & 0.08 \\
\hline Caraguatatuba & 0.01 & - & - & - & - & 0.01 & - & 0.01 & - & - & - & - & - & - & - & - & . & - & . & 0.03 \\
\hline Registro & - & - & - & 0.03 & - & - & - & - & - & - & - & - & - & - & - & - & - & - & - & 0.04 \\
\hline Itanhaem & - & - & - & - & - & 0.02 & 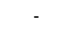 & - & - & - & - & - & - & - & - & - & - & - & - & 0.02 \\
\hline Osasco & - & 0.01 & - & 0.03 & 0.04 & - & 0.01 & 0.02 & 0.02 & 0.02 & - & - & 0.01 & - & 0.01 & - & - & 0.01 & - & 0.22 \\
\hline Franco da Rc & 0.02 & - & 0.02 & 0.02 & 0.06 & 0.01 & 0.02 & 0.02 & 0.03 & & 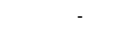 & - & 0.02 & - & 0.03 & - & - & - & - & 0.04 \\
\hline Guarulhos & 0.04 & 0.01 & - & 0.03 & 0.05 & 0.02 & 0.03 & 0.05 & 0.04 & 0.02 & 0.01 & - & 0.07 & - & 0.01 & - & - & - & - & 0.05 \\
\hline Itapecerica da Serra & 0.01 & 0.02 & - & 0.06 & 0.04 & - & 0.01 & 0.03 & 0.02 & 0.02 & - & - & 0.02 & - & 0.02 & - & - & - & - & 0.30 \\
\hline Sao Paulo & 0.01 & 0.02 & - & 0.02 & 0.02 & - & - & 0.02 & 0.02 & - & - & - & 0.03 & - & - & - & - & - & - & 0.08 \\
\hline Moji das Cruzes & 0.04 & - & 0.01 & 0.04 & 0.03 & 0.03 & 0.03 & 0.04 & 0.05 & 0.02 & - & - & - & - & 0.03 & - & - & - & - & 0.10 \\
\hline Santos & - & - & - & 0.02 & - & - & 0.03 & - & - & - & - & - & - & - & - & - & - & - & - & 0.08 \\
\hline
\end{tabular}

Observações/Filtro: $C C \geq 0,01$ (ou, $1 \%$ ).

FONTE: Elaborado pelo auto com base nos dados da RAIS/MTE 
Anexo XVII. Coeficiente de concentração para as atividades da indústria de transformação selecionadas - São Paulo/1997.

\begin{tabular}{|c|c|c|c|c|c|c|c|c|c|c|c|c|c|c|c|c|c|c|c|c|}
\hline Divisão & 17 & 18 & 19 & 24 & 25 & 26 & 27 & 28 & 29 & 31 & 32 & 33 & 34 & 35 & 36 & 37 & 71 & 72 & 7 & 74 \\
\hline & 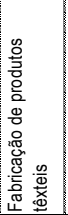 & 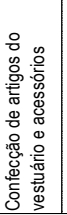 & 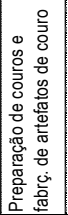 & 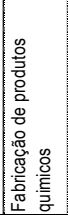 & 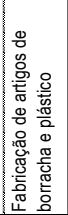 & 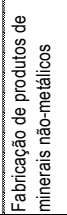 & 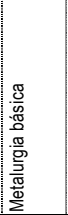 & 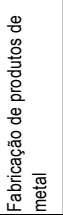 & 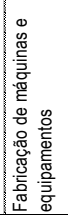 & 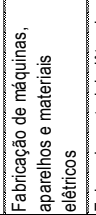 & 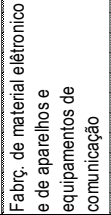 & 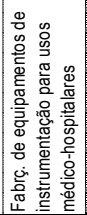 & 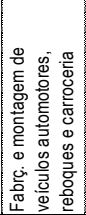 & 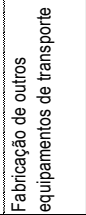 & 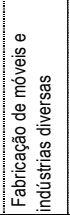 & 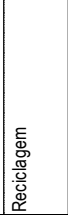 & 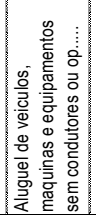 & 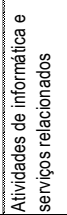 & 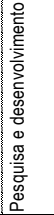 & 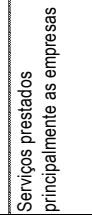 \\
\hline $\begin{array}{l}\text { Jales } \\
\end{array}$ & - & - & 0.02 & - & - & - & - & - & - & - & - & - & - & - & 0.02 & - & - & - & - & - \\
\hline Fernandopolis & - & 0.03 & 0.01 & - & - & - & - & 0.01 & - & 0.02 & - & - & 0.01 & - & 0.03 & - & - & - & - & 0.01 \\
\hline Votuporanga & - & 0.03 & - & - & - & - & - & - & - & - & - & - & 0.05 & 0.01 & 0.17 & - & - & - & - & 0.01 \\
\hline Sao Jose do Rio Preto & - & 0.03 & - & - & - & - & - & 0.03 & - & - & - & - & - & - & 0.05 & - & - & - & - & 0.03 \\
\hline Catanduva & - & 0.01 & - & - & - & - & - & 0.01 & 0.03 & - & - & - & - & - & 0.01 & - & - & - & - & 0.02 \\
\hline Auriflama & - & 0.15 & - & & - & - & - & - & - & - & - & - & - & - & 0.02 & - & - & - & - & - \\
\hline Nhandeara & - & 0.03 & 0.04 & 0.01 & - & - & - & 0.04 & 0.01 & - & - & - & - & - & 0.02 & - & - & - & - & 0.01 \\
\hline Novo Horizonte & - & 0.04 & - & - & - & - & - & - & 0.04 & - & - & - & - & - & - & - & - & - & - & - \\
\hline Barretos & - & - & 0.01 & - & - & - & - & - & - & . & - & - & - & - & - & - & - & - & - & 0.03 \\
\hline Sao Joaquim da Barra & - & - & - & - & - & - & - & 0.04 & 0.01 & 0.01 & - & - & - & - & - & - & - & - & - & 0.04 \\
\hline Ituverava & 0.02 & - & - & 0.02 & - & - & - & - & 0.01 & - & - & - & - & - & 0.03 & - & - & - & - & 0.03 \\
\hline Franca & - & - & 0.30 & - & 0.04 & - & - & - & - & - & - & - & - & - & - & - & - & - & - & 0.02 \\
\hline Jaboticabal & - & - & - & & 0.02 & 0.01 & 0.03 & - & 0.03 & - & - & - & - & - & - & - & 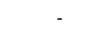 & - & - & 0.03 \\
\hline Ribeirao Preto & - & - & - & 0.02 & - & - & - & - & 0.02 & - & - & 0.01 & - & - & - & - & - & - & - & 0.05 \\
\hline Batatais & - & 0.03 & - & - & - & - & 0.02 & 0.01 & 0.05 & - & - & - & 0.02 & - & 0.01 & - & - & - & - & 0.02 \\
\hline Andradina & - & - & - & - & - & - & - & - & - & - & - & - & - & - & - & - & - & - & - & 0.02 \\
\hline Aracatuba & - & 0.01 & 0.01 & - & - & 0.01 & - & - & 0.02 & - & - & - & - & - & 0.02 & - & - & - & - & 0.03 \\
\hline Birigui & - & 0.01 & 0.25 & - & 0.01 & 0.02 & - & - & - & - & - & - & - & - & 0.04 & - & - & - & - & 0.03 \\
\hline Lins & - & - & 0.07 & - & - & - & - & 0.01 & - & - & - & - & - & - & - & - & - & - & - & 0.01 \\
\hline Bauru & 0.01 & - & - & - & - & - & - & - & - & 0.01 & - & - & - & - & - & - & - & - & - & 0.08 \\
\hline Jau & 0.02 & - & 0.08 & - & - & 0.03 & - & - & - & - & - & - & - & - & 0.01 & - & - & - & - & 0.04 \\
\hline Avare & - & 0.03 & - & - & 0.01 & 0.01 & - & - & - & 0.01 & - & - & 0.01 & - & - & - & - & - & - & 0.02 \\
\hline Botucatu & 0.04 & 0.02 & - & - & 0.02 & 0.01 & - & - & - & - & - & - & 0.05 & - & - & - & - & - & - & 0.02 \\
\hline Araraquara & 0.04 & 0.02 & - & - & - & - & - & 0.01 & 0.05 & - & - & - & - & - & - & - & - & - & - & 0.04 \\
\hline Sao Carlos & 0.03 & - & - & - & 0.02 & - & - & 0.02 & 0.14 & - & - & - & 0.01 & - & 0.05 & - & - & - & - & 0.05 \\
\hline Rio Claro & - & 0.02 & - & 0.03 & 0.06 & 0.03 & - & 0.02 & 0.03 & 0.02 & - & - & - & - & 0.02 & - & - & - & - & 0.04 \\
\hline Limeira & - & 0.01 & - & - & - & 0.07 & 0.01 & 0.03 & 0.06 & - & - & - & 0.05 & - & 0.05 & - & - & - & - & 0.02 \\
\hline Piracicaba & 0.02 & 0.03 & - & - & - & 0.02 & 0.02 & 0.02 & 0.06 & 0.01 & - & - & 0.01 & - & - & - & - & - & - & 0.06 \\
\hline Pirassununga & - & 0.01 & 0.02 & - & - & 0.11 & - & - & - & 0.03 & - & - & - & - & 0.02 & - & - & - & - & 0.02 \\
\hline Sao Joao da Boa Vista & - & 0.01 & - & - & - & 0.06 & - & 0.02 & 0.02 & - & - & - & - & - & - & - & - & - & - & 0.02 \\
\hline Moji-Mirim & 0.02 & 0.01 & 0.01 & 0.02 & - & 0.04 & - & 0.02 & 0.03 & - & - & - & 0.05 & - & 0.03 & - & - & - & - & 0.03 \\
\hline Campinas & 0.06 & 0.02 & - & 0.04 & 0.02 & 0.02 & - & 0.02 & 0.03 & 0.01 & - & - & 0.04 & - & - & - & - & - & - & 0.06 \\
\hline Amparo & 0.05 & 0.02 & - & 0.03 & - & 0.01 & - & 0.03 & 0.01 & - & - & - & 0.02 & - & - & - & - & - & - & 0.06 \\
\hline Dracena & - & - & - & - & - & 0.08 & - & - & - & - & - & - & - & - & 0.02 & - & - & - & - & 0.02 \\
\hline Adamantina & - & 0.03 & - & - & - & - & - & - & - & - & - & - & - & - & 0.02 & - & - & - & - & 0.11 \\
\hline Presidente Prudente & - & - & - & - & - & - & - & - & - & - & - & - & - & - & - & - & 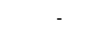 & - & - & 0.03 \\
\hline Tupa & 0.09 & - & - & - & - & - & - & 0.01 & 0.02 & - & - & - & - & - & 0.03 & - & - & - & - & 0.02 \\
\hline Marilia & - & - & - & - & 0.02 & - & - & 0.04 & 0.03 & - & - & - & - & - & 0.01 & - & - & - & - & 0.04 \\
\hline Assis & - & - & - & - & - & - & - & - & - & - & - & - & - & - & - & - & - & - & - & 0.03 \\
\hline Ourinhos & - & 0.04 & 0.02 & & - & 0.02 & - & 0.01 & 0.02 & - & - & - & - & - & 0.01 & - & - & - & - & 0.02 \\
\hline Itapeva & - & - & - & - & - & 0.05 & - & - & - & - & - & - & - & - & - & - & - & - & - & 0.02 \\
\hline Itapetininga & 0.02 & 0.03 & - & 0.03 & - & 0.01 & - & - & - & - & - & - & - & - & - & - & - & - & - & 0.03 \\
\hline Tatui & 0.06 & 0.03 & - & 0.01 & 0.05 & 0.07 & - & 0.03 & - & 0.04 & - & - & 0.01 & - & 0.01 & - & - & - & - & 0.08 \\
\hline Capao Bonito & - & - & - & & & 0.07 & - & - & - & & - & - & - & - & 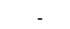 & - & 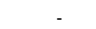 & - & - & 0.04 \\
\hline Piedade & - & - & - & - & . & & - & - & - & . & - & - & - & - & - & - & - & - & - & 0.60 \\
\hline Sorocaba & 0.03 & 0.02 & - & 0.02 & 0.03 & 0.04 & 0.02 & 0.03 & 0.03 & 0.02 & 0.02 & - & 0.04 & - & 0.02 & - & - & - & - & 0.05 \\
\hline Jundiai & 0.03 & & - & 0.04 & 0.03 & 0.05 & - & 0.07 & 0.02 & 0.01 & - & - & 0.02 & - & - & - & - & - & - & 0.06 \\
\hline Braganca Paulista & 0.07 & 0.02 & - & 0.01 & 0.01 & 0.01 & - & 0.01 & - & 0.02 & - & - & 0.02 & - & 0.01 & - & - & - & - & 0.22 \\
\hline Campos do Jordao & 0.03 & - & - & & & & - & - & - & & - & - & & & & - & - & - & - & 0.03 \\
\hline Sao Jose dos Campos & 0.02 & - & - & 0.02 & 0.01 & 0.01 & 0.05 & 0.02 & 0.02 & 0.01 & 0.03 & - & 0.06 & 0.02 & 0.01 & - & - & - & - & 0.09 \\
\hline Guaratingueta & - & - & - & 0.05 & 0.02 & 0.01 & - & 0.02 & - & - & - & - & 0.05 & - & - & - & - & - & - & 0.04 \\
\hline Bananal & - & - & - & - & - & - & - & 0.08 & - & - & - & - & - & - & - & - & - & - & - & - \\
\hline Paraibuna/Paraitinga & - & - & - & - & - & - & - & - & - & - & - & - & - & - & - & - & - & - & - & 0.05 \\
\hline Caraguatatuba & 0.01 & - & - & - & - & - & - & - & - & - & - & - & - & - & - & - & - & - & - & 0.03 \\
\hline Registro & - & - & - & 0.02 & 0.05 & 0.02 & - & - & - & - & - & - & - & - & - & - & - & - & - & 0.03 \\
\hline Itanhaem & - & - & - & 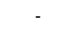 & - & 0.01 & - & - & - & - & - & - & - & - & - & - & - & - & - & 0.02 \\
\hline Osasco & - & 0.01 & - & 0.02 & 0.03 & - & 0.01 & 0.02 & 0.02 & 0.02 & - & - & 0.01 & - & 0.01 & - & - & 0.01 & - & 0.29 \\
\hline Franco da Rocha & 0.02 & 0.01 & 0.01 & 0.02 & 0.06 & 0.01 & - & 0.03 & 0.03 & - & - & - & 0.02 & - & 0.02 & - & - & - & - & 0.08 \\
\hline Guarulhos & 0.04 & - & - & 0.04 & 0.04 & 0.02 & 0.03 & 0.04 & 0.03 & 0.02 & 0.01 & - & 0.07 & - & 0.02 & - & - & - & - & 0.06 \\
\hline Itapecerica da Serra & 0.01 & 0.01 & - & 0.06 & 0.04 & - & 0.01 & 0.03 & 0.02 & 0.02 & - & - & 0.02 & - & 0.02 & - & - & - & - & 0.30 \\
\hline Sao Paulo & - & 0.02 & - & 0.02 & 0.02 & - & - & 0.02 & 0.02 & - & - & - & 0.03 & - & - & - & - & - & - & 0.08 \\
\hline Moji das Cruzes & 0.03 & - & - & 0.03 & 0.03 & 0.03 & 0.03 & 0.04 & 0.04 & 0.02 & - & - & - & - & 0.04 & - & - & - & - & 0.11 \\
\hline Santos & - & - & - & 0.02 & - & - & 0.03 & - & - & - & - & - & - & - & - & - & - & - & - & 0.09 \\
\hline
\end{tabular}

Observações/Filtro: $C C \geq 0,01$ (ou, $1 \%$ ).

FONTE: Elaborado pelo auto com base nos dados da RAIS/MTE 
Anexo XVIII. Coeficiente de concentração para as atividades da indústria de transformação selecionadas - São Paulo/1998.

\begin{tabular}{|c|c|c|c|c|c|c|c|c|c|c|c|c|c|c|c|c|c|c|c|c|}
\hline Divisão & 17 & 18 & 19 & 24 & 25 & 26 & 27 & 28 & 29 & 31 & 32 & 33 & 34 & 35 & 36 & 37 & 71 & 72 & & 74 \\
\hline & 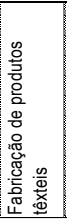 & 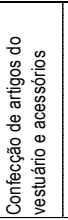 & 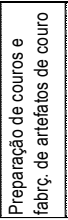 & 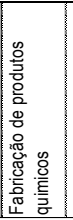 & 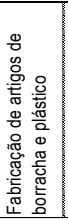 & 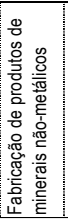 & 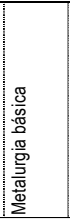 & 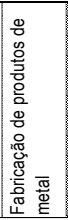 & 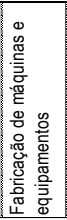 & 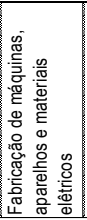 & 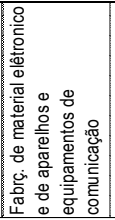 & 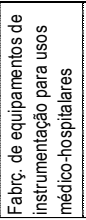 & 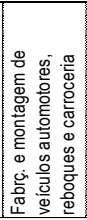 & 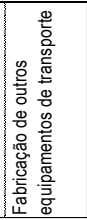 & 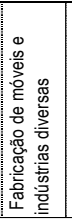 & 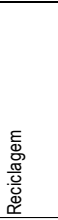 & 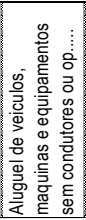 & 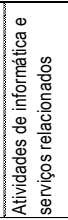 & 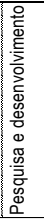 & 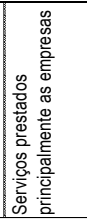 \\
\hline Jales & - & - & 0.02 & - & - & - & - & - & - & - & - & - & - & - & 0.02 & - & - & - & - & 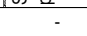 \\
\hline Fernandopolis & - & 0.04 & - & - & - & - & 0.01 & - & - & 0.02 & - & - & & - & 0.03 & - & - & - & - & 0.01 \\
\hline Votuporanga & - & 0.03 & - & - & - & - & - & - & - & - & - & - & 0.03 & 0.01 & 0.17 & - & - & - & - & 0.01 \\
\hline Sao Jose do Rio Preto & - & 0.02 & - & - & - & - & - & 0.03 & & - & - & - & - & - & 0.05 & - & - & - & - & 0.04 \\
\hline Catanduva & - & 0.01 & - & - & - & - & - & 0.01 & 0.03 & - & - & - & - & - & 0.01 & - & - & - & - & 0.03 \\
\hline Auriflama & - & 0.13 & - & - & - & - & - & - & - & - & - & - & - & - & 0.02 & - & - & - & - & - \\
\hline Nhandeara & - & 0.01 & 0.04 & - & - & - & - & 0.05 & 0.01 & - & - & - & - & - & 0.02 & - & - & - & - & - \\
\hline Novo Horizonte & - & 0.04 & - & - & - & - & - & - & 0.03 & - & - & - & - & - & - & - & - & - & - & - \\
\hline Barretos & - & - & - & - & - & - & - & - & - & & - & - & - & - & - & - & - & - & - & 0.02 \\
\hline Sao Joaquim da Barra & - & - & - & - & - & - & - & 0.04 & 0.01 & 0.01 & - & - & - & - & - & - & - & - & - & 0.06 \\
\hline Ituverava & 0.02 & - & - & 0.02 & - & 0.01 & - & - & - & - & - & - & - & - & 0.01 & - & - & - & - & 0.03 \\
\hline Franca & - & - & 0.29 & - & 0.04 & - & - & - & - & - & - & - & - & - & - & - & - & - & - & 0.02 \\
\hline Jaboticabal & - & - & - & & 0.02 & 0.01 & 0.02 & - & 0.02 & & - & & - & - & - & - & - & - & - & 0.02 \\
\hline Ribeirao Preto & - & - & - & 0.01 & 0.01 & - & - & - & 0.02 & - & - & 0.01 & - & - & - & - & - & - & - & 0.05 \\
\hline Batatais & - & 0.03 & - & - & - & - & 0.02 & 0.01 & 0.05 & - & - & - & 0.02 & - & - & - & - & - & - & 0.02 \\
\hline Andradina & - & - & - & - & - & - & - & - & - & - & - & - & - & - & - & - & - & - & - & 0.02 \\
\hline Aracatuba & - & - & 0.01 & - & - & - & - & - & 0.02 & - & - & - & - & - & 0.03 & - & - & - & - & 0.03 \\
\hline Birigui & - & 0.01 & 0.28 & - & 0.01 & 0.02 & - & 0.01 & - & - & - & - & - & - & 0.04 & - & - & - & - & 0.03 \\
\hline Lins & - & - & 0.03 & - & - & - & - & 0.01 & - & - & - & - & - & - & - & - & - & - & - & 0.03 \\
\hline Bauru & 0.01 & - & - & - & - & - & - & 0.01 & - & 0.01 & - & - & - & - & - & - & - & - & - & 0.08 \\
\hline Jau & 0.03 & - & 0.07 & - & - & 0.03 & - & - & - & - & - & - & - & - & 0.02 & - & - & - & - & 0.06 \\
\hline Avare & - & 0.02 & - & - & 0.01 & 0.02 & - & - & - & 0.01 & - & - & - & - & - & - & - & - & - & 0.02 \\
\hline Botucatu & 0.04 & 0.02 & - & - & 0.01 & 0.02 & - & - & - & - & - & - & 0.04 & 0.01 & - & - & - & - & - & 0.02 \\
\hline Araraquara & 0.05 & 0.02 & - & - & - & - & - & 0.02 & 0.04 & - & - & - & - & - & - & - & - & - & - & 0.05 \\
\hline Sao Carlos & 0.03 & - & - & - & 0.02 & 0.01 & - & 0.02 & 0.13 & - & - & - & 0.01 & - & 0.05 & - & - & - & - & 0.05 \\
\hline Rio Claro & - & 0.02 & - & 0.03 & 0.05 & 0.03 & - & 0.03 & 0.03 & 0.02 & - & - & - & - & 0.02 & - & - & - & - & 0.04 \\
\hline Limeira & - & - & - & - & - & 0.07 & 0.01 & 0.03 & 0.06 & - & - & - & 0.04 & - & 0.05 & - & - & - & - & 0.03 \\
\hline Piracicaba & 0.02 & 0.04 & - & - & - & 0.02 & 0.01 & 0.03 & 0.07 & - & - & - & - & - & 0.01 & - & - & - & - & 0.05 \\
\hline Pirassununga & - & 0.01 & 0.02 & - & - & 0.10 & - & 0.01 & - & 0.03 & - & - & - & - & 0.02 & - & - & - & - & 0.02 \\
\hline Sao Joao da Boa Vista & - & 0.01 & - & - & - & 0.06 & - & 0.02 & 0.02 & - & - & - & - & - & - & - & - & - & - & 0.02 \\
\hline Moji-Mirim & 0.02 & 0.01 & 0.01 & 0.02 & - & 0.04 & - & 0.02 & 0.03 & & - & - & 0.04 & - & 0.02 & - & - & - & - & 0.04 \\
\hline Campinas & 0.05 & 0.02 & - & 0.03 & 0.03 & 0.02 & - & 0.02 & 0.03 & 0.01 & - & - & 0.04 & - & - & - & - & - & - & 0.06 \\
\hline Amparo & 0.06 & 0.03 & - & 0.03 & - & 0.01 & - & 0.02 & 0.01 & - & - & - & 0.02 & - & - & - & - & - & - & 0.04 \\
\hline Dracena & - & 0.01 & - & - & - & 0.08 & - & - & 0.01 & - & - & - & - & - & 0.02 & - & - & - & - & 0.01 \\
\hline Adamantina & - & 0.04 & - & 0.01 & - & - & - & - & - & - & - & - & - & - & 0.03 & - & - & - & - & 0.09 \\
\hline Presidente Prudente & - & - & - & - & - & - & - & - & - & - & - & - & - & - & - & - & - & - & - & 0.04 \\
\hline Tupa & 0.06 & - & - & - & - & - & - & 0.01 & 0.02 & - & - & - & - & - & 0.03 & - & - & - & - & 0.03 \\
\hline Marilia & - & - & - & - & 0.02 & - & - & 0.04 & 0.03 & - & - & - & - & - & 0.01 & - & - & - & - & 0.03 \\
\hline Assis & - & - & - & - & - & - & - & - & - & - & - & - & - & - & - & - & - & - & - & 0.05 \\
\hline Ourinhos & - & 0.04 & 0.01 & - & - & 0.02 & - & 0.01 & 0.02 & - & - & - & - & - & 0.01 & - & - & - & & 0.02 \\
\hline Itapeva & - & - & - & - & - & 0.04 & - & - & - & - & - & - & - & - & - & - & - & - & - & 0.03 \\
\hline Itapetininga & 0.02 & 0.03 & - & - & - & 0.01 & - & - & - & & - & - & - & - & - & - & - & - & - & 0.03 \\
\hline Tatui & 0.06 & 0.03 & - & 0.02 & 0.04 & 0.07 & - & 0.03 & - & 0.05 & - & - & - & - & 0.02 & - & - & - & - & 0.09 \\
\hline Capao Bonito & - & - & - & - & - & 0.06 & - & - & - & & - & 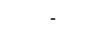 & - & - & - & - & - & - & - & 0.02 \\
\hline Piedade & - & - & - & - & - & & - & - & - & & - & - & 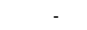 & - & - & - & - & - & - & 0.66 \\
\hline Sorocaba & 0.02 & 0.02 & - & 0.02 & 0.02 & 0.03 & 0.04 & 0.03 & 0.04 & 0.02 & 0.02 & - & 0.04 & - & 0.02 & - & - & - & - & 0.04 \\
\hline Jundiai & 0.03 & - & - & 0.03 & 0.03 & 0.05 & - & 0.07 & 0.02 & 0.01 & - & - & 0.02 & - & 0.01 & - & - & - & - & 0.07 \\
\hline Braganca $\mathrm{Pa}$ & 0.05 & 0.02 & - & - & 0.01 & 0.01 & - & 0.01 & - & - & - & - & 0.02 & - & 0.01 & - & - & - & - & 0.29 \\
\hline Campos do Jordao & 0.02 & - & - & & & & & & & & - & & & 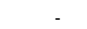 & - & - & - & - & - & 0.03 \\
\hline Sao Jose do & 0.01 & - & - & 0.03 & 0.01 & 0.01 & 0.02 & 0.02 & 0.02 & - & 0.03 & - & 0.09 & 0.03 & - & - & - & - & - & 0.09 \\
\hline Guaratingueta & - & - & - & 0.05 & 0.02 & 0.01 & - & 0.01 & - & - & - & - & 0.04 & - & - & - & - & - & - & 0.03 \\
\hline Bananal & - & - & - & - & - & - & - & - & - & - & - & - & - & - & - & - & - & - & - & - \\
\hline Paraibuna & - & - & - & - & - & - & 0.01 & - & - & 0.04 & - & - & - & - & - & - & - & - & - & 0.02 \\
\hline Caraguatatuba & - & - & - & - & - & - & - & - & - & - & - & - & - & - & - & - & - & - & - & 0.02 \\
\hline Registro & - & - & - & 0.04 & 0.05 & 0.02 & - & - & - & - & - & - & - & - & - & - & - & - & - & 0.05 \\
\hline Itanhaem & - & - & - & - & - & 0.01 & - & - & - & - & - & - & - & - & - & - & - & - & - & 0.02 \\
\hline Osasco & - & - & - & 0.02 & 0.03 & - & - & 0.02 & 0.02 & 0.02 & - & - & 0.01 & - & 0.01 & - & - & 0.02 & - & 0.28 \\
\hline Franco da Rocha & 0.01 & 0.01 & 0.02 & 0.01 & 0.06 & 0.02 & - & 0.02 & 0.03 & & - & - & 0.01 & - & 0.02 & - & - & - & - & 0.08 \\
\hline Guarulhos & 0.03 & - & - & 0.04 & 0.05 & 0.02 & 0.03 & 0.04 & 0.03 & 0.02 & - & - & 0.06 & - & 0.01 & - & - & - & - & 0.07 \\
\hline Itapecerica da Serra & 0.01 & - & - & 0.05 & 0.03 & - & 0.01 & 0.02 & 0.01 & 0.02 & - & - & 0.02 & - & 0.02 & - & - & 0.01 & - & 0.35 \\
\hline Sao Paulo & - & 0.02 & - & 0.02 & 0.02 & - & - & 0.02 & 0.01 & - & - & - & 0.02 & - & - & - & - & - & - & 0.09 \\
\hline Moji das Cruzes & 0.03 & - & - & 0.03 & 0.03 & 0.03 & 0.02 & 0.03 & 0.03 & 0.02 & - & - & 0.01 & - & 0.03 & - & - & - & - & 0.15 \\
\hline Santos & - & - & - & 0.02 & - & - & 0.03 & - & - & - & - & - & - & - & - & - & - & - & - & 0.09 \\
\hline
\end{tabular}

Observações/Filtro: $C C \geq 0,01$ (ou, 1\%).

FONTE: Elaborado pelo auto com base nos dados da RAIS/MTE 
Anexo XIX. Coeficiente de concentração para as atividades da indústria de transformação selecionadas - São Paulo/1999.

\begin{tabular}{|c|c|c|c|c|c|c|c|c|c|c|c|c|c|c|c|c|c|c|c|c|}
\hline Divisão & 17 & 18 & 19 & 24 & 25 & 26 & 27 & 28 & 29 & 31 & 32 & 33 & 34 & 35 & 36 & 37 & 71 & 72 & 7 & 74 \\
\hline & 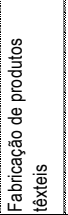 & 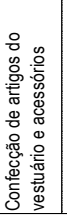 & 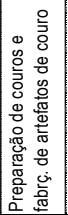 & 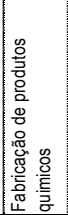 & 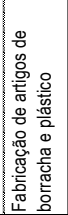 & 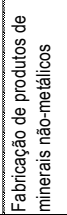 & 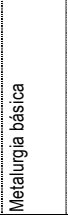 & 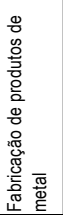 & 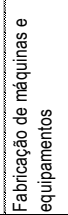 & 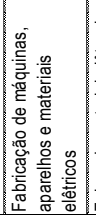 & 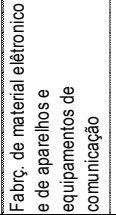 & 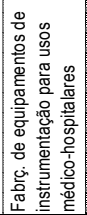 & 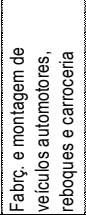 & 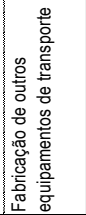 & 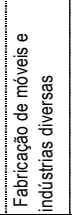 & 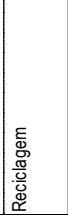 & 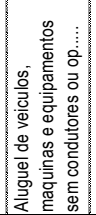 & 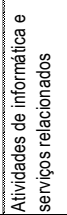 & 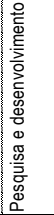 & 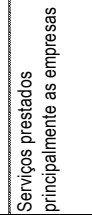 \\
\hline $\begin{array}{l}\text { Jales } \\
\end{array}$ & - & - & 0.02 & - & - & - & - & - & - & - & - & - & - & - & 0.01 & - & - & - & - & 0.18 \\
\hline Fernandopolis & - & 0.04 & 0.01 & - & - & - & - & - & - & 0.02 & - & - & - & - & 0.04 & - & - & - & - & 0.01 \\
\hline Votuporanga & - & 0.03 & - & - & - & - & - & - & - & - & - & - & 0.05 & 0.01 & 0.19 & - & - & - & - & 0.02 \\
\hline Sao Jose do Rio Preto & - & 0.02 & - & & - & - & - & 0.03 & - & - & - & - & - & - & 0.05 & - & - & - & - & 0.04 \\
\hline Catanduva & - & 0.01 & - & 0.01 & - & - & - & 0.01 & 0.03 & - & - & - & - & - & 0.01 & - & - & - & - & 0.04 \\
\hline Auriflama & - & 0.17 & - & & - & - & - & - & - & - & - & - & - & - & 0.02 & - & - & - & - & - \\
\hline Nhandeara & - & - & 0.03 & 0.01 & - & 0.01 & - & 0.05 & - & - & - & - & - & - & 0.02 & - & - & - & - & - \\
\hline Novo Horizonte & - & 0.04 & - & - & - & - & - & 0.01 & - & - & - & - & - & - & 0.07 & - & - & - & - & - \\
\hline Barretos & - & - & - & - & - & - & - & - & - & - & - & - & - & - & - & - & - & - & - & 0.01 \\
\hline Sao Joaquim da Barra & - & - & - & - & - & - & - & 0.04 & 0.01 & - & - & - & - & - & - & - & - & - & - & 0.03 \\
\hline Ituverava & - & - & - & 0.02 & - & 0.02 & - & - & 0.01 & - & - & - & - & - & 0.02 & - & - & - & - & 0.02 \\
\hline Franca & - & - & 0.31 & - & 0.04 & - & - & - & - & - & - & - & - & - & - & - & - & - & - & 0.02 \\
\hline Jaboticabal & - & - & - & & 0.02 & 0.01 & 0.02 & - & 0.02 & - & - & - & - & - & - & - & 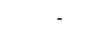 & - & - & 0.02 \\
\hline Ribeirao Preto & - & - & - & 0.02 & 0.01 & - & - & 0.01 & 0.01 & - & - & - & - & - & - & - & - & - & - & 0.05 \\
\hline Batatais & - & 0.03 & - & - & - & - & 0.02 & 0.01 & 0.05 & - & - & - & 0.02 & - & - & - & - & - & - & 0.02 \\
\hline Andradina & - & - & - & - & - & - & - & - & - & - & - & - & - & - & - & - & - & - & - & 0.03 \\
\hline Aracatuba & - & 0.01 & 0.01 & - & - & - & - & 0.01 & 0.02 & - & - & - & - & - & 0.02 & - & - & - & - & 0.03 \\
\hline Birigui & - & 0.01 & 0.33 & - & 0.01 & 0.01 & - & 0.01 & - & - & - & - & - & - & 0.04 & - & - & - & - & 0.03 \\
\hline Lins & - & - & 0.07 & - & - & - & - & 0.01 & - & - & - & - & - & - & - & - & - & - & - & 0.02 \\
\hline Bauru & 0.01 & - & - & - & - & - & - & 0.01 & - & 0.01 & - & - & - & - & - & - & - & - & - & 0.06 \\
\hline Jau & 0.03 & - & 0.08 & - & 0.01 & 0.04 & - & - & - & - & - & - & - & - & 0.02 & - & - & - & - & 0.08 \\
\hline Avare & - & 0.02 & - & - & 0.01 & 0.02 & - & - & - & - & - & - & - & - & - & - & - & - & - & 0.02 \\
\hline Botucatu & 0.03 & 0.02 & - & - & 0.01 & 0.02 & - & 0.01 & - & - & - & - & 0.02 & 0.01 & - & - & - & - & - & 0.10 \\
\hline Araraquara & 0.05 & 0.02 & - & - & - & - & - & 0.01 & 0.05 & - & - & - & - & - & - & - & - & - & - & 0.04 \\
\hline Sao Carlos & 0.03 & - & - & - & 0.01 & - & - & 0.02 & 0.15 & - & - & - & 0.01 & - & 0.05 & - & - & - & - & 0.06 \\
\hline Rio Claro & - & 0.02 & - & 0.03 & 0.06 & 0.04 & - & 0.03 & 0.03 & 0.02 & - & - & - & - & 0.02 & - & - & - & - & 0.04 \\
\hline Limeira & - & - & - & - & 0.01 & 0.07 & 0.01 & 0.03 & 0.05 & - & - & - & 0.04 & - & 0.05 & - & - & - & - & 0.03 \\
\hline Piracicaba & 0.02 & 0.03 & - & - & - & 0.02 & 0.01 & 0.02 & 0.07 & - & - & - & 0.02 & - & 0.01 & - & - & - & - & 0.06 \\
\hline Pirassununga & - & 0.02 & 0.02 & - & - & 0.11 & - & 0.01 & - & 0.03 & - & - & - & - & 0.03 & - & - & - & - & 0.02 \\
\hline Sao Joao da Boa Vista & - & 0.01 & - & - & - & 0.06 & - & 0.02 & 0.02 & - & - & - & 0.01 & - & - & - & - & - & - & 0.02 \\
\hline Moji-Mirim & 0.02 & 0.01 & 0.01 & 0.02 & - & 0.03 & - & 0.02 & 0.02 & - & - & - & 0.06 & - & 0.02 & - & 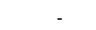 & - & - & 0.04 \\
\hline Campinas & 0.05 & 0.01 & - & 0.04 & 0.02 & 0.02 & - & 0.02 & 0.03 & 0.02 & - & - & 0.03 & - & - & - & - & - & - & 0.07 \\
\hline Amparo & 0.07 & 0.03 & - & 0.03 & - & 0.01 & - & 0.02 & 0.05 & - & - & - & 0.02 & - & - & - & - & - & - & 0.05 \\
\hline Dracena & - & - & - & - & - & 0.08 & - & - & 0.01 & - & - & - & - & - & 0.01 & - & - & - & - & 0.01 \\
\hline Adamantina & - & 0.03 & - & - & - & - & - & - & - & - & - & - & - & - & 0.03 & - & - & - & - & 0.07 \\
\hline Presidente Prudente & - & - & - & - & - & - & - & - & - & - & - & - & - & - & - & - & 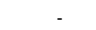 & - & - & 0.04 \\
\hline Tupa & 0.05 & - & - & - & - & - & - & 0.01 & 0.02 & - & - & - & - & - & 0.04 & - & - & - & - & 0.02 \\
\hline Marilia & - & - & - & - & 0.02 & - & - & 0.04 & 0.04 & - & - & - & - & - & - & - & - & - & - & 0.04 \\
\hline Assis & - & - & - & - & - & - & - & - & - & - & - & - & - & - & - & - & - & - & - & 0.03 \\
\hline Ourinhos & - & 0.04 & 0.01 & & - & 0.02 & 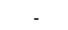 & 0.01 & 0.02 & - & - & - & - & - & 0.02 & - & - & - & - & 0.02 \\
\hline Itapeva & - & - & - & - & - & 0.04 & 0.01 & - & - & - & - & - & - & - & - & - & - & - & - & 0.04 \\
\hline Itapetininga & 0.02 & 0.03 & - & 0.03 & - & & - & - & - & - & - & - & - & - & - & - & - & - & - & 0.04 \\
\hline Tatui & 0.05 & 0.03 & - & 0.01 & 0.04 & 0.06 & - & 0.03 & - & 0.04 & - & - & - & - & 0.02 & - & - & - & - & 0.12 \\
\hline Capao Bonito & - & - & - & & & 0.06 & - & - & - & & - & - & - & - & 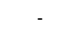 & - & 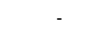 & - & - & 0.03 \\
\hline Piedade & - & - & - & - & . & & - & - & - & 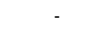 & - & - & - & - & - & - & - & - & - & 0.64 \\
\hline Sorocaba & 0.02 & 0.03 & - & 0.02 & 0.03 & 0.03 & 0.04 & 0.03 & 0.03 & 0.02 & 0.02 & - & 0.04 & - & 0.02 & - & - & - & - & 0.05 \\
\hline Jundiai & 0.03 & 0.01 & - & 0.03 & 0.04 & 0.04 & - & 0.07 & 0.02 & & - & - & 0.02 & - & 0.01 & - & - & - & - & 0.07 \\
\hline Braganca Paulista & 0.06 & 0.02 & - & 0.01 & 0.01 & 0.01 & - & 0.01 & - & 0.02 & - & - & 0.01 & - & - & - & - & - & - & 0.31 \\
\hline Campos do Jordao & 0.02 & - & - & & & & - & - & - & 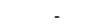 & - & - & & & & - & - & - & - & 0.03 \\
\hline Sao Jose dos Campos & 0.01 & - & - & 0.02 & 0.01 & - & 0.02 & 0.02 & 0.02 & - & 0.03 & - & 0.08 & 0.04 & 0.02 & - & - & - & - & 0.10 \\
\hline Guaratingueta & - & - & - & 0.05 & 0.02 & 0.01 & - & 0.02 & - & - & - & - & 0.05 & - & - & - & - & - & - & 0.03 \\
\hline Bananal & - & - & - & - & 0.04 & - & - & - & - & - & - & - & - & - & 0.02 & - & - & - & - & - \\
\hline Paraibuna/Paraitinga & - & - & - & - & - & 0.01 & - & - & - & - & - & - & 0.05 & - & - & - & - & - & - & 0.14 \\
\hline Caraguatatuba & - & - & - & - & - & - & - & - & - & - & - & - & - & - & - & - & - & - & - & 0.02 \\
\hline Registro & - & - & - & 0.02 & - & 0.01 & - & - & - & - & - & - & - & - & - & - & - & - & - & 0.04 \\
\hline Itanhaem & - & - & - & 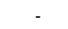 & - & 0.01 & - & - & - & - & - & - & - & - & - & - & - & - & - & 0.02 \\
\hline Osasco & - & - & - & 0.02 & 0.03 & - & - & 0.02 & 0.02 & 0.02 & - & - & - & - & - & - & - & 0.02 & - & 0.29 \\
\hline Franco da Rocha & 0.02 & - & 0.02 & - & 0.06 & 0.02 & - & 0.02 & 0.02 & - & - & - & 0.01 & - & 0.02 & - & - & - & - & 0.10 \\
\hline Guarulhos & 0.04 & 0.01 & - & 0.04 & 0.05 & 0.02 & 0.02 & 0.04 & 0.02 & 0.03 & - & - & 0.04 & - & 0.01 & - & - & - & - & 0.08 \\
\hline Itapecerica da Serra & 0.01 & - & - & 0.05 & 0.03 & - & - & 0.02 & 0.01 & 0.01 & - & - & 0.02 & - & 0.01 & - & - & - & - & 0.39 \\
\hline Sao Paulo & - & 0.02 & - & 0.02 & 0.02 & - & - & 0.02 & 0.01 & - & - & - & 0.02 & - & - & - & - & - & - & 0.09 \\
\hline Moji das Cruzes & 0.02 & - & 0.01 & 0.03 & 0.03 & 0.02 & 0.02 & 0.04 & 0.02 & 0.01 & - & - & 0.01 & - & 0.03 & - & - & - & - & 0.21 \\
\hline Santos & - & - & - & 0.02 & - & - & 0.05 & - & - & - & - & - & - & - & - & - & - & - & - & 0.09 \\
\hline
\end{tabular}

Observações/Filtro: CC $\geq 0,01$ (ou, 1\%).

FONTE: Elaborado pelo auto com base nos dados da RAIS/MTE 
Anexo XX. Coeficiente de concentração para as atividades da indústria de transformação selecionadas - São Paulo/2000.

\begin{tabular}{|c|c|c|c|c|c|c|c|c|c|c|c|c|c|c|c|c|c|c|c|c|}
\hline Divisão & 17 & 18 & 19 & 24 & 25 & 26 & 27 & 28 & 29 & 31 & 32 & 33 & 34 & 35 & 36 & 37 & 71 & 72 & & 74 \\
\hline & 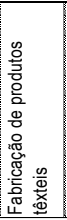 & 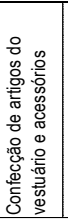 & 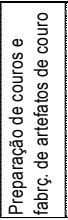 & 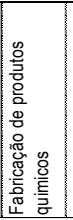 & 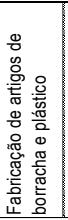 & 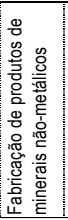 & 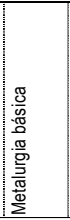 & 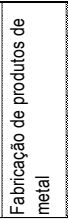 & 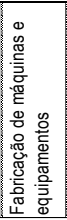 & 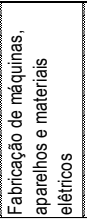 & 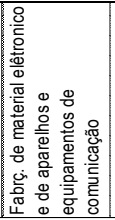 & 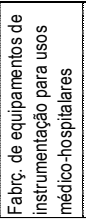 & 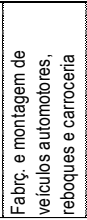 & 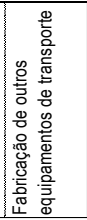 & 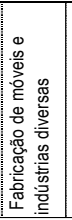 & 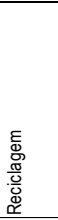 & 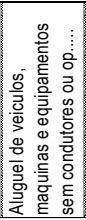 & 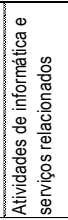 & 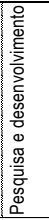 & 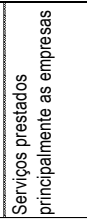 \\
\hline Jales & - & - & 0.02 & - & - & 0.01 & - & - & - & - & - & - & - & - & 0.01 & - & - & - & - & 0.16 \\
\hline Fernandopolis & - & 0.04 & - & - & - & - & - & 0.01 & - & 0.02 & - & - & & - & 0.04 & - & - & - & - & 0.01 \\
\hline Votuporanga & - & 0.03 & - & - & - & - & - & - & - & - & - & - & 0.05 & 0.01 & 0.21 & - & - & - & - & 0.03 \\
\hline Sao Jose do Rio Preto & - & 0.02 & - & - & - & - & - & 0.03 & & - & - & - & - & - & 0.05 & - & - & - & - & 0.03 \\
\hline Catanduva & - & 0.01 & - & 0.01 & - & - & - & 0.02 & 0.04 & - & - & - & - & - & 0.01 & - & - & - & - & 0.03 \\
\hline Auriflama & - & 0.19 & - & - & - & - & - & - & 0.01 & - & - & - & - & - & 0.02 & - & - & - & - & - \\
\hline Nhandeara & - & 0.02 & 0.02 & 0.01 & 0.01 & - & - & 0.05 & 0.01 & - & - & - & - & - & 0.02 & - & - & - & - & - \\
\hline Novo Horizonte & - & 0.04 & - & - & - & - & - & - & - & - & - & - & - & - & 0.06 & - & - & - & - & - \\
\hline Barretos & - & - & - & - & - & - & - & - & - & & - & - & - & - & - & - & - & - & - & 0.01 \\
\hline Sao Joaquim da Barra & - & - & - & - & - & - & - & 0.03 & 0.01 & 0.01 & - & - & - & - & - & - & - & - & - & 0.06 \\
\hline Ituverava & 0.02 & - & - & 0.02 & - & 0.02 & - & - & 0.02 & - & - & - & - & - & 0.02 & - & - & - & - & 0.01 \\
\hline Franca & - & - & 0.33 & - & 0.04 & - & - & - & - & - & - & - & - & - & - & - & - & - & - & 0.03 \\
\hline Jaboticabal & - & - & - & & 0.02 & - & 0.02 & 0.01 & 0.02 & & - & & - & - & - & - & - & - & 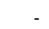 & 0.02 \\
\hline Ribeirao Preto & - & - & - & 0.02 & 0.01 & - & - & 0.01 & 0.02 & - & - & 0.01 & - & - & - & - & - & - & - & 0.07 \\
\hline Batatais & - & 0.03 & - & - & - & - & 0.02 & 0.01 & 0.05 & - & - & - & 0.02 & - & 0.01 & - & - & - & - & 0.02 \\
\hline Andradina & - & - & - & - & - & - & - & - & - & - & - & - & - & - & - & - & - & - & - & 0.03 \\
\hline Aracatuba & - & 0.01 & 0.01 & - & - & - & - & - & 0.02 & - & - & - & - & - & 0.02 & - & - & - & - & 0.03 \\
\hline Birigui & - & 0.02 & 0.37 & - & 0.01 & 0.01 & - & - & - & - & - & - & - & - & 0.03 & - & - & - & - & 0.01 \\
\hline Lins & - & - & 0.08 & - & - & - & - & 0.01 & - & - & - & - & - & - & - & - & - & - & - & 0.02 \\
\hline Bauru & 0.01 & 0.01 & - & - & - & - & - & 0.01 & - & 0.02 & - & - & - & - & 0.01 & - & - & - & - & 0.06 \\
\hline Jau & 0.03 & 0.01 & 0.09 & - & 0.01 & 0.04 & - & - & - & - & - & - & - & - & 0.02 & - & - & - & - & 0.05 \\
\hline Avare & - & 0.02 & - & 0.01 & 0.01 & 0.02 & - & - & - & - & - & - & - & - & - & - & . & - & . & 0.01 \\
\hline Botucatu & 0.03 & 0.02 & - & - & 0.01 & 0.01 & - & 0.01 & - & - & - & - & - & 0.03 & - & - & - & - & - & 0.08 \\
\hline Araraquara & 0.05 & 0.02 & - & - & - & - & - & 0.01 & 0.04 & - & - & - & - & - & - & - & - & - & - & 0.06 \\
\hline Sao Carlos & 0.02 & - & - & - & 0.01 & 0.02 & - & 0.02 & 0.13 & - & - & - & 0.01 & - & 0.04 & - & - & - & - & 0.07 \\
\hline Rio Claro & - & 0.02 & - & 0.02 & 0.06 & 0.04 & - & 0.04 & 0.03 & 0.02 & - & - & - & - & 0.02 & - & - & - & - & 0.04 \\
\hline Limeira & - & - & - & - & 0.01 & 0.06 & - & 0.04 & 0.05 & - & - & - & 0.04 & - & 0.05 & - & - & - & - & 0.03 \\
\hline Piracicaba & 0.02 & 0.03 & - & - & - & 0.02 & 0.01 & 0.02 & 0.07 & - & - & - & 0.02 & - & - & - & - & - & - & 0.06 \\
\hline Pirassununga & - & 0.01 & 0.01 & - & - & 0.10 & - & 0.01 & - & 0.03 & - & - & - & - & 0.03 & - & - & - & - & 0.02 \\
\hline Sao Joao da Boa Vista & - & 0.01 & - & - & - & 0.06 & - & 0.02 & 0.01 & - & - & - & 0.02 & - & - & - & - & - & - & 0.02 \\
\hline Moji-Mirim & 0.02 & 0.01 & 0.01 & 0.02 & - & 0.03 & - & 0.02 & 0.03 & & - & 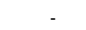 & 0.07 & - & 0.02 & - & - & - & - & 0.05 \\
\hline Campinas & 0.05 & 0.02 & - & 0.04 & 0.02 & 0.02 & - & 0.02 & 0.03 & 0.01 & 0.01 & - & 0.03 & - & - & - & - & - & - & 0.07 \\
\hline Amparo & 0.07 & 0.03 & - & 0.03 & - & 0.01 & - & 0.02 & 0.01 & - & - & - & 0.02 & - & - & - & - & - & - & 0.10 \\
\hline Dracena & - & - & - & - & - & 0.08 & - & - & 0.01 & - & - & - & - & - & 0.01 & - & - & - & - & 0.02 \\
\hline Adamantina & - & 0.04 & - & - & - & - & - & - & - & - & - & - & - & - & 0.03 & - & - & - & - & 0.06 \\
\hline Presidente Prudente & - & - & - & - & - & - & - & - & - & . & - & - & - & - & - & - & - & - & - & 0.04 \\
\hline Tupa & 0.05 & - & - & - & - & - & - & 0.01 & 0.02 & - & - & - & - & - & 0.04 & - & - & - & - & 0.03 \\
\hline Marilia & - & - & - & - & 0.02 & - & - & 0.04 & 0.03 & - & - & - & - & - & - & - & - & - & - & 0.04 \\
\hline Assis & - & - & - & - & - & - & - & - & - & - & - & - & - & - & - & - & - & - & - & 0.03 \\
\hline Ourinhos & - & 0.04 & 0.01 & - & - & 0.02 & & 0.01 & 0.02 & 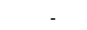 & - & - & - & - & 0.01 & - & - & - & & 0.02 \\
\hline Itapeva & - & - & - & - & - & 0.04 & 0.01 & - & - & - & - & - & - & - & - & - & - & - & - & 0.05 \\
\hline Itapetininga & 0.01 & 0.04 & - & 0.02 & - & - & - & - & - & & - & - & - & - & - & - & - & - & - & 0.04 \\
\hline Tatui & 0.05 & 0.03 & - & 0.01 & 0.03 & 0.06 & - & 0.03 & - & 0.04 & - & - & - & - & 0.03 & - & - & - & - & 0.12 \\
\hline Capao Bonito & - & - & - & - & - & 0.05 & - & - & - & & - & 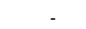 & . & - & - & - & - & - & - & 0.02 \\
\hline Piedade & - & - & - & - & - & & 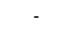 & - & - & & - & - & 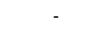 & - & - & - & - & - & - & 0.68 \\
\hline Sorocaba & 0.02 & 0.02 & - & 0.02 & 0.03 & 0.03 & 0.03 & 0.03 & 0.04 & 0.02 & 0.02 & - & 0.04 & - & 0.02 & - & - & - & - & 0.05 \\
\hline Jundiai & 0.03 & 0.01 & - & 0.03 & 0.05 & 0.04 & - & 0.05 & 0.02 & 0.01 & - & - & 0.01 & - & 0.01 & - & - & - & - & 0.07 \\
\hline Braganca P & 0.05 & 0.02 & - & 0.01 & 0.01 & 0.02 & - & 0.01 & - & 0.02 & - & - & 0.01 & - & - & - & - & - & - & 0.30 \\
\hline Campos do Jordao & 0.02 & - & - & & & & & & & & - & & & 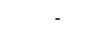 & - & - & - & - & - & 0.05 \\
\hline Sao Jose $d$ & 0.01 & - & - & 0.02 & 0.01 & 0.01 & 0.02 & 0.02 & 0.02 & - & 0.03 & - & 0.09 & 0.04 & 0.02 & - & - & - & - & 0.12 \\
\hline Guaratingueta & - & - & - & 0.05 & 0.03 & 0.01 & - & 0.02 & - & - & - & - & 0.06 & - & - & - & - & - & - & 0.03 \\
\hline Bananal & - & - & - & - & 0.07 & - & - & - & - & - & - & - & - & - & - & - & - & - & - & - \\
\hline Paraibun & - & - & - & - & - & - & - & - & 0.01 & - & - & - & 0.06 & - & - & - & - & - & - & 0.18 \\
\hline Caraguatatuba & - & - & - & - & - & - & - & - & - & - & - & - & - & - & - & - & - & - & - & 0.03 \\
\hline Registro & - & - & - & 0.02 & - & 0.01 & - & - & - & - & - & - & - & - & - & - & - & - & - & 0.04 \\
\hline Itanhaem & - & - & - & - & - & 0.01 & - & - & - & 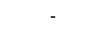 & - & - & - & - & - & - & - & - & - & 0.02 \\
\hline Osasco & - & - & - & 0.02 & 0.03 & - & - & 0.02 & 0.02 & 0.01 & - & - & - & - & - & - & - & 0.02 & - & 0.30 \\
\hline Franco da Rocha & 0.02 & - & 0.01 & - & 0.07 & 0.02 & - & 0.02 & 0.02 & - & - & - & 0.01 & - & 0.03 & - & - & - & 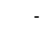 & 0.07 \\
\hline Guarulhos & 0.04 & 0.01 & - & 0.04 & 0.05 & 0.01 & 0.02 & 0.04 & 0.03 & 0.03 & - & - & 0.05 & - & 0.02 & - & - & - & - & 0.07 \\
\hline Itapecerica da Ser & 0.01 & - & - & 0.05 & 0.03 & - & - & 0.02 & 0.02 & 0.01 & - & - & 0.02 & - & 0.02 & - & - & 0.02 & - & 0.36 \\
\hline Sao Paulo & - & 0.02 & - & 0.02 & 0.02 & - & - & 0.02 & 0.01 & - & - & - & 0.02 & - & - & - & - & 0.01 & - & 0.10 \\
\hline Moji das Cruzes & 0.02 & - & 0.01 & 0.03 & 0.03 & 0.03 & 0.02 & 0.04 & 0.02 & 0.02 & - & - & - & - & 0.03 & - & - & - & - & 0.18 \\
\hline Santos & - & - & - & 0.02 & - & - & 0.03 & - & - & - & - & - & - & - & - & - & - & - & - & 0.09 \\
\hline
\end{tabular}

Observações/Filtro: $C C \geq 0,01$ (ou, 1\%).

FONTE: Elaborado pelo auto com base nos dados da RAIS/MTE 
Anexo XXI. Coeficiente de concentração para as atividades da indústria de transformação selecionadas - São Paulo/2001.

\begin{tabular}{|c|c|c|c|c|c|c|c|c|c|c|c|c|c|c|c|c|c|c|c|c|}
\hline Divisão & 17 & 18 & 19 & 24 & 25 & 26 & 27 & 28 & 29 & 31 & 32 & 33 & 34 & 35 & 36 & 37 & 71 & 72 & 7 & 74 \\
\hline & 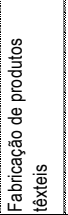 & 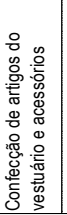 & 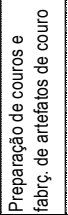 & 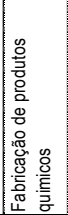 & 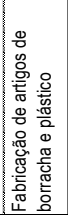 & 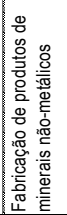 & 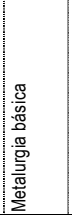 & 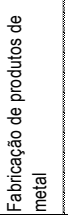 & 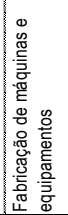 & 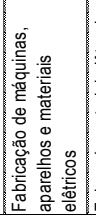 & 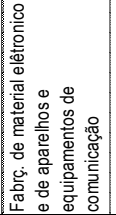 & 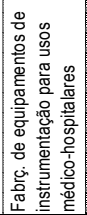 & 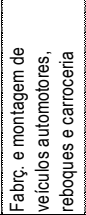 & 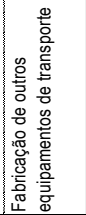 & 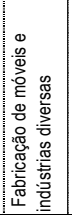 & 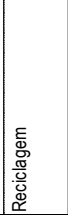 & 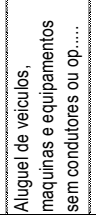 & 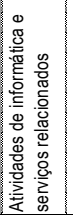 & 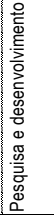 & 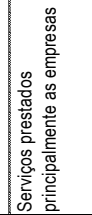 \\
\hline $\begin{array}{l}\text { Jales } \\
\end{array}$ & - & - & - & - & - & 0.01 & - & - & - & - & - & - & - & - & 0.01 & - & - & - & - & 0.13 \\
\hline Fernandopolis & - & 0.03 & - & - & - & - & - & 0.01 & - & 0.02 & - & - & - & - & 0.03 & - & - & - & - & 0.02 \\
\hline Votuporanga & - & 0.02 & - & - & - & - & - & - & - & - & - & - & 0.05 & 0.01 & 0.19 & - & - & - & - & 0.05 \\
\hline Sao Jose do Rio Preto & - & 0.02 & - & - & - & - & - & 0.03 & - & - & - & - & - & - & 0.05 & - & - & - & - & 0.04 \\
\hline Catanduva & - & 0.01 & - & - & - & - & - & 0.01 & 0.02 & - & - & - & - & - & 0.01 & - & - & - & - & 0.08 \\
\hline Auriflama & - & 0.19 & - & & - & - & - & - & 0.02 & - & - & - & - & - & 0.01 & - & - & - & - & - \\
\hline Nhandeara & - & 0.02 & 0.01 & 0.01 & 0.01 & 0.01 & - & 0.05 & 0.01 & - & - & - & - & - & 0.02 & - & - & - & - & - \\
\hline Novo Horizonte & - & 0.04 & - & - & - & - & - & - & - & - & - & - & - & - & 0.05 & - & - & - & - & 0.02 \\
\hline Barretos & - & - & - & - & - & - & - & - & - & . & - & - & - & - & - & - & - & - & - & 0.06 \\
\hline Sao Joaquim da Barra & - & - & - & - & - & - & - & 0.03 & 0.02 & 0.01 & - & - & - & - & - & - & - & - & - & 0.05 \\
\hline Ituverava & 0.01 & - & - & 0.02 & - & 0.01 & - & - & 0.01 & - & - & - & - & - & 0.02 & - & - & - & - & 0.05 \\
\hline Franca & - & 0.01 & 0.32 & - & 0.04 & - & - & - & - & - & - & - & - & - & - & - & - & - & - & 0.03 \\
\hline Jaboticabal & - & 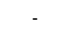 & 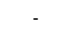 & & 0.02 & - & 0.02 & 0.01 & 0.02 & - & - & - & - & - & - & - & 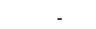 & - & - & 0.04 \\
\hline Ribeirao Preto & - & - & - & 0.01 & 0.01 & - & - & 0.01 & 0.02 & - & - & 0.01 & - & - & - & - & - & - & - & 0.08 \\
\hline Batatais & - & 0.03 & - & - & 0.01 & - & 0.02 & 0.01 & 0.04 & - & - & - & 0.02 & - & 0.01 & - & - & - & - & 0.02 \\
\hline Andradina & - & - & - & - & - & - & - & - & - & - & - & - & - & - & - & - & - & - & - & 0.03 \\
\hline Aracatuba & - & 0.01 & 0.01 & - & - & - & - & - & 0.02 & - & - & - & - & - & 0.02 & - & - & - & - & 0.02 \\
\hline Birigui & - & 0.02 & 0.34 & - & 0.01 & 0.01 & - & 0.01 & - & - & - & - & - & - & 0.04 & - & - & - & - & 0.01 \\
\hline Lins & - & - & 0.08 & - & - & - & - & 0.02 & - & - & - & - & - & - & - & - & - & - & - & 0.01 \\
\hline Bauru & 0.01 & 0.01 & - & - & - & - & - & 0.01 & - & 0.02 & - & - & - & - & - & - & - & - & - & 0.07 \\
\hline Jau & 0.02 & 0.01 & 0.08 & - & 0.01 & 0.03 & - & - & - & - & - & - & - & - & 0.02 & - & - & - & - & 0.06 \\
\hline Avare & 0.01 & 0.02 & - & - & 0.01 & 0.01 & - & - & - & - & - & - & - & - & - & - & - & - & - & 0.02 \\
\hline Botucatu & 0.02 & 0.02 & - & - & - & 0.01 & - & 0.02 & - & - & - & - & 0.04 & 0.02 & - & - & - & - & - & 0.07 \\
\hline Araraquara & 0.05 & 0.02 & - & - & - & - & - & 0.01 & 0.04 & - & - & - & - & - & - & - & - & - & - & 0.06 \\
\hline Sao Carlos & 0.02 & - & - & - & 0.01 & - & - & 0.02 & 0.13 & - & - & - & 0.01 & - & 0.04 & - & - & - & - & 0.06 \\
\hline Rio Claro & - & 0.02 & - & 0.02 & 0.05 & 0.04 & - & 0.04 & 0.03 & 0.02 & - & 0.01 & - & - & 0.02 & - & - & - & - & 0.04 \\
\hline Limeira & - & - & - & - & 0.01 & 0.06 & 0.01 & 0.03 & 0.04 & - & - & - & 0.04 & - & 0.05 & - & - & - & - & 0.03 \\
\hline Piracicaba & 0.02 & 0.03 & - & - & - & 0.02 & 0.01 & 0.03 & 0.07 & - & - & - & 0.02 & - & - & - & - & - & - & 0.06 \\
\hline Pirassununga & - & - & 0.01 & - & 0.02 & 0.09 & - & 0.01 & - & 0.02 & - & - & - & - & 0.02 & - & - & - & - & 0.02 \\
\hline Sao Joao da Boa Vista & - & 0.02 & - & - & - & 0.06 & - & 0.03 & 0.02 & - & - & - & 0.01 & - & - & - & - & - & - & 0.02 \\
\hline Moji-Mirim & 0.03 & - & - & 0.02 & - & 0.03 & - & 0.02 & 0.03 & - & - & - & 0.07 & - & 0.02 & - & - & - & - & 0.07 \\
\hline Campinas & 0.05 & 0.02 & - & 0.03 & 0.03 & 0.01 & - & 0.02 & 0.03 & 0.01 & 0.01 & - & 0.03 & - & - & - & - & - & - & 0.07 \\
\hline Amparo & 0.07 & 0.03 & - & 0.03 & - & 0.02 & - & 0.02 & 0.01 & - & - & - & 0.02 & - & - & - & - & - & - & 0.04 \\
\hline Dracena & - & - & - & - & - & 0.08 & - & - & 0.01 & - & - & - & - & - & 0.02 & - & - & - & - & 0.01 \\
\hline Adamantina & - & 0.04 & - & - & - & - & - & - & - & - & - & - & - & - & 0.03 & - & - & - & - & 0.06 \\
\hline Presidente Prudente & - & - & 0.02 & - & - & - & - & - & - & - & - & - & - & - & - & - & 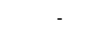 & - & - & 0.03 \\
\hline Tupa & 0.05 & - & - & - & - & - & - & 0.01 & 0.01 & - & - & - & - & - & 0.05 & - & - & - & - & 0.02 \\
\hline Marilia & - & - & - & - & 0.02 & - & - & 0.04 & 0.04 & - & - & - & - & - & - & - & - & - & - & 0.04 \\
\hline Assis & - & - & - & - & - & - & - & - & - & - & - & - & - & - & - & - & - & - & - & 0.03 \\
\hline Ourinhos & - & 0.04 & 0.02 & - & - & 0.02 & 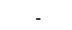 & - & 0.02 & - & - & - & - & - & 0.01 & - & - & - & - & 0.02 \\
\hline Itapeva & - & - & - & - & - & 0.03 & 0.01 & - & - & - & - & - & - & - & - & - & - & - & - & 0.05 \\
\hline Itapetininga & 0.01 & 0.03 & - & - & 0.02 & 0.01 & - & - & - & - & - & - & - & - & - & - & - & - & - & 0.06 \\
\hline Tatui & 0.04 & 0.03 & - & - & 0.02 & 0.05 & - & 0.03 & - & 0.04 & - & - & - & - & 0.03 & - & - & - & - & 0.12 \\
\hline Capao Bonito & - & - & - & - & & 0.04 & - & - & - & & - & - & - & - & 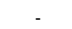 & - & 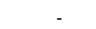 & - & - & 0.02 \\
\hline Piedade & - & - & - & & - & & - & - & - & . & - & - & - & - & - & - & - & - & - & 0.63 \\
\hline Sorocaba & 0.02 & 0.02 & - & 0.02 & 0.03 & 0.03 & 0.03 & 0.03 & 0.05 & 0.01 & 0.02 & - & 0.03 & - & 0.02 & - & - & - & - & 0.06 \\
\hline Jundiai & 0.02 & 0.01 & - & 0.03 & 0.04 & 0.04 & - & 0.07 & 0.02 & & - & - & 0.02 & - & 0.01 & - & - & - & - & 0.08 \\
\hline Braganca Paulista & 0.05 & 0.02 & - & 0.01 & 0.01 & 0.02 & - & 0.01 & 0.01 & 0.01 & - & - & 0.02 & - & - & - & - & - & - & 0.29 \\
\hline Campos do Jordao & 0.02 & - & - & & & & - & - & - & - & - & - & & & & - & - & - & - & 0.05 \\
\hline Sao Jose dos Campos & - & - & - & 0.02 & 0.01 & - & 0.02 & 0.02 & 0.03 & - & 0.02 & - & 0.08 & 0.04 & 0.01 & - & - & - & - & 0.11 \\
\hline Guaratingueta & - & - & - & 0.05 & 0.02 & 0.01 & - & 0.02 & - & - & - & - & 0.05 & - & - & - & - & - & - & 0.04 \\
\hline Bananal & - & - & - & - & 0.05 & - & - & - & - & - & - & - & - & - & - & - & - & - & - & - \\
\hline Paraibuna/Paraitinga & - & - & - & - & - & - & - & - & - & - & - & - & 0.07 & - & - & - & - & - & - & 0.14 \\
\hline Caraguatatuba & - & - & - & - & - & - & - & - & - & - & - & - & - & - & - & - & - & - & - & 0.03 \\
\hline Registro & - & - & - & 0.02 & - & 0.01 & - & - & - & - & - & - & - & - & - & - & - & - & - & 0.04 \\
\hline Itanhaem & - & - & - & 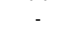 & - & 0.01 & - & - & - & - & - & - & - & - & - & - & - & - & - & 0.02 \\
\hline Osasco & - & - & - & 0.02 & 0.02 & - & 0.01 & 0.02 & 0.02 & 0.01 & - & - & - & - & - & - & - & 0.02 & - & 0.30 \\
\hline Franco da Rocha & 0.02 & - & 0.01 & - & 0.05 & - & - & 0.02 & 0.02 & 0.01 & 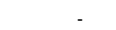 & - & 0.01 & - & 0.03 & - & - & - & - & 0.08 \\
\hline Guarulhos & 0.03 & 0.01 & - & 0.04 & 0.05 & 0.01 & 0.02 & 0.05 & 0.02 & 0.03 & - & - & 0.04 & - & 0.01 & - & - & - & - & 0.06 \\
\hline Itapecerica da Serra & 0.01 & - & - & 0.05 & 0.03 & - & - & 0.02 & 0.02 & 0.02 & - & - & 0.02 & - & 0.01 & - & - & 0.02 & - & 0.36 \\
\hline Sao Paulo & - & 0.02 & - & 0.02 & 0.02 & - & - & 0.02 & 0.01 & - & - & - & 0.02 & - & - & - & - & 0.01 & - & 0.10 \\
\hline Moji das Cruzes & 0.02 & - & 0.01 & 0.03 & 0.02 & 0.03 & 0.02 & 0.03 & 0.02 & 0.02 & - & - & - & - & 0.03 & - & - & - & - & 0.21 \\
\hline Santos & - & - & - & 0.02 & - & - & 0.02 & - & - & - & - & - & - & - & - & - & - & - & - & 0.08 \\
\hline
\end{tabular}

Observações/Filtro: $C C \geq 0,01$ (ou, 1\%).

FONTE: Elaborado pelo auto com base nos dados da RAIS/MTE 
Anexo XXII. Coeficiente de concentração para as atividades da indústria de transformação selecionadas - São Paulo/2002.

\begin{tabular}{|c|c|c|c|c|c|c|c|c|c|c|c|c|c|c|c|c|c|c|c|c|}
\hline Divisão & 17 & 18 & 19 & 24 & 25 & 26 & 27 & 28 & 29 & 31 & 32 & 33 & 34 & 35 & 36 & 37 & 71 & 72 & 7 & 74 \\
\hline & 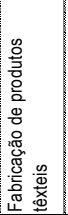 & 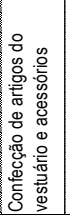 & 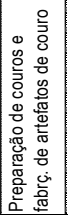 & 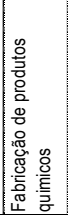 & 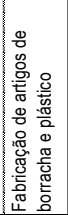 & 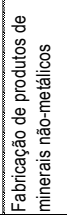 & 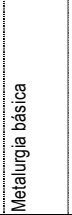 & 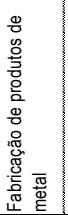 & 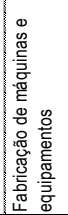 & 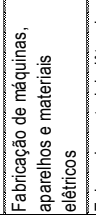 & 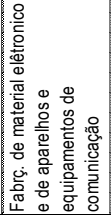 & 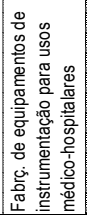 & 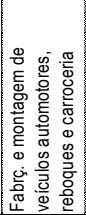 & 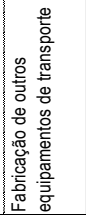 & 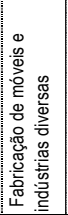 & 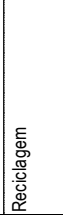 & 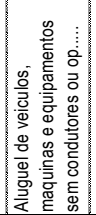 & 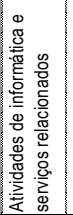 & 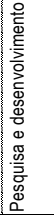 & 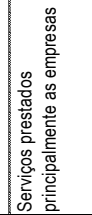 \\
\hline $\begin{array}{l}\text { Jales } \\
\end{array}$ & - & 0.01 & - & - & - & 0.01 & - & - & - & - & - & - & - & - & - & - & - & - & - & 0.14 \\
\hline Fernandopolis & - & 0.04 & - & - & - & - & - & 0.01 & - & - & - & - & - & - & 0.05 & - & - & - & - & 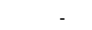 \\
\hline Votuporanga & - & 0.03 & - & - & - & - & - & - & - & - & - & - & 0.04 & 0.01 & 0.16 & - & - & - & - & 0.04 \\
\hline Sao Jose do Rio Preto & - & 0.02 & - & - & - & - & - & 0.03 & - & - & - & - & - & - & 0.05 & - & - & - & - & 0.04 \\
\hline Catanduva & - & - & - & - & - & - & - & 0.01 & 0.02 & - & - & - & - & - & 0.01 & - & - & - & - & 0.05 \\
\hline Auriflama & - & 0.16 & - & - & - & - & - & - & 0.02 & - & - & - & - & - & 0.02 & - & - & - & - & - \\
\hline Nhandeara & - & 0.02 & 0.01 & - & - & - & - & 0.04 & 0.01 & - & - & - & - & - & 0.02 & - & - & - & - & - \\
\hline Novo Horizonte & 0.01 & 0.05 & - & - & - & - & - & 0.01 & - & - & - & - & - & - & 0.04 & - & - & - & - & 0.01 \\
\hline Barretos & - & - & - & - & - & - & - & - & - & 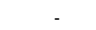 & - & - & - & - & - & - & - & - & - & 0.01 \\
\hline Sao Joaquim da Barra & - & - & - & - & - & - & - & 0.03 & 0.02 & 0.01 & - & - & - & - & - & - & - & - & - & 0.02 \\
\hline Ituverava & 0.01 & - & - & 0.02 & - & 0.02 & - & - & 0.01 & - & - & - & - & - & 0.02 & - & - & - & - & 0.02 \\
\hline Franca & - & - & 0.32 & - & 0.04 & - & - & - & - & - & - & - & - & - & - & - & - & - & - & 0.03 \\
\hline Jaboticabal & - & - & - & & 0.02 & - & 0.01 & 0.01 & 0.02 & - & - & - & - & - & - & - & 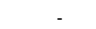 & - & - & 0.02 \\
\hline Ribeirao Preto & - & - & - & 0.01 & - & - & - & 0.01 & 0.02 & - & - & 0.01 & - & - & - & - & - & - & - & 0.09 \\
\hline Batatais & - & 0.03 & - & 0.01 & 0.02 & - & 0.03 & 0.01 & 0.04 & - & - & - & 0.02 & - & - & - & - & - & - & 0.02 \\
\hline Andradina & - & - & - & - & - & - & - & - & - & - & - & - & - & - & - & - & - & - & - & 0.02 \\
\hline Aracatuba & - & 0.01 & 0.01 & - & - & - & - & - & 0.02 & - & - & - & - & - & 0.02 & - & - & - & - & 0.02 \\
\hline Birigui & - & 0.02 & 0.32 & - & 0.01 & - & - & 0.01 & - & - & - & - & - & - & 0.04 & - & - & - & - & 0.05 \\
\hline Lins & - & - & 0.09 & - & - & - & - & 0.01 & - & - & - & - & - & - & - & - & - & - & - & 0.01 \\
\hline Bauru & 0.01 & 0.01 & - & - & - & - & - & 0.01 & - & 0.02 & - & - & - & - & - & - & - & - & - & 0.09 \\
\hline Jau & 0.03 & 0.01 & 0.08 & - & 0.01 & 0.03 & - & - & - & - & - & - & - & - & 0.02 & - & - & - & - & 0.12 \\
\hline Avare & 0.01 & 0.03 & - & - & 0.01 & 0.01 & - & - & - & - & - & - & - & - & - & - & - & - & - & 0.01 \\
\hline Botucatu & 0.02 & 0.03 & - & - & 0.01 & 0.01 & - & 0.02 & - & - & - & - & 0.04 & 0.03 & - & - & - & - & - & 0.06 \\
\hline Araraquara & 0.05 & 0.02 & - & - & - & - & - & 0.01 & 0.04 & - & - & - & - & - & - & - & - & - & - & 0.05 \\
\hline Sao Carlos & 0.02 & - & - & - & 0.01 & - & - & 0.02 & 0.13 & - & - & - & 0.01 & - & 0.03 & - & - & - & - & 0.08 \\
\hline Rio Claro & - & 0.02 & - & 0.03 & 0.05 & 0.05 & - & 0.04 & 0.03 & 0.02 & - & 0.01 & - & - & 0.02 & - & - & - & - & 0.05 \\
\hline Limeira & - & - & - & 0.01 & 0.01 & 0.06 & 0.01 & 0.03 & 0.04 & - & - & - & 0.04 & - & 0.05 & - & - & - & - & 0.03 \\
\hline Piracicaba & 0.02 & 0.03 & - & - & - & 0.02 & 0.01 & 0.03 & 0.07 & - & - & - & 0.02 & - & - & - & - & - & - & 0.06 \\
\hline Pirassununga & - & - & 0.01 & 0.01 & 0.02 & 0.08 & - & 0.01 & - & 0.02 & - & - & - & - & 0.02 & - & - & - & - & 0.02 \\
\hline Sao Joao da Boa Vista & - & 0.02 & - & - & - & 0.05 & - & 0.02 & 0.02 & - & - & - & 0.02 & - & - & - & - & - & - & 0.02 \\
\hline Moji-Mirim & 0.04 & - & - & 0.02 & - & 0.03 & - & 0.02 & 0.03 & - & - & - & 0.06 & - & 0.02 & - & - & - & - & 0.06 \\
\hline Campinas & 0.05 & 0.02 & - & 0.03 & 0.02 & 0.02 & - & 0.02 & 0.03 & - & 0.01 & - & 0.03 & - & - & - & - & - & - & 0.08 \\
\hline Amparo & 0.07 & 0.03 & - & 0.03 & - & 0.01 & - & 0.02 & 0.01 & - & - & - & 0.02 & - & - & - & - & - & - & 0.05 \\
\hline Dracena & - & - & - & - & - & 0.07 & - & - & 0.01 & - & - & - & - & - & 0.01 & - & - & - & - & 0.01 \\
\hline Adamantina & - & 0.04 & - & - & - & - & - & - & - & - & - & - & - & - & 0.03 & - & - & - & - & 0.04 \\
\hline Presidente Prudente & - & - & 0.02 & - & - & - & - & - & - & - & - & - & - & - & 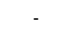 & - & 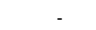 & - & - & 0.03 \\
\hline Tupa & 0.05 & - & - & - & - & - & - & 0.02 & 0.01 & - & - & - & - & - & 0.04 & - & - & - & - & 0.02 \\
\hline Marilia & - & - & - & - & 0.02 & - & - & 0.04 & 0.04 & - & - & - & - & - & - & - & - & - & - & 0.04 \\
\hline Assis & - & - & - & - & - & - & - & - & - & - & - & - & - & - & - & - & - & - & - & 0.03 \\
\hline Ourinhos & - & 0.05 & 0.01 & & - & 0.02 & - & 0.01 & 0.03 & - & - & - & - & - & 0.02 & - & - & - & - & 0.03 \\
\hline Itapeva & - & - & - & - & - & 0.04 & - & - & - & - & - & - & - & - & - & - & - & - & - & 0.06 \\
\hline Itapetininga & 0.01 & 0.04 & - & 0.02 & - & 0.01 & - & - & - & - & - & - & - & - & - & - & - & - & - & 0.08 \\
\hline Tatui & 0.02 & 0.03 & - & 0.01 & 0.02 & 0.05 & - & 0.03 & - & 0.05 & - & - & - & - & 0.03 & - & - & - & - & 0.09 \\
\hline Capao Bonito & - & - & - & & & 0.04 & - & - & - & & - & - & - & - & 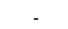 & - & 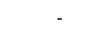 & - & - & 0.02 \\
\hline Piedade & - & - & - & 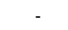 & - & & - & - & - & 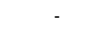 & - & - & - & - & - & - & - & - & - & 0.50 \\
\hline Sorocaba & 0.02 & 0.02 & - & 0.02 & 0.03 & 0.03 & 0.03 & 0.03 & 0.04 & 0.01 & 0.01 & - & 0.04 & - & 0.02 & - & - & - & - & 0.05 \\
\hline Jundiai & 0.02 & 0.01 & - & 0.03 & 0.04 & 0.04 & - & 0.07 & 0.02 & & - & - & 0.01 & - & 0.01 & - & - & - & - & 0.08 \\
\hline Braganca Paulista & 0.04 & 0.02 & - & 0.01 & 0.01 & 0.02 & - & 0.01 & - & 0.02 & - & - & 0.02 & - & - & - & - & - & - & 0.29 \\
\hline Campos do Jordao & 0.01 & - & - & & & & - & - & - & 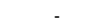 & - & - & & & & - & - & - & - & 0.05 \\
\hline Sao Jose dos Campos & - & - & - & 0.02 & 0.01 & - & 0.02 & 0.02 & 0.02 & - & 0.02 & - & 0.07 & 0.04 & 0.01 & - & - & - & - & 0.12 \\
\hline Guaratingueta & - & - & - & 0.04 & 0.02 & 0.01 & - & 0.02 & - & - & - & - & 0.06 & - & - & - & - & - & - & 0.03 \\
\hline Bananal & - & - & - & - & 0.04 & - & - & - & - & - & - & - & - & - & - & - & - & - & - & - \\
\hline Paraibuna/Paraitinga & - & - & - & - & - & - & - & 0.03 & - & - & - & - & 0.07 & - & - & - & - & - & - & 0.19 \\
\hline Caraguatatuba & - & - & - & - & - & - & - & - & - & - & - & - & - & - & - & - & - & - & - & 0.03 \\
\hline Registro & - & - & - & 0.02 & - & 0.01 & - & - & - & - & - & - & - & - & - & - & - & - & - & 0.04 \\
\hline Itanhaem & - & - & - & . & - & 0.01 & - & - & - & - & - & - & - & - & - & - & - & - & - & 0.02 \\
\hline Osasco & - & - & - & 0.02 & 0.02 & - & - & 0.02 & 0.01 & 0.01 & - & - & - & - & - & - & - & 0.02 & - & 0.30 \\
\hline Franco da Rocha & 0.02 & - & 0.01 & - & 0.05 & 0.01 & - & 0.02 & 0.02 & - & 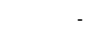 & - & 0.01 & - & 0.02 & - & - & - & - & 0.08 \\
\hline Guarulhos & 0.03 & - & - & 0.04 & 0.05 & 0.01 & 0.02 & 0.04 & 0.03 & 0.03 & - & - & 0.04 & - & 0.01 & - & - & - & - & 0.07 \\
\hline Itapecerica da Serra & 0.01 & - & - & 0.04 & 0.03 & - & - & 0.02 & 0.01 & 0.02 & - & - & 0.01 & - & 0.02 & - & - & - & - & 0.36 \\
\hline Sao Paulo & - & 0.02 & - & 0.01 & 0.02 & - & - & 0.01 & 0.01 & - & - & - & 0.02 & - & - & - & - & 0.01 & - & 0.10 \\
\hline Moji das Cruzes & 0.02 & - & 0.01 & 0.03 & 0.02 & 0.02 & 0.01 & 0.03 & 0.02 & 0.02 & - & - & - & - & 0.03 & - & - & 0.01 & - & 0.20 \\
\hline Santos & - & - & - & 0.02 & - & - & 0.02 & - & - & - & - & - & - & - & - & - & - & - & - & 0.08 \\
\hline
\end{tabular}

Observações/Filtro: CC $\geq 0,01$ (ou, 1\%).

FONTE: Elaborado pelo auto com base nos dados da RAIS/MTE 
Anexo XXIII. Coeficiente de concentração para as atividades da indústria de transformação selecionadas - São Paulo/2003.

\begin{tabular}{|c|c|c|c|c|c|c|c|c|c|c|c|c|c|c|c|c|c|c|c|c|}
\hline Divisão & 17 & 18 & 19 & 24 & 25 & 26 & 27 & 28 & 29 & 31 & 32 & 33 & 34 & 35 & 36 & 37 & 71 & 72 & 7 & 74 \\
\hline & 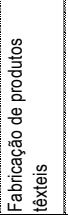 & 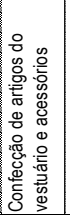 & 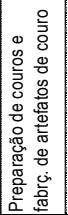 & 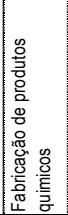 & 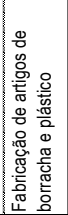 & 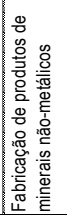 & 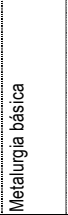 & 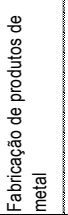 & 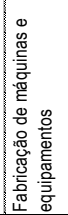 & 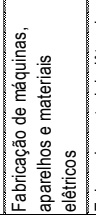 & 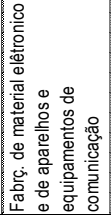 & 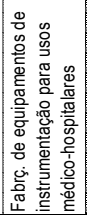 & 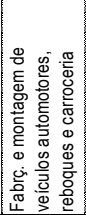 & 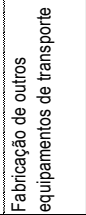 & 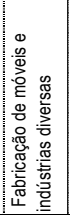 & 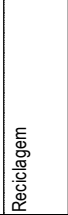 & 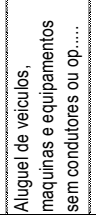 & 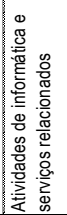 & 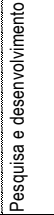 & 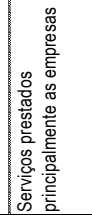 \\
\hline $\begin{array}{l}\text { Jales } \\
\end{array}$ & - & 0.01 & - & - & - & 0.01 & - & - & - & - & - & - & - & - & - & - & - & - & - & 0.19 \\
\hline Fernandopolis & - & 0.03 & - & - & - & - & - & 0.01 & - & - & - & - & - & - & 0.04 & - & - & - & - & 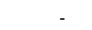 \\
\hline Votuporanga & - & 0.03 & - & - & - & - & - & - & - & - & - & - & 0.07 & - & 0.13 & - & - & - & - & 0.03 \\
\hline Sao Jose do Rio Preto & - & 0.02 & - & - & - & - & - & 0.03 & - & - & - & - & - & - & 0.04 & - & - & - & - & 0.04 \\
\hline Catanduva & - & - & - & - & - & - & - & 0.02 & 0.02 & - & - & - & - & - & 0.01 & - & - & - & - & 0.04 \\
\hline Auriflama & - & 0.16 & - & - & - & - & - & - & 0.02 & - & - & - & - & - & 0.01 & - & - & - & - & - \\
\hline Nhandeara & - & 0.02 & 0.01 & - & - & 0.01 & 0.01 & 0.04 & - & - & - & - & - & - & 0.02 & - & - & - & - & - \\
\hline Novo Horizonte & 0.02 & 0.04 & - & - & - & - & - & - & - & - & - & - & - & - & 0.02 & - & - & - & - & 0.01 \\
\hline Barretos & - & - & - & - & 0.01 & - & - & - & - & - & - & - & - & - & - & - & - & - & - & 0.01 \\
\hline Sao Joaquim da Barra & - & - & - & - & - & - & 0.03 & - & 0.02 & - & - & - & - & - & - & - & - & - & - & 0.01 \\
\hline Ituverava & 0.01 & - & - & 0.02 & - & 0.01 & - & 0.01 & 0.02 & - & - & - & - & - & 0.02 & - & - & - & - & 0.03 \\
\hline Franca & - & 0.01 & 0.33 & - & 0.04 & - & - & - & - & - & - & - & - & - & - & - & - & - & - & 0.04 \\
\hline Jaboticabal & - & 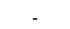 & 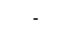 & & 0.02 & - & 0.01 & 0.01 & 0.02 & - & - & - & - & - & - & - & 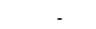 & - & - & 0.02 \\
\hline Ribeirao Preto & - & - & - & 0.01 & - & - & - & 0.02 & 0.02 & - & - & 0.01 & - & - & - & - & - & - & - & 0.08 \\
\hline Batatais & - & 0.03 & - & 0.01 & 0.01 & - & 0.03 & 0.01 & 0.04 & - & - & - & 0.02 & - & - & - & - & - & - & 0.02 \\
\hline Andradina & - & - & - & - & - & - & - & - & - & - & - & - & - & - & - & - & - & - & - & 0.08 \\
\hline Aracatuba & - & 0.01 & 0.01 & - & - & - & - & - & 0.02 & - & - & - & - & - & 0.02 & - & - & - & - & 0.04 \\
\hline Birigui & - & 0.02 & 0.31 & - & 0.02 & 0.01 & - & 0.01 & - & - & - & - & - & - & 0.04 & - & - & - & - & 0.03 \\
\hline Lins & - & - & 0.08 & - & - & - & - & 0.01 & - & - & - & - & - & - & - & - & - & - & - & 0.04 \\
\hline Bauru & 0.01 & 0.01 & - & - & 0.01 & - & - & 0.01 & - & 0.02 & - & - & - & - & - & - & - & - & - & 0.07 \\
\hline Jau & 0.02 & 0.01 & 0.09 & - & 0.02 & 0.02 & - & - & - & - & - & - & - & - & 0.01 & - & - & - & - & 0.12 \\
\hline Avare & - & 0.04 & - & - & 0.01 & 0.01 & - & - & - & - & - & - & - & - & - & - & - & - & - & 0.01 \\
\hline Botucatu & 0.01 & 0.04 & - & - & 0.02 & 0.01 & - & 0.02 & - & - & - & - & 0.05 & 0.03 & - & - & - & - & - & 0.04 \\
\hline Araraquara & 0.05 & 0.02 & - & - & - & - & - & 0.01 & 0.05 & - & - & - & - & - & - & - & - & - & - & 0.04 \\
\hline Sao Carlos & 0.02 & - & - & - & - & - & - & 0.02 & 0.12 & - & - & - & 0.01 & - & 0.03 & - & - & - & - & 0.08 \\
\hline Rio Claro & - & 0.01 & - & 0.02 & 0.05 & 0.04 & - & 0.03 & 0.04 & 0.02 & - & 0.01 & - & - & 0.03 & - & - & - & - & 0.04 \\
\hline Limeira & - & - & - & 0.01 & 0.01 & 0.05 & 0.01 & 0.04 & 0.04 & - & - & - & 0.04 & - & 0.04 & - & - & - & - & 0.03 \\
\hline Piracicaba & 0.02 & 0.03 & - & - & - & 0.02 & 0.01 & 0.02 & 0.08 & - & - & - & 0.02 & - & - & - & - & - & - & 0.06 \\
\hline Pirassununga & - & - & 0.01 & 0.01 & 0.02 & 0.07 & - & - & - & 0.03 & - & - & - & - & 0.02 & - & - & - & - & 0.02 \\
\hline Sao Joao da Boa Vista & - & 0.02 & - & - & - & 0.05 & - & 0.03 & 0.02 & - & - & - & 0.02 & - & - & - & - & - & - & 0.01 \\
\hline Moji-Mirim & 0.03 & - & - & 0.02 & - & 0.02 & - & 0.02 & 0.03 & - & - & - & 0.07 & - & 0.02 & - & 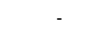 & - & - & 0.06 \\
\hline Campinas & 0.05 & 0.01 & - & 0.04 & 0.02 & 0.02 & - & 0.02 & 0.02 & - & 0.01 & - & 0.04 & - & - & - & - & - & - & 0.07 \\
\hline Amparo & 0.06 & 0.03 & - & 0.03 & - & 0.01 & - & 0.02 & 0.01 & - & - & - & 0.02 & - & - & - & - & - & - & 0.06 \\
\hline Dracena & - & - & - & - & - & 0.07 & - & - & 0.01 & - & - & - & - & - & 0.02 & - & - & - & - & 0.01 \\
\hline Adamantina & - & 0.05 & - & - & - & - & - & - & - & - & - & - & - & - & 0.03 & - & - & - & - & 0.04 \\
\hline Presidente Prudente & - & 0.01 & 0.02 & - & . & - & - & - & - & - & - & - & - & - & - & - & 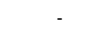 & - & - & 0.03 \\
\hline Tupa & 0.05 & - & - & - & - & - & - & 0.02 & 0.02 & - & - & - & - & - & 0.03 & - & - & - & - & 0.02 \\
\hline Marilia & - & - & - & - & 0.02 & - & - & 0.04 & 0.04 & - & - & - & - & - & - & - & - & - & - & 0.04 \\
\hline Assis & - & - & - & - & - & - & - & - & - & - & - & - & - & - & - & - & - & - & - & 0.03 \\
\hline Ourinhos & - & 0.05 & 0.01 & & - & 0.02 & - & 0.01 & 0.03 & - & - & - & - & - & 0.02 & - & - & - & - & 0.02 \\
\hline Itapeva & - & - & - & - & - & 0.03 & - & - & - & - & - & - & - & - & - & - & - & - & - & 0.05 \\
\hline Itapetininga & 0.01 & 0.03 & - & 0.02 & - & 0.01 & - & - & - & - & - & - & - & - & - & - & - & - & - & 0.08 \\
\hline Tatui & 0.05 & 0.02 & - & 0.01 & 0.03 & 0.05 & - & 0.03 & - & 0.05 & - & - & - & - & 0.03 & - & - & - & - & 0.10 \\
\hline Capao Bonito & - & - & - & & & 0.03 & - & - & - & & - & - & - & - & 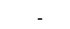 & - & 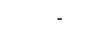 & - & - & 0.03 \\
\hline Piedade & - & - & - & . & - & & - & - & - & . & - & - & - & - & - & - & - & - & - & 0.39 \\
\hline Sorocaba & 0.02 & 0.02 & - & 0.02 & 0.03 & 0.02 & 0.03 & 0.03 & 0.03 & 0.02 & - & - & 0.04 & - & 0.02 & - & - & - & - & 0.07 \\
\hline Jundiai & 0.02 & 0.01 & - & 0.02 & 0.04 & 0.04 & - & 0.07 & 0.02 & & - & - & 0.02 & - & - & - & - & 0.01 & - & 0.07 \\
\hline Braganca Paulista & 0.05 & 0.02 & - & 0.01 & 0.01 & 0.01 & - & 0.02 & 0.01 & 0.02 & - & - & 0.02 & - & - & - & - & - & - & 0.24 \\
\hline Campos do Jordao & 0.01 & - & - & & & & - & - & - & 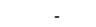 & - & - & & & & - & - & - & - & 0.03 \\
\hline Sao Jose dos Campos & - & - & - & 0.02 & 0.01 & - & 0.02 & 0.02 & 0.02 & - & 0.01 & - & 0.08 & 0.04 & 0.01 & - & - & - & - & 0.12 \\
\hline Guaratingueta & - & - & - & 0.05 & 0.02 & - & - & 0.02 & - & - & - & - & 0.07 & - & - & - & - & - & - & 0.03 \\
\hline Bananal & - & - & - & - & - & - & - & - & - & - & - & - & - & - & - & - & - & - & - & 0.01 \\
\hline Paraibuna/Paraitinga & - & - & - & - & - & - & - & - & - & - & - & - & 0.06 & - & - & - & - & 0.02 & - & 0.16 \\
\hline Caraguatatuba & - & - & - & - & - & - & - & - & - & - & - & - & - & - & - & - & - & - & - & 0.04 \\
\hline Registro & - & - & - & 0.02 & - & 0.01 & - & - & - & - & - & - & - & - & - & - & - & - & - & 0.06 \\
\hline Itanhaem & - & - & - & - & - & - & - & - & - & - & - & - & - & - & - & - & - & - & - & 0.02 \\
\hline Osasco & - & - & - & 0.02 & 0.02 & - & - & 0.02 & 0.01 & - & - & - & - & - & - & - & - & 0.02 & - & 0.30 \\
\hline Franco da Rocha & 0.02 & - & 0.01 & 0.01 & 0.04 & 0.01 & - & 0.02 & 0.02 & 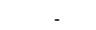 & - & - & 0.01 & - & 0.02 & - & - & - & - & 0.07 \\
\hline Guarulhos & 0.03 & - & - & 0.04 & 0.05 & 0.01 & 0.03 & 0.04 & 0.03 & 0.03 & - & - & 0.04 & - & 0.01 & - & - & - & - & 0.06 \\
\hline Itapecerica da Serra & 0.01 & - & - & 0.05 & 0.03 & - & - & 0.02 & 0.02 & 0.01 & - & - & 0.02 & - & 0.02 & - & - & - & - & 0.29 \\
\hline Sao Paulo & - & 0.02 & - & 0.01 & 0.01 & - & - & 0.01 & 0.01 & - & - & - & 0.02 & - & - & - & - & 0.01 & - & 0.11 \\
\hline Moji das Cruzes & 0.02 & - & 0.01 & 0.03 & 0.02 & 0.02 & 0.02 & 0.03 & 0.02 & 0.02 & - & - & - & - & 0.03 & - & - & 0.02 & - & 0.20 \\
\hline Santos & - & - & - & 0.02 & - & - & 0.02 & - & - & - & - & - & - & - & - & - & - & - & - & 0.08 \\
\hline
\end{tabular}

Observações/Filtro: $C C \geq 0,01$ (ou, 1\%).

FONTE: Elaborado pelo auto com base nos dados da RAIS/MTE 
Anexo XXIV. Coeficiente de concentração para as atividades da indústria de transformação selecionadas - São Paulo/2004.

\begin{tabular}{|c|c|c|c|c|c|c|c|c|c|c|c|c|c|c|c|c|c|c|c|c|}
\hline Divisão & 17 & 18 & 19 & 24 & 25 & 26 & 27 & 28 & 29 & 31 & 32 & 33 & 34 & 35 & 36 & 37 & 71 & 72 & 7 & 74 \\
\hline & 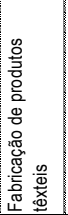 & 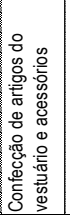 & 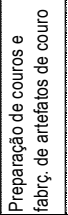 & 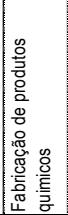 & 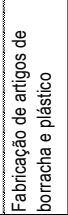 & 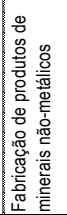 & 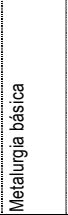 & 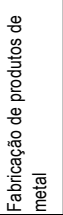 & 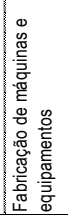 & 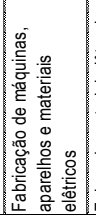 & 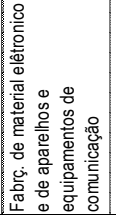 & 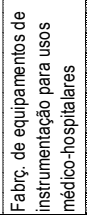 & 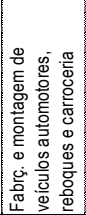 & 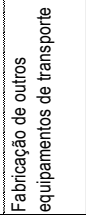 & 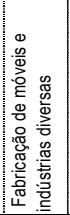 & 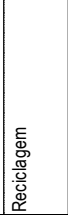 & 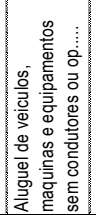 & 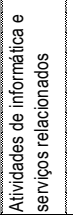 & 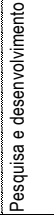 & 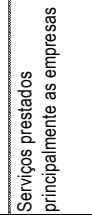 \\
\hline $\begin{array}{l}\text { Jales } \\
\end{array}$ & - & 0.01 & - & - & - & - & - & - & - & - & - & - & - & - & - & - & - & - & - & 0.21 \\
\hline Fernandopolis & - & 0.02 & - & - & - & - & - & 0.02 & - & - & - & - & - & - & 0.04 & - & - & - & - & - \\
\hline Votuporanga & - & 0.03 & - & - & - & - & - & - & - & - & - & - & 0.08 & - & 0.14 & - & - & - & - & - \\
\hline Sao Jose do Rio Preto & - & 0.03 & - & - & - & - & - & 0.02 & 0.01 & - & - & - & - & - & 0.04 & - & - & - & - & 0.04 \\
\hline Catanduva & - & 0.01 & - & - & - & - & - & 0.01 & 0.03 & - & - & - & - & - & 0.01 & - & - & - & - & 0.02 \\
\hline Auriflama & - & 0.19 & - & - & - & - & - & - & 0.02 & - & - & - & - & - & 0.01 & - & - & - & - & - \\
\hline Nhandeara & - & 0.02 & 0.02 & - & - & - & 0.01 & 0.04 & - & - & - & - & - & - & 0.02 & - & - & - & - & 0.02 \\
\hline Novo Horizonte & - & 0.05 & - & - & - & - & - & - & - & - & - & - & - & - & 0.02 & - & - & - & - & - \\
\hline Barretos & - & - & - & - & - & - & - & - & - & 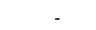 & - & - & - & - & - & - & - & - & - & 0.02 \\
\hline Sao Joaquim da Barra & - & - & - & - & - & - & 0.03 & - & 0.02 & 0.01 & - & - & - & - & - & - & - & - & - & 0.02 \\
\hline Ituverava & 0.01 & - & - & 0.02 & - & 0.01 & - & - & 0.02 & - & - & - & - & - & 0.02 & - & - & - & - & 0.03 \\
\hline Franca & - & 0.01 & 0.37 & - & 0.04 & - & - & - & - & - & - & - & - & - & - & - & - & - & - & 0.03 \\
\hline Jaboticabal & - & 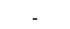 & 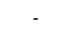 & & 0.03 & - & - & 0.02 & 0.02 & . & - & - & - & - & - & - & 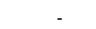 & - & - & 0.03 \\
\hline Ribeirao Preto & - & 0.01 & - & 0.02 & - & - & - & 0.01 & 0.02 & - & - & 0.01 & - & - & - & - & - & - & - & 0.08 \\
\hline Batatais & - & 0.04 & - & 0.01 & 0.02 & - & 0.04 & 0.01 & 0.04 & - & - & - & 0.02 & - & - & - & - & - & - & 0.02 \\
\hline Andradina & - & - & - & - & - & - & - & - & - & - & - & - & - & - & - & - & - & - & - & 0.05 \\
\hline Aracatuba & - & 0.01 & 0.02 & - & - & - & - & - & 0.02 & - & - & - & - & - & 0.02 & - & - & - & - & 0.03 \\
\hline Birigui & - & 0.03 & 0.33 & - & 0.02 & - & - & 0.01 & - & - & - & - & - & - & 0.03 & - & - & - & - & 0.01 \\
\hline Lins & - & - & 0.09 & - & - & - & - & - & - & - & - & - & - & - & - & - & - & - & - & 0.02 \\
\hline Bauru & - & 0.01 & - & - & 0.01 & - & - & 0.01 & - & 0.02 & - & - & - & - & - & - & - & - & - & 0.06 \\
\hline Jau & 0.01 & 0.01 & 0.12 & - & 0.01 & 0.02 & - & - & - & - & - & - & - & - & 0.01 & - & - & 0.01 & - & 0.02 \\
\hline Avare & - & 0.04 & - & - & 0.01 & - & - & - & - & - & - & - & - & - & - & - & - & - & - & 0.01 \\
\hline Botucatu & 0.02 & 0.06 & - & - & 0.02 & 0.01 & - & 0.02 & - & - & - & - & 0.05 & 0.03 & - & - & - & - & - & 0.04 \\
\hline Araraquara & 0.06 & 0.02 & - & - & - & - & - & 0.01 & 0.04 & - & - & - & - & - & - & - & - & - & - & 0.03 \\
\hline Sao Carlos & 0.02 & - & - & - & - & 0.01 & - & 0.02 & 0.13 & - & - & - & 0.01 & - & 0.03 & - & - & - & - & 0.07 \\
\hline Rio Claro & - & 0.01 & - & 0.02 & 0.04 & 0.05 & - & 0.03 & 0.04 & 0.03 & - & 0.01 & - & - & 0.03 & - & - & - & - & 0.04 \\
\hline Limeira & - & - & - & 0.01 & 0.02 & 0.06 & 0.01 & 0.04 & 0.04 & - & - & - & 0.04 & - & 0.04 & - & - & - & - & 0.03 \\
\hline Piracicaba & 0.02 & 0.03 & - & - & - & 0.02 & 0.01 & 0.02 & 0.08 & - & - & - & 0.03 & - & - & - & - & - & - & 0.05 \\
\hline Pirassununga & - & - & - & - & 0.02 & 0.07 & - & - & - & 0.03 & - & - & - & - & 0.02 & - & - & - & - & 0.01 \\
\hline Sao Joao da Boa Vista & - & 0.02 & - & 0.01 & - & 0.05 & - & 0.02 & 0.02 & 0.02 & - & - & - & - & - & - & - & - & - & 0.01 \\
\hline Moji-Mirim & 0.03 & - & - & 0.02 & - & 0.02 & - & 0.03 & 0.03 & - & - & - & 0.08 & - & 0.02 & - & - & - & - & 0.05 \\
\hline Campinas & 0.04 & 0.01 & - & 0.03 & 0.02 & 0.02 & - & 0.02 & 0.02 & - & 0.01 & - & 0.04 & - & - & - & - & - & - & 0.07 \\
\hline Amparo & 0.07 & 0.04 & - & 0.03 & - & 0.01 & - & 0.02 & 0.01 & - & - & - & 0.02 & - & - & - & - & - & - & 0.01 \\
\hline Dracena & - & - & - & - & - & 0.07 & - & - & 0.01 & - & - & - & - & - & 0.01 & - & - & - & - & 0.01 \\
\hline Adamantina & - & 0.06 & 0.01 & - & - & - & - & - & - & - & - & - & - & - & 0.02 & - & - & - & - & 0.03 \\
\hline Presidente Prudente & - & 0.01 & 0.03 & - & . & . & - & - & - & - & - & - & - & - & - & - & 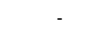 & - & - & 0.02 \\
\hline Tupa & 0.05 & - & - & - & - & - & - & 0.01 & 0.02 & - & - & - & - & - & 0.02 & - & - & - & - & 0.02 \\
\hline Marilia & - & - & - & - & 0.02 & - & - & 0.03 & 0.04 & - & - & - & - & - & - & - & - & - & - & 0.05 \\
\hline Assis & - & - & - & - & - & - & - & - & - & - & - & - & - & - & - & - & - & - & - & 0.03 \\
\hline Ourinhos & - & 0.06 & 0.02 & & - & 0.02 & 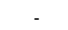 & 0.01 & 0.03 & - & - & - & - & - & 0.02 & - & - & - & - & 0.02 \\
\hline Itapeva & - & - & - & - & - & 0.02 & 0.01 & - & - & - & - & - & - & - & - & - & - & - & - & 0.05 \\
\hline Itapetininga & 0.01 & 0.03 & - & 0.02 & - & & - & - & - & . & - & - & - & - & 0.01 & - & - & - & - & 0.08 \\
\hline Tatui & 0.03 & 0.03 & - & 0.01 & 0.03 & 0.04 & 0.01 & 0.03 & - & 0.05 & - & - & 0.01 & - & 0.03 & - & - & - & - & 0.07 \\
\hline Capao Bonito & - & - & - & & & 0.03 & - & - & - & & - & - & - & - & & - & 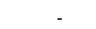 & - & - & 0.01 \\
\hline Piedade & - & - & - & & & & - & 0.01 & - & 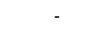 & - & - & - & - & - & - & - & - & - & 0.34 \\
\hline Sorocaba & 0.02 & 0.02 & - & 0.02 & 0.03 & 0.02 & 0.03 & 0.03 & 0.03 & 0.02 & - & - & 0.04 & - & 0.02 & - & - & - & - & 0.07 \\
\hline Jundiai & 0.02 & 0.01 & - & 0.02 & 0.04 & 0.04 & - & 0.08 & 0.02 & & - & - & 0.02 & - & - & - & - & 0.02 & - & 0.07 \\
\hline Braganca Paulista & 0.06 & 0.02 & - & 0.02 & 0.01 & 0.01 & - & 0.02 & 0.01 & 0.03 & - & - & 0.02 & - & - & - & - & - & - & 0.22 \\
\hline Campos do Jordao & 0.01 & - & - & & & & - & - & - & 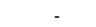 & - & - & & & & - & - & - & - & 0.04 \\
\hline Sao Jose dos Campos & - & - & - & 0.02 & 0.02 & - & 0.02 & 0.02 & 0.02 & - & 0.02 & - & 0.08 & 0.05 & 0.01 & - & - & - & - & 0.12 \\
\hline Guaratingueta & - & - & - & 0.04 & 0.03 & - & - & 0.02 & 0.01 & - & - & - & 0.08 & - & - & - & - & - & - & 0.03 \\
\hline Bananal & - & - & - & - & - & - & - & - & - & - & - & - & - & - & - & - & - & - & - & - \\
\hline Paraibuna/Paraitinga & - & - & - & - & 0.01 & - & - & 0.02 & - & - & - & - & 0.06 & - & - & - & - & - & - & 0.14 \\
\hline Caraguatatuba & - & - & - & - & - & - & - & - & - & - & - & - & - & - & - & - & - & - & - & 0.04 \\
\hline Registro & - & - & - & 0.02 & - & 0.01 & - & - & - & - & - & - & - & - & - & - & - & - & - & 0.04 \\
\hline Itanhaem & - & - & - & 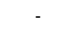 & - & - & - & - & - & - & - & - & - & - & - & - & - & - & - & 0.02 \\
\hline Osasco & - & - & - & 0.02 & 0.02 & - & - & 0.02 & 0.01 & 0.01 & - & - & 0.01 & - & - & - & - & 0.02 & - & 0.29 \\
\hline Franco da Rocha & 0.02 & - & 0.01 & 0.01 & 0.05 & 0.01 & - & 0.02 & 0.02 & - & 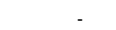 & - & 0.01 & - & 0.02 & - & - & - & - & 0.08 \\
\hline Guarulhos & 0.03 & - & - & 0.04 & 0.05 & 0.01 & 0.03 & 0.04 & 0.03 & 0.02 & - & - & 0.04 & - & 0.01 & - & - & - & - & 0.06 \\
\hline Itapecerica da Serra & 0.01 & - & - & 0.05 & 0.04 & - & - & 0.02 & 0.02 & 0.01 & - & - & 0.02 & - & 0.02 & - & 0.01 & 0.01 & - & 0.29 \\
\hline Sao Paulo & - & 0.02 & - & 0.01 & 0.02 & - & - & 0.02 & 0.01 & - & - & - & 0.02 & - & - & - & - & 0.01 & - & 0.12 \\
\hline Moji das Cruzes & 0.02 & - & 0.01 & 0.03 & 0.02 & 0.02 & 0.02 & 0.03 & 0.02 & 0.02 & - & - & - & - & 0.03 & - & - & - & - & 0.18 \\
\hline Santos & - & - & - & 0.02 & - & - & 0.02 & - & - & - & - & - & - & - & - & - & - & - & - & 0.08 \\
\hline
\end{tabular}

Observações/Filtro: CC $\geq 0,01$ (ou, 1\%).

FONTE: Elaborado pelo auto com base nos dados da RAIS/MTE 
Anexo XXV. Coeficiente de concentração para as atividades da indústria de transformação selecionadas - São Paulo/2005.

\begin{tabular}{|c|c|c|c|c|c|c|c|c|c|c|c|c|c|c|c|c|c|c|c|c|}
\hline Divisão & 17 & 18 & 19 & 24 & 25 & 26 & 27 & 28 & 29 & 31 & 32 & 33 & 34 & 35 & 36 & 37 & 71 & 72 & 7 & 74 \\
\hline & 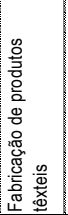 & 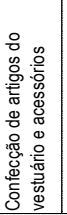 & 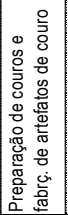 & 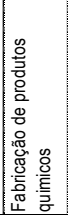 & 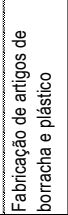 & 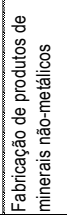 & 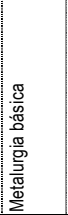 & 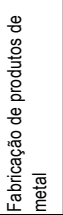 & 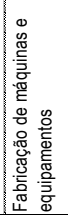 & 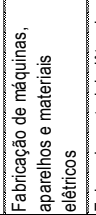 & 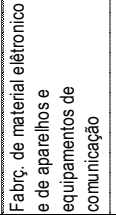 & 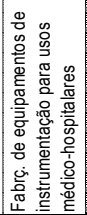 & 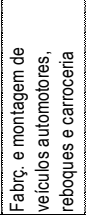 & 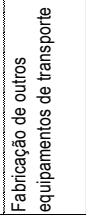 & 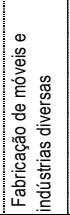 & 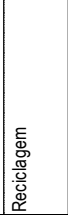 & 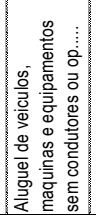 & 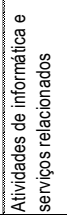 & 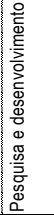 & 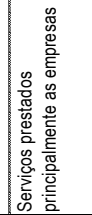 \\
\hline $\begin{array}{l}\text { Jales } \\
\end{array}$ & - & - & 0.01 & - & - & - & - & 0.01 & - & - & - & - & - & - & - & - & - & - & - & 0.09 \\
\hline Fernandopolis & - & 0.02 & - & - & - & - & - & 0.02 & - & - & - & - & - & - & 0.03 & - & - & - & - & - \\
\hline Votuporanga & - & 0.02 & - & - & - & - & - & - & - & - & - & - & 0.06 & - & 0.13 & - & - & - & - & - \\
\hline Sao Jose do Rio Preto & - & 0.03 & - & - & - & - & - & 0.03 & - & - & - & - & - & - & 0.04 & - & - & - & - & 0.03 \\
\hline Catanduva & - & 0.02 & - & - & - & - & - & 0.01 & 0.03 & - & - & - & - & - & 0.01 & - & - & - & - & 0.03 \\
\hline Auriflama & - & 0.18 & - & - & - & - & - & - & 0.01 & - & - & - & - & - & 0.01 & - & - & - & - & - \\
\hline Nhandeara & - & 0.02 & 0.02 & - & - & - & 0.01 & 0.04 & - & - & - & - & - & - & 0.01 & - & - & - & - & 0.02 \\
\hline Novo Horizonte & - & 0.06 & - & - & - & - & - & - & - & - & - & - & - & - & - & - & - & - & - & - \\
\hline Barretos & - & - & - & - & 0.01 & - & - & - & - & 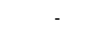 & - & - & - & - & - & - & - & - & - & 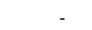 \\
\hline Sao Joaquim da Barra & - & - & - & - & - & - & 0.03 & - & 0.01 & 0.01 & - & - & - & - & - & - & - & - & - & 0.01 \\
\hline Ituverava & 0.01 & - & - & 0.02 & - & 0.01 & - & - & 0.01 & - & - & - & - & - & 0.02 & - & - & - & - & 0.03 \\
\hline Franca & - & 0.01 & 0.33 & - & 0.04 & - & - & - & - & - & - & - & - & - & - & - & - & - & - & 0.03 \\
\hline Jaboticabal & - & 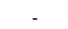 & 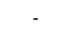 & & 0.03 & - & - & 0.02 & 0.02 & . & - & - & - & - & - & - & 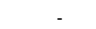 & - & - & 0.03 \\
\hline Ribeirao Preto & - & 0.01 & - & 0.02 & - & - & - & 0.02 & 0.02 & - & - & 0.01 & - & - & - & - & - & - & - & 0.08 \\
\hline Batatais & - & 0.04 & - & - & 0.01 & - & 0.03 & 0.01 & 0.04 & - & - & - & 0.02 & - & - & - & - & - & - & 0.02 \\
\hline Andradina & - & - & - & - & - & - & - & - & - & - & - & - & - & - & - & - & - & - & - & 0.06 \\
\hline Aracatuba & - & 0.01 & 0.01 & - & - & - & - & - & 0.02 & - & - & - & - & - & 0.02 & - & - & - & - & 0.03 \\
\hline Birigui & - & 0.03 & 0.31 & - & 0.02 & 0.01 & - & 0.01 & - & - & - & - & - & - & 0.03 & - & - & - & - & 0.01 \\
\hline Lins & - & - & 0.09 & - & - & - & - & - & - & - & - & - & - & - & - & - & - & - & - & 0.02 \\
\hline Bauru & - & - & - & - & 0.01 & - & - & 0.01 & - & 0.02 & - & - & - & - & - & - & - & - & - & 0.06 \\
\hline Jau & - & 0.01 & 0.12 & - & 0.02 & 0.02 & - & - & - & - & - & - & 0.01 & - & 0.01 & - & - & 0.02 & - & 0.02 \\
\hline Avare & - & 0.04 & - & - & 0.02 & - & - & - & - & - & - & - & - & - & - & - & - & - & - & 0.01 \\
\hline Botucatu & 0.02 & 0.05 & - & - & 0.02 & 0.01 & - & 0.01 & - & - & - & - & 0.05 & 0.03 & - & - & - & - & - & 0.06 \\
\hline Araraquara & 0.06 & 0.02 & - & - & - & - & - & 0.01 & 0.04 & - & - & - & - & - & - & - & - & - & - & 0.06 \\
\hline Sao Carlos & 0.02 & - & - & - & - & 0.01 & - & 0.02 & 0.11 & - & - & - & 0.01 & - & 0.03 & - & - & - & - & 0.07 \\
\hline Rio Claro & - & 0.01 & - & 0.02 & 0.02 & 0.02 & - & 0.03 & 0.03 & 0.05 & - & 0.01 & - & - & 0.02 & - & - & - & - & 0.03 \\
\hline Limeira & - & - & - & - & 0.02 & 0.06 & 0.01 & 0.04 & 0.04 & - & - & - & 0.05 & - & 0.05 & - & - & - & - & 0.03 \\
\hline Piracicaba & 0.02 & 0.03 & - & - & - & 0.02 & 0.01 & 0.02 & 0.08 & - & - & - & 0.02 & - & - & - & - & - & - & 0.06 \\
\hline Pirassununga & - & 0.01 & 0.01 & 0.01 & 0.02 & 0.07 & - & 0.01 & - & 0.03 & - & - & - & - & 0.02 & - & - & - & - & 0.02 \\
\hline Sao Joao da Boa Vista & - & 0.02 & - & 0.01 & - & 0.05 & - & 0.02 & 0.02 & - & - & - & 0.02 & - & - & - & - & - & - & 0.01 \\
\hline Moji-Mirim & 0.04 & - & - & 0.02 & - & 0.02 & - & 0.02 & 0.03 & 0.01 & - & - & 0.08 & - & 0.02 & - & 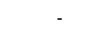 & - & - & 0.05 \\
\hline Campinas & 0.04 & 0.01 & - & 0.03 & 0.02 & 0.02 & - & 0.02 & 0.02 & - & 0.01 & - & 0.04 & - & - & - & - & - & - & 0.08 \\
\hline Amparo & 0.07 & 0.04 & - & 0.04 & - & 0.01 & - & 0.02 & 0.01 & - & - & - & 0.02 & - & - & - & - & - & - & 0.02 \\
\hline Dracena & - & - & - & - & - & 0.07 & - & - & 0.01 & - & - & - & - & - & 0.01 & - & - & - & - & 0.01 \\
\hline Adamantina & - & 0.07 & 0.02 & - & - & - & - & - & - & - & - & - & - & - & 0.02 & - & - & - & - & 0.03 \\
\hline Presidente Prudente & - & 0.01 & 0.03 & - & . & - & - & - & - & . & - & - & - & - & - & - & 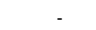 & - & - & 0.02 \\
\hline Tupa & 0.05 & - & - & - & - & - & - & 0.01 & 0.01 & - & - & - & - & - & 0.02 & - & - & - & - & 0.02 \\
\hline Marilia & - & - & - & - & 0.02 & - & - & 0.03 & 0.04 & 0.02 & - & - & - & - & - & - & - & - & - & 0.04 \\
\hline Assis & - & - & - & - & - & - & - & - & - & - & - & - & - & - & - & - & - & - & - & 0.03 \\
\hline Ourinhos & - & 0.06 & 0.01 & & - & 0.01 & 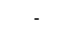 & 0.01 & 0.02 & - & - & - & - & - & 0.02 & - & - & - & - & 0.02 \\
\hline Itapeva & - & - & - & - & - & 0.02 & 0.01 & - & - & - & - & - & - & - & - & - & - & - & - & 0.04 \\
\hline Itapetininga & 0.01 & 0.03 & - & 0.02 & - & & - & - & - & - & - & - & - & - & 0.01 & - & - & - & - & 0.07 \\
\hline Tatui & 0.04 & 0.03 & - & 0.01 & 0.02 & 0.04 & 0.02 & 0.03 & - & 0.04 & - & - & 0.04 & - & 0.03 & - & - & - & - & 0.10 \\
\hline Capao Bonito & - & - & - & & & 0.03 & - & - & - & & - & - & - & - & & - & 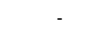 & - & - & 0.02 \\
\hline Piedade & - & - & - & & & & - & 0.01 & - & . & - & - & - & - & - & - & - & - & - & 0.20 \\
\hline Sorocaba & 0.02 & 0.02 & - & 0.02 & 0.03 & 0.03 & 0.03 & 0.03 & 0.04 & 0.02 & - & - & 0.04 & - & 0.02 & - & - & - & - & 0.07 \\
\hline Jundiai & 0.02 & 0.01 & - & 0.02 & 0.04 & 0.03 & - & 0.07 & 0.03 & & - & - & 0.02 & - & - & - & - & - & - & 0.10 \\
\hline Braganca Paulista & 0.05 & 0.02 & - & 0.02 & 0.01 & 0.02 & - & 0.02 & 0.02 & 0.03 & - & - & 0.02 & - & - & - & - & - & - & 0.22 \\
\hline Campos do Jordao & 0.01 & - & - & & & & - & - & - & 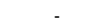 & - & - & & & & - & - & - & - & 0.04 \\
\hline Sao Jose dos Campos & - & - & - & 0.02 & 0.02 & 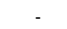 & 0.02 & 0.02 & 0.02 & - & 0.01 & - & 0.07 & 0.05 & 0.01 & - & - & - & - & 0.12 \\
\hline Guaratingueta & - & - & - & 0.04 & 0.03 & 0.01 & - & 0.02 & 0.01 & - & - & - & 0.08 & - & - & - & - & - & - & 0.03 \\
\hline Bananal & - & - & - & - & - & - & - & - & - & - & - & - & - & - & 0.01 & - & - & - & - & - \\
\hline Paraibuna/Paraitinga & - & - & - & - & 0.01 & - & - & 0.02 & - & - & - & - & 0.06 & - & - & - & - & - & - & 0.07 \\
\hline Caraguatatuba & - & - & - & - & - & - & - & - & - & - & - & - & - & - & - & - & - & - & - & 0.04 \\
\hline Registro & - & - & - & 0.02 & - & 0.01 & - & - & - & - & - & - & - & - & - & - & - & - & - & 0.03 \\
\hline Itanhaem & - & - & - & - & - & - & - & - & - & - & - & - & - & - & - & - & - & - & - & 0.01 \\
\hline Osasco & - & - & - & 0.02 & 0.02 & - & - & 0.02 & 0.02 & - & - & - & 0.01 & - & - & - & - & 0.02 & - & 0.28 \\
\hline Franco da Rocha & 0.02 & - & - & 0.01 & 0.06 & - & - & 0.03 & 0.02 & - & - & - & 0.01 & - & 0.02 & - & - & - & - & 0.05 \\
\hline Guarulhos & 0.03 & - & - & 0.04 & 0.05 & 0.01 & 0.03 & 0.05 & 0.03 & 0.02 & - & - & 0.04 & - & 0.01 & - & - & - & - & 0.06 \\
\hline Itapecerica da Serra & 0.01 & - & - & 0.05 & 0.04 & - & - & 0.02 & 0.02 & 0.01 & - & - & 0.02 & - & 0.02 & - & - & 0.02 & - & 0.25 \\
\hline Sao Paulo & - & 0.02 & - & 0.01 & 0.01 & - & - & 0.02 & 0.01 & - & - & - & 0.02 & - & - & - & - & 0.01 & - & 0.13 \\
\hline Moji das Cruzes & 0.02 & - & 0.01 & 0.03 & 0.02 & 0.03 & 0.02 & 0.03 & 0.02 & 0.02 & - & - & 0.01 & - & 0.02 & - & - & 0.01 & - & 0.16 \\
\hline Santos & - & - & - & 0.01 & - & - & 0.02 & - & - & - & - & - & - & - & - & - & - & - & - & 0.08 \\
\hline
\end{tabular}

Observações/Filtro: CC $\geq 0,01$ (ou, 1\%).

FONTE: Elaborado pelo auto com base nos dados da RAIS/MTE 
Anexo XXVI. Coeficiente de concentração para as atividades da indústria de transformação selecionadas - São Paulo/2006.

\begin{tabular}{|c|c|c|c|c|c|c|c|c|c|c|c|c|c|c|c|c|c|c|c|c|}
\hline Divisão & 17 & 18 & 19 & 24 & 25 & 26 & 27 & 28 & 29 & 31 & 32 & 33 & 34 & 35 & 36 & 37 & 71 & 72 & 7 & 74 \\
\hline & 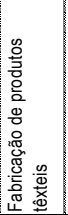 & 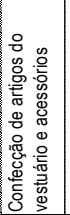 & 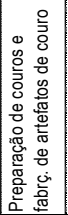 & 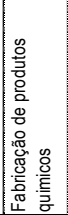 & 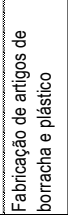 & 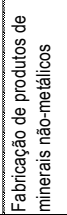 & 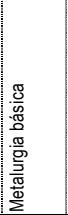 & 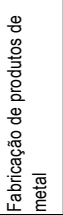 & 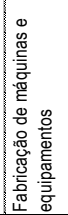 & 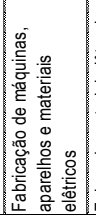 & 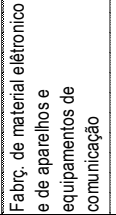 & 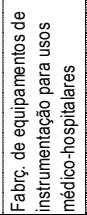 & 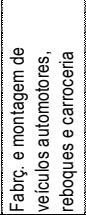 & 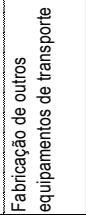 & 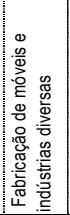 & 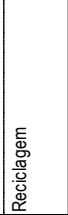 & 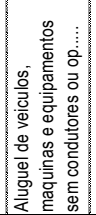 & 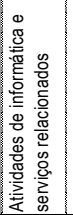 & 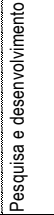 & 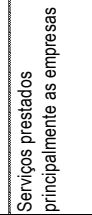 \\
\hline $\begin{array}{l}\text { Jales } \\
\end{array}$ & - & 0.01 & 0.02 & - & - & 0.01 & - & 0.01 & - & - & - & - & - & - & - & - & - & - & - & 0.07 \\
\hline Fernandopolis & - & 0.03 & - & - & - & - & - & 0.02 & - & - & - & - & - & - & 0.03 & - & - & - & - & - \\
\hline Votuporanga & - & 0.02 & - & - & - & - & - & 0.01 & - & - & - & - & 0.07 & - & 0.12 & - & - & - & - & - \\
\hline Sao Jose do Rio Preto & - & 0.02 & - & - & - & - & - & 0.03 & - & - & - & - & - & - & 0.04 & - & - & - & - & 0.03 \\
\hline Catanduva & - & 0.02 & - & - & - & - & - & 0.01 & 0.03 & - & - & - & - & - & 0.01 & - & - & - & - & 0.03 \\
\hline Auriflama & - & 0.19 & - & & - & - & - & - & 0.01 & - & - & - & - & - & 0.01 & - & - & - & - & - \\
\hline Nhandeara & - & 0.01 & 0.01 & 0.01 & - & - & 0.01 & 0.04 & 0.01 & - & - & - & - & - & 0.01 & - & - & - & - & 0.04 \\
\hline Novo Horizonte & 0.01 & 0.07 & - & - & - & - & - & - & - & - & - & - & - & - & 0.01 & - & 0.02 & - & - & - \\
\hline Barretos & - & - & - & - & 0.01 & - & - & - & - & 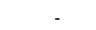 & - & - & - & - & - & - & - & - & - & 0.02 \\
\hline Sao Joaquim da Barra & - & - & - & - & - & - & 0.03 & - & 0.01 & 0.01 & - & - & - & - & - & - & - & - & - & - \\
\hline Ituverava & 0.01 & - & - & 0.02 & - & 0.01 & - & - & 0.01 & - & - & - & - & - & 0.02 & - & - & - & - & 0.02 \\
\hline Franca & - & - & 0.30 & - & 0.04 & - & - & - & - & - & - & - & - & - & - & - & - & - & - & 0.03 \\
\hline Jaboticabal & - & - & - & & 0.03 & - & - & 0.01 & 0.03 & - & - & - & - & - & - & - & 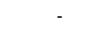 & - & - & 0.03 \\
\hline Ribeirao Preto & - & 0.01 & - & 0.02 & - & - & - & 0.02 & 0.03 & - & - & - & - & - & - & - & - & - & - & 0.08 \\
\hline Batatais & - & 0.04 & - & - & 0.01 & - & 0.03 & 0.01 & 0.03 & - & - & - & 0.02 & - & - & - & - & - & - & 0.02 \\
\hline Andradina & - & - & - & - & - & - & - & - & - & - & - & - & - & - & - & - & - & - & - & 0.02 \\
\hline Aracatuba & - & 0.01 & 0.02 & - & - & - & - & - & 0.02 & - & - & - & - & - & 0.02 & - & - & - & - & 0.03 \\
\hline Birigui & - & 0.03 & 0.30 & - & 0.02 & - & - & 0.01 & - & - & - & - & - & - & 0.03 & - & - & - & - & 0.01 \\
\hline Lins & - & - & 0.10 & - & - & - & - & - & - & - & - & - & - & - & - & - & - & - & - & 0.02 \\
\hline Bauru & - & 0.01 & - & - & 0.01 & - & - & - & 0.01 & 0.02 & - & - & - & - & - & - & - & - & - & 0.07 \\
\hline Jau & - & 0.02 & 0.12 & - & 0.02 & 0.01 & - & - & 0.02 & - & - & - & - & - & 0.01 & - & - & 0.01 & - & 0.02 \\
\hline Avare & - & 0.05 & - & - & - & - & - & - & - & - & - & - & - & - & - & - & - & - & - & 0.01 \\
\hline Botucatu & 0.02 & 0.05 & - & - & 0.02 & - & - & 0.02 & - & - & - & - & 0.05 & 0.03 & - & - & - & - & - & 0.06 \\
\hline Araraquara & 0.07 & 0.02 & - & - & - & - & - & 0.01 & 0.05 & - & - & - & - & 0.01 & - & - & - & - & - & 0.05 \\
\hline Sao Carlos & 0.02 & - & - & - & - & 0.01 & - & 0.02 & 0.11 & 0.02 & - & - & - & - & 0.02 & - & - & - & - & 0.04 \\
\hline Rio Claro & - & 0.01 & - & 0.02 & 0.03 & 0.04 & - & 0.03 & 0.03 & 0.13 & - & 0.01 & - & - & 0.03 & - & - & - & - & 0.04 \\
\hline Limeira & - & - & - & - & 0.02 & 0.06 & 0.01 & 0.04 & 0.04 & - & - & - & 0.05 & - & 0.03 & - & - & - & - & 0.03 \\
\hline Piracicaba & 0.02 & 0.03 & - & - & - & 0.02 & 0.01 & 0.03 & 0.08 & - & - & - & 0.02 & - & - & - & - & - & - & 0.05 \\
\hline Pirassununga & - & - & 0.01 & 0.01 & 0.02 & 0.07 & - & 0.01 & - & 0.03 & - & - & - & - & 0.02 & - & - & - & - & 0.01 \\
\hline Sao Joao da Boa Vista & - & 0.02 & - & - & - & 0.05 & - & 0.02 & 0.02 & 0.02 & - & - & - & - & - & - & - & - & - & 0.02 \\
\hline Moji-Mirim & 0.03 & - & - & 0.01 & 0.01 & 0.02 & - & 0.02 & 0.03 & 0.01 & - & - & 0.08 & - & 0.02 & - & 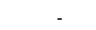 & 0.01 & - & 0.05 \\
\hline Campinas & 0.04 & 0.01 & - & 0.03 & 0.02 & 0.01 & - & 0.02 & 0.03 & - & 0.01 & - & 0.04 & - & - & - & - & 0.01 & - & 0.08 \\
\hline Amparo & 0.06 & 0.04 & - & 0.04 & - & 0.01 & - & 0.02 & 0.02 & - & - & - & 0.02 & - & - & - & - & - & - & 0.03 \\
\hline Dracena & - & - & - & - & - & 0.06 & - & - & - & - & - & - & - & - & 0.01 & - & - & - & - & 0.01 \\
\hline Adamantina & - & 0.07 & 0.02 & - & - & - & - & - & - & - & - & - & - & - & 0.02 & - & - & - & - & 0.05 \\
\hline Presidente Prudente & - & 0.01 & 0.04 & - & . & - & - & - & - & . & - & - & - & - & - & - & - & - & - & 0.04 \\
\hline Tupa & 0.04 & - & - & - & - & - & - & 0.01 & 0.01 & - & - & - & - & - & 0.01 & - & - & - & - & 0.02 \\
\hline Marilia & - & - & - & - & 0.02 & - & - & 0.03 & 0.04 & 0.02 & - & - & - & - & - & - & - & - & - & 0.03 \\
\hline Assis & - & - & - & - & - & - & - & 0.01 & - & - & - & - & - & - & - & - & - & - & - & 0.03 \\
\hline Ourinhos & - & 0.07 & 0.01 & & - & 0.01 & 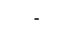 & 0.01 & 0.02 & - & - & - & - & - & 0.02 & - & - & - & - & 0.02 \\
\hline Itapeva & - & - & - & - & - & 0.02 & 0.01 & - & - & - & - & - & - & - & - & - & - & - & - & 0.03 \\
\hline Itapetininga & 0.01 & 0.03 & - & 0.02 & - & & - & - & - & - & - & - & - & - & - & - & - & - & - & 0.06 \\
\hline Tatui & 0.03 & 0.03 & - & 0.01 & 0.02 & 0.04 & 0.01 & 0.03 & - & 0.04 & - & - & 0.03 & - & 0.03 & - & - & - & - & 0.12 \\
\hline Capao Bonito & - & - & - & & & 0.03 & - & - & - & & - & - & - & - & 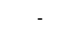 & - & 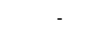 & - & - & 0.03 \\
\hline Piedade & - & - & - & & & & - & 0.01 & - & - & - & - & - & - & - & - & - & - & - & 0.12 \\
\hline Sorocaba & 0.02 & 0.02 & - & 0.02 & 0.03 & 0.02 & 0.03 & 0.03 & 0.04 & 0.02 & - & - & 0.04 & - & 0.01 & - & - & - & - & 0.07 \\
\hline Jundiai & 0.02 & 0.01 & - & 0.02 & 0.05 & 0.03 & - & 0.04 & 0.02 & & - & - & 0.04 & - & - & - & - & 0.01 & - & 0.10 \\
\hline Braganca Paulista & 0.05 & 0.02 & - & 0.01 & 0.02 & 0.01 & - & 0.02 & 0.02 & 0.03 & - & - & 0.01 & - & - & - & - & - & - & 0.22 \\
\hline Campos do Jordao & 0.01 & - & - & & & & 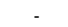 & - & - & 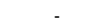 & - & - & & & - & - & - & - & - & 0.04 \\
\hline Sao Jose dos Campos & - & - & - & 0.02 & 0.01 & 0.01 & 0.02 & 0.02 & 0.02 & - & 0.01 & - & 0.06 & 0.05 & - & - & - & - & - & 0.11 \\
\hline Guaratingueta & - & - & - & 0.03 & 0.02 & - & - & 0.02 & 0.01 & - & - & - & 0.08 & - & - & - & - & - & - & 0.05 \\
\hline Bananal & - & - & - & - & - & - & - & - & - & - & - & - & - & - & - & - & - & - & - & - \\
\hline Paraibuna/Paraitinga & - & - & - & - & 0.02 & - & - & 0.02 & - & - & - & - & 0.06 & - & - & - & - & - & - & 0.01 \\
\hline Caraguatatuba & - & - & - & - & - & - & - & - & - & - & - & - & - & - & - & - & - & - & - & 0.03 \\
\hline Registro & - & - & - & 0.02 & - & 0.01 & - & - & - & - & - & - & - & - & - & - & - & - & - & 0.02 \\
\hline Itanhaem & - & - & - & - & - & - & - & - & - & - & - & - & - & - & - & - & - & - & - & 0.02 \\
\hline Osasco & - & - & - & 0.02 & 0.02 & - & - & 0.02 & 0.02 & - & - & - & 0.01 & - & - & - & - & 0.03 & - & 0.25 \\
\hline Franco da Rocha & 0.02 & - & - & 0.02 & 0.06 & 0.01 & - & 0.04 & 0.02 & - & - & - & - & - & 0.01 & - & - & - & - & 0.06 \\
\hline Guarulhos & 0.03 & - & - & 0.04 & 0.05 & 0.01 & 0.03 & 0.04 & 0.02 & 0.02 & - & - & 0.04 & - & 0.01 & - & - & - & - & 0.06 \\
\hline Itapecerica da Serra & 0.01 & - & - & 0.05 & 0.04 & - & - & 0.02 & 0.02 & 0.01 & - & - & 0.02 & - & 0.01 & - & - & 0.02 & - & 0.24 \\
\hline Sao Paulo & - & 0.02 & - & 0.02 & 0.02 & - & - & 0.02 & 0.01 & - & - & - & 0.02 & - & - & - & - & 0.01 & - & 0.13 \\
\hline Moji das Cruzes & 0.02 & - & - & 0.03 & 0.02 & 0.02 & 0.02 & 0.03 & 0.03 & 0.02 & - & - & 0.01 & - & 0.02 & - & - & 0.01 & - & 0.15 \\
\hline Santos & - & - & - & 0.01 & - & - & 0.02 & - & - & - & - & - & - & - & - & - & - & - & - & 0.08 \\
\hline
\end{tabular}

Observações/Filtro: $C C \geq 0,01$ (ou, 1\%).

FONTE: Elaborado pelo auto com base nos dados da RAIS/MTE 
Anexo XXVII. Coeficiente de concentração para as atividades da indústria de transformação selecionadas - São Paulo/2007.

\begin{tabular}{|c|c|c|c|c|c|c|c|c|c|c|c|c|c|c|c|c|c|c|c|c|}
\hline Divisão & 17 & 18 & 19 & 24 & 25 & 26 & 27 & 28 & 29 & 31 & 32 & 33 & 34 & 35 & 36 & 37 & 71 & 72 & 7 & 74 \\
\hline & 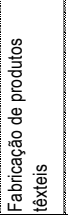 & 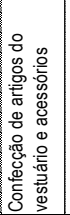 & 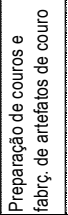 & 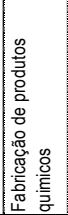 & 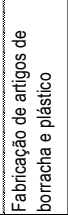 & 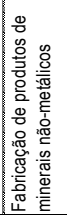 & 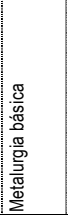 & 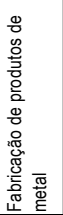 & 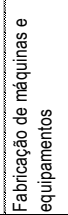 & 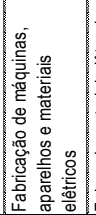 & 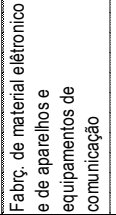 & 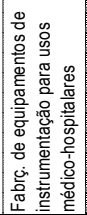 & 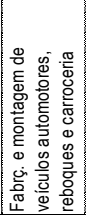 & 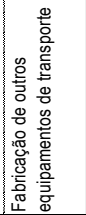 & 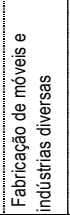 & 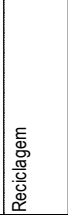 & 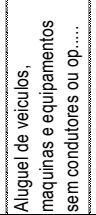 & 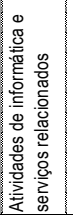 & 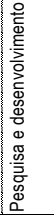 & 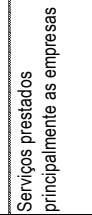 \\
\hline $\begin{array}{l}\text { Jales } \\
\end{array}$ & - & 0.01 & 0.02 & - & - & 0.01 & - & 0.01 & - & - & - & - & - & - & - & - & - & - & - & 0.04 \\
\hline Fernandopolis & - & 0.03 & - & - & - & - & - & 0.02 & - & - & - & - & - & - & 0.03 & - & - & - & - & - \\
\hline Votuporanga & - & 0.03 & - & - & 0.01 & - & - & - & - & - & - & - & 0.07 & - & 0.12 & - & - & - & - & - \\
\hline Sao Jose do Rio Preto & - & 0.02 & - & - & - & - & - & 0.03 & 0.01 & - & - & - & - & - & 0.04 & - & - & - & - & 0.04 \\
\hline Catanduva & - & 0.02 & - & - & - & - & - & 0.02 & 0.03 & - & - & - & - & - & - & - & - & - & - & 0.03 \\
\hline Auriflama & - & 0.19 & - & . & - & - & - & - & - & - & - & - & - & - & 0.02 & - & - & - & - & - \\
\hline Nhandeara & - & 0.01 & - & 0.01 & - & - & 0.01 & 0.03 & - & - & - & - & - & - & 0.01 & - & - & - & - & 0.04 \\
\hline Novo Horizonte & - & 0.07 & - & - & - & - & - & - & - & - & - & - & - & - & 0.02 & - & - & - & - & - \\
\hline Barretos & - & - & - & - & 0.02 & - & - & - & - & 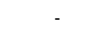 & - & - & - & - & - & - & - & - & - & 0.02 \\
\hline Sao Joaquim da Barra & - & - & - & - & - & - & 0.02 & - & 0.02 & 0.01 & - & - & - & - & - & - & - & - & - & - \\
\hline Ituverava & 0.01 & - & - & 0.02 & - & - & - & - & 0.02 & - & - & - & - & - & 0.02 & - & - & - & - & 0.02 \\
\hline Franca & - & 0.01 & 0.29 & - & 0.04 & - & - & - & - & - & - & - & - & - & - & - & - & - & - & 0.04 \\
\hline Jaboticabal & - & . & 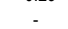 & & 0.04 & - & 0.01 & 0.02 & 0.03 & 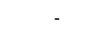 & - & - & - & - & - & - & . & - & - & 0.02 \\
\hline Ribeirao Preto & - & - & - & 0.01 & - & - & - & 0.03 & 0.04 & - & - & 0.01 & - & - & - & - & - & - & - & 0.08 \\
\hline Batatais & - & 0.03 & - & 0.01 & 0.01 & - & 0.03 & 0.01 & 0.04 & - & - & - & 0.02 & - & - & - & - & - & - & 0.02 \\
\hline Andradina & - & - & - & - & - & - & - & - & - & - & - & - & - & - & - & - & - & - & - & 0.03 \\
\hline Aracatuba & - & 0.02 & 0.02 & - & - & - & - & - & 0.02 & - & - & - & - & - & 0.02 & - & - & - & - & 0.03 \\
\hline Birigui & - & 0.03 & 0.28 & - & 0.02 & - & - & 0.01 & - & - & - & - & - & - & 0.03 & - & - & - & - & 0.01 \\
\hline Lins & - & - & 0.09 & - & - & - & - & - & - & - & - & - & - & - & - & - & - & - & - & 0.02 \\
\hline Bauru & - & - & - & - & 0.01 & - & - & - & 0.01 & 0.02 & - & - & - & - & - & - & - & - & - & 0.07 \\
\hline Jau & - & 0.02 & 0.12 & - & 0.02 & 0.01 & - & - & 0.02 & - & - & - & 0.01 & - & 0.01 & - & - & 0.01 & - & 0.02 \\
\hline Avare & - & 0.04 & - & - & 0.01 & - & - & - & - & - & - & - & - & - & - & - & - & - & - & 0.03 \\
\hline Botucatu & 0.02 & 0.03 & - & - & 0.02 & 0.01 & - & 0.01 & - & - & - & - & 0.06 & 0.03 & - & - & - & - & - & 0.04 \\
\hline Araraquara & 0.07 & 0.02 & - & - & - & - & - & 0.01 & 0.06 & - & - & - & - & 0.02 & - & - & - & - & - & 0.04 \\
\hline Sao Carlos & 0.02 & - & - & - & - & 0.01 & - & 0.02 & 0.10 & - & - & 0.01 & 0.01 & - & 0.03 & - & - & - & - & 0.06 \\
\hline Rio Claro & - & 0.01 & - & 0.01 & 0.02 & 0.02 & - & 0.02 & 0.06 & 0.19 & - & - & - & - & 0.04 & - & - & - & - & 0.04 \\
\hline Limeira & - & - & - & 0.01 & 0.02 & 0.06 & 0.02 & 0.04 & 0.04 & - & - & - & 0.06 & - & 0.03 & - & - & - & - & 0.03 \\
\hline Piracicaba & 0.02 & 0.02 & - & 0.01 & - & 0.02 & - & 0.02 & 0.09 & - & - & - & 0.02 & - & - & - & - & - & - & 0.07 \\
\hline Pirassununga & - & - & - & - & 0.02 & 0.06 & - & 0.01 & - & 0.03 & - & - & - & - & 0.02 & - & - & - & - & 0.01 \\
\hline Sao Joao da Boa Vista & - & 0.02 & - & - & - & 0.05 & - & 0.02 & 0.02 & 0.02 & - & - & - & - & - & - & - & - & - & 0.02 \\
\hline Moji-Mirim & 0.03 & - & - & 0.02 & 0.01 & 0.02 & - & 0.02 & 0.03 & 0.01 & - & - & 0.08 & - & 0.02 & - & 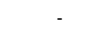 & 0.01 & - & 0.05 \\
\hline Campinas & 0.04 & 0.01 & - & 0.03 & 0.02 & 0.01 & - & 0.02 & 0.03 & - & 0.01 & - & 0.04 & - & - & - & - & 0.01 & - & 0.09 \\
\hline Amparo & 0.06 & 0.04 & - & 0.05 & - & 0.01 & - & 0.02 & 0.02 & - & - & - & 0.02 & - & - & - & - & - & - & 0.02 \\
\hline Dracena & - & - & - & - & - & 0.06 & - & - & - & - & - & - & - & - & 0.01 & - & - & - & - & 0.02 \\
\hline Adamantina & - & 0.06 & 0.03 & - & - & - & - & - & - & - & - & - & - & - & 0.02 & - & - & - & - & 0.07 \\
\hline Presidente Prudente & - & 0.01 & 0.04 & - & 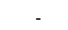 & - & - & - & - & - & - & - & - & - & - & - & 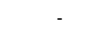 & - & - & 0.03 \\
\hline Tupa & 0.04 & - & - & - & - & - & - & - & 0.02 & - & - & - & - & - & 0.01 & - & - & - & - & 0.02 \\
\hline Marilia & - & - & - & - & 0.02 & - & - & 0.03 & 0.05 & 0.02 & - & - & - & - & - & - & - & - & - & 0.03 \\
\hline Assis & - & - & - & - & - & - & - & - & - & - & - & - & - & - & - & - & - & - & - & 0.03 \\
\hline Ourinhos & - & 0.07 & 0.01 & & - & 0.01 & - & 0.01 & 0.03 & - & - & - & - & - & 0.02 & - & - & - & - & 0.01 \\
\hline Itapeva & - & - & - & - & - & 0.02 & - & - & - & - & - & - & - & - & - & - & - & - & - & 0.03 \\
\hline Itapetininga & 0.01 & 0.04 & - & 0.03 & - & & - & - & - & - & - & - & - & - & 0.01 & - & - & - & - & 0.04 \\
\hline Tatui & 0.04 & 0.03 & - & 0.01 & 0.03 & 0.04 & 0.01 & 0.03 & - & 0.04 & - & - & 0.03 & - & 0.03 & - & - & - & - & 0.08 \\
\hline Capao Bonito & - & - & - & & & 0.05 & - & - & - & & - & - & - & - & 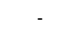 & - & 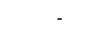 & - & - & 0.01 \\
\hline Piedade & - & - & - & & - & & - & 0.01 & - & 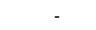 & - & - & - & - & - & - & - & - & - & 0.05 \\
\hline Sorocaba & 0.02 & 0.02 & - & 0.02 & 0.03 & 0.02 & 0.03 & 0.04 & 0.05 & 0.02 & - & - & 0.04 & - & 0.01 & - & - & - & - & 0.07 \\
\hline Jundiai & 0.01 & 0.01 & - & 0.02 & 0.04 & 0.03 & - & 0.04 & 0.03 & 0.02 & 0.01 & - & 0.05 & - & - & - & - & 0.02 & - & 0.10 \\
\hline Braganca Paulista & 0.05 & 0.02 & - & 0.02 & 0.02 & 0.02 & - & 0.03 & 0.02 & 0.03 & - & - & 0.02 & - & - & - & - & - & - & 0.12 \\
\hline Campos do Jordao & - & - & - & & & & - & - & - & & - & - & & & - & - & - & - & - & 0.02 \\
\hline Sao Jose dos Campos & - & - & - & 0.02 & 0.01 & 0.01 & 0.02 & 0.03 & 0.02 & - & 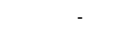 & - & 0.06 & 0.06 & - & - & - & - & - & 0.11 \\
\hline Guaratingueta & - & - & - & 0.04 & 0.02 & - & 0.03 & 0.02 & 0.02 & - & - & - & 0.06 & - & - & - & - & - & - & 0.04 \\
\hline Bananal & - & - & - & - & - & - & - & - & - & - & - & - & - & - & - & - & - & - & - & - \\
\hline Paraibuna/Paraitinga & - & - & - & - & 0.02 & - & - & 0.04 & 0.01 & - & - & - & 0.06 & - & - & - & - & - & - & 0.01 \\
\hline Caraguatatuba & - & - & - & - & - & - & - & - & - & - & - & - & - & - & - & - & - & - & - & 0.03 \\
\hline Registro & - & - & - & 0.02 & - & 0.01 & - & - & - & - & - & - & - & - & - & - & - & - & - & 0.03 \\
\hline Itanhaem & - & - & - & - & - & - & - & - & - & - & - & - & - & - & - & - & - & - & - & 0.15 \\
\hline Osasco & - & - & - & 0.02 & 0.02 & - & - & 0.02 & 0.02 & - & - & - & 0.01 & - & - & - & - & 0.04 & - & 0.24 \\
\hline Franco da Rocha & 0.02 & - & - & 0.02 & 0.06 & 0.01 & - & 0.03 & 0.02 & - & - & - & 0.01 & - & 0.01 & - & - & - & - & 0.03 \\
\hline Guarulhos & 0.03 & - & - & 0.04 & 0.05 & 0.01 & 0.03 & 0.05 & 0.03 & 0.01 & - & - & 0.04 & - & 0.01 & - & - & - & - & 0.06 \\
\hline Itapecerica da Serra & 0.01 & - & - & 0.05 & 0.04 & - & - & 0.03 & 0.02 & 0.01 & - & - & 0.02 & - & 0.02 & - & - & 0.02 & - & 0.21 \\
\hline Sao Paulo & - & 0.02 & - & 0.01 & 0.02 & - & - & 0.02 & 0.01 & - & - & - & 0.02 & - & - & - & - & 0.01 & - & 0.14 \\
\hline Moji das Cruzes & 0.02 & - & - & 0.03 & 0.02 & 0.02 & 0.02 & 0.03 & 0.03 & 0.02 & - & - & 0.02 & - & 0.02 & - & - & - & - & 0.15 \\
\hline Santos & - & - & - & 0.01 & - & - & 0.02 & - & - & - & - & - & - & - & - & - & - & - & - & 0.08 \\
\hline
\end{tabular}

Observações/Filtro: $C C \geq 0,01$ (ou, 1\%).

FONTE: Elaborado pelo auto com base nos dados da RAIS/MTE 
Anexo XXVIII. Coeficiente de concentração para as atividades da indústria de transformação selecionadas - São Paulo/2008.

\begin{tabular}{|c|c|c|c|c|c|c|c|c|c|c|c|c|c|c|c|c|c|c|c|c|}
\hline Divisão & 17 & 18 & 19 & 24 & 25 & 26 & 27 & 28 & 29 & 31 & 32 & 33 & 34 & 35 & 36 & 37 & 71 & 72 & 7 & 74 \\
\hline & 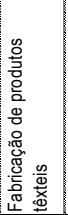 & 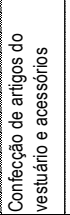 & 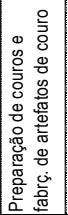 & 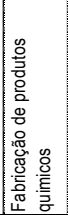 & 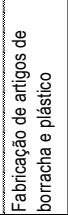 & 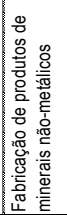 & 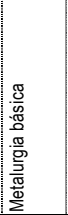 & 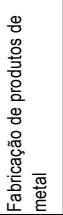 & 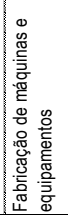 & 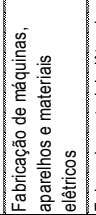 & 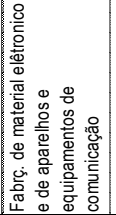 & 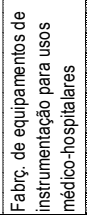 & 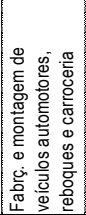 & 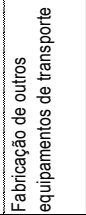 & 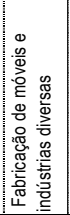 & 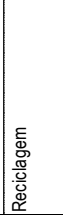 & 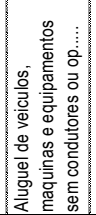 & 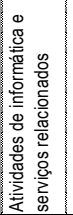 & 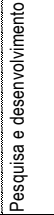 & 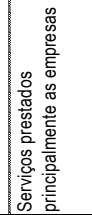 \\
\hline $\begin{array}{l}\text { Jales } \\
\end{array}$ & - & 0.01 & 0.02 & - & - & 0.02 & - & 0.02 & - & - & - & - & - & - & - & - & - & - & - & - \\
\hline Fernandopolis & - & 0.03 & - & - & - & - & - & 0.02 & - & - & - & - & - & - & 0.03 & - & - & - & - & 0.01 \\
\hline Votuporanga & - & 0.03 & - & - & - & - & - & - & - & - & - & - & 0.08 & - & 0.11 & - & - & - & - & - \\
\hline Sao Jose do Rio Preto & - & 0.02 & - & - & - & - & - & 0.03 & 0.01 & - & - & - & - & - & 0.04 & - & - & - & - & 0.04 \\
\hline Catanduva & - & 0.02 & - & - & - & - & - & 0.02 & 0.03 & - & - & - & - & - & - & - & - & - & - & 0.03 \\
\hline Auriflama & - & 0.18 & - & & - & - & - & - & - & - & - & - & - & - & 0.02 & - & - & - & - & - \\
\hline Nhandeara & - & 0.01 & 0.01 & 0.01 & - & - & - & 0.02 & 0.02 & - & - & - & - & - & 0.01 & - & - & - & - & 0.05 \\
\hline Novo Horizonte & - & 0.08 & - & - & - & - & - & - & - & - & - & - & - & - & 0.02 & - & - & - & - & - \\
\hline Barretos & - & - & - & . & 0.02 & - & - & - & - & 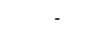 & - & - & - & - & - & - & - & - & - & 0.01 \\
\hline Sao Joaquim da Barra & - & - & - & 0.02 & - & - & 0.02 & - & 0.02 & 0.01 & - & - & - & - & - & - & - & - & - & - \\
\hline Ituverava & 0.01 & - & - & 0.01 & - & - & - & 0.02 & 0.01 & - & - & - & - & - & 0.02 & - & - & - & - & 0.02 \\
\hline Franca & - & - & 0.27 & - & 0.03 & - & - & - & - & - & - & - & - & - & - & - & - & - & - & 0.04 \\
\hline Jaboticabal & - & - & - & & 0.03 & - & 0.01 & 0.02 & 0.02 & . & - & - & - & - & - & - & 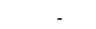 & - & - & 0.02 \\
\hline Ribeirao Preto & - & - & - & 0.02 & - & - & - & 0.02 & 0.04 & - & - & - & - & - & - & - & - & - & - & 0.07 \\
\hline Batatais & - & 0.03 & - & - & 0.01 & - & 0.03 & 0.01 & 0.05 & - & - & - & 0.02 & - & - & - & - & - & - & 0.02 \\
\hline Andradina & - & - & - & - & - & - & - & - & - & - & - & - & - & - & - & - & - & - & - & 0.03 \\
\hline Aracatuba & - & 0.01 & 0.01 & - & - & - & - & - & 0.02 & - & - & - & - & - & 0.02 & - & - & - & - & 0.05 \\
\hline Birigui & - & 0.03 & 0.25 & - & 0.01 & - & - & 0.01 & - & - & - & - & - & - & 0.02 & - & - & - & - & 0.01 \\
\hline Lins & - & - & 0.10 & - & - & - & - & - & - & - & - & - & - & - & - & - & - & - & - & 0.03 \\
\hline Bauru & - & - & - & - & 0.01 & - & - & 0.01 & 0.01 & 0.02 & - & - & - & - & - & - & - & - & - & 0.07 \\
\hline Jau & - & 0.02 & 0.11 & - & 0.01 & 0.01 & - & - & 0.02 & - & - & - & 0.01 & - & 0.01 & - & - & - & - & 0.01 \\
\hline Avare & - & 0.04 & - & - & 0.01 & - & - & - & - & - & - & - & - & - & - & - & - & - & - & 0.04 \\
\hline Botucatu & 0.02 & 0.03 & - & 0.01 & - & 0.01 & - & 0.01 & - & - & - & - & 0.07 & 0.04 & - & - & - & - & - & 0.03 \\
\hline Araraquara & 0.08 & 0.02 & - & - & - & - & - & 0.01 & 0.06 & - & - & - & - & 0.02 & - & - & - & - & - & 0.04 \\
\hline Sao Carlos & 0.02 & - & - & - & - & 0.01 & - & 0.03 & 0.09 & - & - & 0.01 & 0.01 & - & 0.02 & - & - & - & - & 0.07 \\
\hline Rio Claro & - & 0.01 & - & 0.02 & 0.04 & 0.05 & - & 0.02 & 0.06 & 0.02 & - & 0.01 & - & - & 0.05 & - & - & - & - & 0.05 \\
\hline Limeira & - & - & - & 0.02 & 0.02 & 0.06 & 0.01 & 0.04 & 0.04 & - & - & - & 0.05 & - & 0.03 & - & - & - & - & 0.02 \\
\hline Piracicaba & 0.02 & 0.02 & - & - & - & 0.02 & 0.01 & 0.03 & 0.10 & - & - & - & 0.02 & - & - & - & - & - & - & 0.06 \\
\hline Pirassununga & - & - & - & 0.01 & 0.01 & 0.06 & - & 0.01 & - & 0.03 & - & - & - & - & 0.02 & - & - & - & - & 0.01 \\
\hline Sao Joao da Boa Vista & - & 0.01 & - & - & - & 0.05 & - & 0.02 & 0.03 & - & - & - & 0.05 & - & - & - & - & - & - & 0.02 \\
\hline Moji-Mirim & 0.03 & - & - & 0.02 & 0.01 & 0.02 & - & 0.02 & 0.04 & 0.01 & - & - & 0.08 & - & 0.02 & - & - & - & - & 0.05 \\
\hline Campinas & 0.04 & 0.01 & - & 0.03 & 0.02 & 0.01 & - & 0.02 & 0.03 & - & 0.01 & - & 0.04 & - & - & - & - & 0.01 & - & 0.09 \\
\hline Amparo & 0.06 & 0.04 & - & 0.05 & - & 0.01 & - & 0.02 & 0.01 & - & - & - & 0.02 & - & - & - & - & - & - & 0.02 \\
\hline Dracena & - & - & - & - & - & 0.06 & - & - & - & - & - & - & - & - & 0.01 & - & - & - & - & 0.02 \\
\hline Adamantina & - & 0.06 & 0.02 & - & - & - & - & - & - & - & - & - & - & - & 0.02 & - & - & - & - & 0.07 \\
\hline Presidente Prudente & - & 0.01 & 0.02 & - & 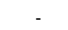 & - & - & - & - & . & - & - & - & - & - & - & 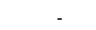 & - & - & 0.02 \\
\hline Tupa & 0.04 & - & - & - & - & - & - & - & 0.02 & - & - & - & - & - & 0.01 & - & - & - & - & 0.02 \\
\hline Marilia & - & - & - & - & 0.02 & - & - & 0.03 & 0.05 & 0.03 & - & - & - & - & - & - & - & - & - & 0.03 \\
\hline Assis & - & - & - & - & - & - & - & - & - & - & - & - & - & - & - & - & - & - & - & 0.03 \\
\hline Ourinhos & - & 0.07 & - & 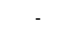 & - & 0.01 & - & 0.01 & 0.03 & - & - & - & - & - & 0.02 & - & - & - & - & 0.02 \\
\hline Itapeva & - & - & - & - & - & 0.02 & - & - & - & - & - & - & - & - & - & - & - & - & - & 0.02 \\
\hline Itapetininga & 0.01 & 0.04 & - & 0.03 & - & & - & - & - & - & - & - & - & - & 0.01 & - & - & - & - & 0.03 \\
\hline Tatui & 0.04 & 0.03 & - & 0.01 & 0.02 & 0.04 & 0.02 & 0.03 & - & 0.05 & - & - & 0.03 & - & 0.03 & - & - & - & - & 0.07 \\
\hline Capao Bonito & - & - & - & & & 0.05 & - & - & - & & - & - & - & - & 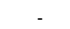 & - & 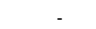 & - & - & 0.05 \\
\hline Piedade & - & - & - & - & 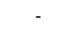 & & - & 0.01 & - & 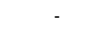 & - & - & - & - & - & - & - & - & - & 0.05 \\
\hline Sorocaba & 0.01 & 0.02 & - & 0.02 & 0.04 & 0.02 & 0.03 & 0.03 & 0.05 & 0.02 & - & - & 0.04 & - & 0.01 & - & - & - & - & 0.07 \\
\hline Jundiai & 0.01 & - & - & 0.02 & 0.04 & 0.02 & - & 0.04 & 0.02 & 0.02 & 0.01 & - & 0.05 & - & - & - & - & 0.03 & - & 0.08 \\
\hline Braganca Paulista & 0.05 & 0.02 & - & 0.02 & 0.02 & 0.02 & - & 0.03 & 0.02 & 0.03 & - & - & 0.02 & - & - & - & - & - & - & 0.11 \\
\hline Campos do Jordao & - & - & - & & & & - & - & - & & - & - & & & - & - & - & - & - & 0.03 \\
\hline Sao Jose dos Campos & - & - & - & 0.01 & 0.02 & - & 0.02 & 0.02 & 0.02 & - & 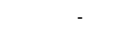 & - & 0.06 & 0.05 & - & - & - & - & - & 0.12 \\
\hline Guaratingueta & - & - & - & 0.04 & 0.02 & - & 0.03 & 0.02 & 0.02 & - & - & - & 0.06 & - & - & - & - & - & - & 0.05 \\
\hline Bananal & - & - & - & - & - & - & - & - & - & - & - & - & - & - & - & - & - & - & - & - \\
\hline Paraibuna/Paraitinga & - & - & - & - & 0.02 & - & - & 0.05 & - & - & - & - & 0.06 & - & - & - & 0.01 & - & - & 0.02 \\
\hline Caraguatatuba & - & - & - & - & - & - & - & - & - & - & - & - & - & - & - & - & - & - & - & 0.03 \\
\hline Registro & - & - & - & 0.02 & - & 0.01 & - & - & - & - & - & - & - & - & - & - & - & - & - & 0.03 \\
\hline Itanhaem & - & - & - & 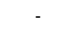 & - & - & - & - & - & - & - & - & - & - & - & - & - & - & - & 0.15 \\
\hline Osasco & - & - & - & 0.02 & 0.02 & - & - & 0.02 & 0.02 & 0.01 & - & - & 0.01 & - & - & - & - & 0.04 & - & 0.21 \\
\hline Franco da Rocha & 0.02 & - & - & 0.02 & 0.06 & 0.01 & - & 0.03 & 0.02 & - & 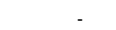 & - & 0.01 & - & 0.01 & - & - & - & - & 0.04 \\
\hline Guarulhos & 0.03 & - & - & 0.04 & 0.05 & 0.01 & 0.03 & 0.05 & 0.03 & 0.02 & - & - & 0.04 & - & 0.01 & - & - & - & - & 0.05 \\
\hline Itapecerica da Serra & 0.01 & - & - & 0.05 & 0.04 & - & - & 0.03 & 0.02 & 0.01 & - & - & 0.02 & - & 0.02 & - & - & 0.03 & - & 0.20 \\
\hline Sao Paulo & - & 0.02 & - & 0.01 & 0.01 & - & - & 0.02 & 0.01 & - & - & - & 0.02 & - & - & - & - & 0.02 & - & 0.15 \\
\hline Moji das Cruzes & 0.02 & - & - & 0.03 & 0.02 & 0.02 & 0.02 & 0.03 & 0.03 & 0.02 & - & - & 0.02 & - & 0.02 & - & - & - & - & 0.15 \\
\hline Santos & - & - & - & 0.01 & - & - & 0.02 & - & - & - & - & - & - & - & - & - & - & - & - & 0.07 \\
\hline
\end{tabular}

Observações/Filtro: $C C \geq 0,01$ (ou, 1\%).

FONTE: Elaborado pelo auto com base nos dados da RAIS/MTE 
Anexo XXIX. Coeficiente de concentração para as atividades da indústria de transformação selecionadas - São Paulo/2009.

\begin{tabular}{|c|c|c|c|c|c|c|c|c|c|c|c|c|c|c|c|c|c|c|c|c|}
\hline Divisão & 17 & 18 & 19 & 24 & 25 & 26 & 27 & 28 & 29 & 31 & 32 & 33 & 34 & 35 & 36 & 37 & 71 & 72 & 7 & 74 \\
\hline & 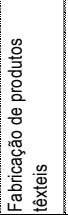 & 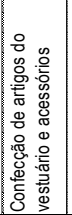 & 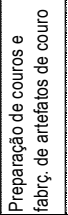 & 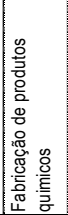 & 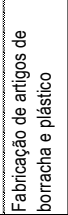 & 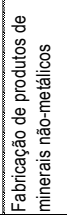 & 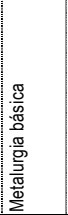 & 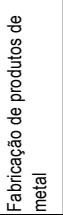 & 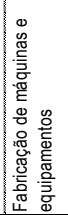 & 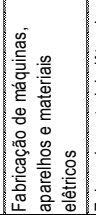 & 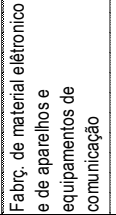 & 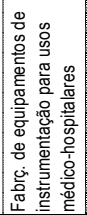 & 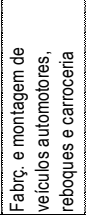 & 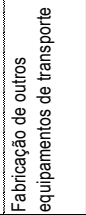 & 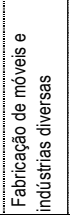 & 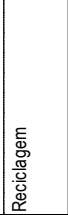 & 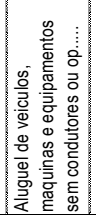 & 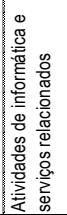 & 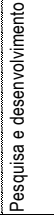 & 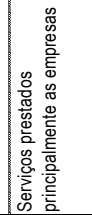 \\
\hline $\begin{array}{l}\text { Jales } \\
\end{array}$ & - & 0.01 & 0.02 & - & - & 0.02 & - & - & - & - & - & - & 0.02 & - & - & - & - & - & - & 0.01 \\
\hline Fernandopolis & - & 0.03 & - & - & - & - & - & 0.01 & - & - & - & - & - & - & 0.03 & - & - & - & - & 0.02 \\
\hline Votuporanga & - & 0.03 & - & - & - & - & - & - & - & - & - & - & 0.07 & - & 0.12 & - & - & - & - & 0.01 \\
\hline Sao Jose do Rio Preto & - & 0.02 & - & - & - & - & - & 0.03 & - & - & - & - & - & - & 0.04 & - & - & - & - & 0.04 \\
\hline Catanduva & - & 0.01 & - & - & - & - & - & 0.01 & 0.04 & - & - & - & - & - & - & - & - & - & - & 0.03 \\
\hline Auriflama & - & 0.18 & - & - & - & - & - & - & - & - & - & - & - & - & 0.02 & - & - & - & - & - \\
\hline Nhandeara & - & 0.01 & - & - & - & - & - & 0.02 & 0.01 & - & - & - & - & - & - & - & - & - & - & 0.05 \\
\hline Novo Horizonte & - & 0.07 & - & - & - & - & - & - & 0.01 & - & - & - & - & - & 0.03 & - & - & - & - & - \\
\hline Barretos & - & - & - & - & 0.02 & - & - & - & - & 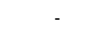 & - & - & - & - & - & - & - & - & - & 0.01 \\
\hline Sao Joaquim da Barra & - & - & - & - & - & - & 0.02 & - & 0.01 & 0.01 & - & - & - & - & - & - & - & - & - & 0.01 \\
\hline Ituverava & - & - & - & - & - & - & - & 0.01 & 0.01 & - & - & - & - & - & 0.03 & - & - & - & - & 0.03 \\
\hline Franca & - & 0.01 & 0.25 & - & 0.03 & - & - & - & - & - & - & - & - & - & - & - & - & - & - & 0.03 \\
\hline Jaboticabal & - & 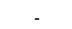 & 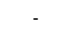 & & 0.03 & - & 0.01 & 0.02 & 0.02 & . & - & - & - & - & - & - & 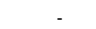 & - & - & 0.02 \\
\hline Ribeirao Preto & - & - & - & 0.02 & - & - & - & 0.02 & 0.04 & - & - & - & - & - & - & - & - & - & - & 0.07 \\
\hline Batatais & - & 0.03 & - & - & 0.01 & - & 0.03 & 0.01 & 0.04 & - & - & - & 0.02 & - & - & - & - & - & - & 0.02 \\
\hline Andradina & - & - & - & - & - & - & - & - & - & - & - & - & - & - & - & - & - & - & - & 0.03 \\
\hline Aracatuba & - & 0.01 & 0.01 & - & - & - & - & - & 0.03 & - & - & - & - & - & 0.02 & - & - & - & - & 0.04 \\
\hline Birigui & - & 0.02 & 0.26 & 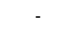 & 0.01 & 0.01 & - & 0.01 & - & - & - & - & - & - & 0.02 & - & - & - & - & 0.01 \\
\hline Lins & - & 0.03 & 0.02 & 0.06 & - & - & - & - & - & - & - & - & - & - & - & - & - & - & - & 0.03 \\
\hline Bauru & - & - & - & - & 0.01 & - & - & 0.01 & 0.01 & 0.02 & - & - & - & - & - & - & - & - & - & 0.10 \\
\hline Jau & - & 0.02 & 0.11 & - & 0.01 & 0.01 & - & - & 0.02 & - & - & - & 0.01 & - & 0.01 & - & - & - & - & 0.01 \\
\hline Avare & - & 0.04 & - & - & 0.01 & - & - & - & - & - & - & - & - & - & - & - & - & - & - & 0.04 \\
\hline Botucatu & 0.02 & 0.02 & - & 0.01 & 0.02 & 0.01 & - & 0.01 & - & - & - & - & 0.07 & 0.03 & - & - & - & - & - & 0.03 \\
\hline Araraquara & 0.07 & 0.02 & - & - & - & - & - & 0.01 & 0.06 & - & - & - & - & 0.01 & - & - & - & - & - & 0.04 \\
\hline Sao Carlos & 0.02 & - & - & - & - & 0.01 & - & 0.02 & 0.08 & - & - & 0.01 & 0.01 & - & 0.02 & - & - & - & - & 0.07 \\
\hline Rio Claro & - & 0.01 & - & 0.02 & 0.04 & 0.04 & - & 0.02 & 0.07 & 0.02 & - & 0.01 & - & - & 0.04 & - & - & - & - & 0.07 \\
\hline Limeira & - & - & - & 0.02 & 0.02 & 0.05 & 0.01 & 0.04 & 0.04 & - & - & - & 0.05 & - & 0.03 & - & - & - & - & 0.02 \\
\hline Piracicaba & 0.02 & 0.02 & - & 0.01 & - & 0.02 & 0.01 & 0.02 & 0.08 & - & - & - & 0.02 & - & 0.01 & - & - & - & - & 0.05 \\
\hline Pirassununga & - & - & - & - & 0.01 & 0.06 & - & - & - & 0.03 & - & - & - & - & 0.02 & - & - & - & - & 0.02 \\
\hline Sao Joao da Boa Vista & - & 0.01 & - & - & - & 0.05 & - & 0.02 & 0.03 & - & - & - & 0.04 & - & - & - & - & - & - & 0.02 \\
\hline Moji-Mirim & 0.02 & - & - & 0.02 & - & 0.02 & - & 0.02 & 0.03 & 0.01 & - & - & 0.08 & - & 0.02 & - & - & - & - & 0.06 \\
\hline Campinas & 0.04 & 0.01 & - & 0.03 & 0.02 & 0.01 & - & 0.02 & 0.02 & - & 0.01 & - & 0.04 & - & - & - & - & 0.02 & - & 0.10 \\
\hline Amparo & 0.06 & 0.04 & - & 0.05 & - & - & - & 0.02 & 0.01 & - & - & - & - & - & - & - & - & - & - & 0.02 \\
\hline Dracena & - & - & - & - & - & 0.06 & - & - & - & - & - & - & - & - & 0.01 & - & - & - & - & 0.03 \\
\hline Adamantina & - & 0.05 & 0.02 & - & - & - & - & - & - & - & - & - & - & - & 0.02 & - & - & - & - & 0.07 \\
\hline Presidente Prudente & - & - & 0.03 & - & . & - & - & - & - & - & - & - & - & - & - & - & 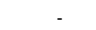 & - & - & 0.02 \\
\hline Tupa & 0.03 & - & - & - & - & - & - & - & 0.02 & - & - & - & - & - & 0.01 & - & - & - & - & 0.02 \\
\hline Marilia & - & - & - & - & 0.02 & - & - & 0.03 & 0.04 & 0.03 & - & - & - & - & - & - & - & - & - & 0.04 \\
\hline Assis & - & - & - & - & - & - & - & - & - & - & - & - & - & - & - & - & - & - & - & 0.04 \\
\hline Ourinhos & - & 0.07 & - & 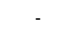 & - & 0.01 & - & 0.01 & 0.03 & - & - & - & - & - & 0.02 & - & - & - & - & 0.03 \\
\hline Itapeva & - & - & - & - & - & 0.01 & - & - & - & - & - & - & - & - & - & - & - & - & - & 0.02 \\
\hline Itapetininga & 0.01 & 0.04 & - & 0.02 & - & & - & - & - & - & - & - & - & - & 0.01 & - & - & - & - & 0.03 \\
\hline Tatui & 0.04 & 0.03 & - & 0.02 & 0.03 & 0.04 & 0.02 & 0.03 & - & 0.04 & - & - & - & - & 0.03 & - & - & - & - & 0.07 \\
\hline Capao Bonito & - & - & - & & & 0.05 & - & - & - & & - & - & - & - & 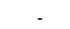 & - & 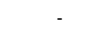 & - & - & 0.01 \\
\hline Piedade & - & - & - & & 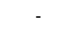 & & - & - & - & 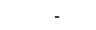 & - & 0.01 & - & - & - & - & - & - & - & 0.06 \\
\hline Sorocaba & 0.02 & 0.02 & - & 0.02 & 0.04 & 0.02 & 0.02 & 0.03 & 0.04 & 0.02 & - & - & 0.04 & - & 0.01 & - & - & - & - & 0.08 \\
\hline Jundiai & 0.01 & - & - & 0.02 & 0.04 & 0.02 & - & 0.03 & 0.02 & 0.02 & - & - & 0.04 & - & - & - & - & 0.03 & - & 0.09 \\
\hline Braganca Paulista & 0.04 & 0.02 & - & 0.02 & 0.02 & 0.02 & - & 0.03 & 0.02 & 0.04 & - & - & 0.02 & - & - & - & - & - & - & 0.15 \\
\hline Campos do Jordao & - & - & - & & & & - & - & - & 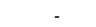 & - & - & & & - & - & - & - & - & 0.02 \\
\hline Sao Jose dos Campos & - & - & - & 0.01 & 0.01 & - & 0.02 & 0.02 & 0.02 & - & - & - & 0.06 & 0.04 & - & - & - & - & - & 0.13 \\
\hline Guaratingueta & - & - & - & 0.04 & 0.02 & - & 0.02 & 0.01 & 0.01 & - & - & - & 0.05 & - & - & - & - & - & - & 0.04 \\
\hline Bananal & - & - & - & - & - & - & - & - & - & - & - & - & - & - & - & - & - & - & - & - \\
\hline Paraibuna/Paraitinga & - & - & - & - & 0.01 & - & - & 0.06 & - & - & - & - & 0.06 & - & - & - & - & - & - & 0.03 \\
\hline Caraguatatuba & - & - & - & - & - & - & - & - & - & - & - & - & - & - & - & - & - & - & - & 0.03 \\
\hline Registro & - & 0.01 & - & - & - & 0.01 & - & - & - & - & - & - & - & - & - & - & - & - & - & 0.03 \\
\hline Itanhaem & - & - & - & - & - & - & - & - & - & - & - & - & - & - & - & - & - & - & - & 0.02 \\
\hline Osasco & - & - & - & 0.02 & 0.02 & - & - & 0.01 & 0.02 & 0.01 & - & - & 0.01 & - & - & - & - & 0.04 & - & 0.21 \\
\hline Franco da Rocha & 0.02 & - & - & 0.02 & 0.06 & 0.01 & - & 0.03 & 0.02 & - & - & - & 0.01 & - & 0.01 & - & - & - & - & 0.02 \\
\hline Guarulhos & 0.03 & - & - & 0.04 & 0.05 & 0.01 & 0.02 & 0.04 & 0.03 & 0.02 & - & - & 0.04 & - & 0.01 & - & - & - & - & 0.06 \\
\hline Itapecerica da Serra & 0.01 & - & - & 0.05 & 0.04 & - & - & 0.02 & 0.02 & 0.01 & - & - & 0.02 & - & 0.02 & - & - & 0.02 & - & 0.18 \\
\hline Sao Paulo & - & 0.02 & - & 0.01 & 0.01 & - & - & 0.01 & 0.01 & - & - & - & 0.02 & - & - & - & - & 0.02 & - & 0.15 \\
\hline Moji das Cruzes & 0.02 & - & - & 0.03 & 0.02 & 0.02 & 0.02 & 0.03 & 0.02 & 0.02 & - & - & 0.02 & - & 0.01 & - & - & - & - & 0.14 \\
\hline Santos & - & - & - & - & - & - & 0.01 & - & - & - & - & - & - & - & - & - & - & - & - & 0.07 \\
\hline
\end{tabular}

Observações/Filtro: CC $\geq 0,01$ (ou, 1\%).

FONTE: Elaborado pelo auto com base nos dados da RAIS/MTE 
Anexo XXX. Coeficiente de concentração para as atividades da indústria de transformação selecionadas - São Paulo/2010.

\begin{tabular}{|c|c|c|c|c|c|c|c|c|c|c|c|c|c|c|c|c|c|c|c|c|}
\hline Divisão & 17 & 18 & 19 & 24 & 25 & 26 & 27 & 28 & 29 & 31 & 32 & 33 & 34 & 35 & 36 & 37 & 71 & 72 & 7 & 74 \\
\hline & 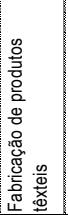 & 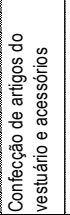 & 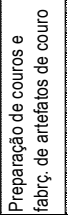 & 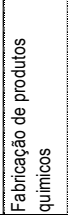 & 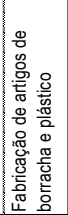 & 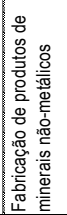 & 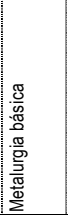 & 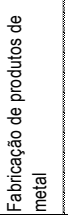 & 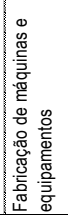 & 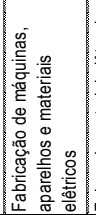 & 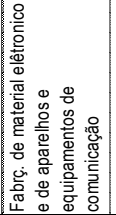 & 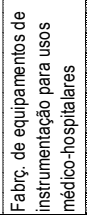 & 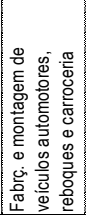 & 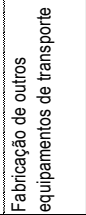 & 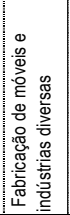 & 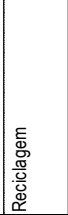 & 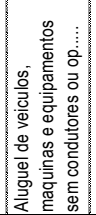 & 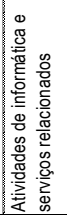 & 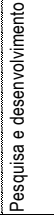 & 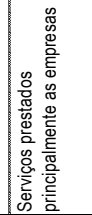 \\
\hline $\begin{array}{l}\text { Jales } \\
\end{array}$ & - & 0.01 & 0.01 & - & - & 0.02 & - & - & - & - & - & - & 0.02 & - & - & - & - & - & - & 0.01 \\
\hline Fernandopolis & - & 0.03 & - & 0.02 & - & - & - & - & - & - & - & - & - & - & 0.03 & - & - & - & - & 0.02 \\
\hline Votuporanga & - & 0.03 & - & - & - & - & - & - & - & - & - & - & 0.08 & - & 0.13 & - & - & - & - & 0.01 \\
\hline Sao Jose do Rio Preto & - & 0.02 & - & 0.01 & - & - & - & 0.03 & - & - & - & - & - & - & 0.04 & - & - & - & - & 0.05 \\
\hline Catanduva & - & 0.01 & - & - & - & - & - & 0.01 & 0.05 & - & - & - & - & - & - & - & - & - & - & 0.03 \\
\hline Auriflama & - & 0.19 & - & - & - & - & - & - & - & - & - & - & - & - & 0.03 & - & - & - & - & 0.01 \\
\hline Nhandeara & - & 0.01 & - & 0.14 & - & - & - & 0.02 & 0.02 & - & - & - & - & - & 0.02 & - & - & - & - & 0.05 \\
\hline Novo Horizonte & - & 0.08 & - & 0.04 & - & - & - & - & 0.02 & - & - & - & - & - & 0.03 & - & - & - & - & - \\
\hline Barretos & - & - & - & 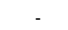 & 0.02 & - & - & - & - & 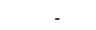 & - & - & - & - & - & - & - & - & - & 0.02 \\
\hline Sao Joaquim da Barra & - & - & - & 0.05 & - & - & 0.02 & 0.01 & 0.02 & 0.01 & - & - & - & - & - & - & - & - & - & 0.02 \\
\hline Ituverava & - & - & - & & - & - & - & 0.01 & 0.02 & - & - & - & - & - & 0.02 & - & - & - & - & 0.03 \\
\hline Franca & - & 0.01 & 0.28 & 0.01 & 0.02 & - & - & - & - & - & - & - & - & - & - & - & - & - & - & 0.03 \\
\hline Jaboticabal & - & 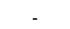 & - & 0.02 & 0.04 & - & 0.01 & 0.03 & 0.02 & . & - & - & - & - & - & - & & - & - & 0.03 \\
\hline Ribeirao Preto & - & - & - & 0.02 & - & - & - & 0.02 & 0.04 & - & - & - & - & - & - & - & - & - & - & 0.08 \\
\hline Batatais & - & 0.04 & - & 0.08 & - & - & 0.03 & - & 0.04 & - & - & - & 0.02 & - & - & - & - & - & - & 0.02 \\
\hline Andradina & - & - & - & 0.04 & - & - & - & - & - & - & - & - & - & - & - & - & - & - & - & 0.03 \\
\hline Aracatuba & - & 0.01 & 0.01 & 0.03 & - & - & - & - & 0.03 & - & - & - & - & - & 0.02 & - & - & - & - & 0.04 \\
\hline Birigui & - & 0.03 & 0.26 & 0.01 & 0.01 & 0.01 & - & 0.01 & - & - & - & - & - & - & 0.02 & - & - & - & - & 0.02 \\
\hline Lins & - & 0.03 & 0.03 & 0.09 & - & - & - & - & - & - & - & - & - & - & - & - & - & - & - & 0.05 \\
\hline Bauru & - & - & - & - & - & - & - & 0.01 & 0.01 & 0.02 & - & - & - & - & - & - & - & - & - & 0.12 \\
\hline Jau & - & 0.02 & 0.12 & 0.02 & - & 0.01 & - & 0.01 & 0.01 & - & - & - & 0.02 & - & 0.02 & - & - & - & - & 0.02 \\
\hline Avare & - & 0.05 & - & 0.03 & 0.01 & - & - & - & - & - & - & - & - & - & - & - & - & - & - & 0.04 \\
\hline Botucatu & 0.02 & 0.01 & - & 0.01 & 0.01 & 0.01 & - & 0.01 & - & - & - & - & 0.08 & 0.03 & - & - & - & - & - & 0.03 \\
\hline Araraquara & 0.08 & 0.02 & - & - & - & - & - & 0.01 & 0.06 & - & - & - & - & 0.01 & - & - & - & - & - & 0.05 \\
\hline Sao Carlos & 0.02 & - & - & - & - & 0.01 & - & 0.03 & 0.08 & - & - & 0.01 & 0.01 & - & 0.02 & - & - & - & - & 0.06 \\
\hline Rio Claro & - & 0.01 & - & 0.02 & 0.04 & 0.04 & - & 0.02 & 0.07 & 0.02 & - & 0.01 & - & - & 0.05 & - & - & - & - & 0.06 \\
\hline Limeira & - & 0.01 & - & 0.03 & 0.02 & 0.05 & 0.02 & 0.04 & 0.04 & - & - & - & 0.05 & - & 0.03 & - & - & - & - & 0.03 \\
\hline Piracicaba & 0.02 & 0.02 & - & 0.01 & 0.01 & 0.02 & 0.01 & 0.02 & 0.09 & - & - & - & 0.02 & - & 0.01 & - & - & - & - & 0.05 \\
\hline Pirassununga & - & - & - & - & 0.02 & 0.06 & - & - & - & 0.03 & - & 0.01 & - & - & 0.02 & - & - & - & - & 0.02 \\
\hline Sao Joao da Boa Vista & - & 0.01 & - & - & - & 0.05 & - & 0.03 & 0.03 & - & - & - & 0.03 & - & - & - & - & - & - & 0.02 \\
\hline Moji-Mirim & 0.02 & - & - & 0.02 & - & 0.02 & - & 0.02 & 0.04 & 0.01 & - & - & 0.08 & - & 0.02 & - & - & - & - & 0.06 \\
\hline Campinas & 0.04 & 0.01 & - & 0.03 & 0.02 & 0.01 & - & 0.02 & 0.03 & - & 0.01 & - & 0.04 & - & - & - & - & 0.02 & - & 0.10 \\
\hline Amparo & 0.06 & 0.04 & - & 0.06 & - & - & - & 0.02 & 0.01 & - & - & - & - & - & - & - & - & - & - & 0.02 \\
\hline Dracena & - & - & - & 0.09 & - & 0.06 & - & - & - & - & - & - & - & - & 0.01 & - & - & - & - & 0.04 \\
\hline Adamantina & - & 0.06 & 0.02 & 0.06 & - & - & - & - & - & - & - & - & - & - & 0.02 & - & - & - & - & 0.07 \\
\hline Presidente Prudente & - & 0.01 & 0.02 & 0.04 & - & - & - & - & - & . & - & - & - & - & - & - & 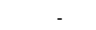 & - & - & 0.03 \\
\hline Tupa & 0.03 & - & - & - & - & - & - & - & 0.02 & - & - & - & - & - & 0.01 & - & - & - & - & 0.02 \\
\hline Marilia & - & - & - & - & 0.02 & - & - & 0.03 & 0.04 & 0.03 & - & - & - & - & - & - & - & - & - & 0.03 \\
\hline Assis & - & - & - & - & - & - & - & 0.01 & - & - & - & - & - & - & - & - & - & - & - & 0.04 \\
\hline Ourinhos & - & 0.08 & - & 0.03 & - & 0.01 & - & 0.01 & 0.02 & - & - & - & - & - & 0.02 & - & - & - & - & 0.03 \\
\hline Itapeva & - & 0.02 & - & - & - & 0.02 & - & - & - & - & - & - & - & - & - & - & - & - & - & 0.02 \\
\hline Itapetininga & 0.01 & 0.05 & - & 0.02 & - & & - & - & - & - & - & - & - & - & 0.02 & - & - & - & - & 0.05 \\
\hline Tatui & 0.04 & 0.03 & - & 0.03 & 0.03 & 0.04 & 0.02 & 0.04 & - & 0.05 & - & - & - & - & 0.03 & - & - & - & - & 0.08 \\
\hline Capao Bonito & - & - & - & & & 0.05 & - & - & - & & - & - & - & - & 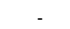 & - & 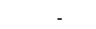 & - & - & 0.01 \\
\hline Piedade & - & 0.01 & - & & . & & - & 0.01 & - & - & - & 0.02 & - & - & - & - & - & - & - & 0.06 \\
\hline Sorocaba & 0.02 & 0.01 & - & 0.02 & 0.04 & 0.02 & 0.02 & 0.04 & 0.04 & 0.02 & - & - & 0.04 & - & 0.01 & - & - & - & - & 0.09 \\
\hline Jundiai & 0.01 & - & - & 0.03 & 0.04 & 0.02 & - & 0.03 & 0.02 & 0.02 & - & - & 0.04 & - & - & - & - & 0.04 & - & 0.09 \\
\hline Braganca Paulista & 0.04 & 0.02 & - & 0.02 & 0.02 & 0.02 & - & 0.03 & 0.03 & 0.04 & - & - & 0.02 & - & - & - & - & - & - & 0.13 \\
\hline Campos do Jordao & - & - & - & & & & - & - & - & 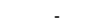 & - & - & & & - & - & - & - & - & 0.03 \\
\hline Sao Jose dos Campos & - & - & - & 0.01 & 0.01 & - & 0.02 & 0.02 & 0.03 & - & 0.01 & - & 0.06 & 0.04 & - & - & - & - & - & 0.13 \\
\hline Guaratingueta & - & - & - & 0.04 & 0.02 & - & 0.03 & 0.02 & 0.02 & - & - & - & 0.06 & - & - & - & - & - & - & 0.04 \\
\hline Bananal & - & - & - & - & - & - & - & - & 0.03 & - & - & - & - & - & - & - & - & - & - & - \\
\hline Paraibuna/Paraitinga & - & - & - & 0.01 & 0.01 & - & - & 0.06 & - & - & - & - & 0.05 & - & - & - & - & - & - & 0.03 \\
\hline Caraguatatuba & - & - & - & - & - & - & - & - & - & - & - & - & - & - & - & - & - & - & - & 0.03 \\
\hline Registro & - & 0.01 & - & - & - & 0.01 & - & - & - & - & - & - & - & - & - & - & - & - & - & 0.04 \\
\hline Itanhaem & - & - & - & - & - & - & - & - & - & - & - & - & - & - & - & - & - & - & - & 0.03 \\
\hline Osasco & - & - & - & 0.02 & 0.02 & - & - & 0.01 & 0.01 & 0.01 & - & - & 0.01 & - & - & - & - & 0.04 & - & 0.21 \\
\hline Franco da Rocha & 0.02 & - & - & 0.02 & 0.05 & 0.01 & - & 0.03 & 0.02 & - & - & - & 0.01 & - & 0.01 & - & - & - & - & 0.10 \\
\hline Guarulhos & 0.03 & - & - & 0.04 & 0.05 & 0.01 & 0.02 & 0.04 & 0.03 & 0.02 & - & - & 0.04 & - & 0.01 & - & - & - & - & 0.06 \\
\hline Itapecerica da Serra & 0.01 & - & - & 0.05 & 0.04 & - & - & 0.03 & 0.02 & 0.01 & - & - & 0.02 & - & 0.02 & - & - & 0.01 & - & 0.17 \\
\hline Sao Paulo & - & 0.02 & - & 0.01 & 0.01 & - & - & 0.01 & 0.01 & - & - & - & 0.02 & - & - & - & - & 0.02 & - & 0.15 \\
\hline Moji das Cruzes & 0.02 & - & - & 0.03 & 0.02 & 0.02 & 0.02 & 0.03 & 0.03 & 0.02 & - & - & 0.02 & - & 0.01 & - & - & - & - & 0.13 \\
\hline Santos & - & - & - & - & - & - & 0.01 & 0.01 & - & - & - & - & - & - & - & - & - & - & - & 0.07 \\
\hline
\end{tabular}

Observações/Filtro: $C C \geq 0,01$ (ou, $1 \%$ ).

FONTE: Elaborado pelo auto com base nos dados da RAIS/MTE 
Anexo XXXI. Jales/SP | Ciclo de vida dos sistemas locais nas atividades selecionadas da indústria de transformação (1996-2010)

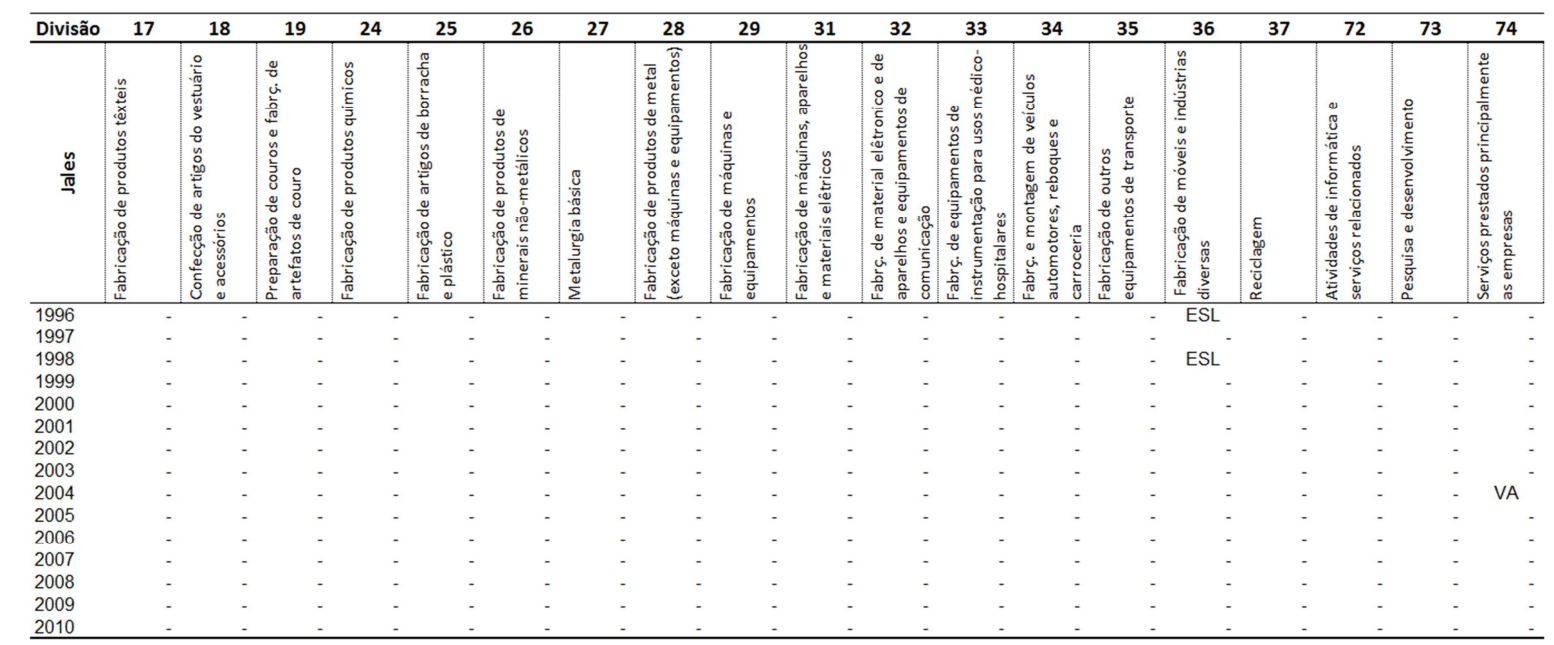

FONTE: Elaborado pelo autor com base nos dados da RAIS/MTE

Anexo XXXIl. Fernandópolis/SP | Ciclo de vida dos sistemas locais nas atividades selecionadas da indústria de transformação (1996-2010)

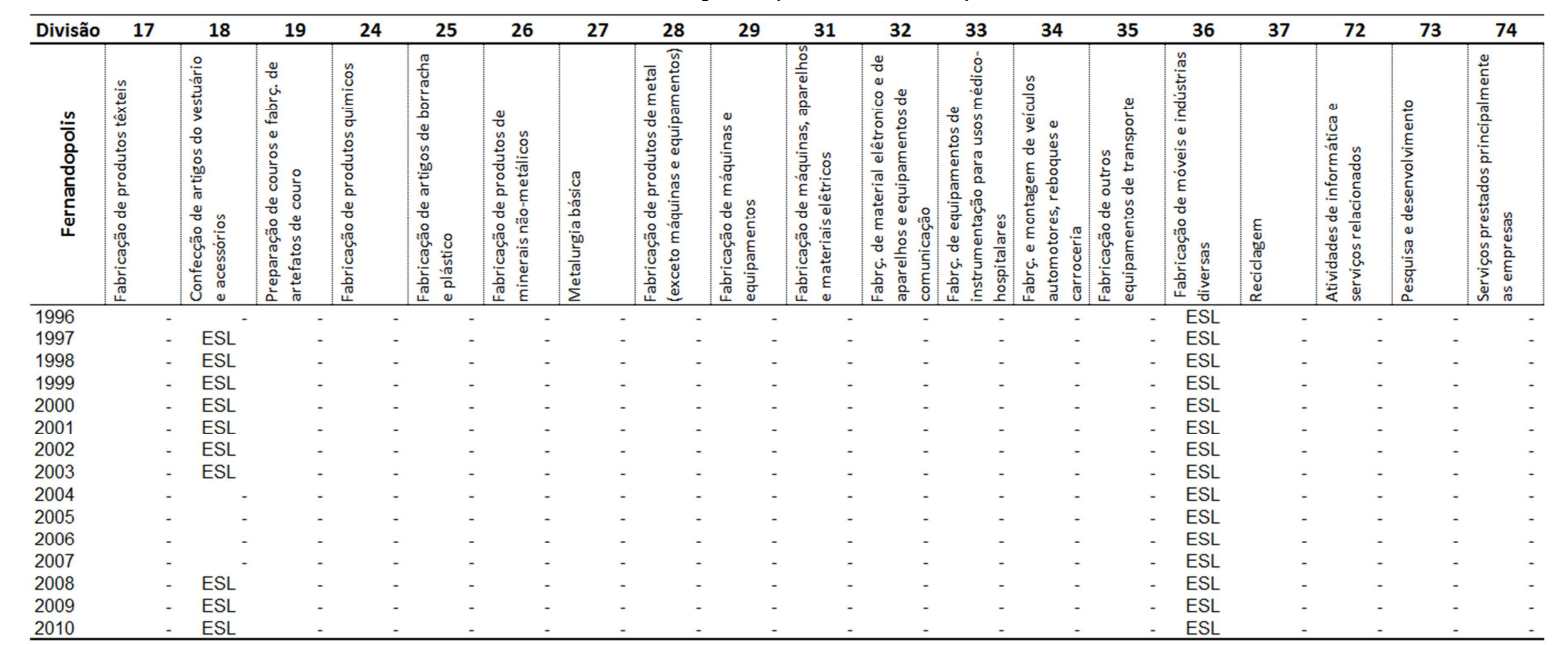

FONTE: Elaborado pelo autor com base nos dados da RAIS/MTE.

Anexo XXXIII. São José do Rio Preto/SP | Ciclo de vida dos sistemas locais nas atividades selecionadas da indústria de transformação (1996-2010)

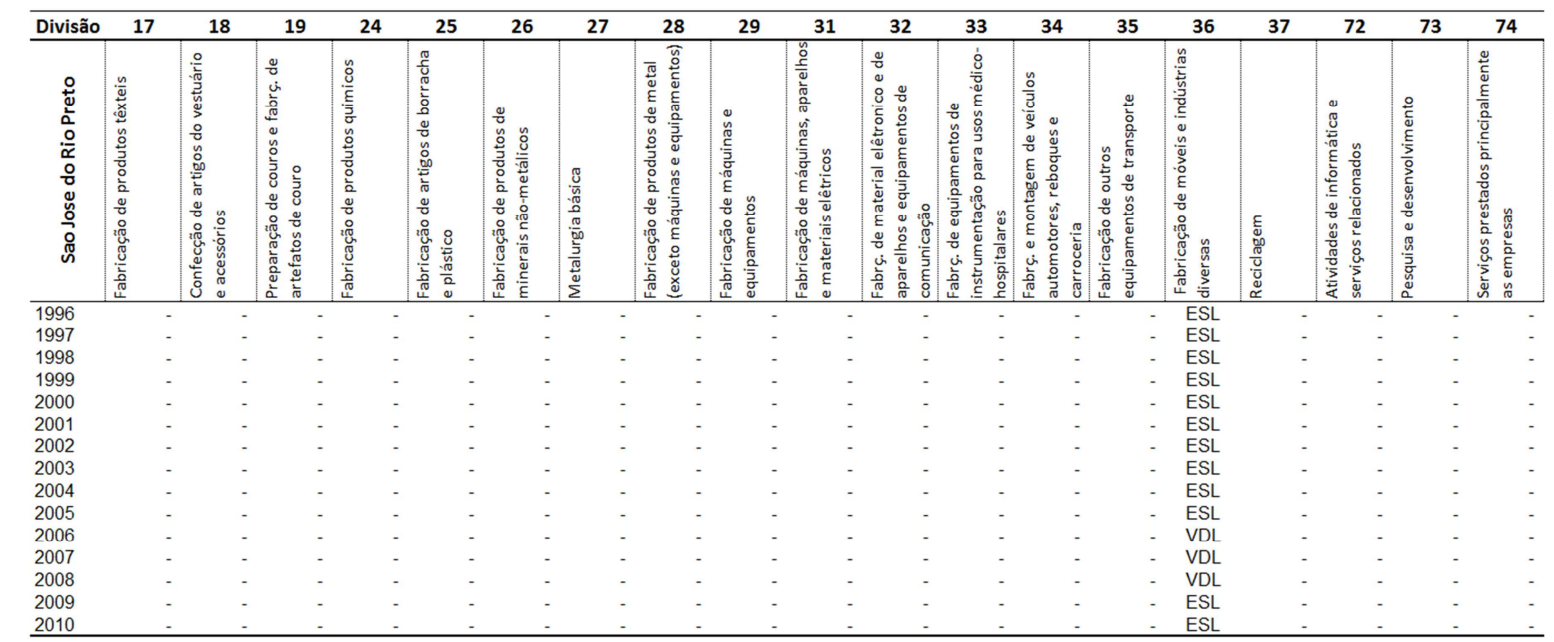

FONTE: Elaborado pelo autor com base nos dados da RAIS/MTE 
Anexo XXXIV. Auriflama/SP | Ciclo de vida dos sistemas locais nas atividades selecionadas da indústria de transformação (1996-2010)

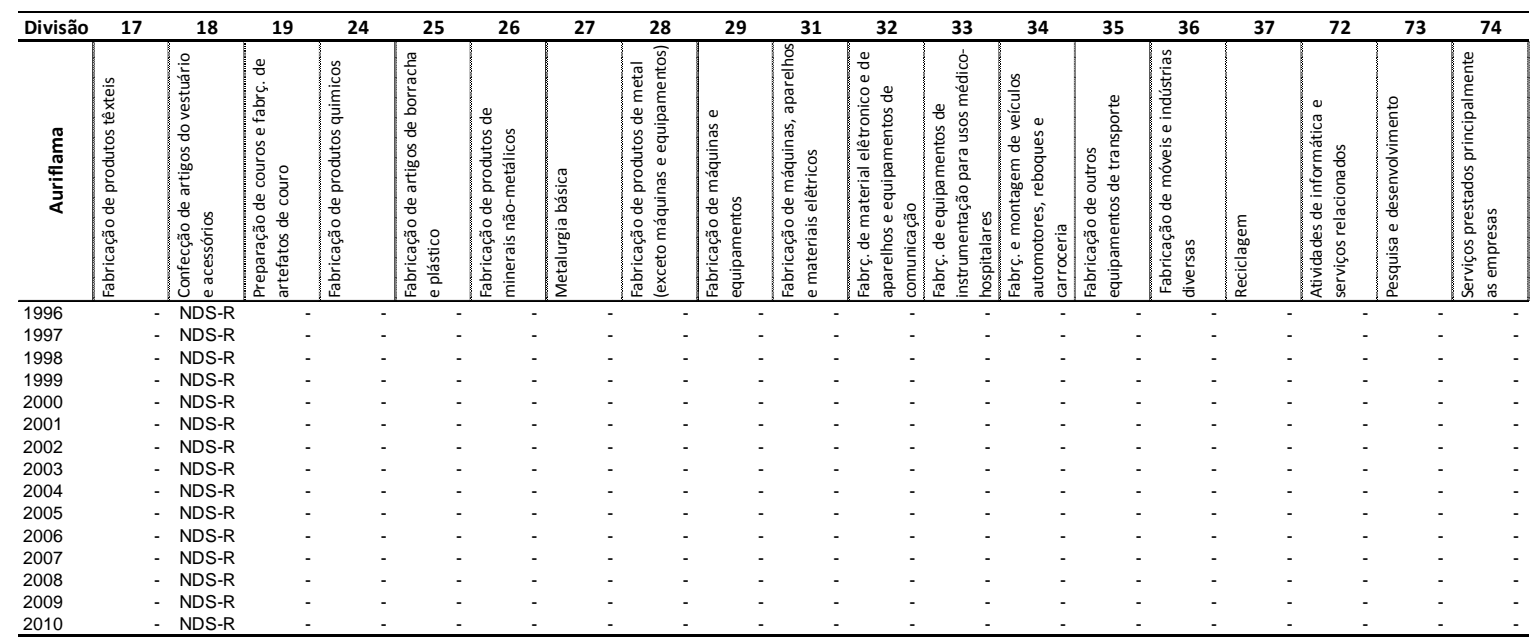

FONTE: Elaborado pelo autor com base nos dados da RAIS/MTE

Anexo XXXV. Nhandeara/SP | Ciclo de vida dos sistemas locais nas atividades selecionadas da indústria de transformação (1996-2010)

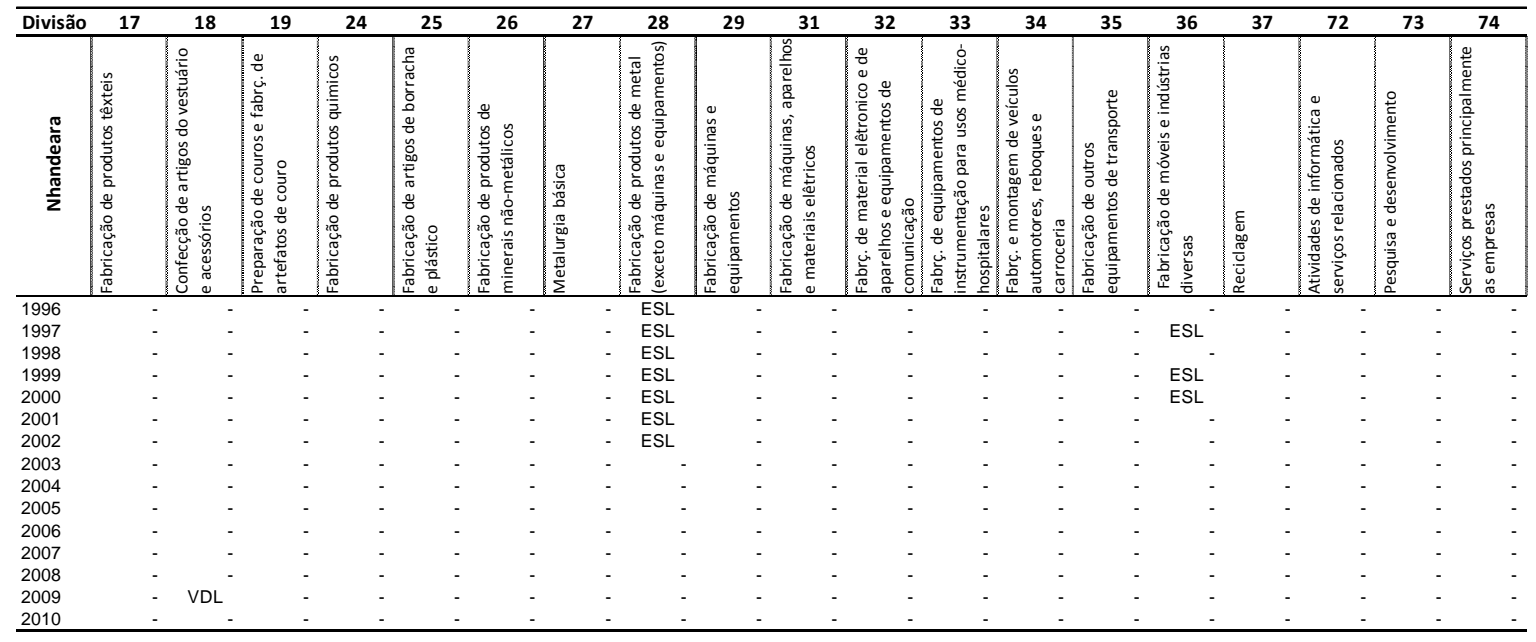

FONTE: Elaborado pelo autor com base nos dados da RAIS/MTE

Anexo XXXVI. Novo Horizonte/SP | Ciclo de vida dos sistemas locais nas atividades selecionadas da indústria de transformação (1996-2010)

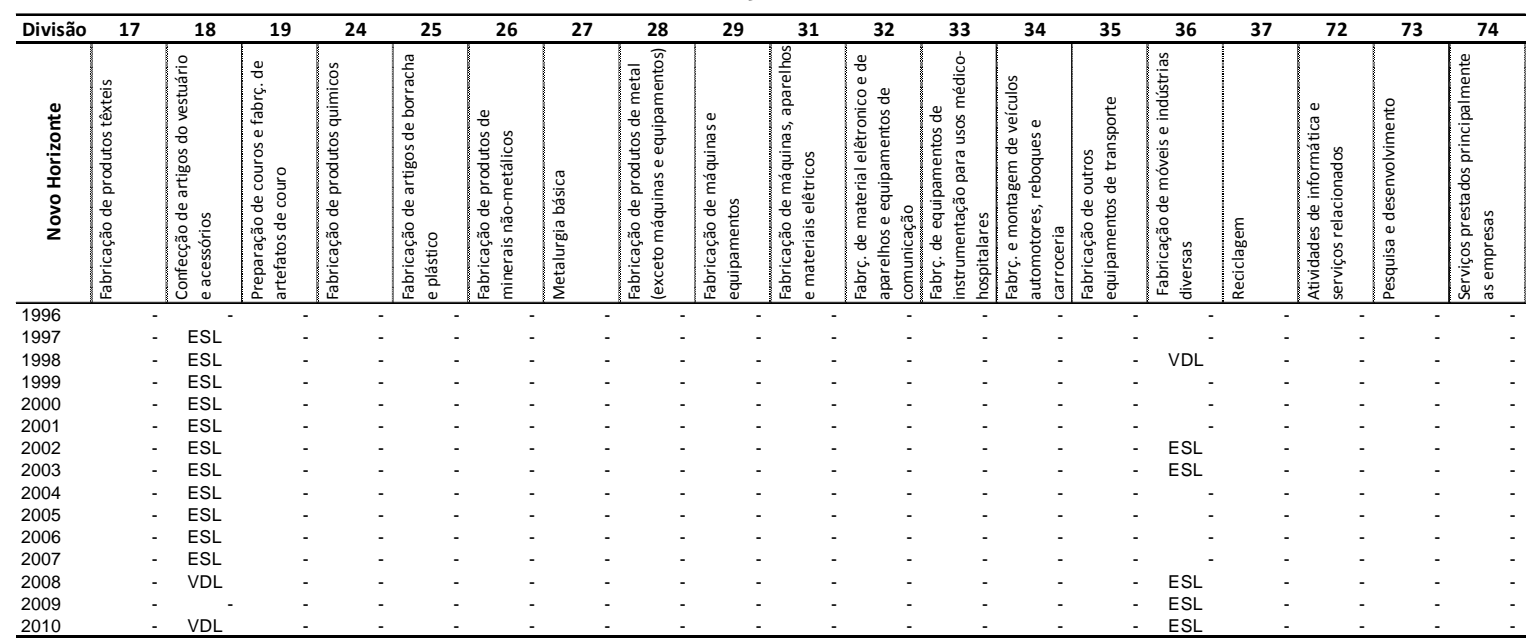

FONTE: Elaborado pelo autor com base nos dados da RAIS/MTE 
Anexo XXXVII. Barretos/SP | Ciclo de vida dos sistemas locais nas atividades selecionadas da indústria de transformação (1996-2010)

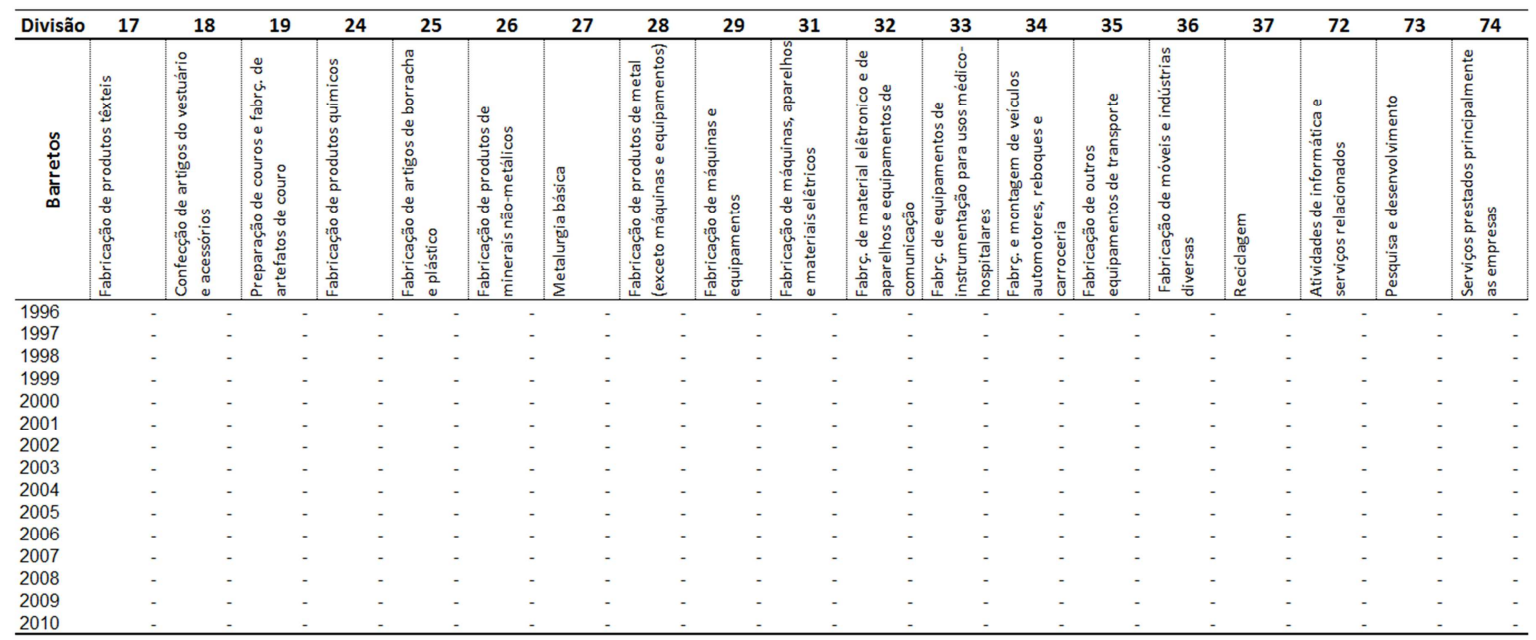

FONTE: Elaborado pelo autor com base nos dados da RAIS/MTE

Anexo XXXVIII. São Joaquim da Barra/SP | Ciclo de vida dos sistemas locais nas atividades selecionadas da indústria de transformação (1996-2010)

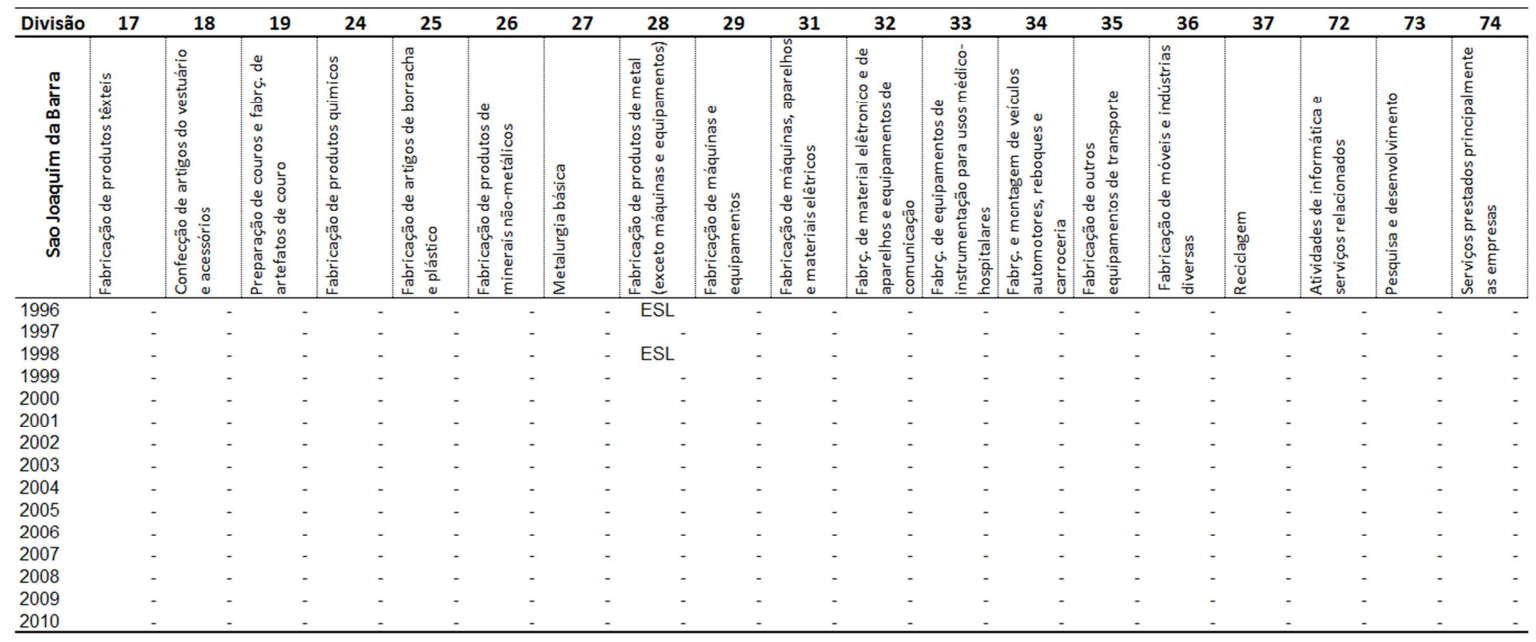

FONTE: Elaborado pelo autor com base nos dados da RAIS/MTE

Anexo XXXIX. Ituverava/SP | Ciclo de vida dos sistemas locais nas atividades selecionadas da indústria de transformação (1996-2010)

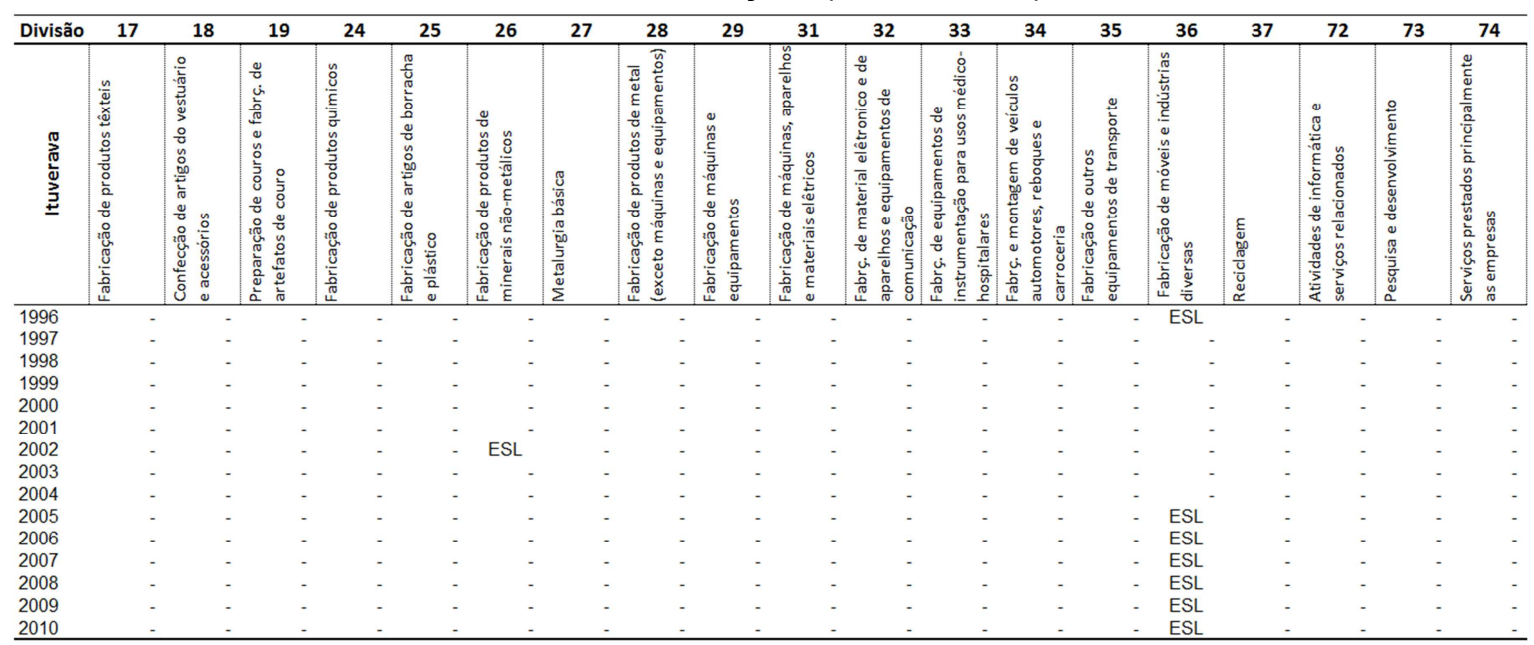

FONTE: Elaborado pelo autor com base nos dados da RAIS/MTE 
Anexo XL. Jaboticabal/SP | Ciclo de vida dos sistemas locais nas atividades selecionadas da indústria de transformação (1996-2010)

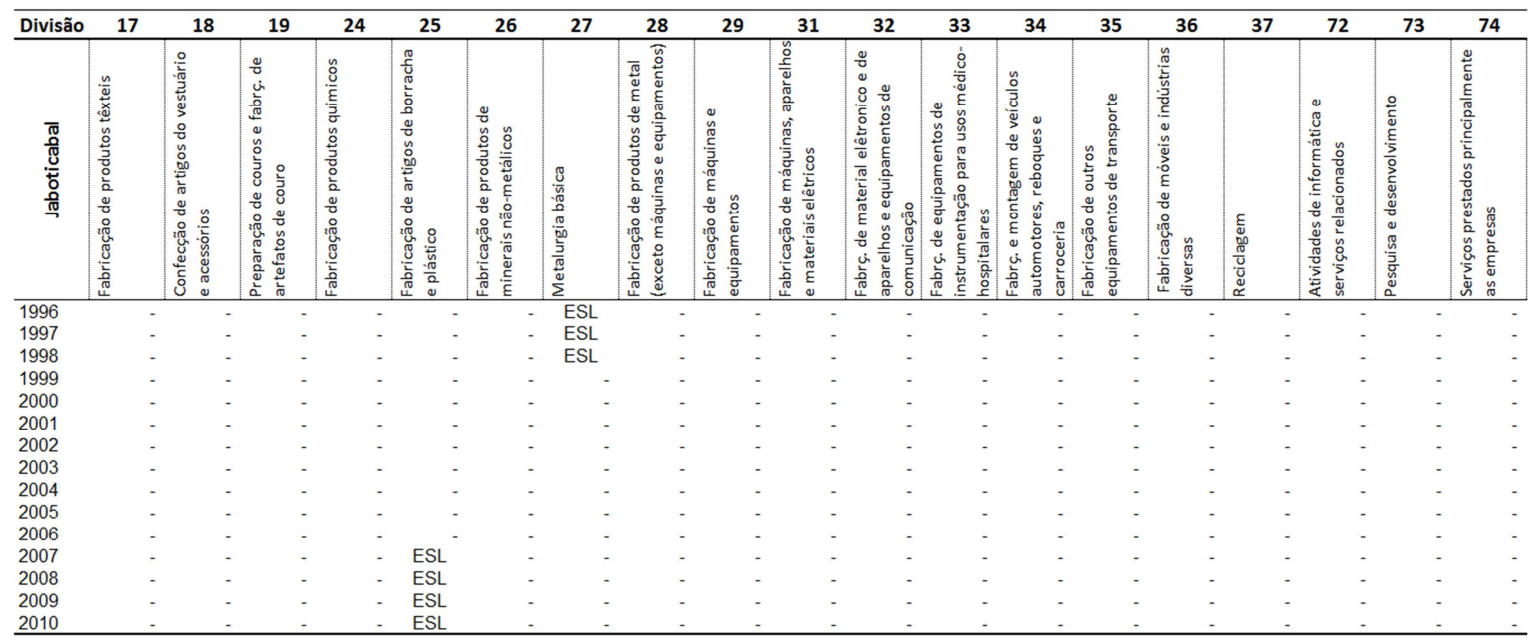

FONTE: Elaborado pelo autor com base nos dados da RAIS/MTE

Anexo L. Ribeirão Preto/SP | Ciclo de vida dos sistemas locais nas atividades selecionadas da indústria de transformação (1996-2010)

\begin{tabular}{|c|c|c|c|c|c|c|c|c|c|c|c|c|c|c|c|c|c|c|c|}
\hline $\begin{array}{l}\text { Divisão } \\
\end{array}$ & 17 & 18 & 19 & 24 & 25 & 26 & 2 & 28 & 29 & 31 & 32 & 33 & 34 & 35 & 36 & 37 & 72 & 73 & 74 \\
\hline 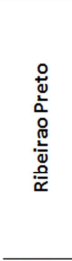 & 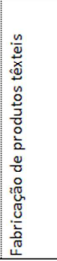 & 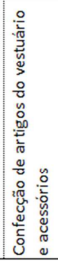 & 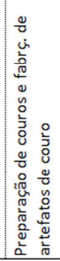 & 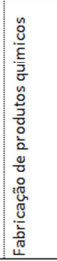 & 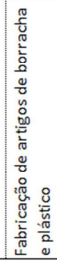 & 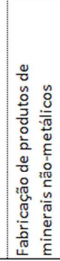 & 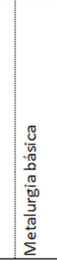 & 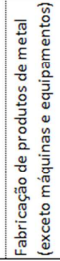 & 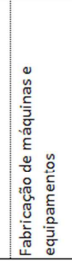 & 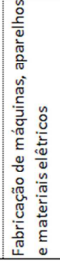 & 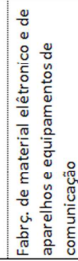 & 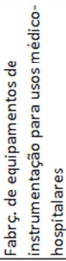 & 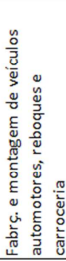 & 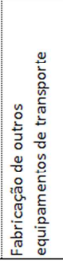 & 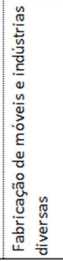 & 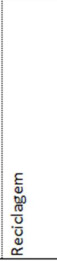 & 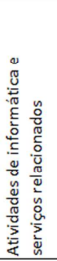 & 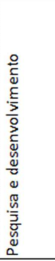 & 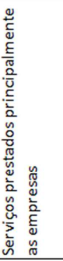 \\
\hline 1996 & & & & & & & & & & & & $\begin{array}{l}\text { ESL } \\
\text { ESL }\end{array}$ & & & & & & & \\
\hline $\begin{array}{l}98 \\
99\end{array}$ & & & & & & & - & & & & & $\mathrm{ESL}^{-}$ & & & & & & & \\
\hline & & & & & & & 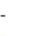 & & & & & G & & & & & & & \\
\hline 2001 & & & & & & & : & & & & & $\begin{array}{l}\text { ESL } \\
\text { ESL }\end{array}$ & & & & & & & \\
\hline 2003 & & & & & & & - & & & & & ES & & & & & & & \\
\hline & & & & & & & . & & & & & ESL & & & & & & & \\
\hline 20 & & & & & & & 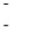 & & ESL & & & ESL & & & & & & & \\
\hline & & & & & & & & & & & & & & & & & & & \\
\hline 2010 & & & & & & & - & & SL & & & & & & & & & & \\
\hline
\end{tabular}

FONTE: Elaborado pelo autor com base nos dados da RAIS/MTE

Anexo LI. Batatais/SP | Ciclo de vida dos sistemas locais nas atividades selecionadas da indústria de transformação (1996-2010)

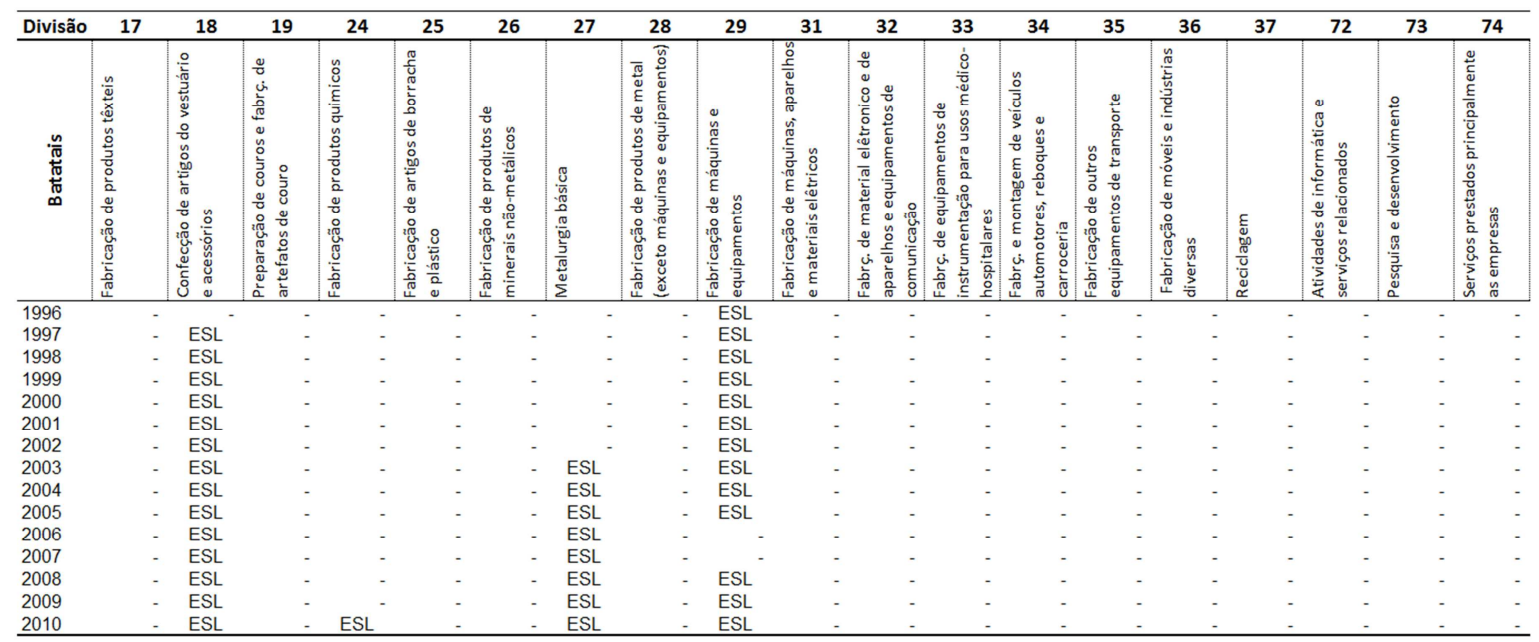

FONTE: Elaborado pelo autor com base nos dados da RAIS/MTE 
Anexo LI. Andradina/SP | Ciclo de vida dos sistemas locais nas atividades selecionadas da indústria de transformação (1996-2010)

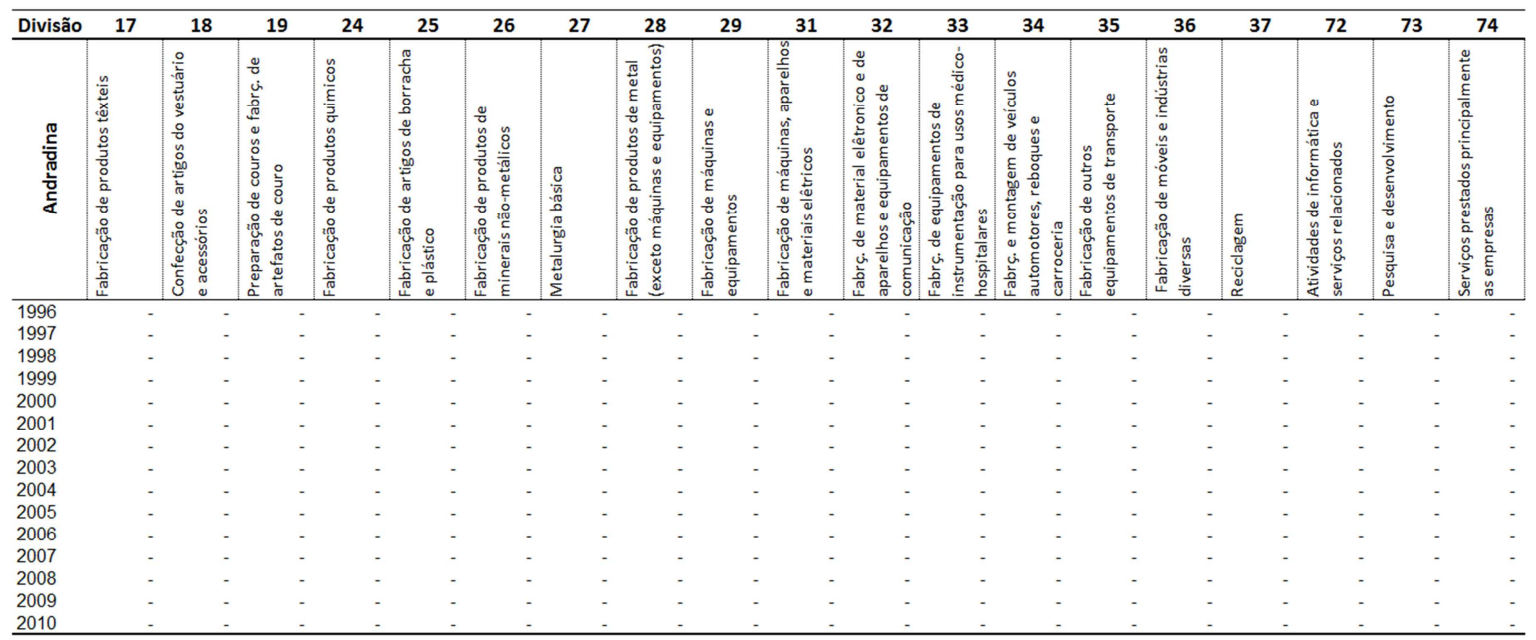

FONTE: Elaborado pelo autor com base nos dados da RAIS/MTE

Anexo Lll. Araçatuba/SP | Ciclo de vida dos sistemas locais nas atividades selecionadas da indústria de transformação (1996-2010)

\begin{tabular}{|c|c|c|c|c|c|c|c|c|c|c|c|c|c|c|c|c|c|c|c|}
\hline Divisãa & 17 & 18 & 19 & 24 & 25 & 26 & 2 & 28 & 29 & 31 & 32 & 33 & 34 & 35 & 36 & 37 & 72 & 73 & 74 \\
\hline 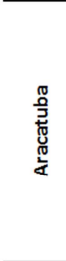 & 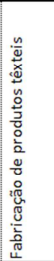 & 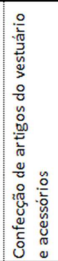 & 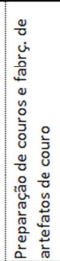 & 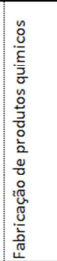 & 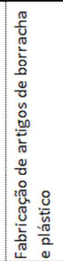 & 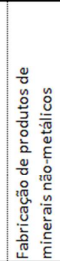 & 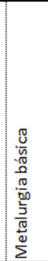 & 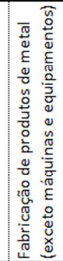 & 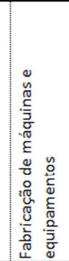 & 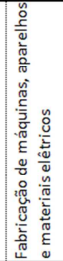 & 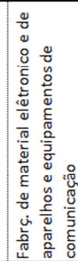 & 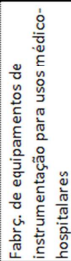 & 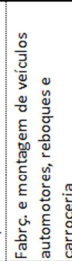 & 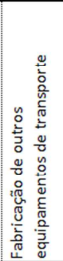 & 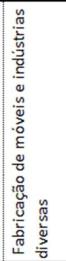 & 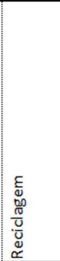 & 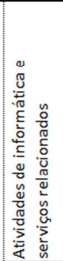 & 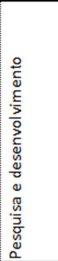 & 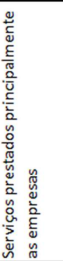 \\
\hline $\begin{array}{l}1996 \\
1997\end{array}$ & & & & & & & & 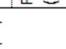 & & & & & & & & & & & \\
\hline & & & & & & & & & & & & - & & & ESL & & & & \\
\hline & & & & & & & & & & & & - & & & & & & & \\
\hline & & & & & & & & & & & & & & & 50 & & & & \\
\hline & & & & & & & & & & & & & & & $\begin{array}{l}\text { ESL } \\
\text { ESL }\end{array}$ & & & & \\
\hline & & & & & & & & & & & . & & & & E & & & & \\
\hline & & & & & & & & & & & & & & & I & & & & \\
\hline 2007 & & & $\begin{array}{l}\text { ESL } \\
\text { ESL }\end{array}$ & & & & & & & & & & & & ESL & & & & \\
\hline & & & ESL & & & & & & & & & & & & & & & & \\
\hline 2009 & & & 5 & & & & & & & & & . & & & ESL & & & & \\
\hline
\end{tabular}

FONTE: Elaborado pelo autor com base nos dados da RAIS/MTE

Anexo LIII. Birigui/SP | Ciclo de vida dos sistemas locais nas atividades selecionadas da indústria de transformação (1996-2010)

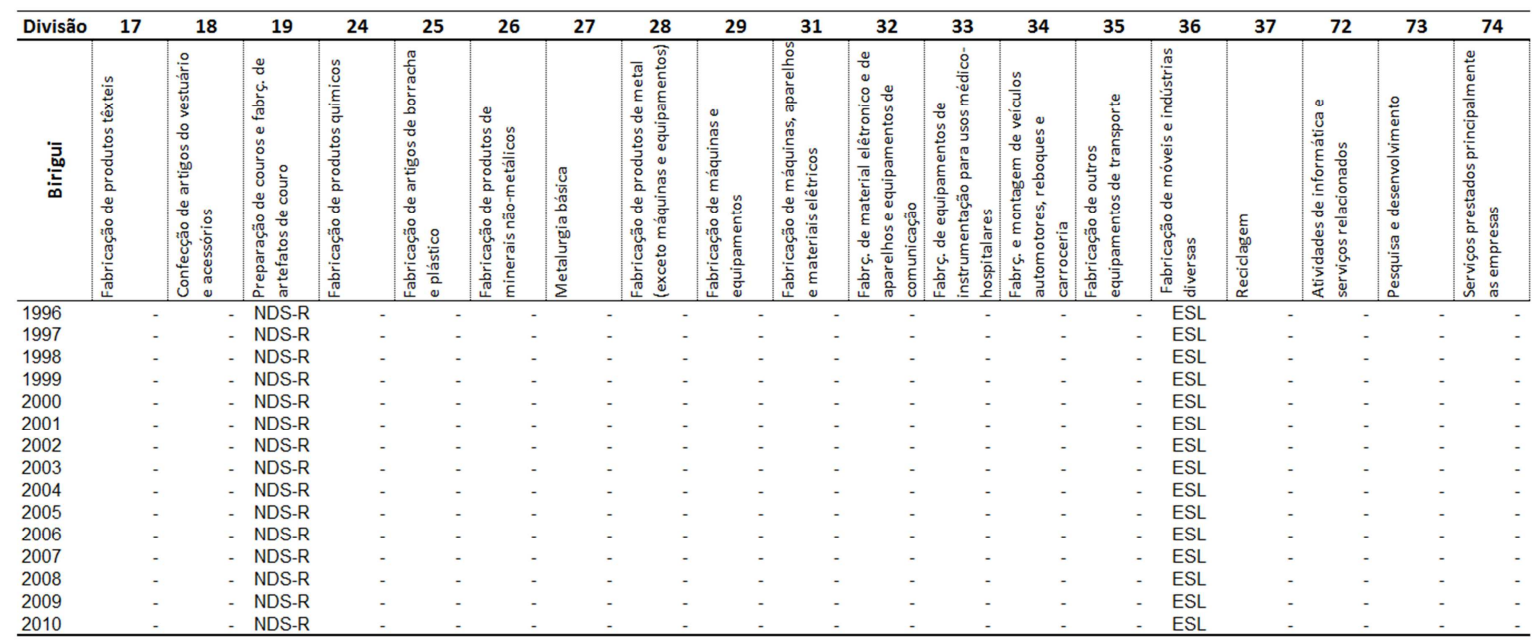

FONTE: Elaborado pelo autor com base nos dados da RAIS/MTE 
Anexo LIV. Lins/SP | Ciclo de vida dos sistemas locais nas atividades selecionadas da indústria de transformação (1996-2010)

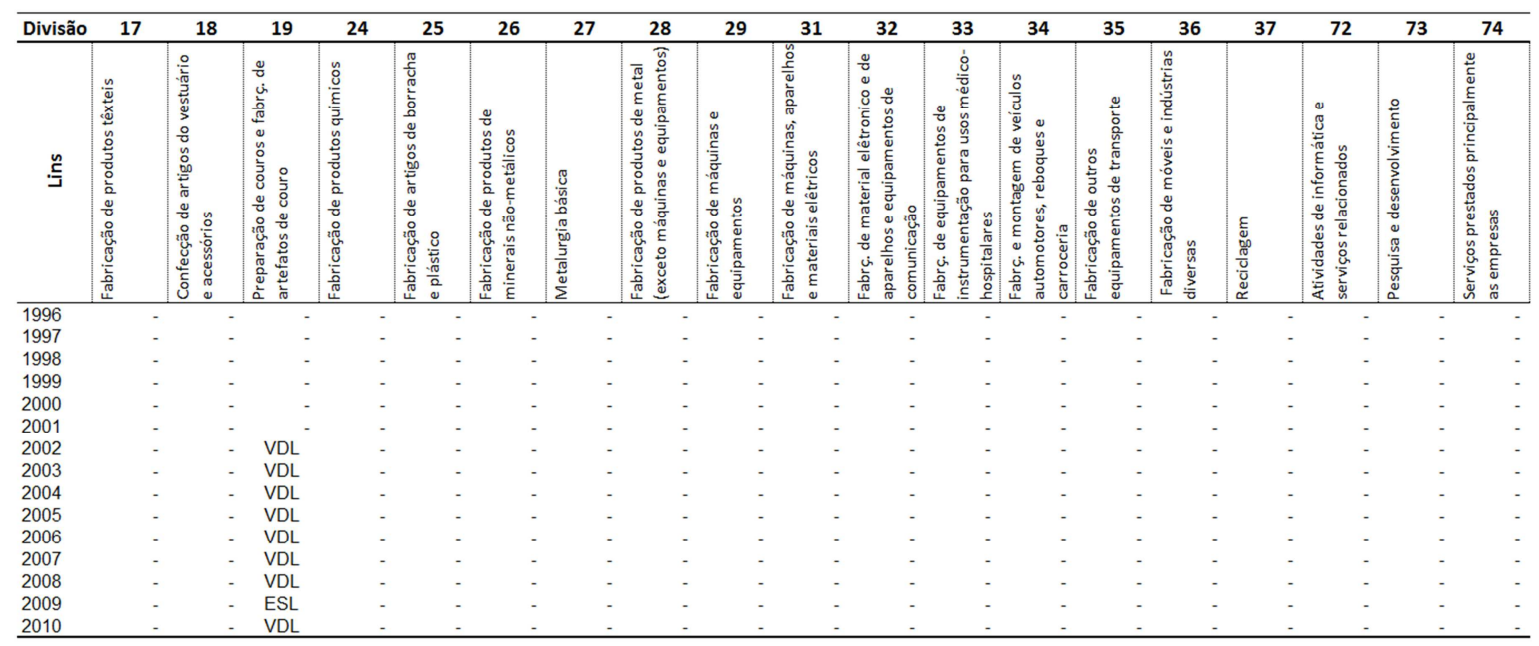

FONTE: Elaborado pelo autor com base nos dados da RAIS/MTE

Anexo LV. Bauru/SP | Ciclo de vida dos sistemas locais nas atividades selecionadas da indústria de transformação (1996-2010)

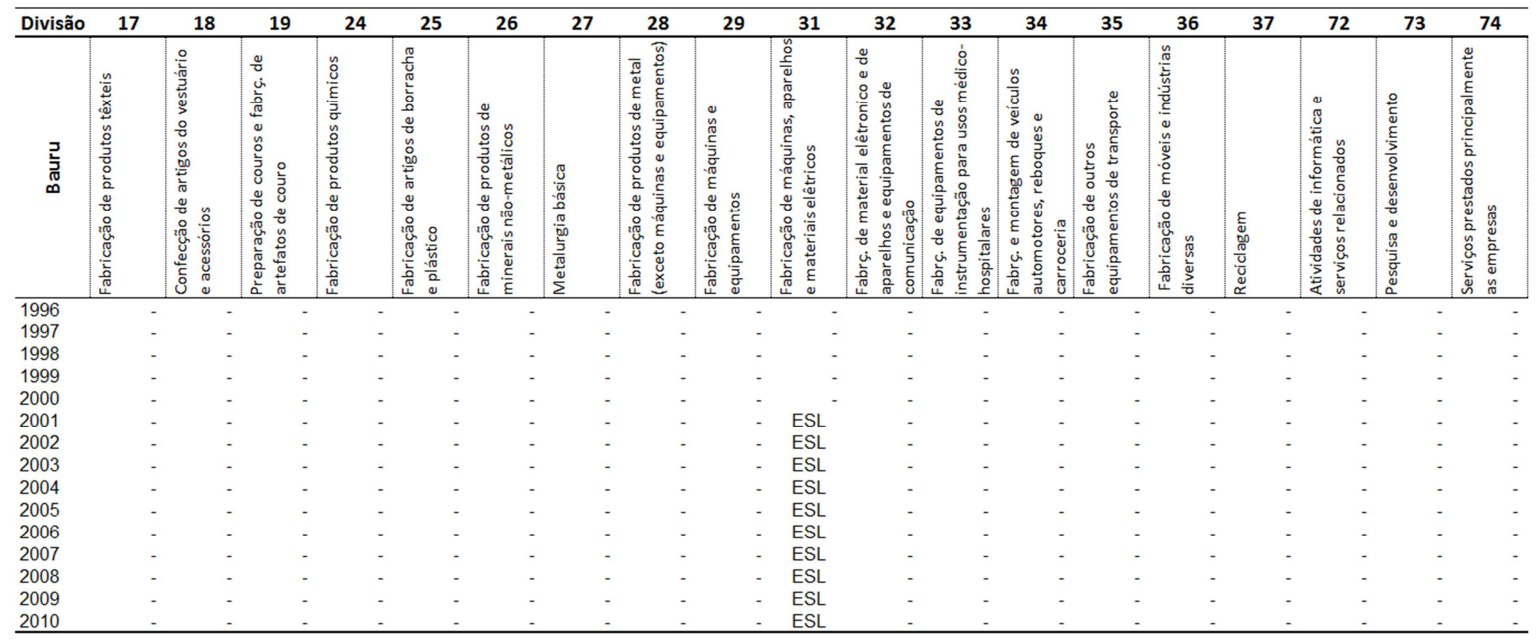

FONTE: Elaborado pelo autor com base nos dados da RAIS/MTE

Anexo LVI. Jaú/SP | Ciclo de vida dos sistemas locais nas atividades selecionadas da indústria de transformação (1996-2010)

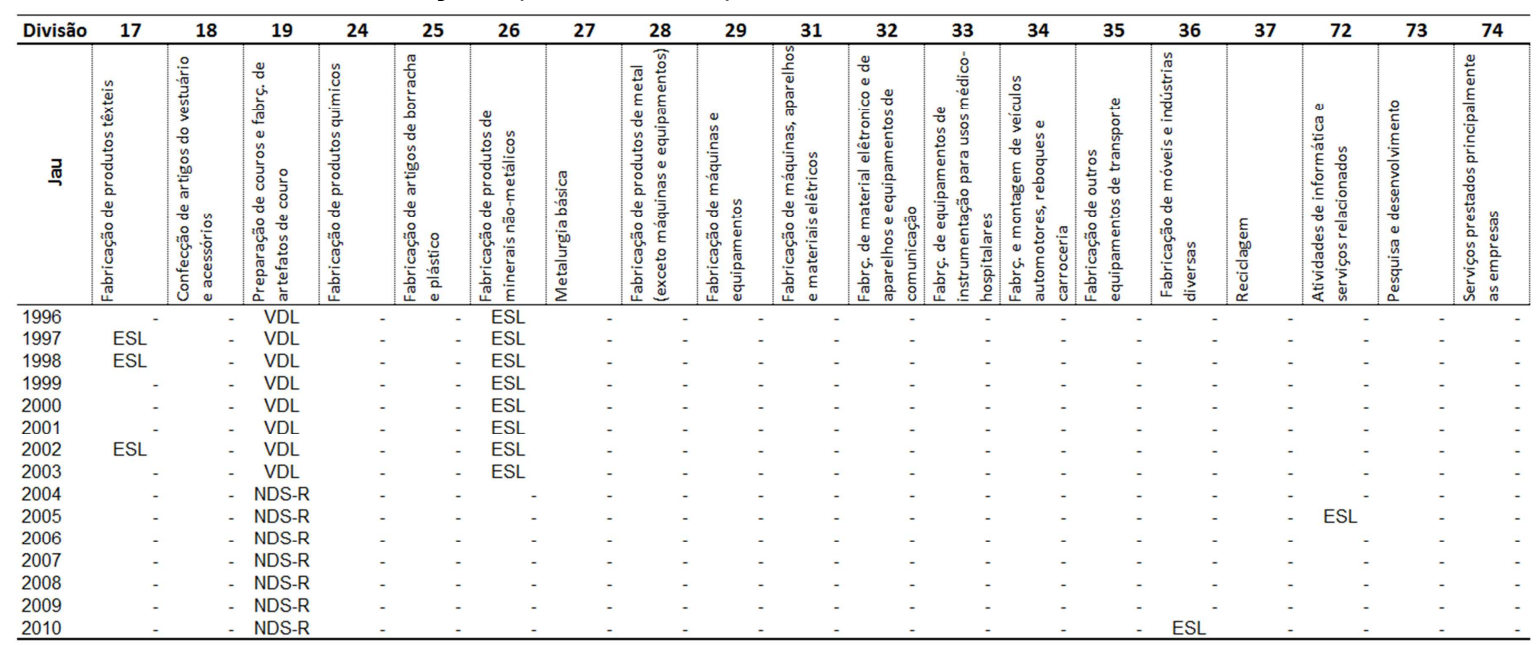

FONTE: Elaborado pelo autor com base nos dados da RAIS/MTE 
Anexo LVII. Avaré/SP | Ciclo de vida dos sistemas locais nas atividades selecionadas da indústria de transformação (1996-2010)

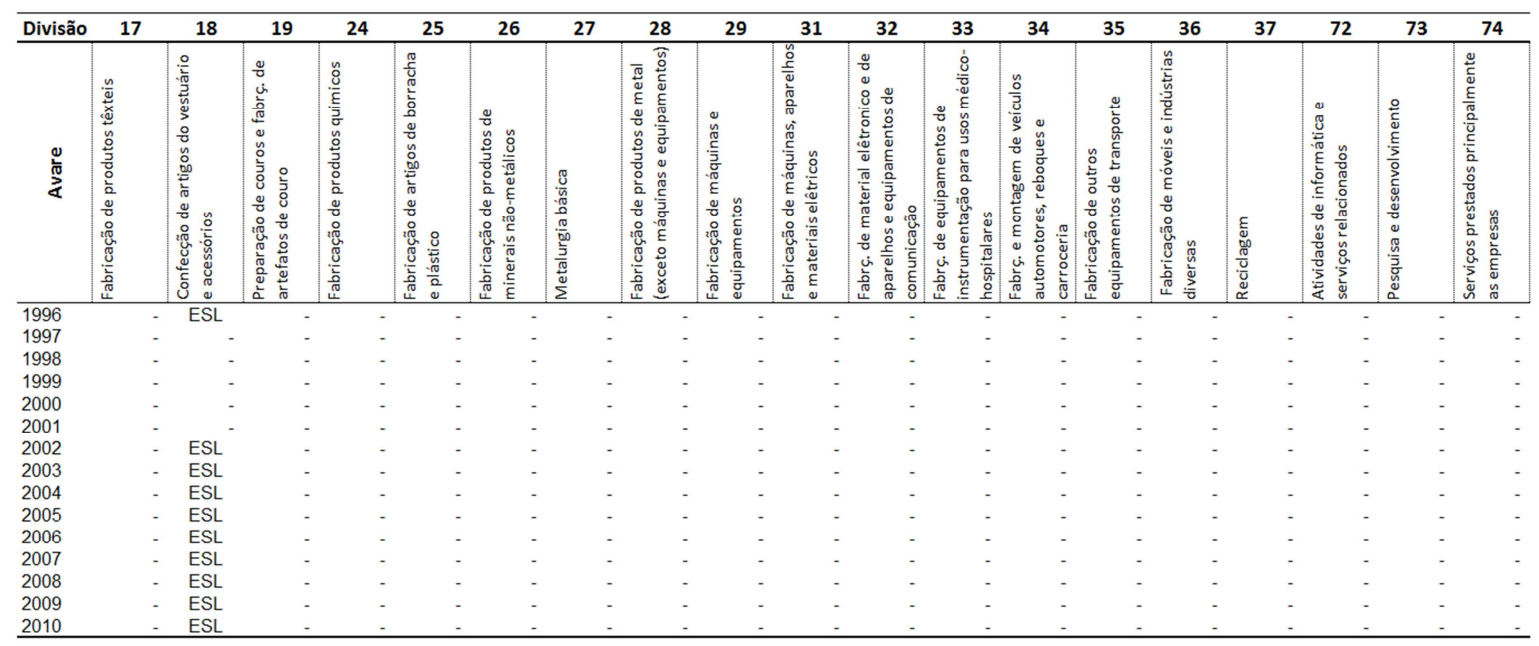

FONTE: Elaborado pelo autor com base nos dados da RAIS/MTE

Anexo LVIII. Botucatu/SP | Ciclo de vida dos sistemas locais nas atividades selecionadas da indústria de transformação (1996-2010)

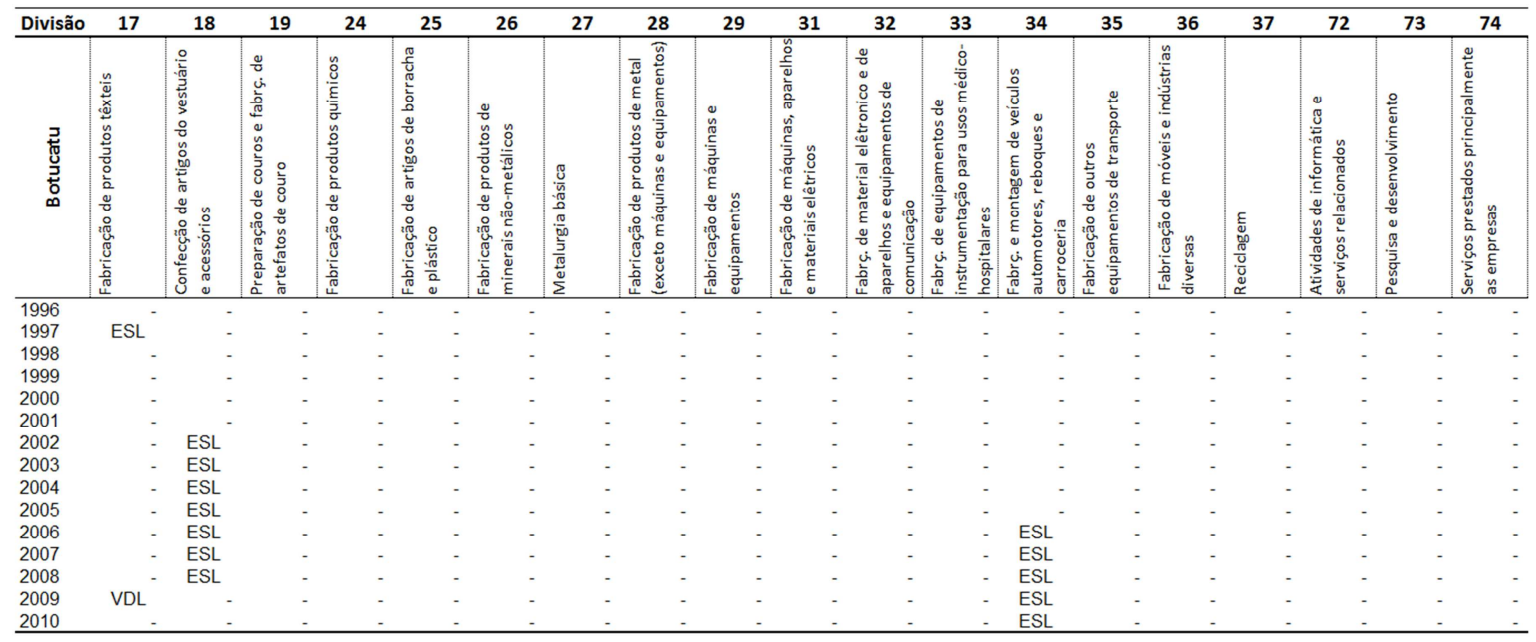

FONTE: Elaborado pelo autor com base nos dados da RAIS/MTE

Anexo LIX. Araraquara/SP | Ciclo de vida dos sistemas locais nas atividades selecionadas da indústria de transformação (1996-2010)

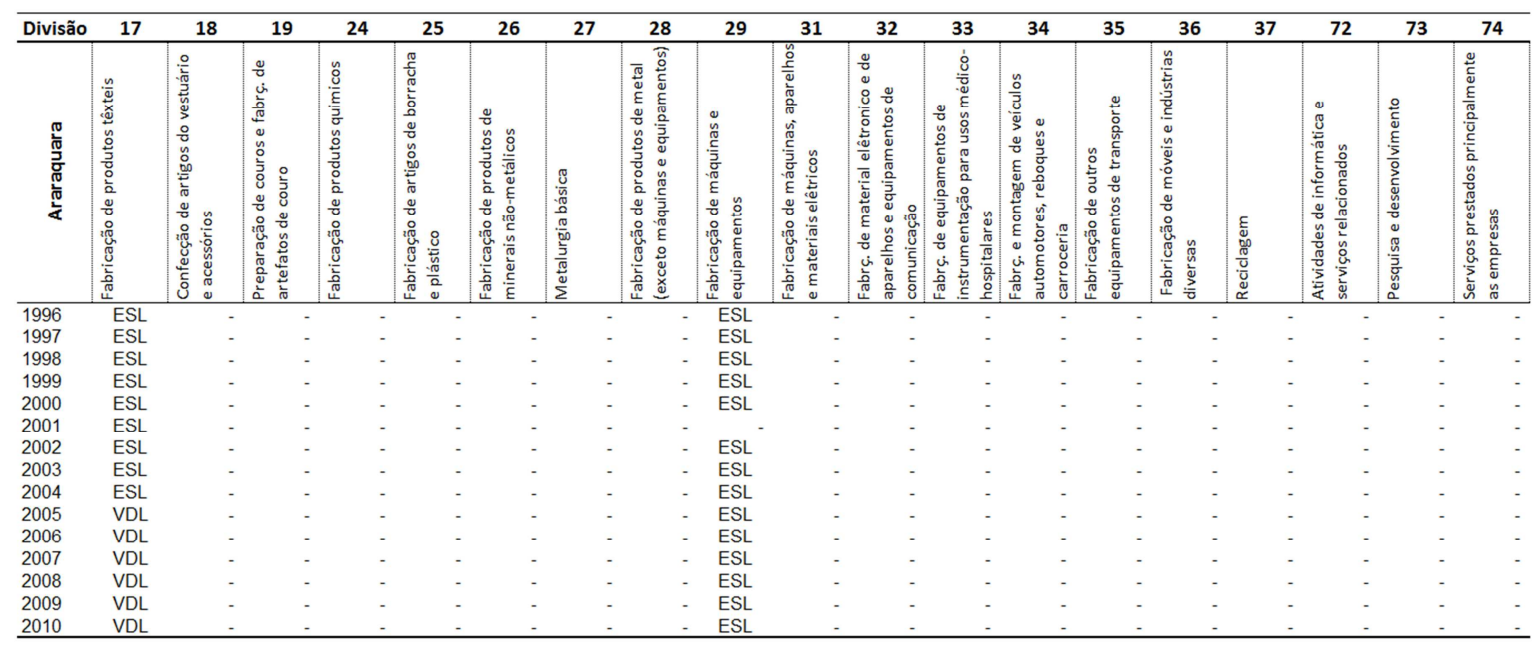

FONTE: Elaborado pelo autor com base nos dados da RAIS/MTE 
Anexo LX. São Carlos/SP | Ciclo de vida dos sistemas locais nas atividades selecionadas da indústria de transformação (1996-2010)

\begin{tabular}{|c|c|c|c|c|c|c|c|c|c|c|c|c|c|c|c|c|c|c|c|}
\hline Divisão & 17 & 18 & 19 & 24 & 25 & 26 & 2 & 28 & 29 & 31 & 32 & 33 & 34 & 35 & 36 & 37 & 72 & & 74 \\
\hline 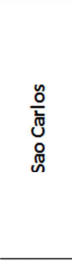 & 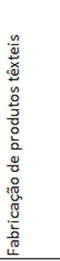 & 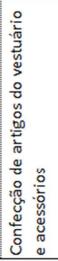 & 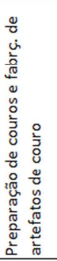 & 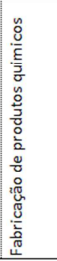 & 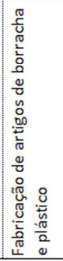 & 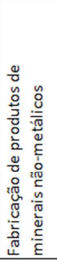 & 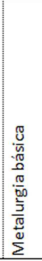 & 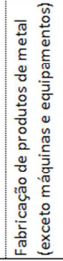 & 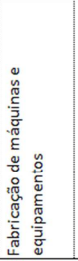 & 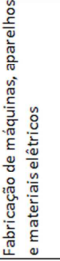 & 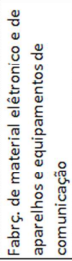 & 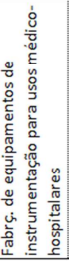 & 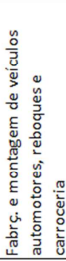 & 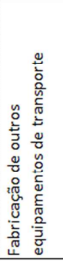 & 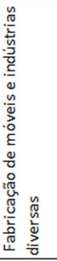 & 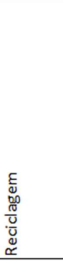 & 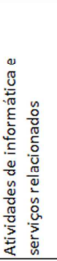 & & 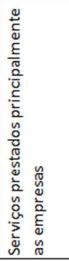 \\
\hline $\begin{array}{l}1996 \\
\end{array}$ & & & & & & & & . & $\begin{array}{l}\text { NDS-R } \\
\text { NDS-R }\end{array}$ & . & & & & & $\begin{array}{l}\text { ESL } \\
\text { ESL }\end{array}$ & & & & \\
\hline $\begin{array}{l}1998 \\
1999\end{array}$ & ESL & & & & & & & & NDS-R & & & & & & Fo & & & & \\
\hline & & & & & & & & & NDS-R & & & & & & & & & & \\
\hline & & & & & & & & & & & & & & & & & & & \\
\hline & & & & & & & & & NDS & & & & & & & & & & \\
\hline & & & & & & & & & & & & & & & & & & & \\
\hline & & & & & & & & & NDS-R & & & & & & ESL & & & & \\
\hline & & & & & & & & & NDS-R & ESL & & & & & & & & & \\
\hline & & & & & & & & & ES & & & & & & ES & & & & \\
\hline 200 & $\begin{array}{l}\text { ESL } \\
\text { ESL }\end{array}$ & & & & & & & & & & & $\begin{array}{l}\text { ESL } \\
\text { ESL }\end{array}$ & & & & & & & \\
\hline 2010 & & & & & & & & & ESL & & & ESL & & & ESL & & & & \\
\hline
\end{tabular}

FONTE: Elaborado pelo autor com base nos dados da RAIS/MTE

Anexo LXI. Pirassununga/SP | Ciclo de vida dos sistemas locais nas atividades selecionadas da indústria de transformação (1996-2010)

\begin{tabular}{|c|c|c|c|c|c|c|c|c|c|c|c|c|c|c|c|c|c|c|c|}
\hline $\begin{array}{l}\text { Divisão } \\
\end{array}$ & 17 & 18 & 19 & 24 & 25 & 26 & 27 & 28 & 29 & 31 & 32 & 33 & 34 & 35 & 36 & 37 & 72 & 73 & 74 \\
\hline 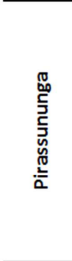 & 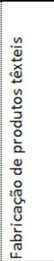 & 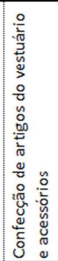 & 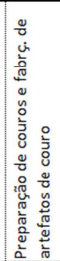 & 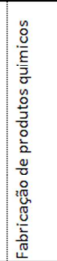 & 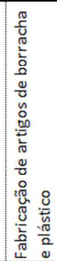 & 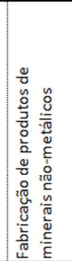 & 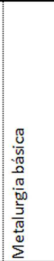 & 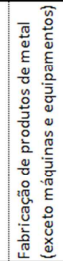 & 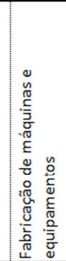 & 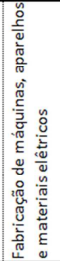 & 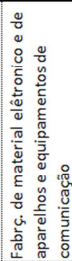 & 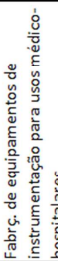 & 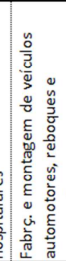 & 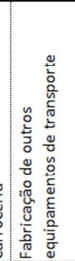 & 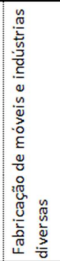 & 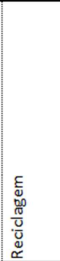 & 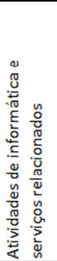 & 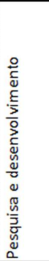 & 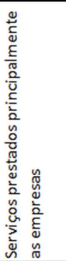 \\
\hline$\overline{1996}$ & & & & & & NDS-R & & & & & & & & & ESL & & & & \\
\hline & & & & & & NDS-R & & & & & & & & & ESL & & & & \\
\hline $\begin{array}{l}19 \\
20\end{array}$ & & & & & & $\begin{array}{l}\text { NDS-R } \\
\text { NDS-R }\end{array}$ & & & 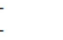 & & & & & & $\begin{array}{l}\text { ESL } \\
\text { ESL }\end{array}$ & & & & \\
\hline & & & & & & V & & & & ESL & & & & & ESL & & & & \\
\hline & & & & & & V & & & & & & & & & & & & & \\
\hline 2003 & & & & & & $\mathrm{Vg}$ & & & & E & & & & & E & & & & \\
\hline & & & & & & $\mathrm{V}$ & & & & & & & & & & & & & \\
\hline & & & & & & $\begin{array}{l}\text { VDL } \\
\text { VDL }\end{array}$ & & & & $\begin{array}{l}\text { ES } \\
\text { ES }\end{array}$ & & & & & $\begin{array}{l}\text { ESL } \\
\text { ESL }\end{array}$ & & & & \\
\hline 20 & & & & & & VDL & & & . & ES & & & & & $E$ & & & & \\
\hline & & & & & & & & & . & & & & & & & & & & \\
\hline 2009 & & & & & & $\begin{array}{l}\text { VDL } \\
\text { VDL }\end{array}$ & & & . & $\begin{array}{l}\text { ESL } \\
\text { ESL }\end{array}$ & & & & & ESL & & & & \\
\hline
\end{tabular}

FONTE: Elaborado pelo autor com base nos dados da RAIS/MTE

Anexo LXII. São João da Boa Vista/SP | Ciclo de vida dos sistemas locais nas atividades selecionadas da indústria de transformação (1996-2010)

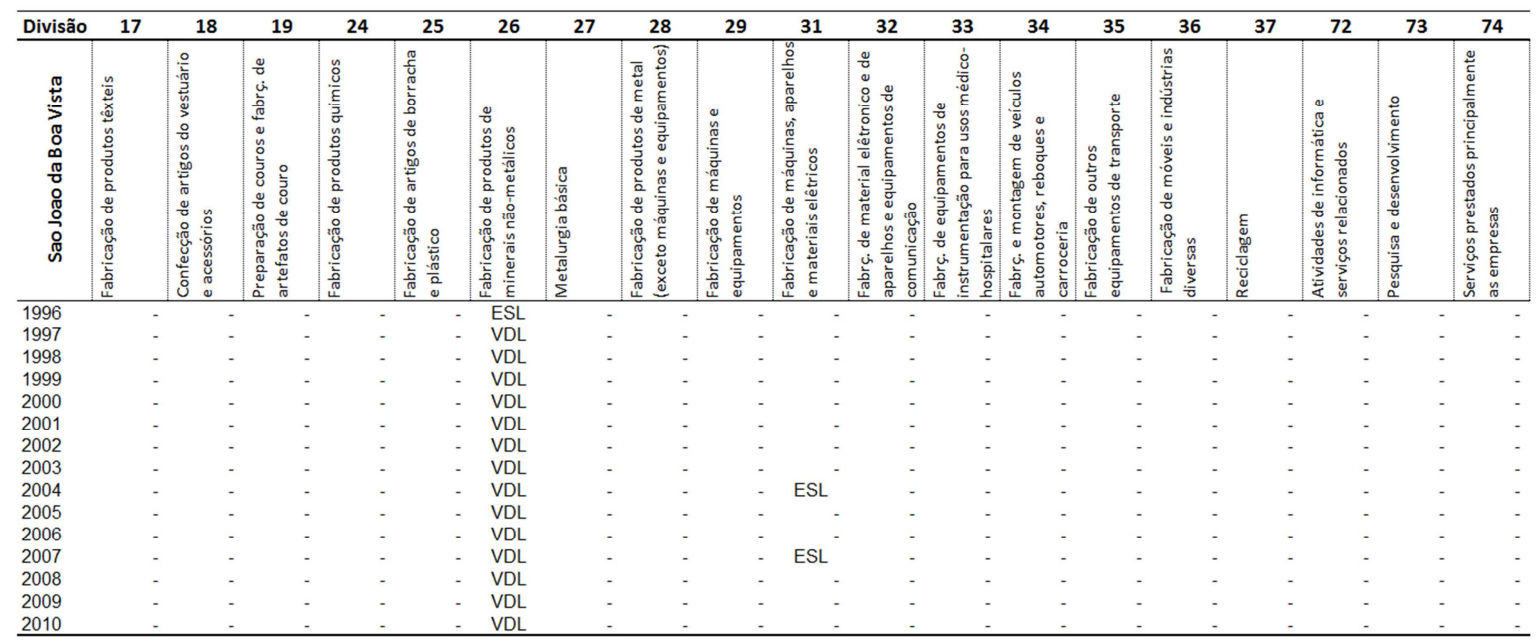

FONTE: Elaborado pelo autor com base nos dados da RAIS/MTE 
Anexo LXIII. Mogi-Mirim/SP | Ciclo de vida dos sistemas locais nas atividades selecionadas da indústria de transformação (1996-2010)

\begin{tabular}{|c|c|c|c|c|c|c|c|c|c|c|c|c|c|c|c|c|c|c|c|}
\hline Divisão & 17 & 18 & 19 & 24 & 25 & 26 & 27 & 28 & 29 & 31 & 32 & 33 & 34 & 35 & 36 & 37 & 72 & & 74 \\
\hline 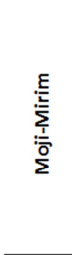 & 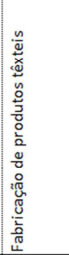 & 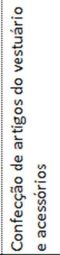 & 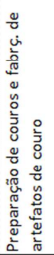 & 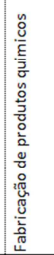 & 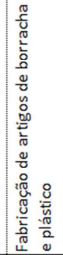 & 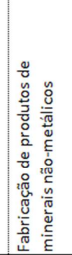 & 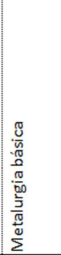 & 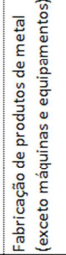 & 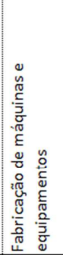 & 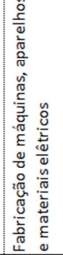 & 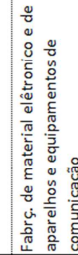 & 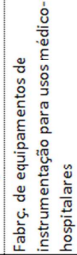 & 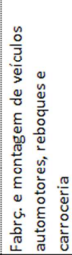 & 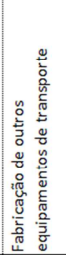 & 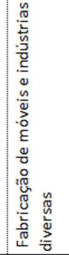 & 总 & 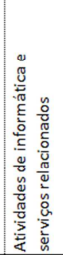 & & 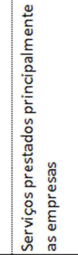 \\
\hline 1996 & & & ESL & & 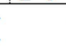 & $\begin{array}{l}\text { ESLL } \\
\text { ESL }\end{array}$ & & & & & & & & & $\begin{array}{l}\text { ESL } \\
\text { ESL }\end{array}$ & & & & \\
\hline 1998 & . & & & & & $E$ & & & & & & & $\begin{array}{l}\text { ESL } \\
\text { ESS }\end{array}$ & & & & & & \\
\hline & & & & & & $\begin{array}{l}\text { ESL } \\
\text { ESL }\end{array}$ & & & & & & & $\begin{array}{l}\text { ESL } \\
\text { ESL }\end{array}$ & & & & & & \\
\hline & ESL & & & & & & & & & & & & & & & & & & \\
\hline 2002 & $\begin{array}{l}\text { ESL } \\
\text { ESL }\end{array}$ & & & & & $\begin{array}{l}E \\
E S\end{array}$ & & & & & & & $\mathrm{ES}$ & & & & & & \\
\hline & 5 & & & & & ESL & & & & & & & $\mathrm{E}$ & & ESL & & & & \\
\hline & & & & & & ESL & & & & & & & & & & & & & \\
\hline & $E S$ & & & & & & & & & & & & ES & & & & & & \\
\hline & & & & & & ESL & & & & & & & & & & & & & \\
\hline 2008 & ES & & & & & ESL & & & & & & & & & & & & & \\
\hline 2010 & $\begin{array}{l}\text { ESL } \\
\text { ESL }\end{array}$ & & & & & & & & & & & & $\begin{array}{l}\text { ESL } \\
\text { ESL }\end{array}$ & & $\begin{array}{l}\text { ESL } \\
\text { ESL }\end{array}$ & & & & \\
\hline
\end{tabular}

FONTE: Elaborado pelo autor com base nos dados da RAIS/MTE

Anexo LXVI. Amparo/SP | Ciclo de vida dos sistemas locais nas atividades selecionadas da indústria de transformação (1996-2010)

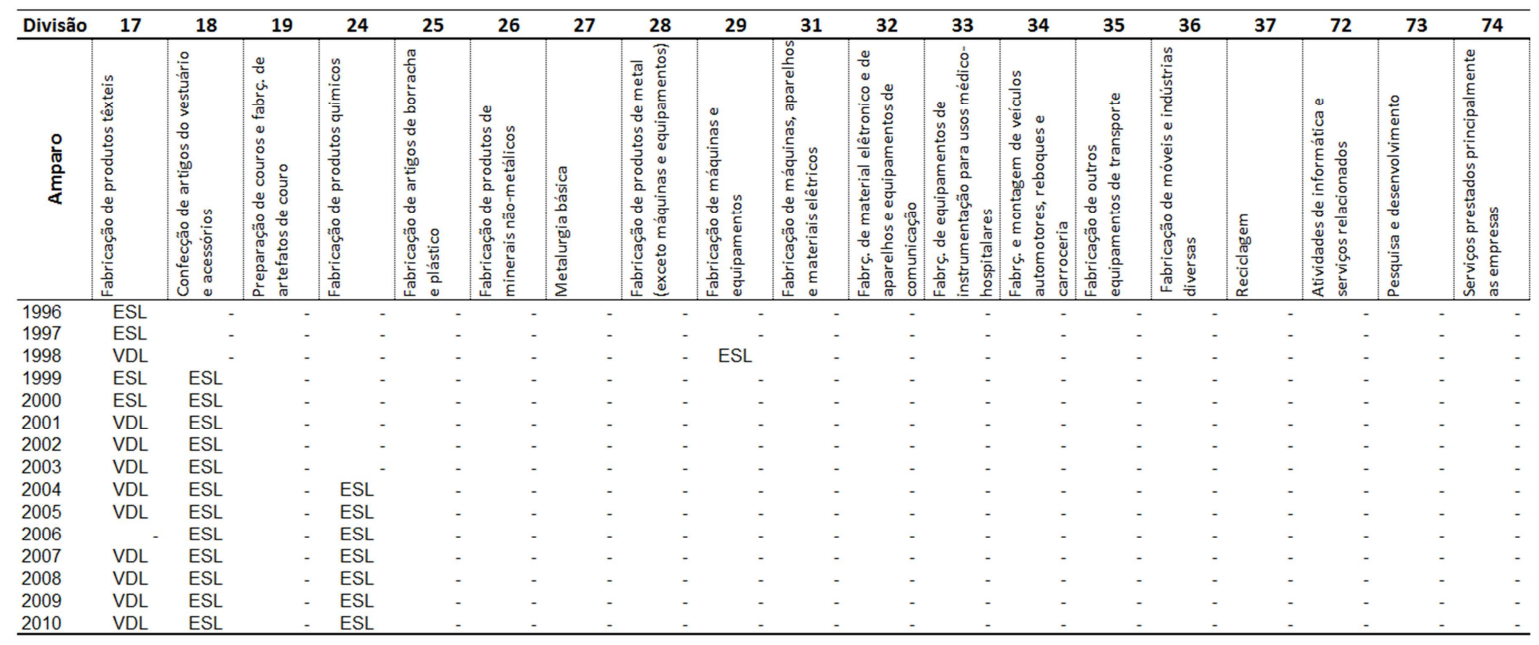

FONTE: Elaborado pelo autor com base nos dados da RAIS/MTE

Anexo LXVII. Dracena/SP | Ciclo de vida dos sistemas locais nas atividades selecionadas da indústria de transformação (1996-2010)

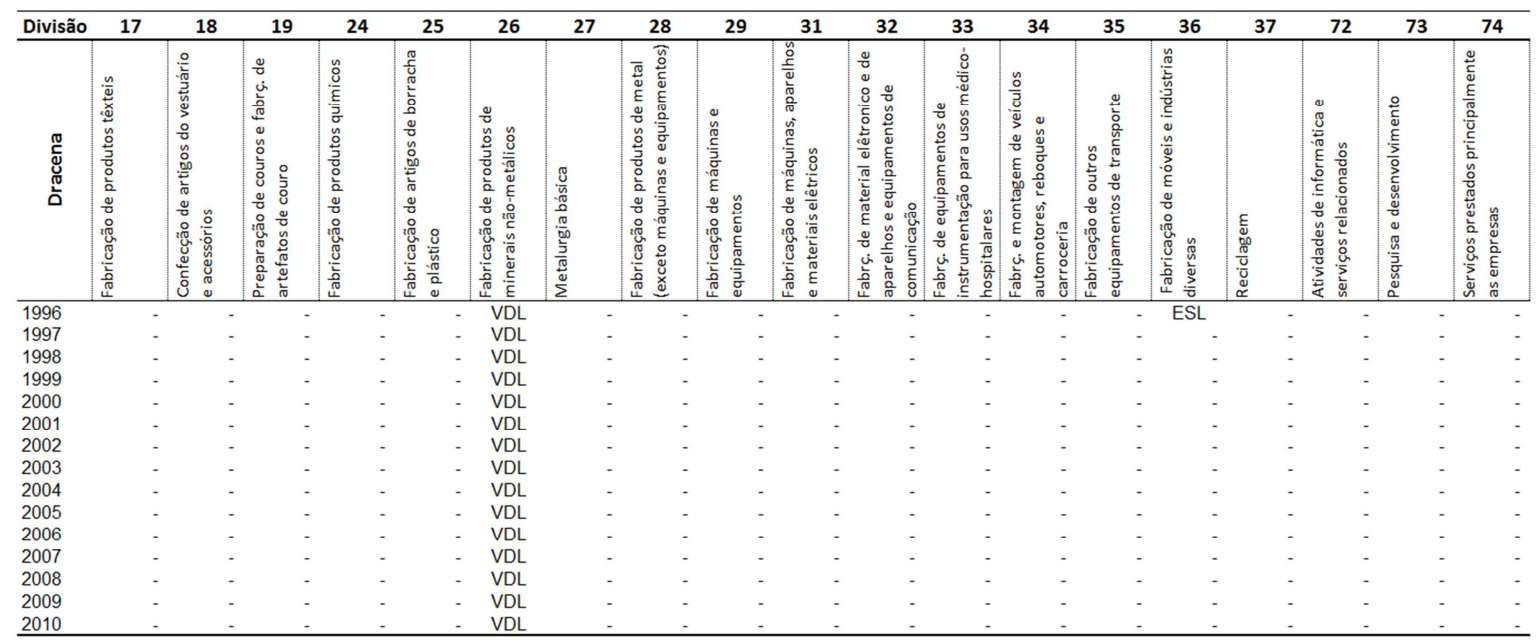

FONTE: Elaborado pelo autor com base nos dados da RAIS/MTE 
Anexo LXVIII. Adamantina/SP | Ciclo de vida dos sistemas locais nas atividades selecionadas da indústria de transformação (1996-2010)

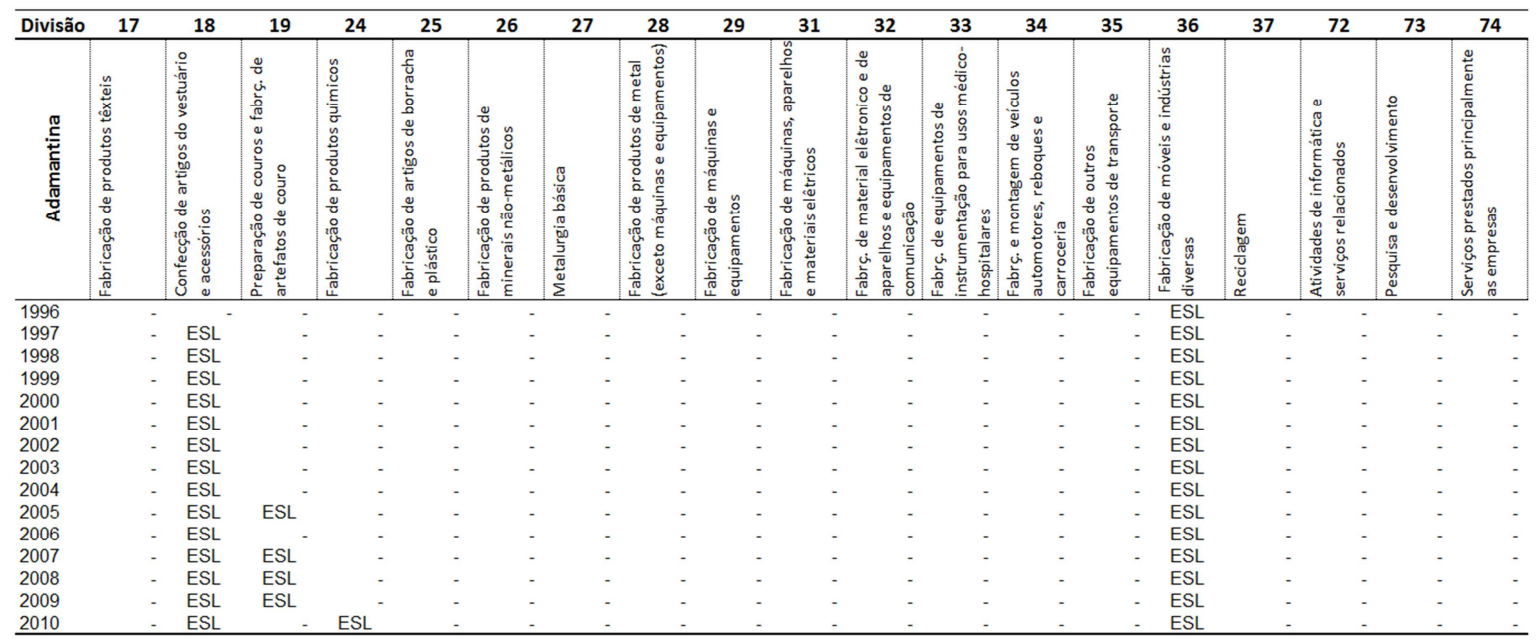

FONTE: Elaborado pelo autor com base nos dados da RAIS/MTE

Anexo LXIX. Presidente Prudente/SP | Ciclo de vida dos sistemas locais nas atividades selecionadas da indústria de transformação (1996-2010)

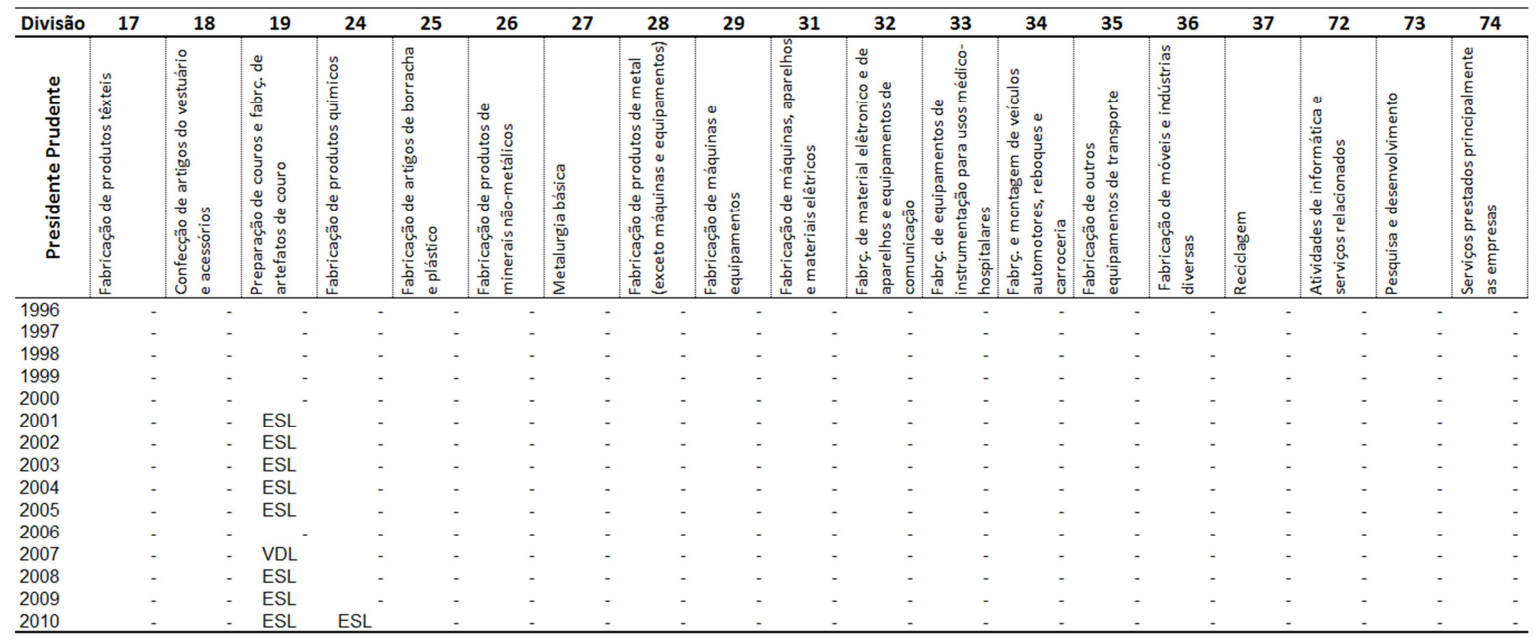

FONTE: Elaborado pelo autor com base nos dados da RAIS/MTE

Anexo LXX. Tupã/SP | Ciclo de vida dos sistemas locais nas atividades selecionadas da indústria de transformação (1996-2010)

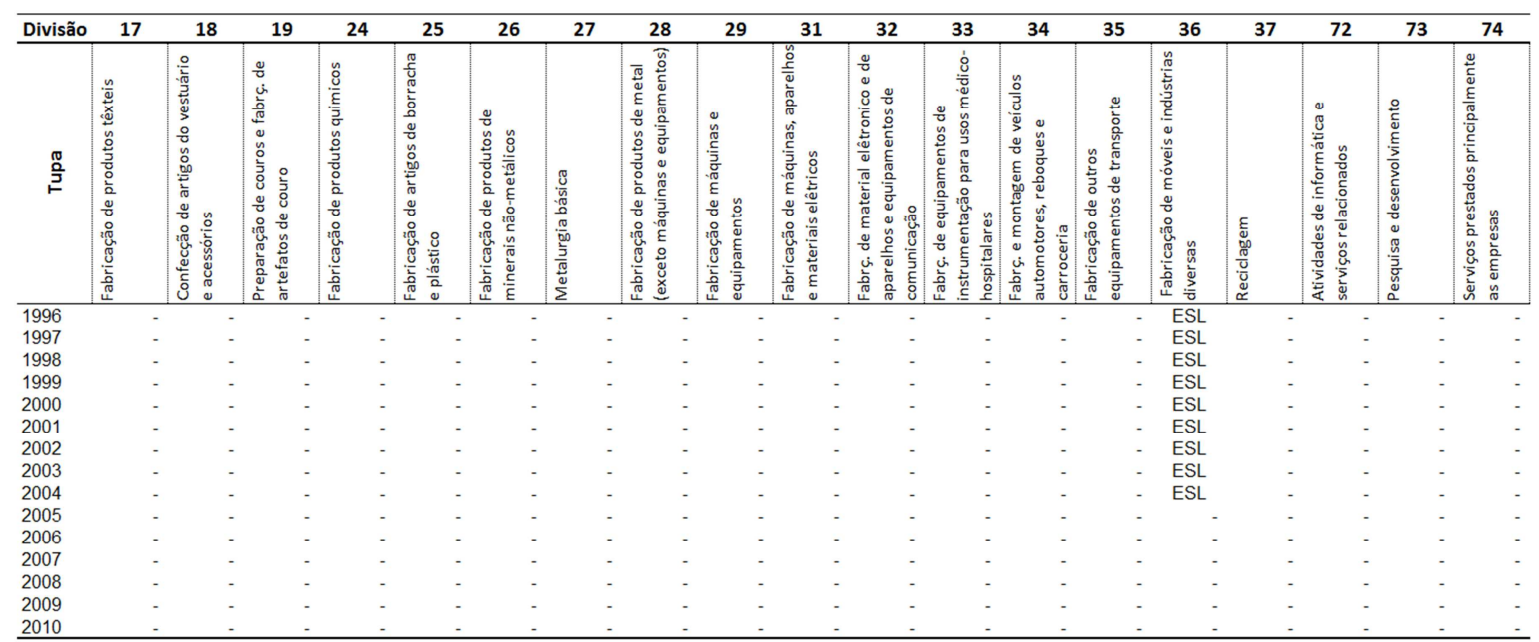

FONTE: Elaborado pelo autor com base nos dados da RAIS/MTE 
Anexo LXXI. Marília/SP | Ciclo de vida dos sistemas locais nas atividades selecionadas da indústria de transformação (1996-2010)

\begin{tabular}{|c|c|c|c|c|c|c|c|c|c|c|c|c|c|c|c|c|c|c|c|}
\hline Divisã & 17 & 18 & 19 & 2 & 25 & 26 & 27 & 28 & 29 & 31 & 32 & 33 & 34 & 35 & 36 & 37 & 72 & 73 & 74 \\
\hline 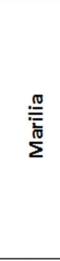 & 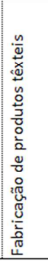 & 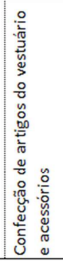 & 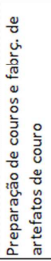 & 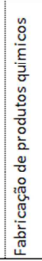 & 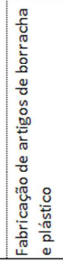 & 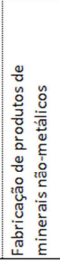 & 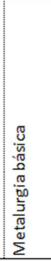 & 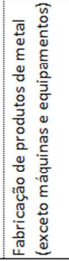 & 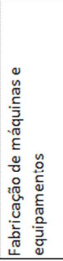 & 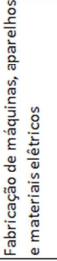 & 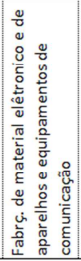 & 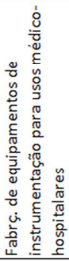 & 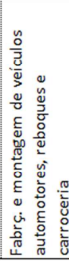 & 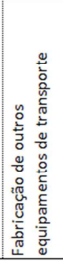 & 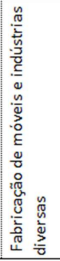 & 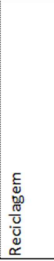 & 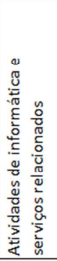 & 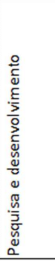 & 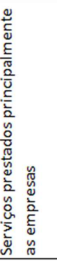 \\
\hline 1996 & & & & & & & & ESL & & & & & & & & & & & \\
\hline $\begin{array}{l}1998 \\
1999\end{array}$ & & & & & & & & $\begin{array}{l}\text { ESL } \\
\text { ESL }\end{array}$ & ESL & & & & & & & & & & \\
\hline & & & & & & & & ESL & & & & & & & & & & & \\
\hline & & & & & & & & ESL & & & & & & & & & & & \\
\hline 2002 & & & & & & & & & $\begin{array}{l}\text { ESL } \\
\text { ESL }\end{array}$ & & & & & & & & & & \\
\hline & & & & & & & & & ESL & & & & & & & & & & \\
\hline & & & & & & & & & $\begin{array}{l}E S \\
E S\end{array}$ & ESL & & & & & & & & & \\
\hline & & & & & & & & & $\begin{array}{l}\mathrm{ES} \\
\mathrm{ES}\end{array}$ & ESL & & & & & & & & & \\
\hline & & & & & & & & & ES & & & & & & & & & & \\
\hline $\begin{array}{l}2009 \\
2010\end{array}$ & & & & & & & & & $\begin{array}{l}\text { ESL } \\
\text { ESL }\end{array}$ & ESL & & & & & & & & & \\
\hline
\end{tabular}

FONTE: Elaborado pelo autor com base nos dados da RAIS/MTE

Anexo LXXIII. Assis/SP | Ciclo de vida dos sistemas locais nas atividades selecionadas da indústria de transformação (1996-2010)

\begin{tabular}{|c|c|c|c|c|c|c|c|c|c|c|c|c|c|c|c|c|c|c|c|c|}
\hline Divisão & 17 & 18 & 19 & 2 & 25 & 26 & 27 & 28 & 29 & 31 & 32 & 33 & 34 & 35 & 36 & 37 & 72 & & & 74 \\
\hline 䋊 & 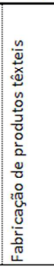 & 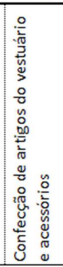 & 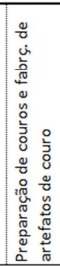 & 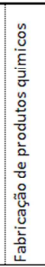 & 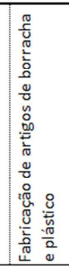 & 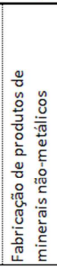 & 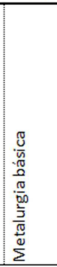 & 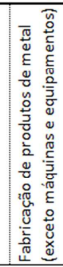 & 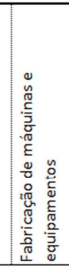 & 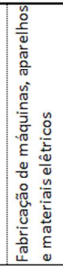 & 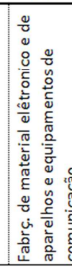 & 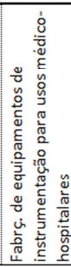 & 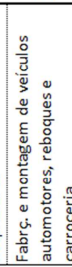 & 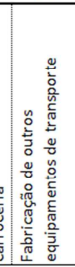 & 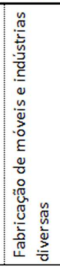 & 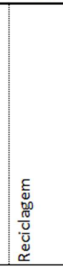 & 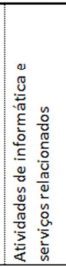 & 을 & & 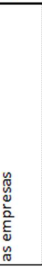 \\
\hline 1996 & & & & & & & & & & & & & & & & & & & & \\
\hline $\begin{array}{l}1998 \\
1999\end{array}$ & & & & & & & & & & & & & & & & & & & & \\
\hline 20 & & & & & & & & & & & & & & & & & & & & - \\
\hline 20 & & & & & & & & & & & & - & & & & & & & & \\
\hline & & & & & & & & & - & & & & & & & & & & & \\
\hline 2004 & & & & & 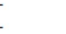 & & & & & & & & & & & & & & & \\
\hline 2006 & & & & & & & & & & & & & & & & & & & & \\
\hline $\begin{array}{r}2007 \\
2008\end{array}$ & & & & & 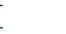 & & & & - & & & & & & & & & & & \\
\hline 2009 & & & & & - & & & & & & & . & & & & & & & & \\
\hline
\end{tabular}

FONTE: Elaborado pelo autor com base nos dados da RAIS/MTE

Anexo LXXIV. Ourinhos/SP | Ciclo de vida dos sistemas locais nas atividades selecionadas da indústria de transformação (1996-2010)

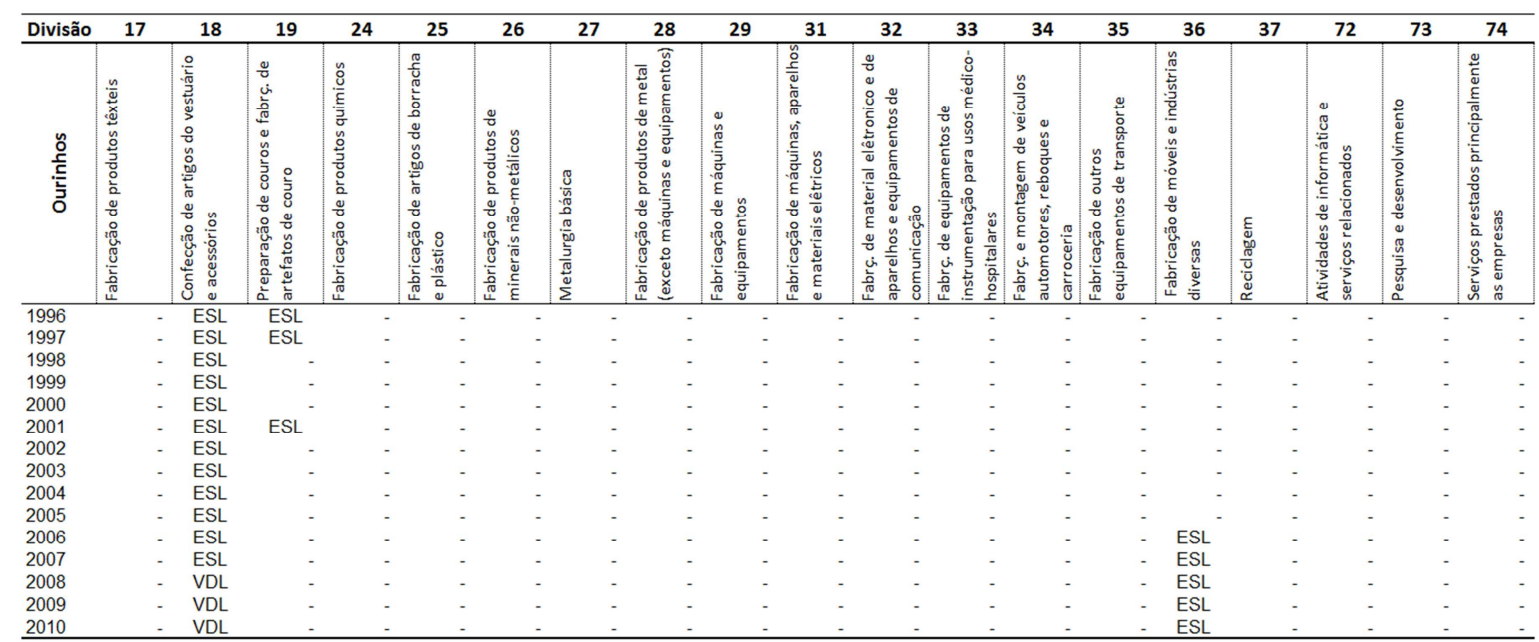

FONTE: Elaborado pelo autor com base nos dados da RAIS/MTE 
Anexo LXXV. Itapetininga/SP | Ciclo de vida dos sistemas locais nas atividades selecionadas da indústria de transformação (1996-2010)

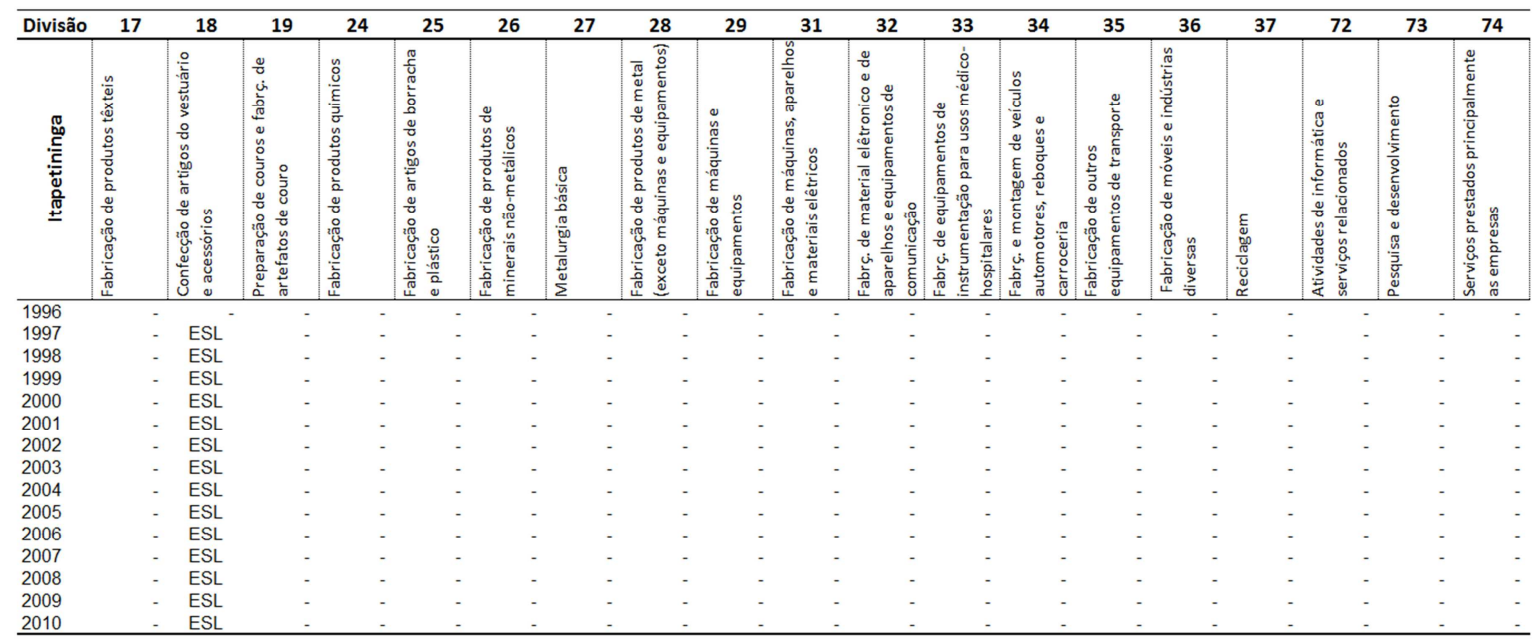

FONTE: Elaborado pelo autor com base nos dados da RAIS/TEM

Anexo LXXVI. Tatuí/SP | Ciclo de vida dos sistemas locais nas atividades selecionadas da indústria de transformação (1996-2010)

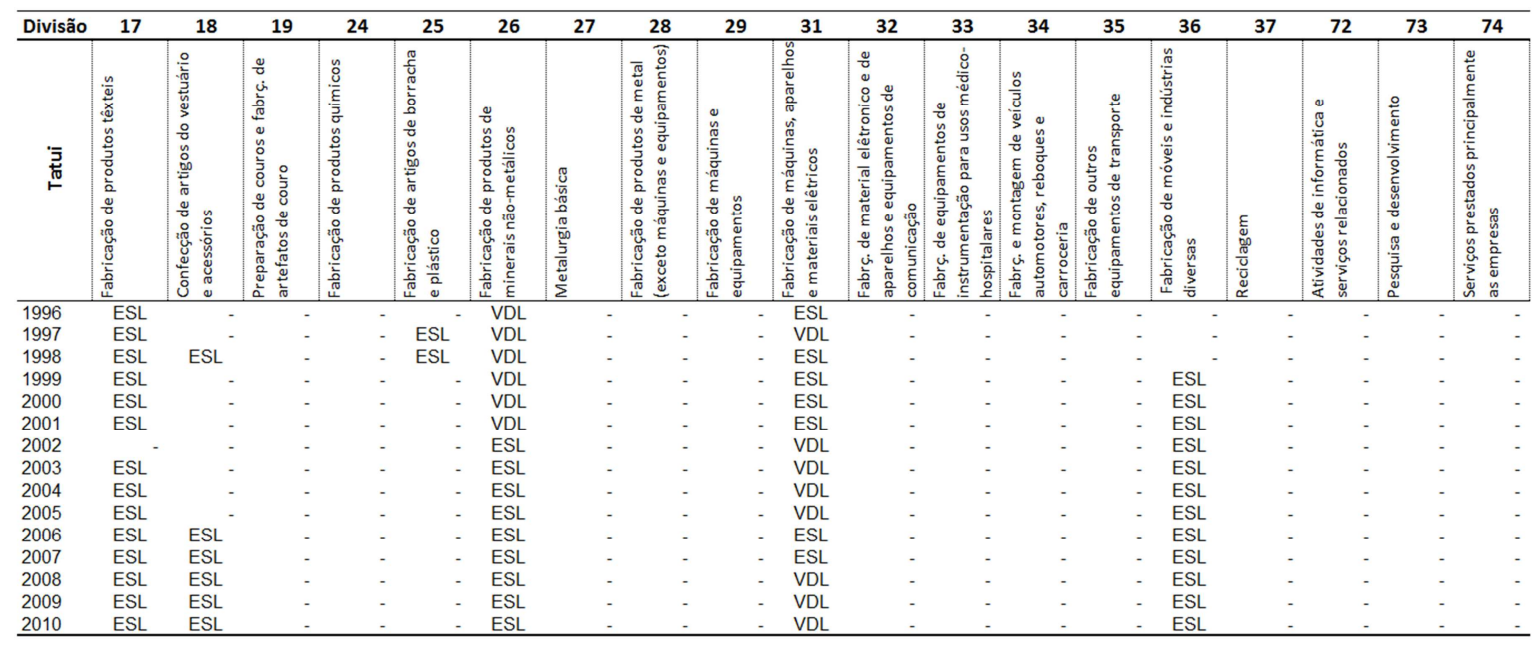

FONTE: Elaborado pelo autor com base nos dados da RAIS/MTE

Anexo LXXVII. Capão Bonito/SP | Ciclo de vida dos sistemas locais nas atividades selecionadas da indústria de transformação (1996-2010)

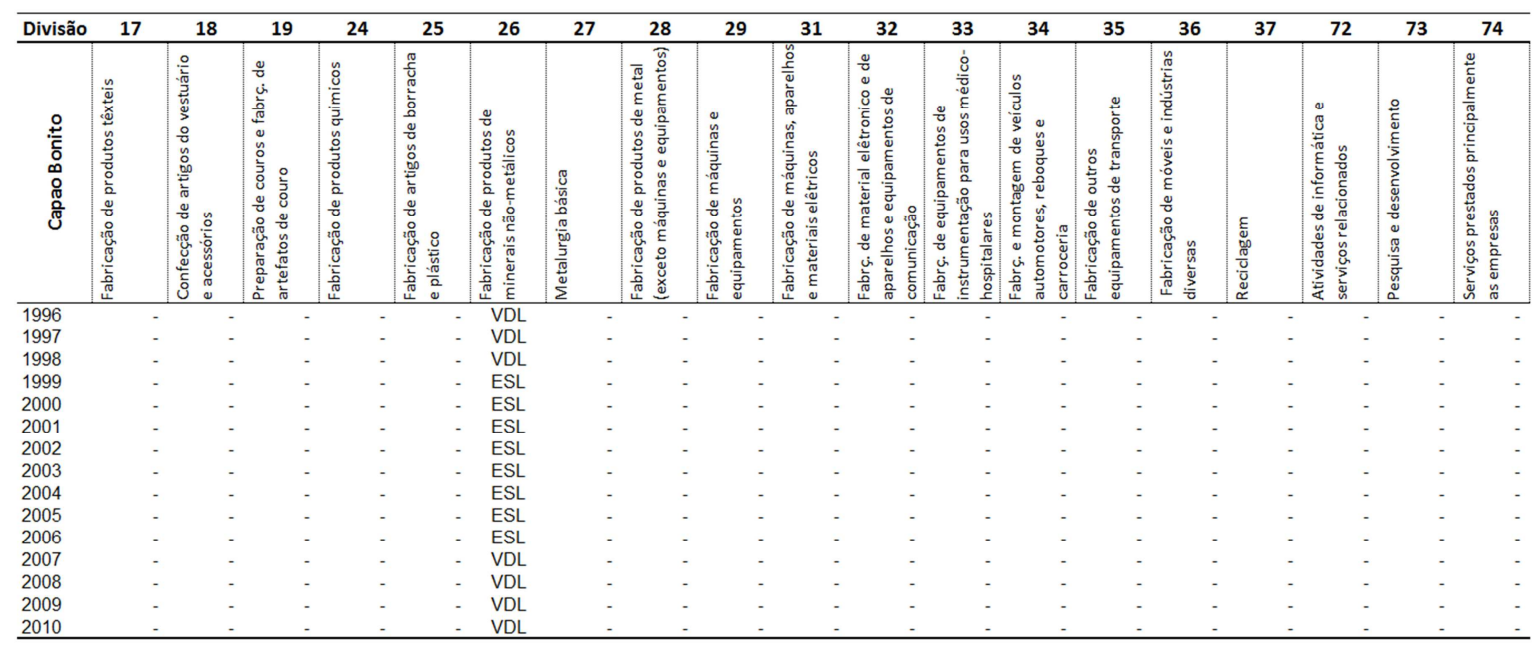

FONTE: Elaborado pelo autor com base nos dados da RAIS/MTE 
Anexo LXXVII. Piedade/SP | Ciclo de vida dos sistemas locais nas atividades selecionadas da indústria de transformação (1996-2010)

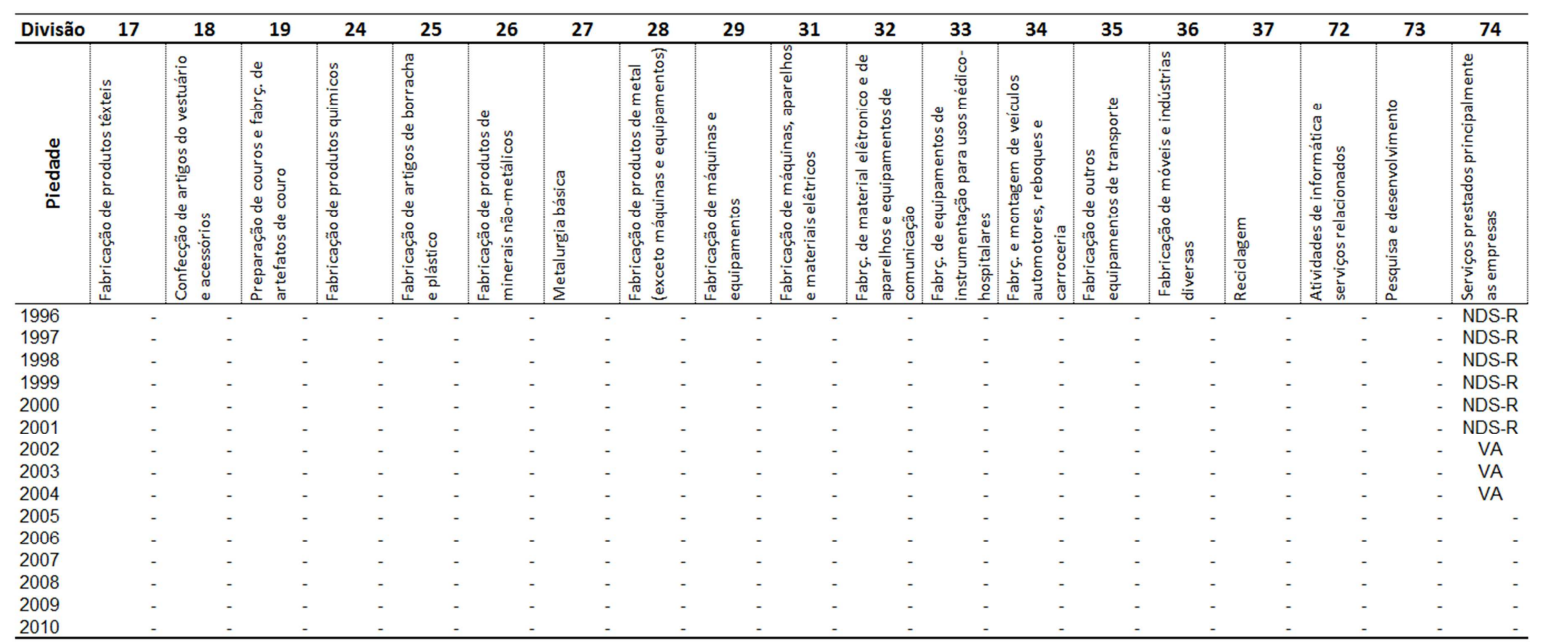

FONTE: Elaborado pelo autor com base nos dados da RAIS/MTE

Anexo LXXVIII. Sorocaba/SP | Ciclo de vida dos sistemas locais nas atividades selecionadas da indústria de transformação (1996-2010)

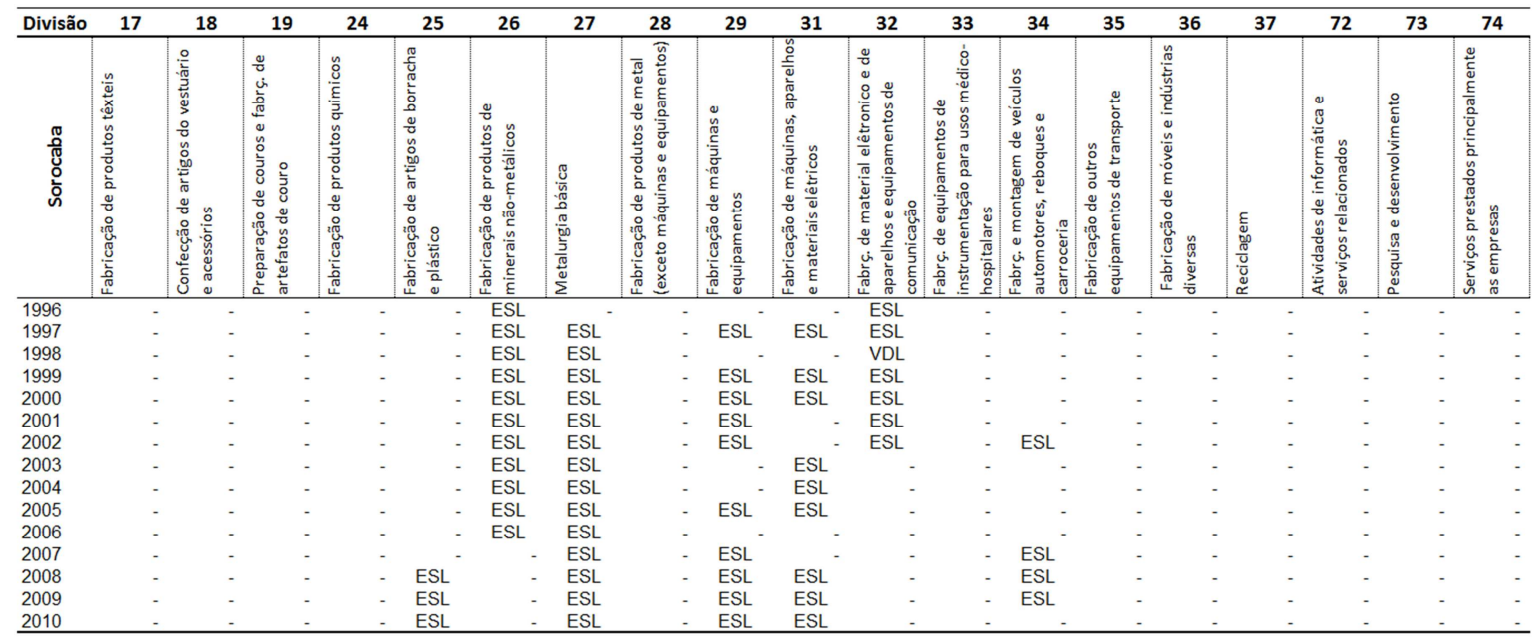

FONTE: Elaborado pelo autor com base nos dados da RAIS/MTE

Anexo LXXIV. Jundiaí/SP | Ciclo de vida dos sistemas locais nas atividades selecionadas da indústria de transformação (1996-2010)

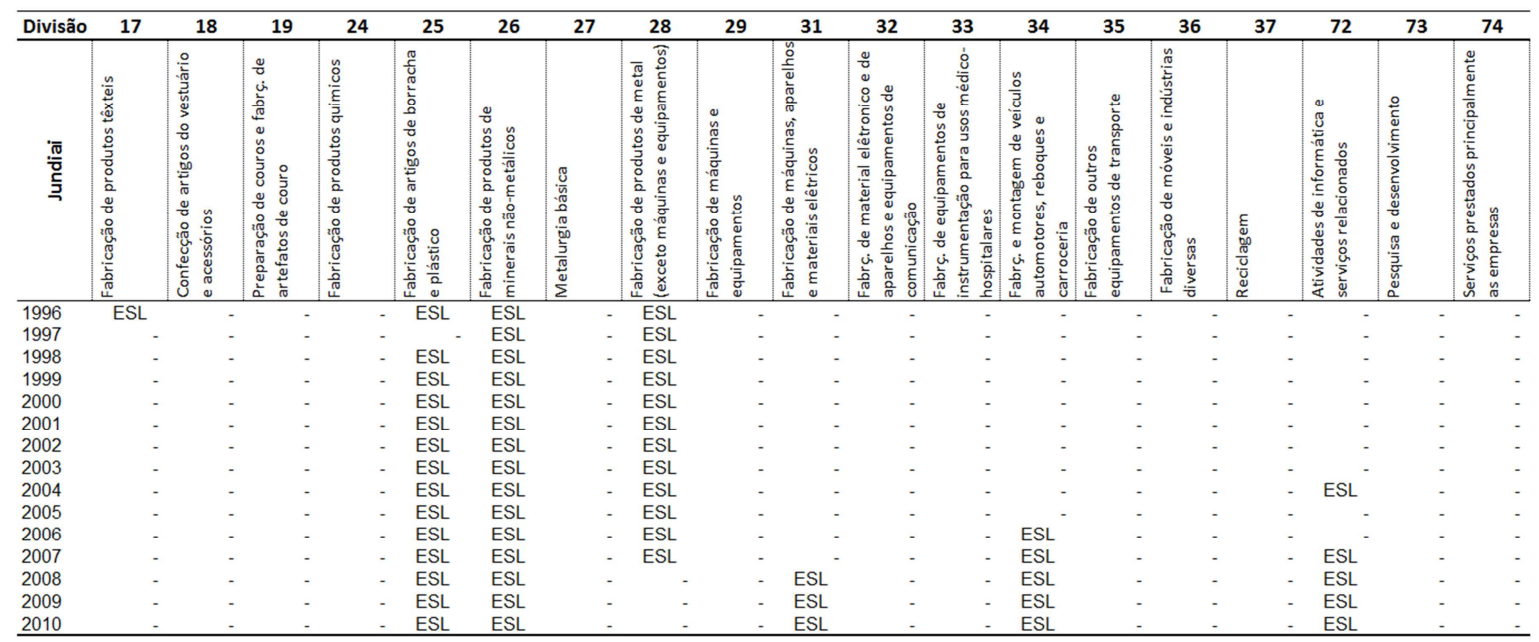

FONTE: Elaborado pelo autor com base nos dados da RAIS/MTE 
Anexo LXXV. Bragança Paulista/SP | Ciclo de vida dos sistemas locais nas atividades selecionadas da indústria de transformação (1996-2010)

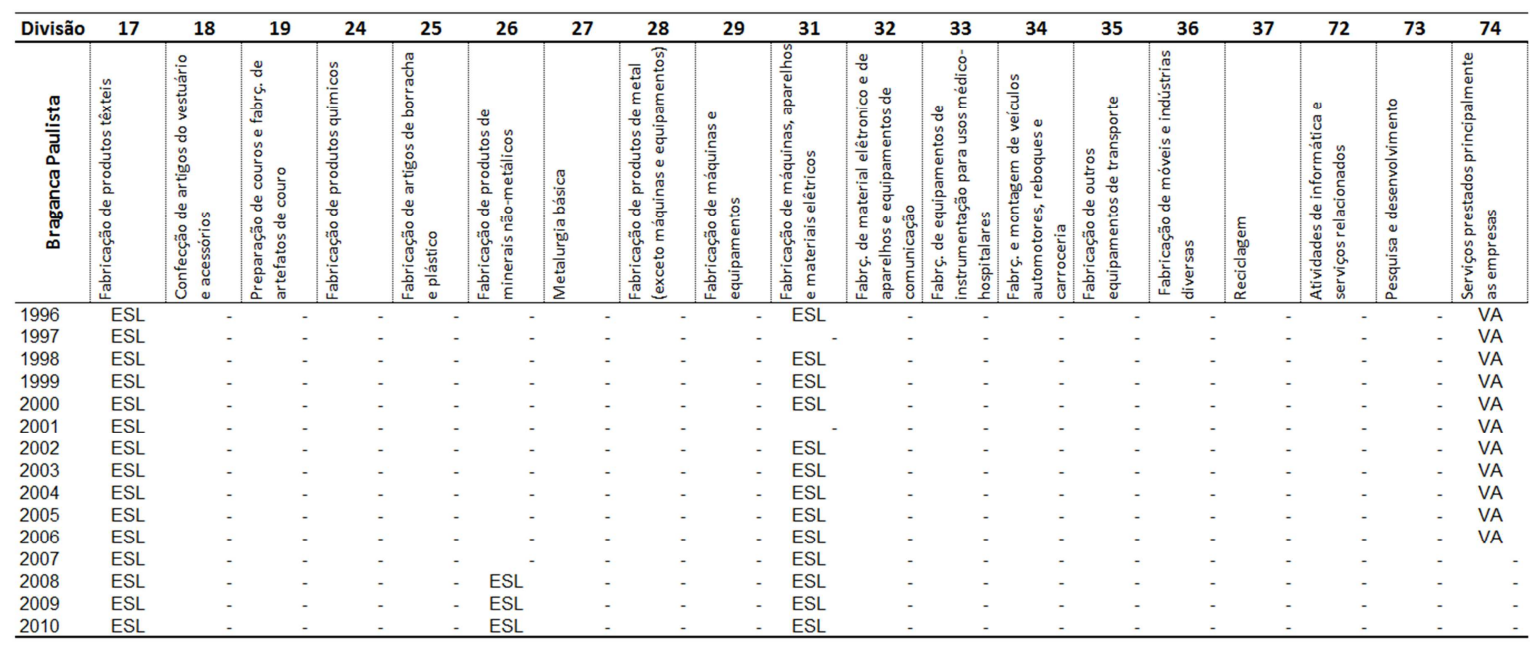

FONTE: Elaborado pelo autor com base nos dados da RAIS/MTE

Anexo LXXVI. Campos do Jordão/SP | Ciclo de vida dos sistemas locais nas atividades selecionadas da indústria de transformação (1996-2010)

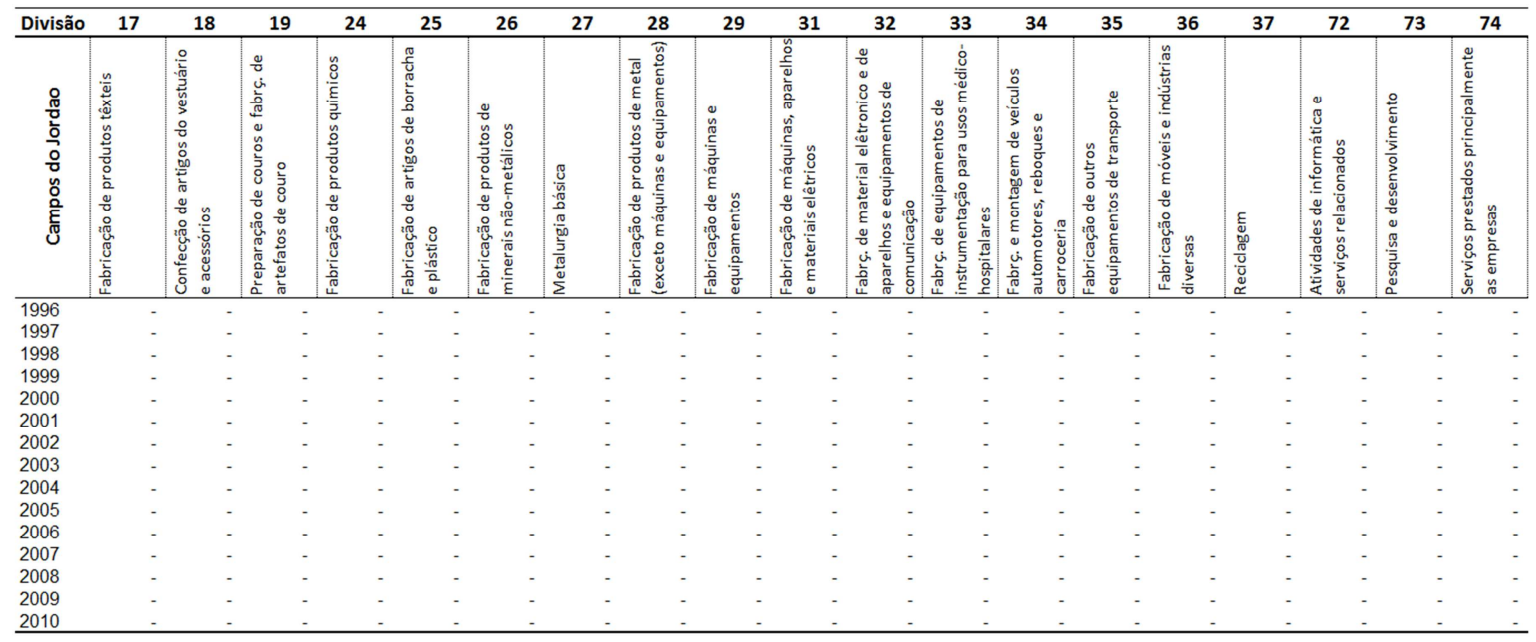

FONTE: Elaborado pelo autor com base nos dados da RAIS/MTE

Anexo LXXVII. São José dos Campos/SP | Ciclo de vida dos sistemas locais nas atividades selecionadas da indústria de transformação (1996-2010)

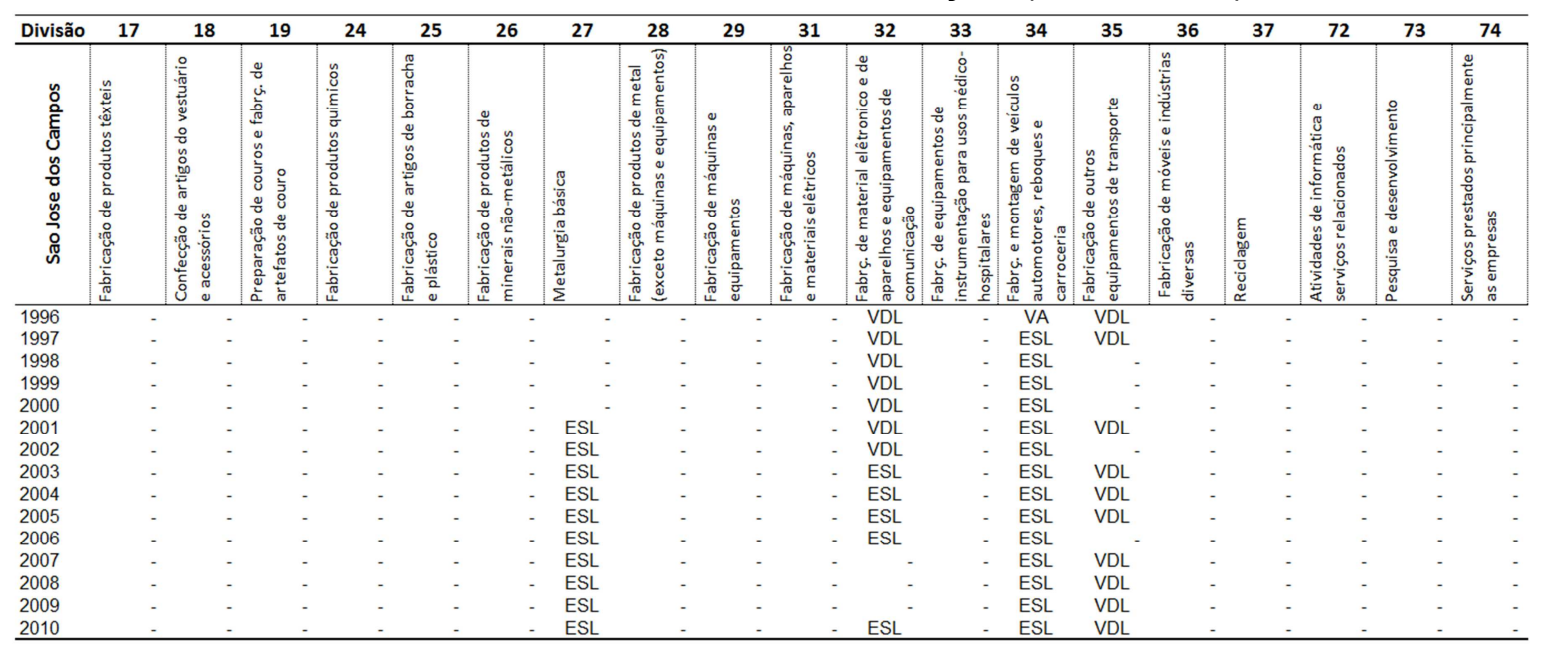

FONTE: Elaborado pelo autor com base nos dados da RAIS/MTE 
Anexo LXXVIII. Guaratinguetá/SP | Ciclo de vida dos sistemas locais nas atividades selecionadas da indústria de transformação (1996-2010)

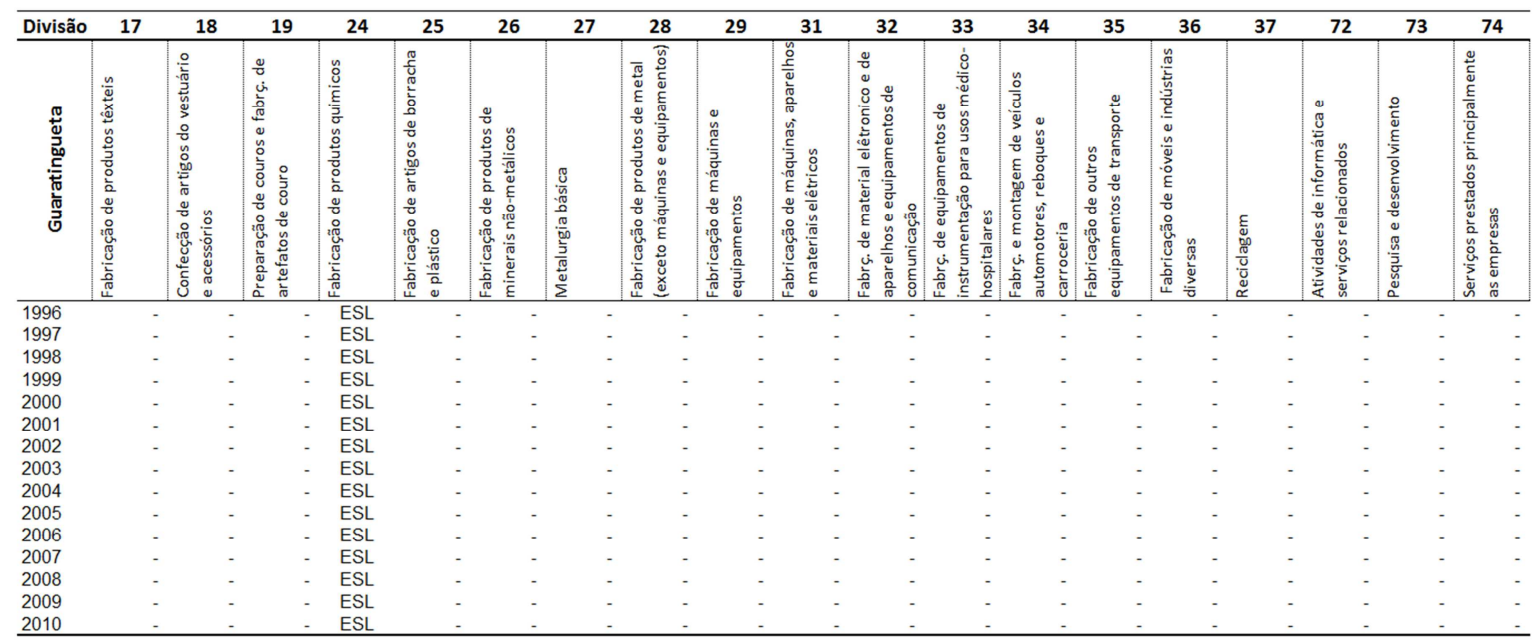

FONTE: Elaborado pelo autor com base nos dados da RAIS/MTE

Anexo LXXIX. Bananal/SP | Ciclo de vida dos sistemas locais nas atividades selecionadas da indústria de transformação (1996-2010)

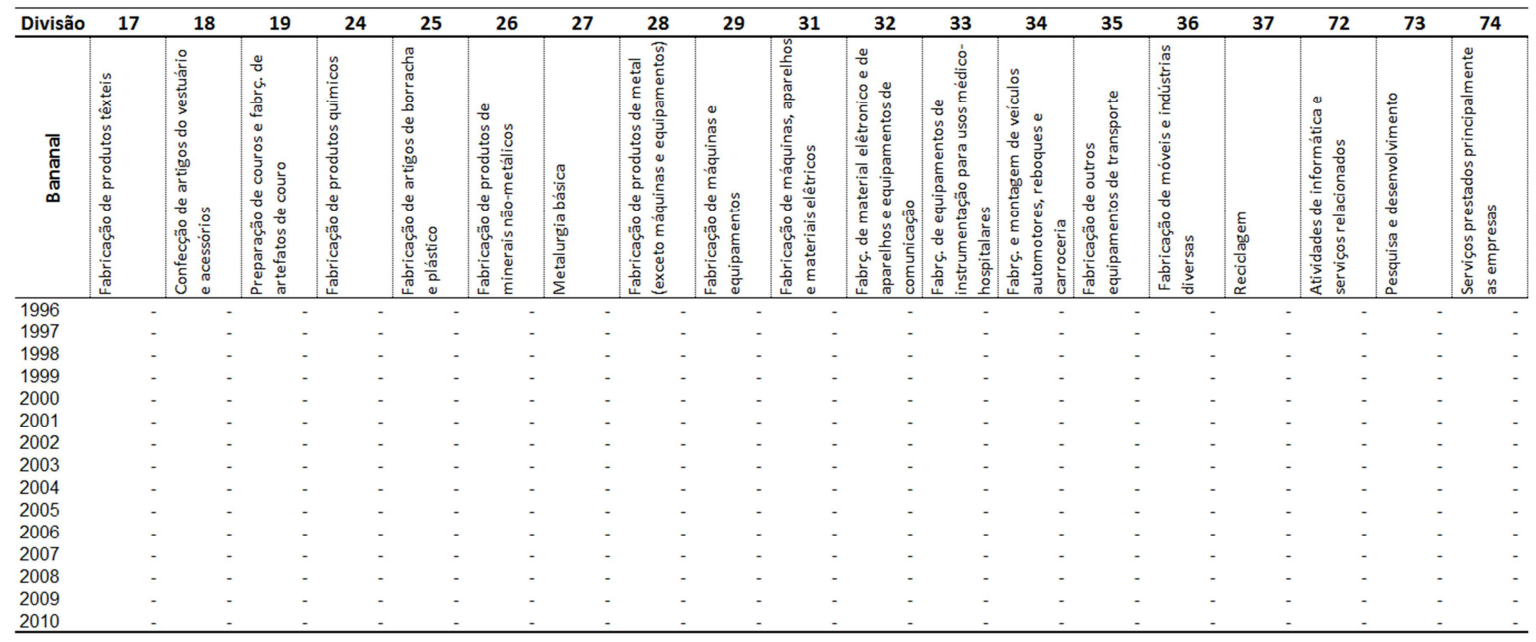

FONTE: Elaborado pelo autor com base nos dados da RAIS/MTE

Anexo LXXX. Paraibana e Paraitinga/SP | Ciclo de vida dos sistemas locais nas atividades selecionadas da indústria de transformação (1996-2010)

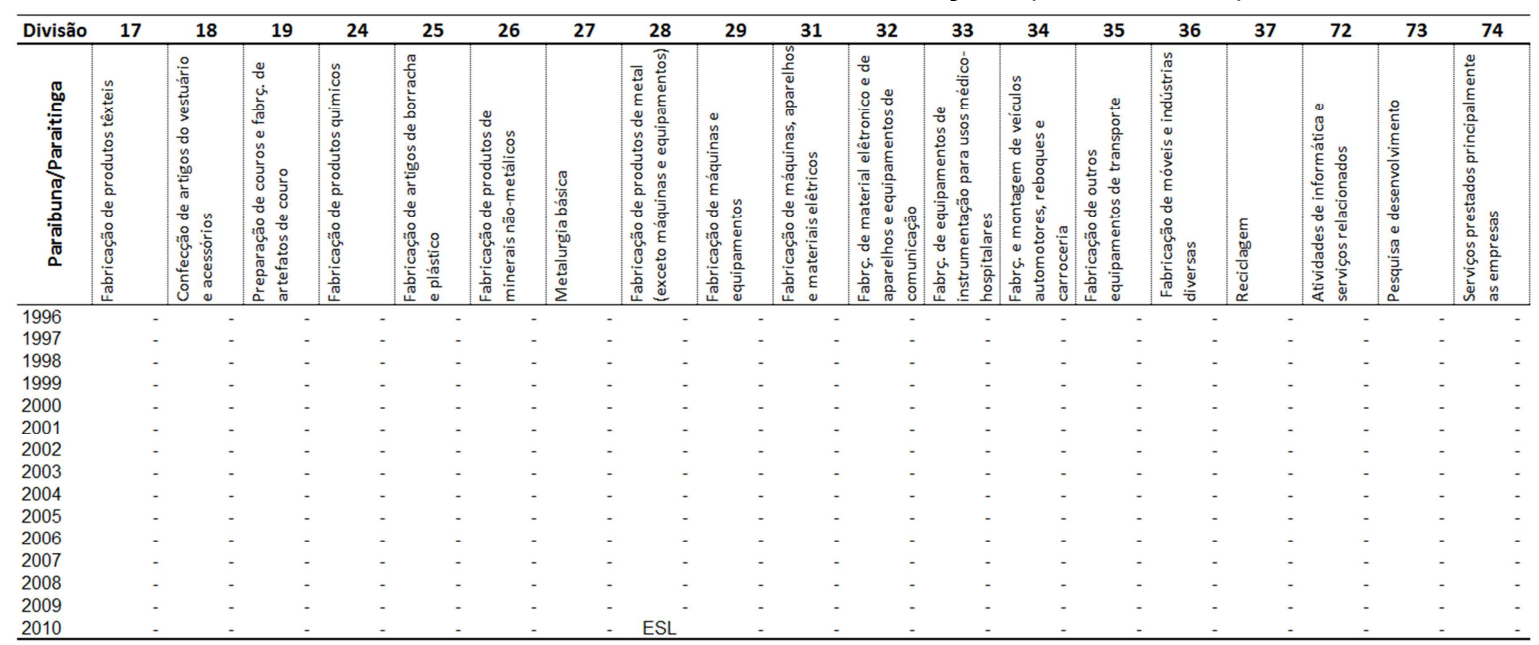

FONTE: Elaborado pelo autor com base nos dados da RAIS/MTE 
Anexo LXXXI. Caraguatatuba/SP | Ciclo de vida dos sistemas locais nas atividades selecionadas da indústria de transformação (1996-2010)

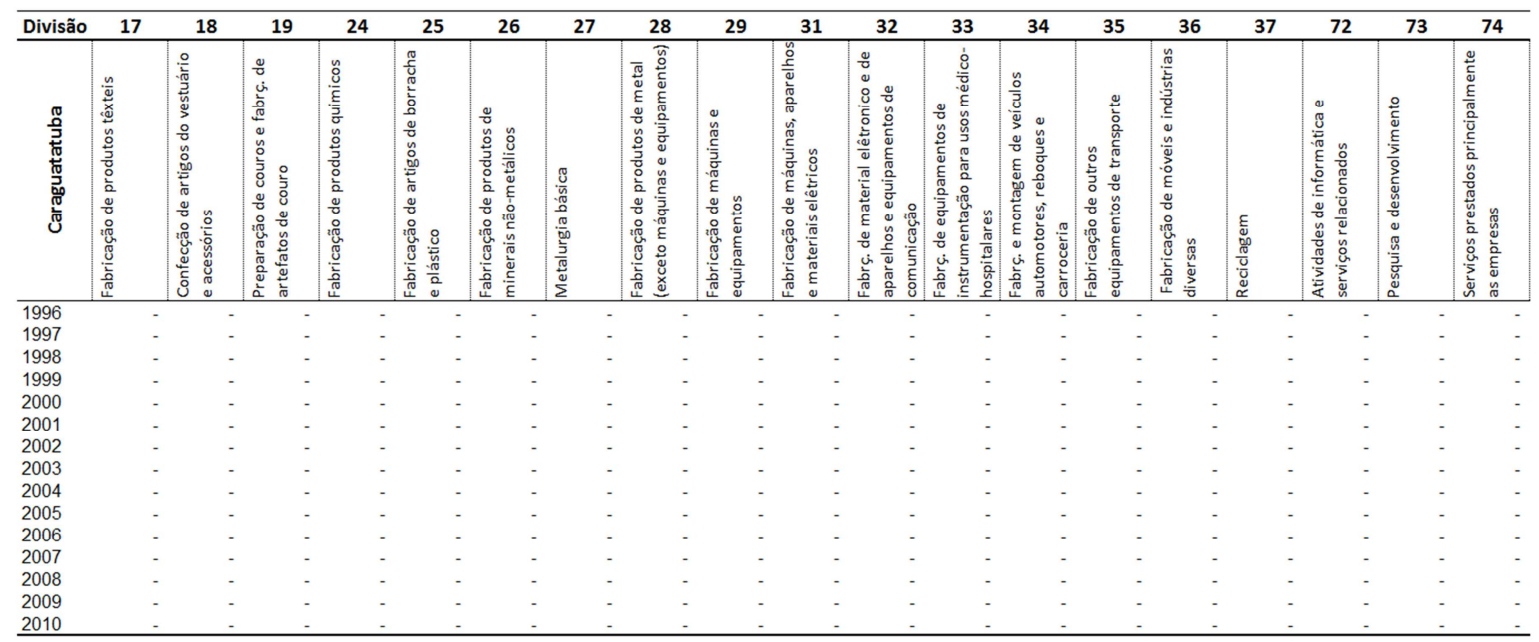

FONTE: Elaborado pelo autor com base nos dados da RAIS/MTE

Anexo LXXXII. Registro/SP | Ciclo de vida dos sistemas locais nas atividades selecionadas da indústria de transformação (1996-2010)

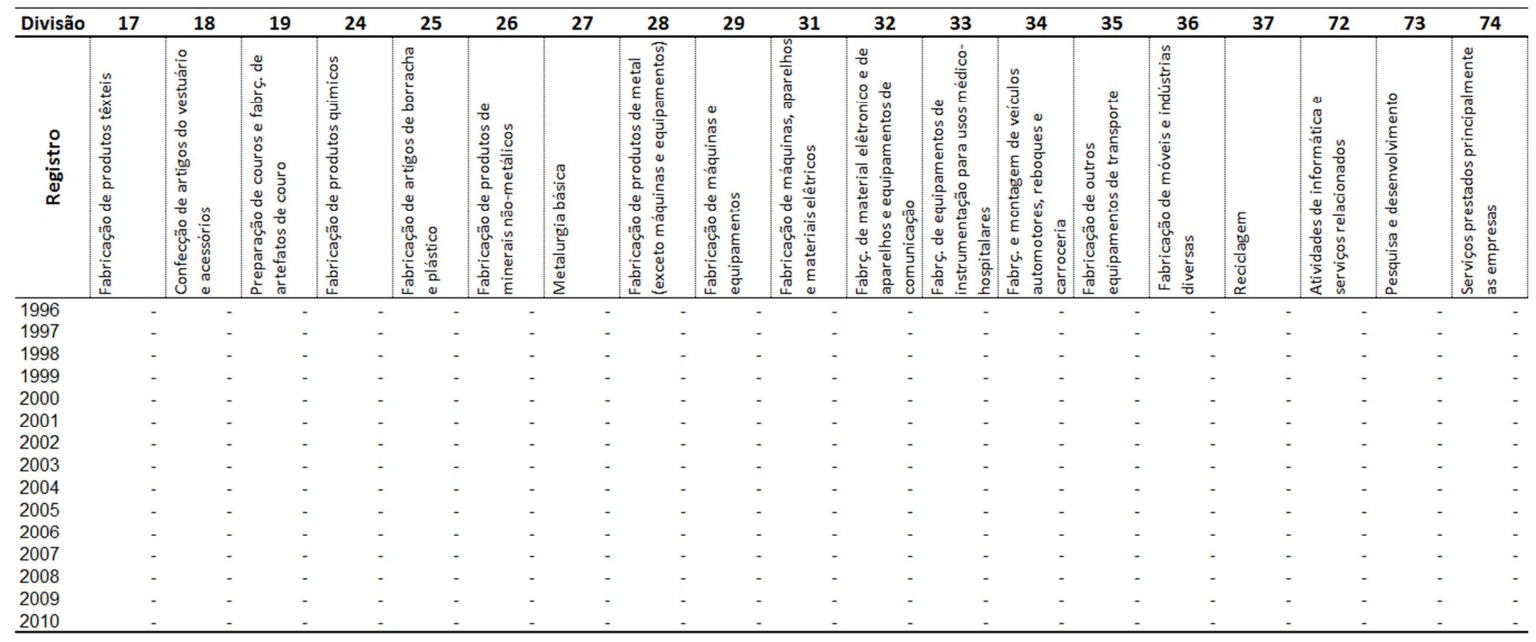

FONTE: Elaborado pelo autor com base nos dados da RAIS/MTE

Anexo LXXXIII. Itanhaém/SP | Ciclo de vida dos sistemas locais nas atividades selecionadas da indústria de transformação (1996-2010)

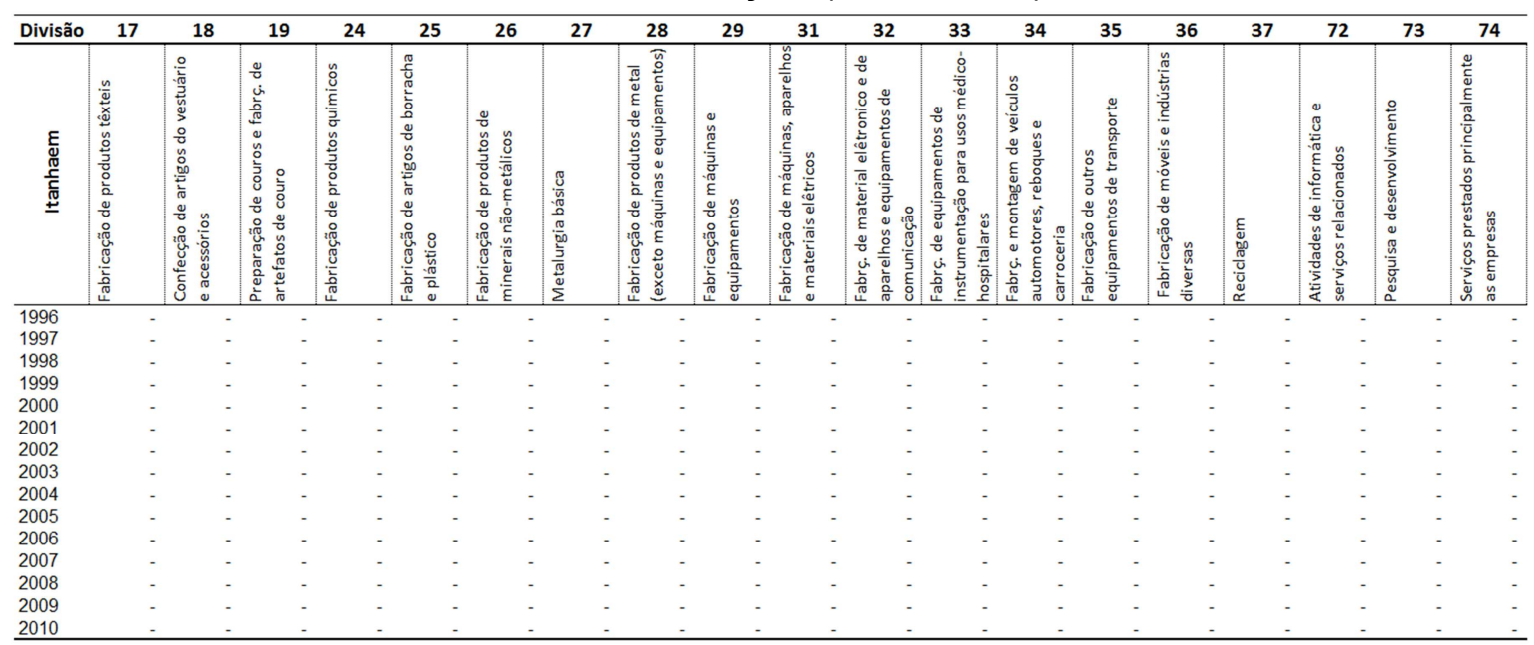

FONTE: Elaborado pelo autor com base nos dados da RAIS/MTE 
Anexo LXXXIV. Franco da Rocha/SP | Ciclo de vida dos sistemas locais nas atividades selecionadas da indústria de transformação (1996-2010)

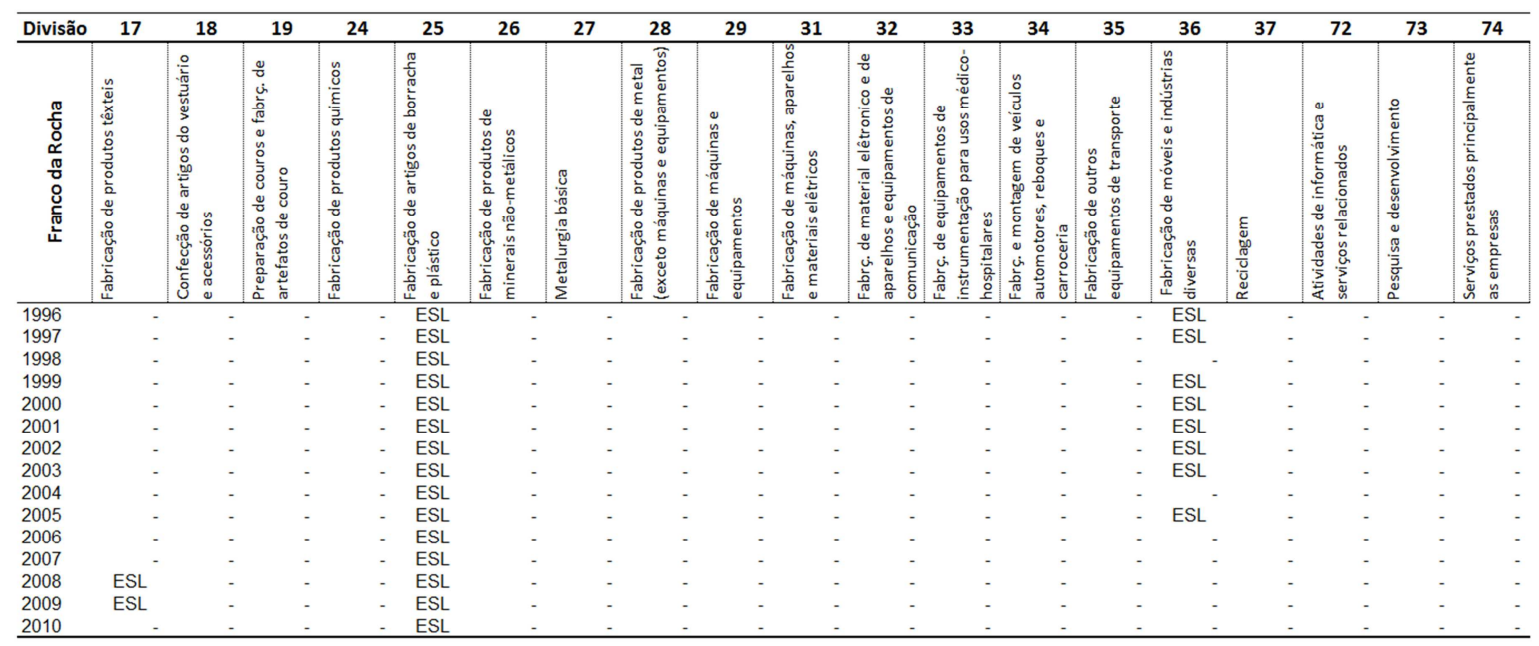

FONTE: Elaborado pelo autor com base nos dados da RAIS/MTE

Anexo LXXXV. Guarulhos/SP | Ciclo de vida dos sistemas locais nas atividades selecionadas da indústria de transformação (1996-2010)

\begin{tabular}{|c|c|c|c|c|c|c|c|c|c|c|c|c|c|c|c|c|c|c|c|c|}
\hline Divisão & 17 & 18 & 19 & 24 & 25 & 26 & 27 & 28 & 29 & 31 & 32 & 33 & 34 & 35 & 36 & 37 & 72 & & 3 & 74 \\
\hline 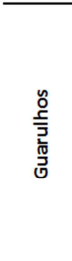 & 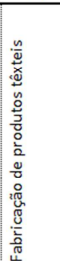 & 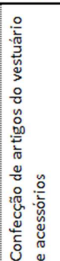 & 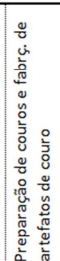 & 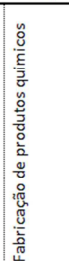 & 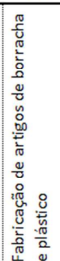 & 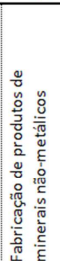 & 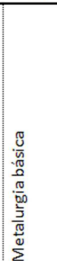 & 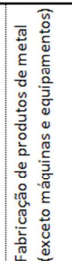 & 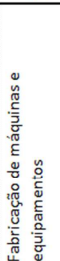 & 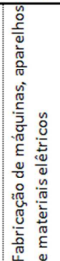 & 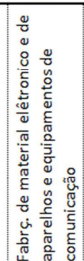 & 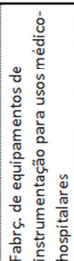 & 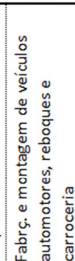 & 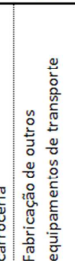 & 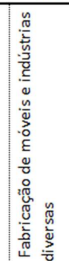 & 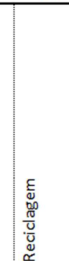 & 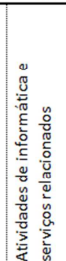 & 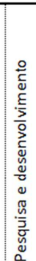 & & 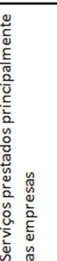 \\
\hline 1996 & ESL & & & & ESL & & ESL & ESL & $\frac{\pi}{E S L}$ & ESL & ESL & & ESL & & & & & & & \\
\hline & ESL & & & ESL & ESL & & $\mathrm{ESL}$ & $\mathrm{ES}$ & & ESL & & . & ESL & & & & & & & \\
\hline & $\mathrm{ESS}$ & & & ESL & ES & & ESL & $\mathrm{ES}$ & & ESL & & . & ES & & & & & & & \\
\hline & ESL & & & ES & ES & & ESL & $\mathrm{E}$ & & ESL & - & & ESL & & & & & & & \\
\hline & & & & $\mathrm{E}$ & ES & & ESL & $\mathrm{E}$ & & ESL & - & & ESL & & & & & & & \\
\hline & ESL & & & $\mathrm{ES}$ & ES & & ESL & $\mathrm{E}$ & & $\mathrm{E}$ & - & . & & & & & & & & \\
\hline & & & & $\mathrm{E}$ & $\mathrm{F}$ & & & & & & & - & & & & & & & & \\
\hline & & & & $E$ & E & & E & E & & $\mathrm{ES}$ & - & & & & & & & & & \\
\hline & & & & ES & ES & & ESL & ES & & $\mathrm{ES}$ & & & & & & & & & & \\
\hline & & & & ESL & ESL & & ESL & ES & & & & - & ESL & & & & & & & \\
\hline 2008 & $\begin{array}{l}\text { ESL } \\
\text { ESL }\end{array}$ & & & $\begin{array}{l}\text { ESL } \\
\text { ESL }\end{array}$ & $\begin{array}{l}\text { ESL } \\
\text { ESL }\end{array}$ & & $\begin{array}{l}\text { ESL } \\
\text { ESL }\end{array}$ & $\begin{array}{l}\mathrm{E} \\
\mathrm{E}\end{array}$ & & ESL & & - & & & & & & & & \\
\hline 200 & & & & $\mathrm{E}$ & $\mathrm{E}$ & & $\mathrm{ES}$ & & & ESL & & . & & & & 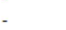 & & & & \\
\hline 2010 & ESL & & & ESL & ESL & & ESL & ESL & & ESL & & & & & & & & & & \\
\hline
\end{tabular}

FONTE: Elaborado pelo autor com base nos dados da RAIS/MTE

Anexo LXXXVI. Itapecerica da Serra/SP | Ciclo de vida dos sistemas locais nas atividades selecionadas da indústria de transformação (1996-2010)

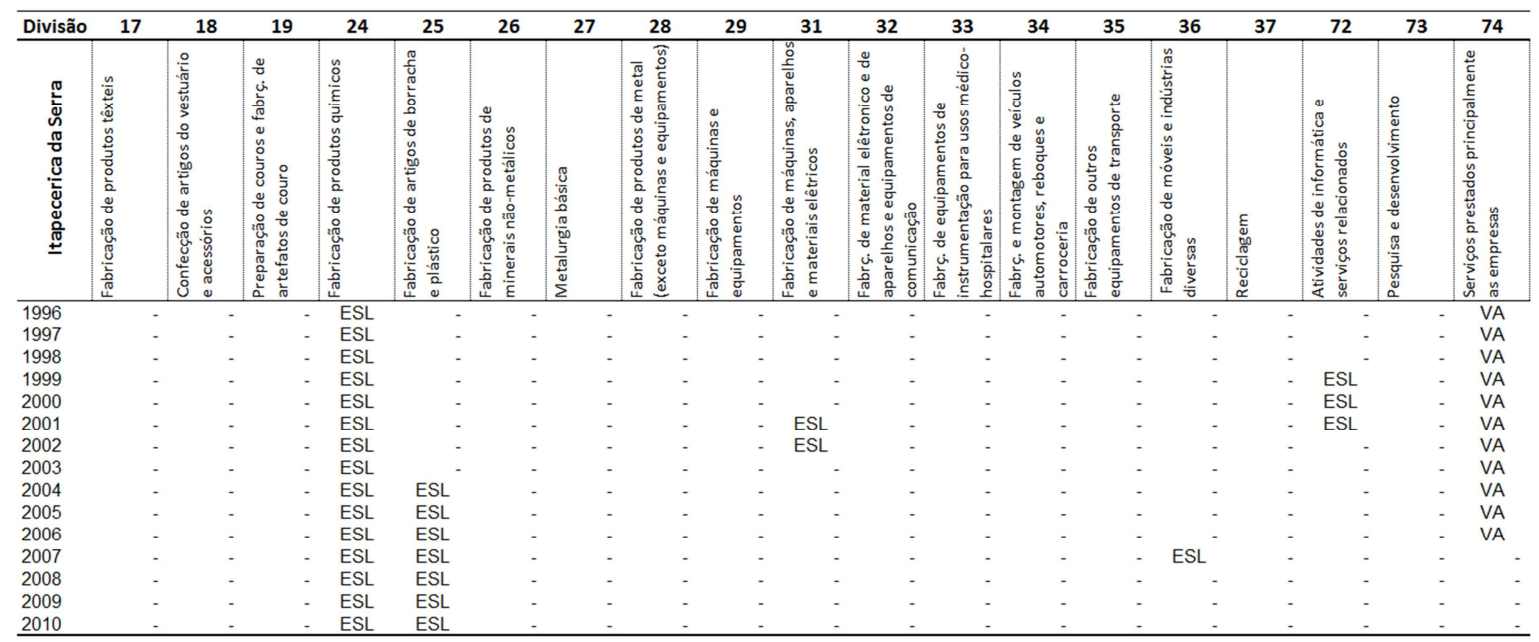

FONTE: Elaborado pelo autor com base nos dados da RAIS/MTE 
Anexo LXXXVI. São Paulo/SP | Ciclo de vida dos sistemas locais nas atividades selecionadas da indústria de transformação (1996-2010)

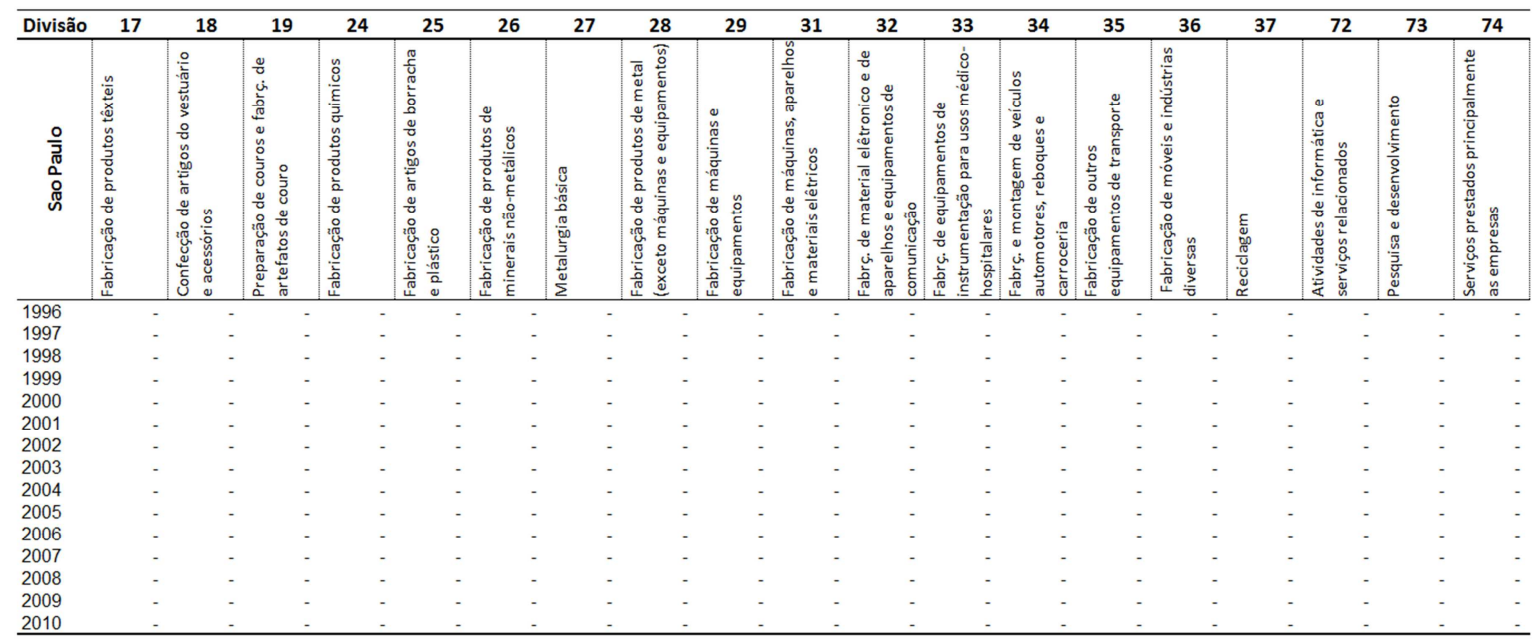

FONTE: Elaborado pelo autor com base nos dados da RAIS/MTE

Anexo LXXXVI. Mogi das Cruzes/SP | Ciclo de vida dos sistemas locais nas atividades selecionadas da indústria de transformação (1996-2010)

\begin{tabular}{|c|c|c|c|c|c|c|c|c|c|c|c|c|c|c|c|c|c|c|c|}
\hline Divisão & 17 & 18 & 19 & 24 & 25 & 26 & 27 & 28 & 29 & 31 & 32 & 33 & 34 & 35 & 36 & 37 & 72 & 73 & 74 \\
\hline 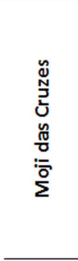 & 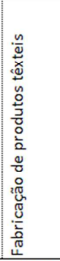 & 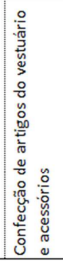 & 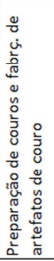 & 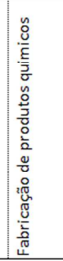 & 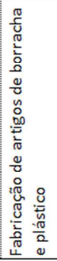 & 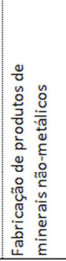 & 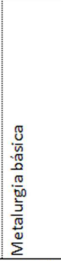 & 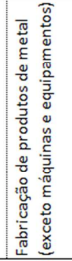 & 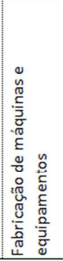 & 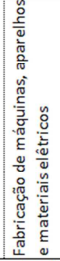 & 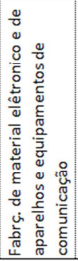 & 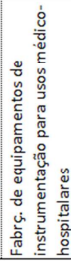 & 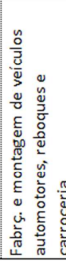 & 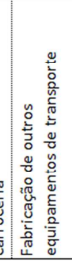 & 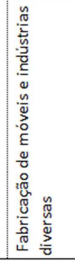 & 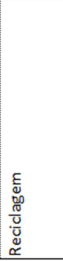 & 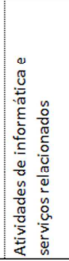 & 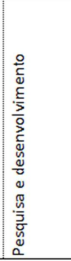 & 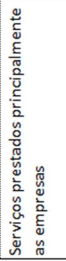 \\
\hline $\begin{array}{l}996 \\
1997\end{array}$ & ESL & & & & & $\begin{array}{l}\text { ESL } \\
\text { ESL }\end{array}$ & ESL & $\begin{array}{l}\text { ESL } \\
\text { ESL }\end{array}$ & ESL & ESL & & & & & $\begin{array}{l}\text { ESLL } \\
\text { ESL } \\
\text { ES }\end{array}$ & & & & VA \\
\hline & & & & & & ESL & ESL & ESL & & ESL & & & & & & & & & \\
\hline & & & & & & ESL & ESL & ESL & & ESL & & & & & & & & & \\
\hline & & & & & & ESL & & & & & & & & & & & & & /A \\
\hline & & & & & & & & & & ESL & & & & & & & & & \\
\hline & & & & & & & ESL & & & & & & & & & & ESL & & \\
\hline & & & & & & & & & & & & & & & & & & & \\
\hline & $\begin{array}{l}\text { ESL } \\
\text { ECI }\end{array}$ & & & & & & 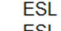 & & & & & & & & & & & & \\
\hline & & & & & & & $\begin{array}{l}\text { ES } \\
\text { ES }\end{array}$ & & & $\begin{array}{l}\text { ES } \\
\text { ES }\end{array}$ & & & & & ESL & & & & \\
\hline & & & & & & & & & & & & & & & & & & & \\
\hline & & & & & & & & & & & & & & & & & & & \\
\hline 2010 & $\mathrm{LL}$ & & & & & & ESL & & & ESL & & & & & & & & & \\
\hline
\end{tabular}

FONTE: Elaborado pelo autor com base nos dados da RAIS/MTE

Anexo LXXXVII. Santos/SP | Ciclo de vida dos sistemas locais nas atividades selecionadas da indústria de transformação (1996-2010)

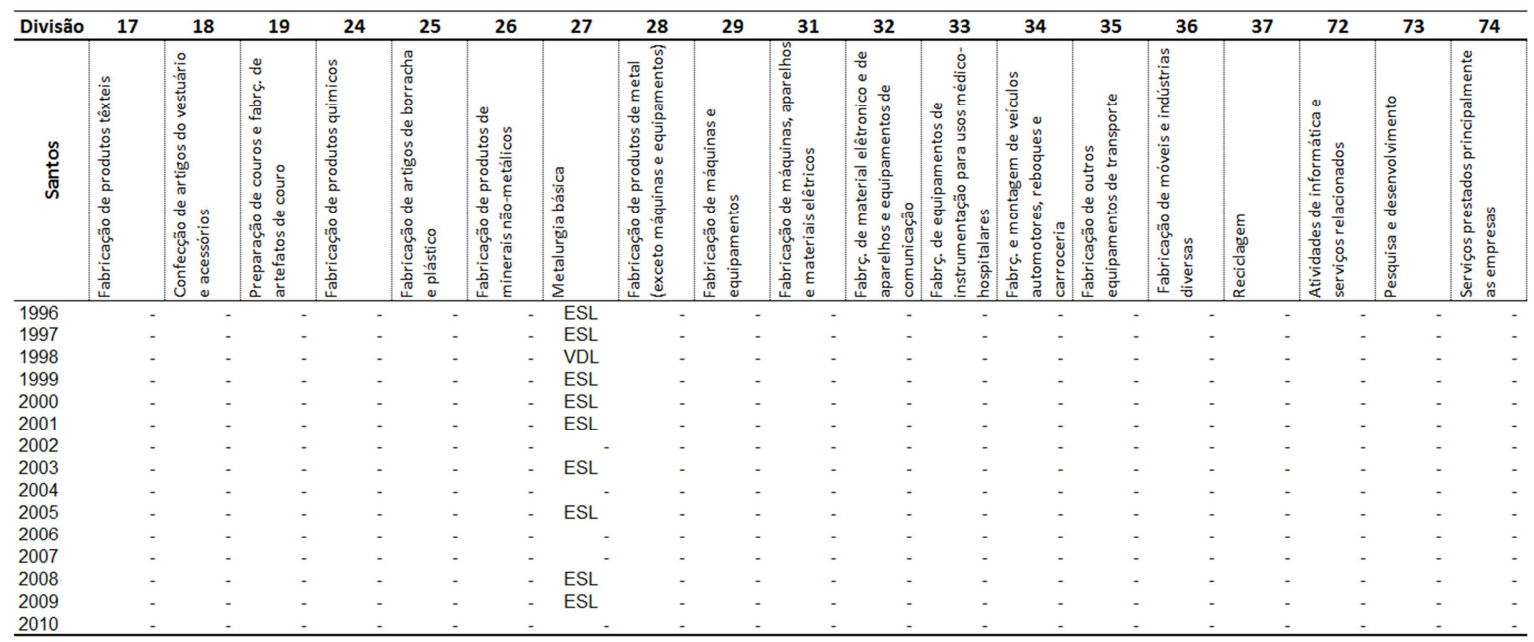

FONTE: Elaborado pelo autor com base nos dados da RAIS/TEM 
Anexo LXXXVII. Catanduva/SP | Ciclo de vida dos sistemas locais nas atividades selecionadas da indústria de transformação (1996-2010)

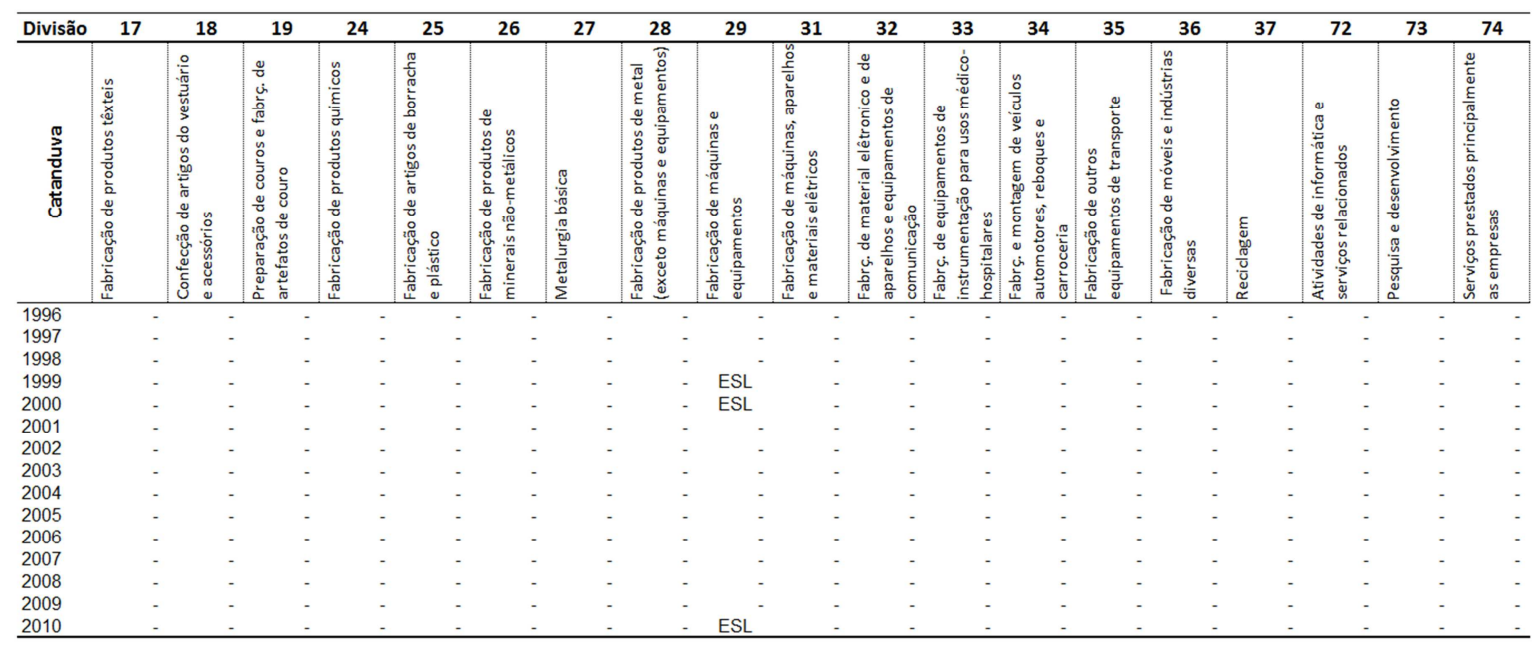

FONTE: Elaborado pelo autor com base nos dados da RAIS/MTE

Anexo LXXXVIII. Itapeva/SP | Ciclo de vida dos sistemas locais nas atividades selecionadas da indústria de transformação (1996-2010)

\begin{tabular}{|c|c|c|c|c|c|c|c|c|c|c|c|c|c|c|c|c|c|c|c|c|}
\hline Divisão & 17 & 18 & 19 & 2 & 25 & 26 & 27 & 28 & 29 & 31 & 32 & 33 & 34 & 35 & 36 & 37 & 72 & & & 74 \\
\hline 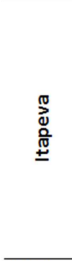 & 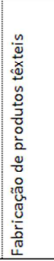 & 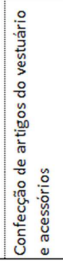 & 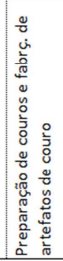 & 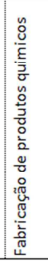 & 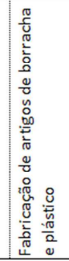 & 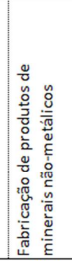 & 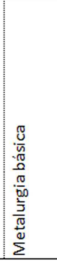 & 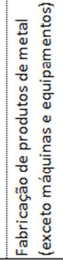 & 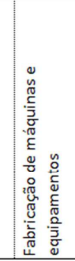 & 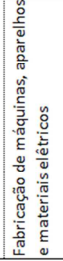 & 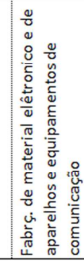 & 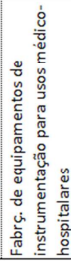 & 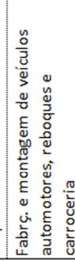 & 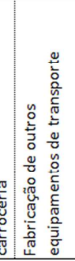 & 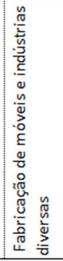 & 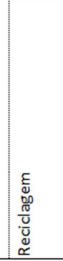 & 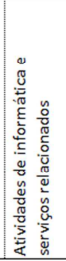 & $\frac{8}{\bar{c}}$ & & . \\
\hline $\begin{array}{l}1996 \\
1997\end{array}$ & & & & & 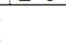 & $\begin{array}{l}\text { VDL } \\
\text { ESL }\end{array}$ & & & & & & . & & & & & & & & \\
\hline 1998 & & & & & & ESL & & & & & & & & & & & & & & \\
\hline $\begin{array}{l}1999 \\
2000\end{array}$ & & & & & & $\begin{array}{l}\text { ESL } \\
\text { ESL }\end{array}$ & & & : & & - & . & & & & & & & & \\
\hline & & & & & & ESL & & & - & & . & & & & & & & & & \\
\hline $\begin{array}{l}2002 \\
200\end{array}$ & & & & & & $\begin{array}{l}\text { ESL } \\
\text { ESL }\end{array}$ & & & - & & - & & & & & & & & & \\
\hline & & & & & & $\mathrm{E}$ & & & . & & . & & & . & & & & & & \\
\hline & & & & & - & ESL & & & & & & & & & & & & & & \\
\hline 2006 & & & & & 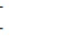 & ESL & & & & & & & & & & & & & & \\
\hline 2008 & & & & & & & & & & & & & & & & & & & & \\
\hline $\begin{array}{r}2009 \\
2010\end{array}$ & & & & & - & & & & - & & & - & & - & & & & & & \\
\hline
\end{tabular}

FONTE: Elaborado pelo autor com base nos dados da RAIS/MTE

Anexo LXXXIX. Osasco/SP | Ciclo de vida dos sistemas locais nas atividades selecionadas da indústria de transformação (1996-2010)

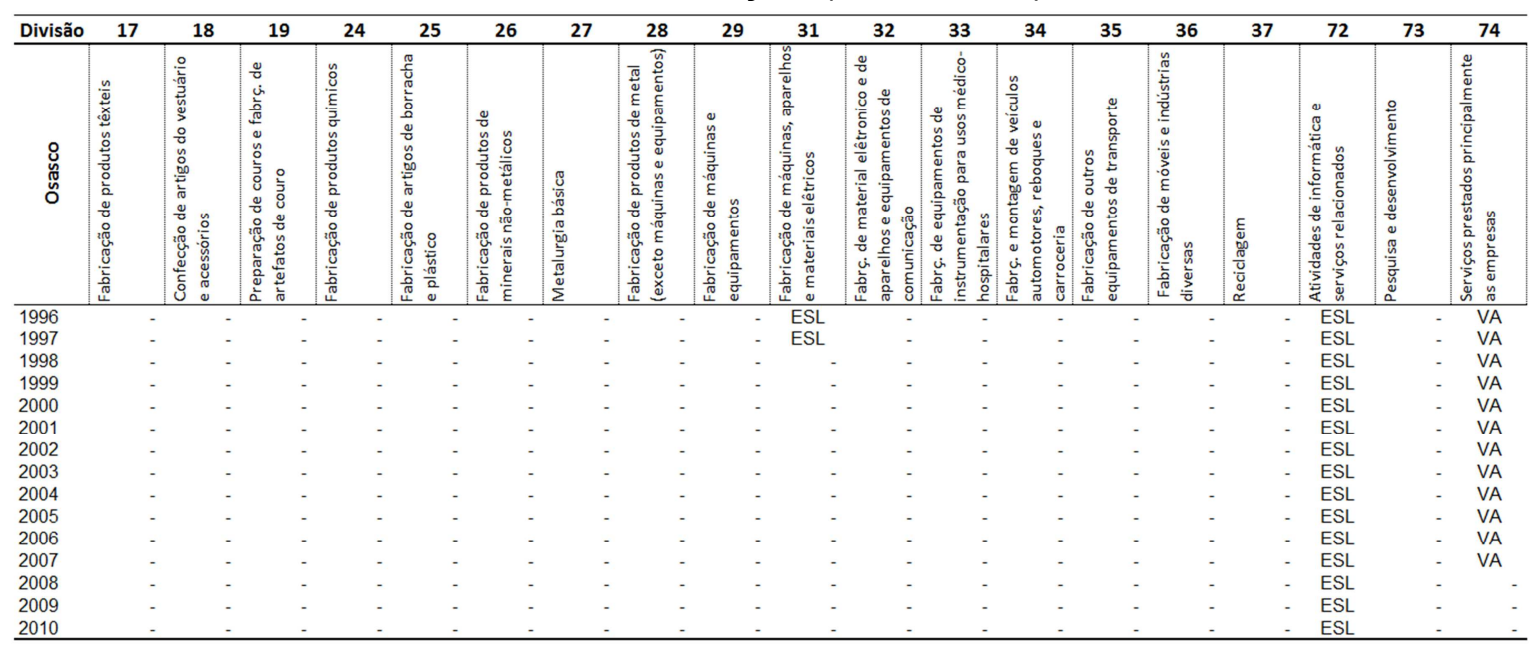

FONTE: Elaborado pelo autor com base nos dados da RAIS/MTE 